\title{
The future of tourism in Antarctica: challenges for sustainability
}

Citation for published version (APA):

Lamers, M. (2009). The future of tourism in Antarctica: challenges for sustainability. [Doctoral Thesis, Maastricht University]. Maastricht University. https://doi.org/10.26481/dis.20091112ml

Document status and date:

Published: 01/01/2009

DOI:

10.26481/dis.20091112ml

Document Version:

Publisher's PDF, also known as Version of record

\section{Please check the document version of this publication:}

- A submitted manuscript is the version of the article upon submission and before peer-review. There can be important differences between the submitted version and the official published version of record.

People interested in the research are advised to contact the author for the final version of the publication, or visit the DOI to the publisher's website.

- The final author version and the galley proof are versions of the publication after peer review.

- The final published version features the final layout of the paper including the volume, issue and page numbers.

Link to publication

\footnotetext{
General rights rights.

- You may freely distribute the URL identifying the publication in the public portal. please follow below link for the End User Agreement:

www.umlib.nl/taverne-license

Take down policy

If you believe that this document breaches copyright please contact us at:

repository@maastrichtuniversity.nl

providing details and we will investigate your claim.
}

Copyright and moral rights for the publications made accessible in the public portal are retained by the authors and/or other copyright owners and it is a condition of accessing publications that users recognise and abide by the legal requirements associated with these

- Users may download and print one copy of any publication from the public portal for the purpose of private study or research.

- You may not further distribute the material or use it for any profit-making activity or commercial gain

If the publication is distributed under the terms of Article $25 \mathrm{fa}$ of the Dutch Copyright Act, indicated by the "Taverne" license above, 
The Future of Tourism in Antarctica

Challenges for Sustainability

Machiel Lamers 
Cover picture: @Machiel Lamers

Picture details: Petermann Island (Antarctic Peninsula) in mid-March 2009

Cartoons on cover page of each chapter: @ZwaarWater, Amsterdam

(C) Copyright Machiel Lamers, Maastricht 2009

Universitaire Pers Maastricht

ISBN 978-90-5278-869-2 


\title{
The Future of Tourism in Antarctica Challenges for Sustainability
}

\author{
PROEFSCHRIFT \\ ter verkrijging van de graad van doctor \\ aan de Universiteit Maastricht \\ op gezag van Rector Magnificus, \\ Prof. mr. G.P.M.F. Mols \\ volgens het besluit van het College van Decanen, \\ in het openbaar te verdedigen \\ op donderdag 12 november 2009 om 16:00 uur \\ door
}

Machiel Lamers

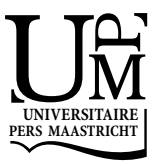




\section{Promotor}

Prof. dr. J.H. Stel

\section{Copromotor}

Dr. S.B. Amelung

\section{Beoordelingscommissie}

Prof. dr. P. Martens (voorzitter)

Prof. mr. C. Bastmeijer, University of Tilburg

Dr. R.J.M. Cörvers

Prof. dr. C.M. Hall, University of Canterbury

This Ph.D. research was funded by the Netherlands AntArctic Programme (NAAP) of the Netherlands Organisation for Scientific Research (NWO), grant number 851.20.025. 


\section{Table of contents}

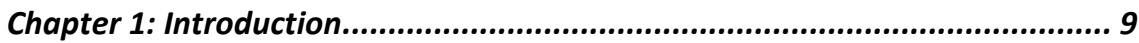

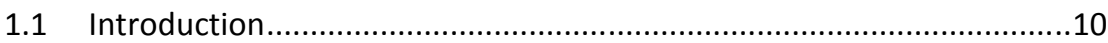

1.2 The development of tourism in Antarctica......................................11

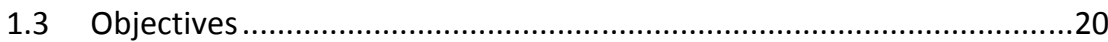

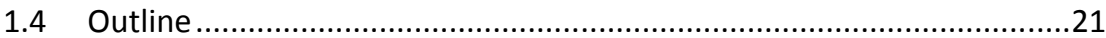

Chapter 2: Conceptual and methodological framework ............................. 25

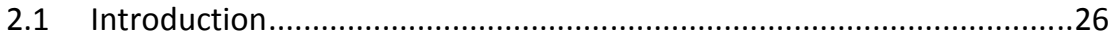

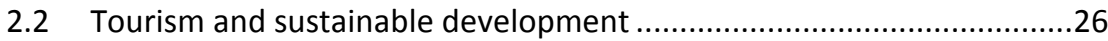

2.3 Integrated assessment and trans-disciplinary research .......................33

2.4 Research approach and methods......................................................36

\section{Chapter 3: Facing the elements:}

Analysing trends in Antarctic tourism .................................. 41

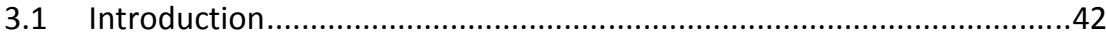

3.2 Methodological and theoretical considerations..................................43

3.3 Key factors influencing Antarctic tourism development .......................45

3.4 Future opportunities and trends in Antarctic tourism ..........................54

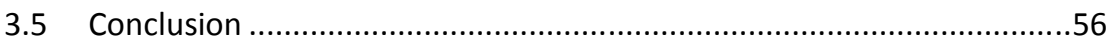

Chapter 4: The environmental impacts of tourism in Antarctica:

A global perspective ..............................................................59

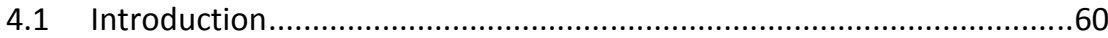

4.2 The environmental impacts of tourism in Antarctica ............................60

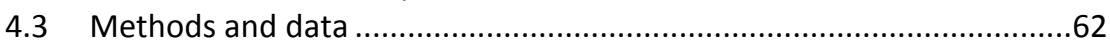

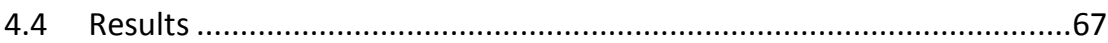

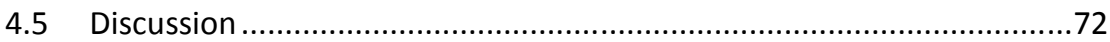

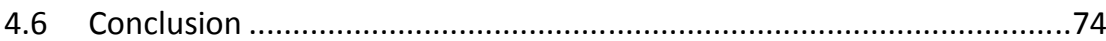

Chapter 5: Adventure tourism and private expeditions in Antarctica:

Conceptualising the risks..................................................... 77

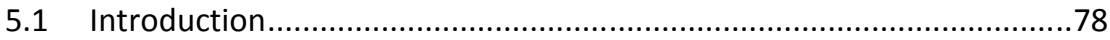

5.2 Adventure tourism in Antarctica ....................................................... 78

5.3 Recent incidents that have caused concern .........................................84

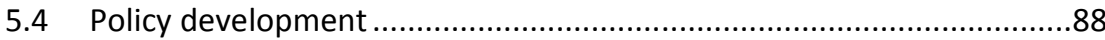

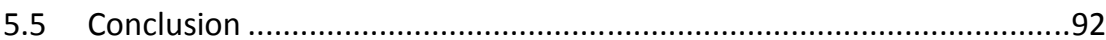


Chapter 6: Permanent land-based facilities for tourism in Antarctica:

The need for regulation........................................................ 93

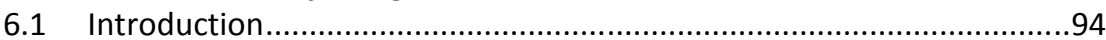

6.2 Definition of permanent land-based facilities for Antarctic tourism .....94

6.3 Permanent facilities for tourism in Antarctica and future trends ..........95

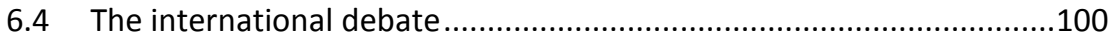

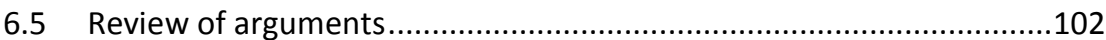

6.6 Management options for consideration.............................................109

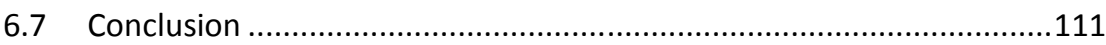

Chapter 7: Self-regulation in Antarctic tourism:

Exploring the institutional robustness .................................115

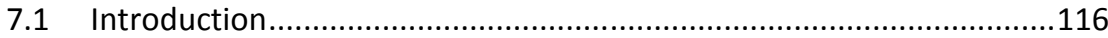

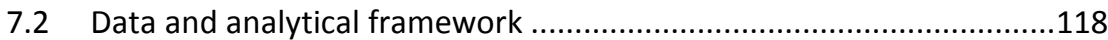

7.3 Tourism regulation in Antarctica ...........................................................122

7.4 The robustness of the Antarctic tourism self-regulatory regime .........124

7.5 Discussion and conclusion ...............................................................131

Chapter 8: Business as (un)usual:

An integrated scenario analysis of Antarctic tourism .............135

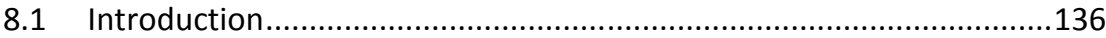

8.2 Theoretical and methodological considerations ..................................137

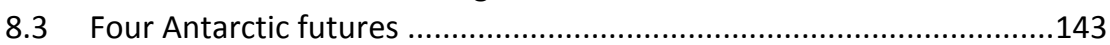

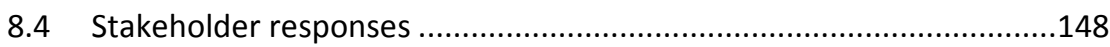

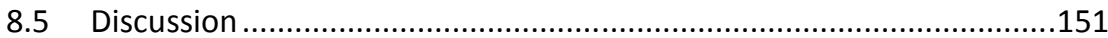

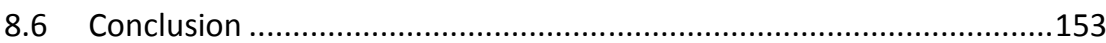

\section{Chapter 9: Sustainable tourism in Antarctica?}

Perspectives, policies and prospects......................................155

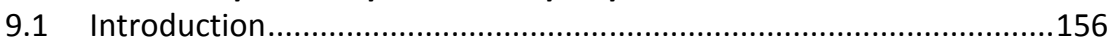

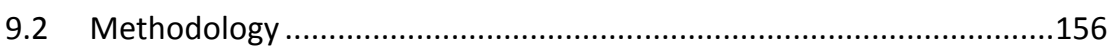

9.3 Perspectives on sustainable Antarctic tourism ................................159

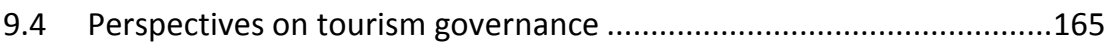

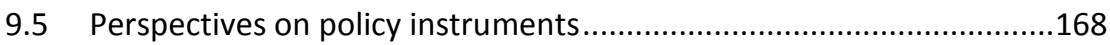

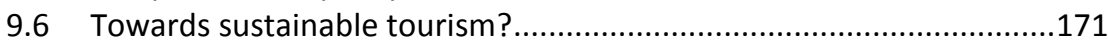

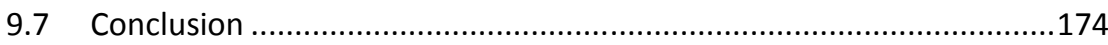

Chapter 10: Conclusions..........................................................................177

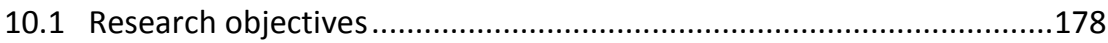

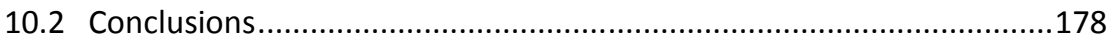

10.3 Reflection on concepts and methods ................................................187

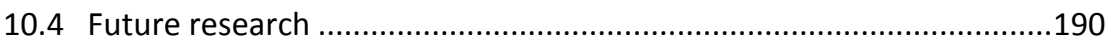




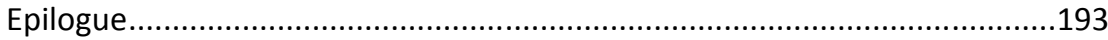

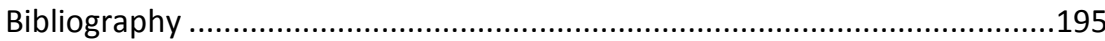

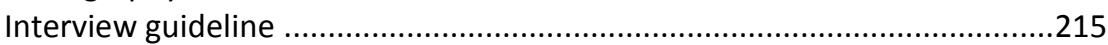

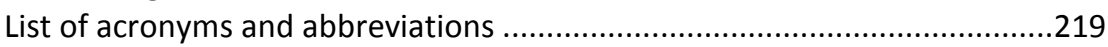

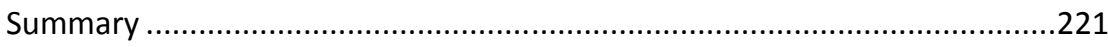

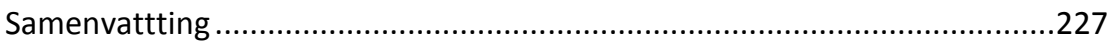

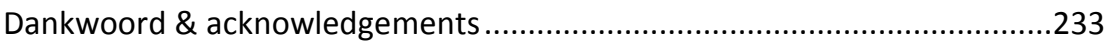

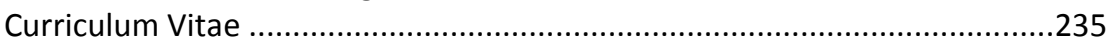



Chapter 1

INTRODUCTION

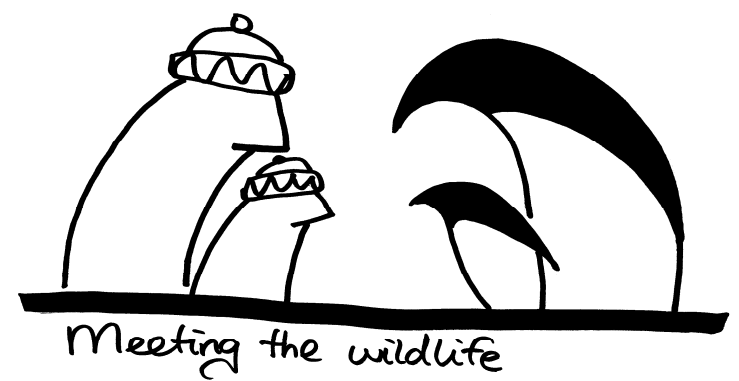




\subsection{Introduction}

Since the mid-1980s, the annual number of people visiting Antarctica for tourism purposes has increased rapidly from a few hundred to over 45.000 (Enzenbacher, 1993; IAATO, 2008b). Most of Antarctic tourism remains ship-based, but other market segments exist as well, such as land-based tourism and Antarctic overflights. Tourism is formally regulated by the Antarctic Treaty System (ATS), a group of countries with Antarctic scientific programmes that collectively manages activities in this region through the 1959 Antarctic Treaty. The 1991 Protocol on Environmental Protection to the Antarctic Treaty ('the Environmental Protocol') provides the main regulatory framework that applies to all human activities, including tourism. In addition, tour operators in Antarctica have managed to maintain a relatively strong record on safety and environmental sensitivities. The establishment of the International Association of Antarctica Tour Operators (IAATO) in 1991 is believed to have played a major role in this (Splettstoesser, 2000; Splettstoesser, et al. 2004; United Kingdom, 2004).

Nevertheless, in recent years the rapid growth of tourism has triggered debates among policy-makers, the tourist industry and other stakeholders about its consequences for safety and the environment. A range of gaps, inconsistencies and weaknesses has been identified with regard to the regulation of tourism operations. Tourism policies have typically been ad hoc and reactive, targeting individual expeditions rather than clusters of activities, focusing on requirements rather than restrictions, and often responding to incidents and plans (Kriwoken \& Rootes, 2000; Hemmings \& Roura, 2003; Bastmeijer \& Roura, 2004). In contrast, the ATS has taken a proactive approach in the context of commercial activities, such as fisheries and mineral resource extraction, to make sure that a comprehensive regulatory system was in place before activities commenced (Scott, 2001; Molenaar, 2005). It has been argued that a similar regulatory system should be developed for tourism (e.g. Hall, 1992; Davis, 1999). Another approach advocated by a range of authors and organisations (Bastmeijer and Roura, 2004; Molenaar, 2005; Amelung and Lamers, 2006; ASOC, 2006) is that a more proactive long term tourism policy is needed, based on a strategic vision on Antarctic tourism. Recently, the tourism industry and a number of Antarctic Treaty Parties have taken up this idea of a strategic tourism policy vision in which these fundamental issues can be clarified (Antarctic Treaty System, 2008; Scully and IAATO, 2008; United Kingdom, 2008; 2009).

There are important issues manifested on the longer term regarding tourism development in Antarctica. The tourism industry is growing and diversifying rapidly in a vulnerable part of the world that is historically largely deprived of human activities and knows no indigenous human population. Tourism and science operations largely take place in the same most accessible parts of the Antarctic, which could 
lead to conflict in terms of infrastructure use, site and station visits and scientific value. In addition, the Antarctic governance system is posing a range of challenges regarding decision-making and enforcement.

To what degree is the growing scale and distribution of tourism activity posing negative impacts in a region that is already affected heavily by global environmental changes? To what degree are we willing to accept impacts, be it environmental impacts, safety risks, or negative impacts for other human activities in the region such as science? Should we allow any form of tourism that we can think of in a region as special as Antarctica? Are we able to control tourism development in a global commons like the Antarctic, also in the future? These strategic questions related to tourism development in Antarctica, or sustainability challenges form the main theme of this thesis. The concept of sustainable development, and sustainable tourism, will be used to address these strategic questions.

Before we embark on this task, chapter one aims to provide a context and introduction to the Antarctic tourism case, including the main concerns and challenges; present the objectives and research questions underlying this study; and outline the structure of this thesis.

\subsection{The development of tourism in Antarctica}

\subsubsection{THE GLOBAL CONTEXT}

Tourism has grown into one of the world's largest industries and a major global societal phenomenon. According to the United Nations World Tourism Organisation (UNWTO), since 1950, the number of international tourists has grown by a factor of 30, reaching 808 million visitors in 2005 (UNWTO, 2006). This is just the tip of the iceberg, as the volume of domestic tourists (inside national borders) is known to greatly exceed that of international tourism. As humans are alien to the Antarctic, the issue of domestic tourism is irrelevant. Therefore, the focus here will be on trends in international long haul tourism, especially cruise tourism and polar tourism. It is in these sectors that the UNWTO is expecting rapid growth levels (WTO, 2001) $)^{1}$.

Amelung (2006) argues that global tourism growth is closely linked to technological innovations, economic development, population growth and institutional arrangements. For example, the introduction and popularisation of passenger aircraft in the second half of the 20th century allowed people to travel long distances (intercontinental) for leisure purposes. At the same time disposable incomes (purchasing power parities) in the developed OECD countries have more than quadrupled

\footnotetext{
${ }^{1}$ In 2003 the World Tourism Organisation received the status of a United Nations specialised body, which transformed the official acronym from WTO into UNWTO.
} 
(Amelung, 2006). Besides the increase in per capita welfare, the population of the OECD countries grew from around 580 million in 1950 to 920 million in 2002 (UNDP, 2004). The significance of international tourist markets of non-OECD countries has been limited leaving the affluent populations of the OECD countries to dominate global tourism volumes (WTO, 2003). However, tables may well turn in the coming decades as the economies of highly populous countries, such as China and India, are developing rapidly. Institutionalisation of labour laws, such as leisure time, holiday pay, and school holidays play an important role in the ability of people to travel. Besides basic global trends tourism is highly influenced by sociocultural factors, such as status and fashion (Prosser, 1994; Urry, 2002). A global trend of tourists is to travel ever-longer distances between home and the destination (Gössling, 2002), of which both Polar Regions and other remote destinations (e.g. the deep sea, outer space) present striking examples.

All around the world remote wilderness destinations have seen similar levels and types of growth. It has been estimated that for the European Arctic region only (consisting of Northern Scandinavia, Iceland, Greenland and Svalbard), tourist numbers have already exceeded 100.000 visitors per year in 2002 (Nordic Council, 2003). Including activities in the Canadian, United States', and Russian Arctic region, Arctic tourism has been estimated as more than tenfold the size of its Antarctic counterpart (Dingwall and Cessford, 1996). Due to the uniqueness and vulnerability of ecosystems, as well as the largely similar ship-based tourism activities, both the Svalbard and the Galapagos Archipelagos present interesting cases for comparison with the Antarctic. Around Svalbard the number of cruise tourists increased from almost 15.500 on 24 ships in 1997 to 34.900 passengers on 49 vessels in 2006 (Sysselmannen på Svalbard, 2006). Visitors to the Galapagos Islands have increased from 40,000 in 1990 to 145,000 in 2006 (Watkins and Cruz, 2007). In contrast to these remote wilderness destinations, activities in the Antarctic region are not regulated by a single sovereign state, but jointly governed by the Antarctic Treaty System (ATS).

Tourism has spread all across the globe and has currently started to move beyond the earth's limits. It seems only logical that tourism in Antarctica was bound to start and develop at some point. However, what do we mean with Antarctic tourism, how did this development come about, and what are the characteristics of Antarctica as a tourism destination? These characteristics will not only introduce the Antarctic tourism case, but it also helps us understand why it is important to conduct research on this topic.

\subsubsection{DEFINING ANTARCTIC TOURISM}

Despite the relatively limited scale of tourism in the Antarctica a broad range of activities, services and products are provided involving different types of stakeholders. Several approaches could be taken towards defining Antarctic tourism. Tourism is defined by the UNWTO as "activities of persons travelling to and staying 
in places outside their usual environment for not more than one consecutive year for leisure, business, and other purposes not related to the exercise of an activity remunerated from within the place visited" (Murray and Jabour, 2004; WTO, 1995: 12). If we were to follow this broad definition, all human activities, including science operations, taking place in Antarctica could be categorised as tourism. Scientists typically stay less than one year in Antarctica (with some exceptions) and it could be argued that even for scientists the Antarctic would not classify as "their usual environment". Clearly, in the context of Antarctica we would have to be more specific.

The 1991 Environmental Protocol makes a distinction between governmental and non-governmental activities and clearly categorises tourism in the last category. Antarctic tourism is increasingly growing to be more complex than consisting of a single activity organised by a single operator. For example, paying tourists are (and have been) travelling with government operated ships (Headland, 1994) and staying in government operated bases (Uruguay, 2005). Molenaar (2005) argues that tourism should not be seen as "an activity per se, but rather a purpose for which particular activities are undertaken". With this definition, he clearly adds the element of purpose or motive for travel to the Antarctic. Both Bauer (2001) and Murray and Jabour (2004) include the purpose of travel, to and in the Antarctic region, as a major component of a tourism definition. The purpose of tourism travel can be various things, including pleasure, education, or adventure.

Following this approach we define Antarctic tourism as those activities that are organised (e.g. governmental, non-governmental or commercial) in the Antarctic region, i.e. south of $60^{\circ}$ South Latitude, with the purpose of enjoying (e.g. pleasure, adventure, education) specific Antarctic values (e.g. wilderness, wildlife, remoteness, extremeness) in any form. Recreational activities undertaken by staff and crew of National Antarctic Programmes (NAPs) are excluded from this definition and are not further considered in this study.

\subsubsection{Milestones IN THE HISTORY OF ANTARCTIC TOURISM}

Tourism in the Antarctic region is not a new phenomenon. The Antarctic tourism industry is generally considered to have started in the 1950s when Chile and Argentina took fare-paying passengers to the South Shetland Islands aboard naval freight ships. The concept of 'expedition-cruising', small to medium sized ships making landings ashore coupled with extensive educational programmes, began in the late 1960s when Lars-Eric Lindblad led the first traveller's expedition to Antarctica (Headland, 1994). Lindblad believed that providing a first-hand experience to tourists would educate them with respect to the ecological sensitivity of the Antarctic environment and promote a greater understanding of the earth's resources and the important role of Antarctica in the global environment. Antarctica's physical isolation, extreme climate and remarkable wilderness values form the major attraction for tourism. Lindblad's model of expedition cruising has become very popular 
and is still followed today by the majority of companies operating ship-borne trips to Antarctica. During the 1990s, the fleet of small passenger ships (appr. 100 passengers) was expanded significantly with Russian icebreakers and polar research vessels that had become available on the free market following the collapse of the Soviet Union (Stonehouse, 1994; Cessford, 1997). However, ship-based tourism is not without incidents. For example, in 1989 the Argentinean naval supply vessel Bahia Paraiso grounded with tourists on board near the US Palmer station and sank. Passengers were rescued. More recently we have been seeing a series of incidents and groundings of tourist ships, most notably the sinking of the $M / S E x$ plorer in the Bransfield Strait in November 2007 (Stewart and Draper, 2008).

Since the Millennium season, ship-based trips to Antarctica have been diversified with voyages of large cruise vessels (appr. 1000 - 3000 passengers). Large cruise vessels typically do not make on-shore landings; industry bylaws state that making landings with a ship carrying more than 500 passengers is not allowed (IAATO, 2008a). This operational rule has recently been codified into formal policy. The largest vessel that operated in Antarctic waters was the Golden Princess in the 2006-07 season, carrying 3,700 people on board. The largest capacity vessel operating from Ushuaia in the 2008-09 season is the Star Princess, which carries up to 2,600 passengers and over 1,000 crew (IAATO, 2008b).

Airborne tourism to the Antarctic Peninsula and the Ross Sea Region also started in the mid 1950s. Regular airborne visits started in early 1980s when the Chilean Air Force organised visits to King George Island providing accommodation at the "Hotel Estrella Polar", a basic facility operated as part of the Teniente Marsch Air force Base (Headland 1994). Visits to King George Island ceased in the 1992/93 season, but have recently been continued by the Chilean commercial air carrier Aerovias DAP organising day visits and overnight trips, making use of basic facilities at the Russian Bellingshausen station and the Uruguayan Artigas station. Air supported expeditions to several destinations in the Antarctic interior commenced in the late 1980s, when Adventure Network International (ANI) started operating their semipermanent field base at Patriot Hills. In 2003 ANI was taken over by Antarctic Logistics and Expeditions (ALE), a company that has continued operating land-based adventure activities and providing service for national science programmes (Lamers et al., 2007).

From 1977 a short series of overflights (making no landing) above the Antarctic continent was organised from New Zealand and Australia, only terminating with the catastrophic crash of an Air New Zealand DC10 on Mount Erebus in the Ross Sea Region in 1979. Overflights were recommenced in 1994 from Australia and later from Chile. Antarctic overflights have been particularly studied by Bauer (Bauer, 2001; Bauer, 2007). Contrary to other tourism activities, passenger numbers of overflight trips have been shrinking over the last decade. 


\subsubsection{CHARACTERISTICS OF ANTARCTIC TOURISM DEVELOPMENT}

The Antarctic tourism market is known to be traditionally North American, European, and Australasian (Bauer, 2001), which reflects the fact that it is an up-market niche product. The total number of tourists taking part in Antarctic travel itineraries exceeded 45,000 in the season of $2007 / 08$, and is projected to continue growing in the future. The last two decades have seen a rapid development of tourism in Antarctica, with annual increasing visitor numbers, and diversifying activities and transport modes.

More than $95 \%$ of the tourism activities take place in the Antarctica Peninsula region. Within a ship voyage reach of around two days from South American ports, the Antarctic Peninsula is the most accessible part of Antarctica. Other regions that attract some visitation are the Ross Sea region, accessible by ship in more than ten days from Australia and New Zealand, and Dronning Maud Land, accessible by air from South Africa. Tourism activities take place between November and March, with a peak around December and January, and are clearly highly seasonal. Within the Antarctic Peninsula activities focus on a limited number of scenic areas and icefree landing sites (Crosbie, 2005). It is no coincidence that in these places in the same period the breeding season of most Antarctic wildlife species occurs. Simultaneously, tourism activities are increasingly spreading to other parts of the continent, including inland sites.

Besides stunningly beautiful the remote Antarctic can also be a dangerous destination. Adding to the remoteness of the area are the treacherous weather conditions and the presence of sea-ice, which limits the accessibility of Antarctica with regular ships. In addition, Antarctic waters are known to be poorly charted (Snyder, 2007). The harsh conditions in the Antarctic region call for extensive preparation, including the acquisition of proper insurance, permits, clothing, logistics, and experienced staff (Stonehouse, 1994; Mason and Legg, 1999). Any omission in planning, any physical inability, sudden weather changes, sea-ice or iceberg can cause disaster and jeopardise the whole expedition, or the operations of other parties in the area.

Antarctic tourism has also become more diverse. Tourism operations are largely ship-based, with a much smaller number of tourists travelling to Antarctica by air. The traditional expedition-cruises, involving small to medium-sized ships, rubber boat landings and educational programmes, have been complemented with large cruise liners making no landings, overflights, fly-sail operations, as well as some land-based tourism using aircraft for transportation. In expedition cruises and landbased itineraries, an increasing range of adventurous activities are offered, including helicopter excursions, camping, kayaking, scuba diving, mountain climbing, and cross-country skiing (Stonehouse and Crosbie, 1995; Bastmeijer and Roura, 2004). A shift has been noted from location-based tourism (i.e. with focus on wildlife and historic sites), to activity-based tourism (i.e. with focus on activities) (ASOC, 2008). 
A unique feature of Antarctica is the absence of indigenous human inhabitants. Also, compared to other tourist destinations there are only a few types of actors involved. Nevertheless, other actors are present in places visited by tourist ships. Scientific operations of NAPs also concentrate in ice-free places, especially in the Antarctic Peninsula, in the same period. Sailing yachts are visiting the same areas. Attention will have to be given to the possible conflicts between these stakeholders. There are also benefits to Antarctic tourism. NAPs may benefit from visiting tourist ships, for example when selling souvenirs. It has been claimed that through tourism ambassadors are created for the conservation and protection of the Antarctic wilderness (Splettstoesser, 2000; Maher et al., 2001).

\subsubsection{REGULATION AND MANAGEMENT OF TOURISM IN ANTARCTICA}

Antarctica is the only landmass on earth without a sovereign government. Seven nations have claimed territories in Antarctica during the first half of the $20^{\text {th }}$ century, i.e. Argentina, Australia, Chile, France, New Zealand, Norway and the United Kingdom. However, the legitimacy of these claims was disputed due to overlap (for example, the Antarctic Peninsula is claimed by the United Kingdom, Chile and Argentina) and the refused recognition of newly appeared world powers like the United States and the Soviet Union. After the International Geophysical Year (IGY) of $1957 / 1958$, the seven claimant states, and five other states involved in Antarctic IGY research, decided to reserve their position regarding the legal status of Antarctica and to manage the continent collectively. In 1959, the Antarctic Treaty was signed; which entered into force in 1961. A central building block is the 'agreement to disagree' with regard to the legitimacy of the sovereignty claims, as was laid down in Article IV of the Antarctic Treaty. Next to safeguarding peace, the Antarctic Treaty ensures freedom of scientific research in the region south of 60 degrees South latitude. Consultative membership to the Antarctic Treaty is based on demonstration of longer term scientific interest in Antarctica. Scientific interest can be showed by setting up a scientific programme and a research infrastructure (e.g. establishing a research station). Other states have joined the Antarctic Treaty since 1961, and today 28 Antarctic Treaty Consultative Parties (ATCPs) jointly take decisions on Antarctic matters based on consensus. The Netherlands became a consultative party in 1990 and was the first country to do so without constructing a research station of its own (Bastmeijer, 2004). In addition to the ATCPs there are eighteen non-Consultative parties to the Antarctic Treaty. The non-Consultative Party status means that countries are invited to attend the annual Antarctic Treaty Consultative Meetings (ATCMs) but do not participate in decision-making (Bastmeijer et al., 2008).

Several other conventions and recommendations have been adopted since the Antarctic Treaty was signed. Jointly, this collection of legal instruments and policies for the international governance of Antarctica is referred to as the Antarctic Treaty System (ATS). In 1991 the Protocol on Environmental Protection to the Antarctic Treaty (also known as Environmental Protocol or Madrid Protocol) was adopted. 
The Environmental Protocol provides a third pillar to the Antarctic Treaty System: the protection of the Antarctic environment, next to the existing pillars of safeguarding peace and freedom of science. The Environmental Protocol entered into force in 1998. It establishes a comprehensive system of obligations and prohibitions, addressing most types of human activity in the Antarctic Treaty area (Bastmeijer et al., 2008).

Tourism was merely non-existent at the time the Antarctic Treaty was drafted, and in the early 1990s tourist numbers were also still relatively small. However, the Environmental Protocol also applies to tourism activities. Consequently, these activities are subjected to the provisions of the Protocol, such as provisions on carrying out environmental impact assessments, waste disposal and the protection of Antarctic flora and fauna. The state parties to the Protocol must ensure that provisions have been implemented in the domestic legal and administrative systems and are applied in practice to all Antarctic activities under their jurisdiction. Annually, the ATCPs discuss the (legal and practical) implementation of the Treaty, the Protocol and measures and resolutions at the ATCM, as well as the need to adopt additional international management policies. In recent years, a number of voluntary and binding measures were added to the ATS on issues such as codes of conduct, pre-trip and post-trip trip notification, information exchange between ATCPs, compulsory insurance and contingency planning, and site specific guidelines (Bastmeijer and Roura, 2004; Molenaar, 2005). In 2005 a Liability Annex was added to the Protocol, but which has not yet been ratified (ASOC, 2008). Antarctic tourism is also directly and indirectly regulated by other governance bodies, such as the IMO in the case of shipping (Molenaar, 2005). In recent years, the regulation of tourism has been a major source of debate at the Antarctic Treaty Consultative Meetings.

Partly due to regulatory difficulties, tour operators have an incentive to organise themselves, coordinate travelling schedules, and institutionalise best-practice guidelines (Splettstoesser, 2000; United Kingdom, 2004a). Through the establishment of the International Association of Antarctica Tour Operators (IAATO) many of the emerging problems related to tourism have been successfully resolved. In 1991, IAATO was founded by seven tour operators to guarantee and promote safe, environmentally sound and responsible travel to Antarctica (Splettstoesser, 2000). IAATO has imposed a wide range of operational procedures and environmental standards upon its member companies. In addition IAATO functions as a main point of contact for the ATS (Haase et al., 2009) as well as the managers of NAPs (Fowler, 2000). IAATO membership has grown from seven members in 1991 to 95 members in 2007 in different membership categories members. Member companies are based in a wide range of countries, although most of the tour operators are based in affluent countries in Europe and North America (IAATO, 2007). 


\subsubsection{CONCERNS AND CHALLENGES}

The characteristics of the above described activities, developments, and context are a cause for concern for a range of actors, including academics, policy makers, tour operators, NAPs and environmental NGOs. Concerns generally focus on the growing scale of tourism, the diversifying forms of tourism, the ability to control tourism, and the associated risks and impacts. Developments may not only affect the environment, but also activities of other stakeholders, cultural and historical sites, and regulatory systems. In addition, effects may not only be conceived here and now but also manifest themselves at larger spatial and temporal scales. In the following paragraphs, we will introduce some of these strategic challenges.

Different variables, such as numbers of tourists, tour operators, and tourist ships, have been growing rapidly over the last two decades and are expected to continue to grow in the future ${ }^{2}$. Although the scale of tourism is still small compared to the size of the continent, activities do concentrate around a limited number of popular sites in the Antarctic Peninsula. The spatial and temporal concentration of tourist activities with other human activities, such as science operations, indicates a potential for both opportunity and conflict between different human users, especially when activities further increase in the future. Growing numbers of tourists might lead to cumulative impacts on vulnerable Antarctic ecosystems, which may not be directly observable (ASOC, 2008). In addition, tourism activities may not be the only ecosystem stressor in the Antarctic Peninsula, for example, climate warming, recovering whale populations, and invasive species may have a large combined impact. A precautionary approach is therefore advocated by a range of authors (Scott, 2001; Bastmeijer and Roura, 2004). Also, should we be looking only at local environmental impacts or should global environmental impacts of travel to and from Antarctic gateway cities be considered?

The diversification of Antarctic tourism into industry segments, modes of transport, and activity forms has been criticised by those who claim that new activities pose strategic judicial challenges in the longer term. The case of high-risk adventure tourism (United Kingdom, 2004b), the use of existing scientific facilities for tourism, or the development of permanent land-based tourism infrastructures (New Zealand and Australia, 2006) are examples of developments that might pose such challenges. State-supported tourism can create conflicts of interest between science and tourism operations for the state concerned; aggravate underlying sovereignty claims of claimant states; and make it harder for ATCPs to reach consensus on regulation (ASOC, 2008). In addition, activities may also not be compatible with intrinsic Antarctic values, such as wilderness values (Australia, 2005).

\footnotetext{
${ }^{2}$ Although the credit crisis and the economic recession that set in end 2008 is believed to have an impact on these growth variables, numbers will likely continue to grow as the global economy picks up again.
} 
The last decade has seen a series of incidents with both independent adventurers and expedition-cruises. A compelling example is the sinking of the $\mathrm{M} / \mathrm{S}$ Explorer in November 2007, which resulted besides risks for human safety in a spillage of fuel. The recent flag-state investigation report of the Liberian Bureau of Maritime Affairs suggests that the lack of experience of the captain and the absence of an ice-pilot were among the main causes of this catastrophe (Republic of Liberia, 2009). It remains unclear what can be done to avoid such incidents, and what could happen if an incident would involve a much larger vessel. The increasing size of cruise vessels, or scale of tourism operations, is important in relation to the Search and Rescue (SAR) capabilities in the Antarctic. Many larger cruise vessels are not icestrengthened and not considered suitable for navigation in polar waters. In addition, many tend to be registered in countries outside of the Antarctic Treaty System, and carry so-called "flags of convenience" (ASOC, 2008). It is not clear to what extent this limits the level of control the ATS can exercise over these ships (Molenaar, 2005).

Growing numbers and types of tour operators from an increasing number of countries might have negative consequences for effective cooperation and communication in the tourism industry. It is not inconceivable that in the future more companies decide to operate outside of the industry's self-regulatory regime. Besides more ships we have been seeing larger ships heading down to the Antarctic, owned by larger companies (Lamers et al., 2008). In fact, smaller companies are increasingly working together with, or are being bought up by, large tourism multinationals (Hemmings and Roura, 2003). It seems as if economies of scale have started to dictate Antarctic tourism development, which might entail negative consequences. Shareholders of large cruise multinationals may be more interested in return on investment than high environmental standards and high quality guides. The bulk of Antarctic tourists and tour operators may also be coming from different countries in the future. Whether these new groups bring the same strong environmental ethics to the Antarctic as the present ones remains to be seen (Snyder, 2007).

Despite the stability of the ATS and its ability to manage other activities in a proactive way, Antarctic tourism regulation has been considered weak. The decisionmaking and implementation process is slow (Bastmeijer and Roura, 2004). It has been argued that Antarctic policy makers generally lack experience and knowledge in Antarctic tourism to really know what is going on (Enzenbacher, 2007). Many regulations specifically applying to Antarctic tourism are not legally binding. Implementation of binding regulations in domestic legislation of individual ATCPs leaves much room for translation and interpretation (Kriwoken and Rootes, 2000; Bastmeijer, 2003). Authorisation of individual tourism activities are given based on environmental impact assessments (EIA) in a range of countries, based on a range of different systems; the larger scale and longer term effects of tourism tend to be ignored (Kriwoken and Rootes, 2000; Hemmings and Roura, 2003; Bastmeijer and Roura, 2008). In addition, rules cannot be policed and enforced effectively in the 
field (Tracey, 2001; Molenaar, 2005), and do not apply to operators from Third Party states. This creates a potential for free-riding.

There is generally no funding available for onsite management, monitoring and enforcement, despite the fact that the Antarctic is designated as a nature reserve (Snyder, 2007). These important tasks are now largely left for the tourism industry to cover. The value of IAATOs work in coordination and environmental management underlines the importance of a continuing co-operation between the ATS and IAATO (United Kingdom, 2004a). However, the ATCPs have a clear responsibility under the ATS and sustainability challenges may not be adequately addressed by self-regulation alone. It is not clear how the ATS should formally and informally relate to self-regulatory organisations like IAATO.

\subsection{Objectives}

The previous section has raised a number of strategic challenges regarding Antarctic tourism. Strategic challenges point at a range of uncertainties in future tourism development, involve a range of stakeholders and hold great potential for change and impacts. Identification of these challenges requires a perspective on tourism that goes beyond the "here and now", i.e. at an aggregated spatial and temporal scale. These requirements are recognised in recent literature reviews and academic papers, such as the need for analysis of polar tourism impacts in the global context (e.g. Stewart et al., 2005), and the need for future oriented studies of Antarctic tourism development (e.g. Bastmeijer and Roura, 2004; Molenaar, 2005). The key scientific goal of this thesis is therefore to explore the strategic challenges of sustainable Antarctic tourism development.

The leading research question in this study reads:

What sustainability challenges will we be facing as tourism in Antarctica develops in the future; and how can these challenges be tackled in the context of this global common?

Challenges may arise as tourism grows further, takes unexpected forms, and poses impacts on natural and human systems in the future. Also, effects of future tourism development may be mitigated or amplified by modes of governance from different stakeholders. The main research question will therefore be approached through the following research objectives:

1. To identify the main development factors and actors driving and constraining Antarctic tourism and analyse opportunities for future tourism development in an integrated way;

2. To assess the risks and impacts of Antarctic tourism development for the environment, tourism operations, and other users; 
3. To explore the future of Antarctic tourism by developing a set of plausible and consistent future scenarios and analyse the implications;

4. To analyse stakeholder perspectives on the options for Antarctic tourism governance towards sustainability.

This thesis aims to contribute to both the academic and political debates on Antarctic tourism by improving the conceptual and empirical knowledge base on the multifaceted nature of Antarctic tourism development. By systematically exploring the future through an integrated scenario analysis (objectives one and three) and analyzing stakeholder perspectives (objective four) a range of strategic challenges and governance options will be presented. Four challenges representing a clear knowledge gap in the literature and a considerable potential for future change are studied in detail (objective two). These sustainability challenges are: the environmental impacts of tourism in a global perspective; adventure tourism and the conceptualisation of human safety risks; the implications of land-based tourism facilities and infrastructures; and the robustness of self-regulation as a sustainable governance strategy.

\subsection{Outline}

The research objectives will be addressed in different chapters of this thesis. Some chapters focus on the overarching and integrative analysis of future tourism in Antarctica (chapters three, eight and nine). Other chapters will explore a number of potential impact areas in greater depth. Figure 1.1 provides an overview of the chapters presented and their positioning within this thesis. The following paragraphs briefly outline the contents of each of the chapters.

Chapter two will present the conceptual and methodological framework underlying this study. Sustainable development, and sustainable tourism in particular, will be introduced as central concepts in this thesis. Further, the transdisciplinary and integrated research approach applied in this study will be introduced, as well as the research methodologies.

Chapter three analyses the trends of different segments of the Antarctic tourism industry based on an assessment of historic and current constraints and opportunities using the concept of Recreation Opportunity Spectrum (Clark and Stankey, 1978). The analysis is based on perspectives derived from three stakeholder workshops organised in the Netherlands and New Zealand, as well as on available literature and data. It is argued that the future holds opportunities for both larger scale tourism operations and niche products in Antarctica. 


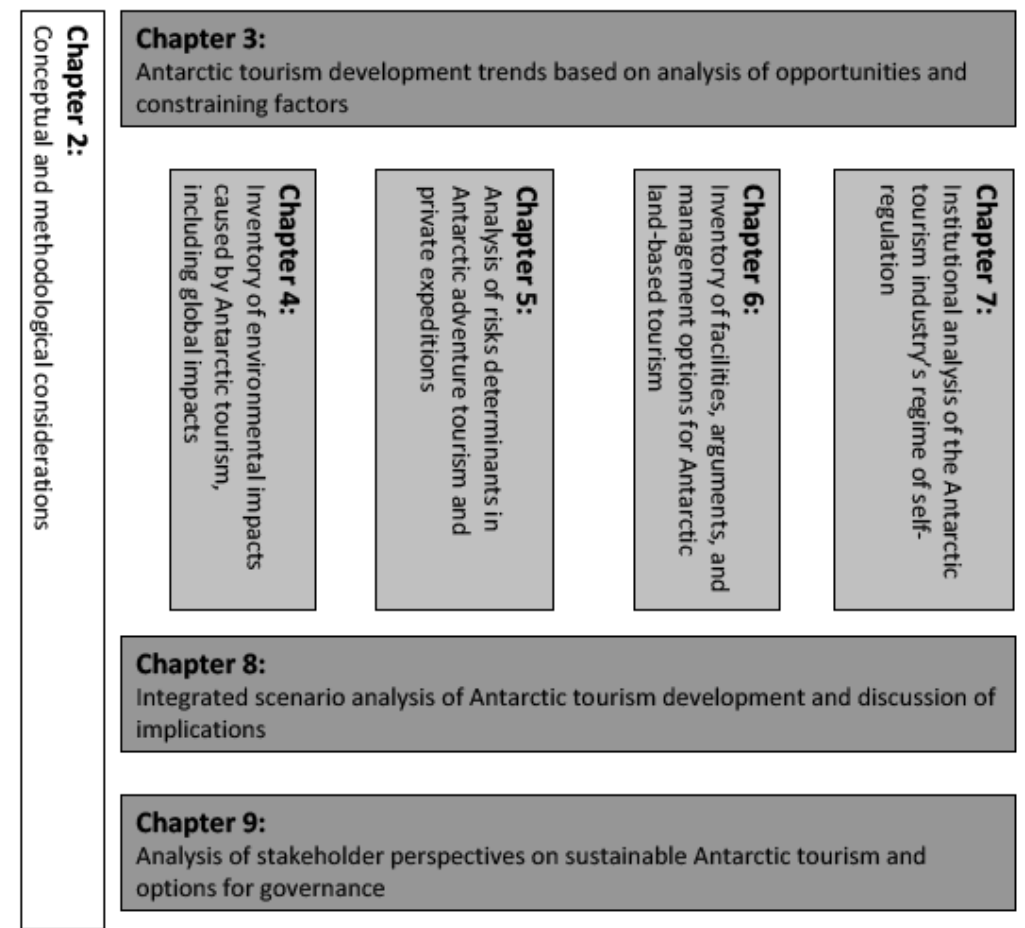

Objective 1

Objective 2

Objective 3

Objective 4

Figure 1.1: Overview of chapters in this thesis

Chapter four discusses the state of knowledge on environmental impacts of tourism in Antarctica. It is argued that, so far, environmental impact assessments have focused on easily observable and localised consequences of tourism activity and ignored to address longer-term cumulative impacts and global impacts of tourism in Antarctica. A first inventory is made of $\mathrm{CO}_{2}$ emissions of Antarctic tourists in the 2004/05 season to start filling this knowledge gap.

Chapter five presents a definition and overview of activities that can be classified as Antarctic adventure tourism and independent expeditions. Based on various Antarctic information databases an analysis of the different risk determinants is made. It is argued that human safety risks and related claims on other parties' search and rescue capabilities are determined by a range of factors and should be addressed accordingly.

Chapter six poses a definition and classification of land-based facilities and infrastructures for tourism, and presents an overview of historic and current cases. Based on an analysis of policy documents an inventory of arguments in favour and against future development of land-based tourism facilities is made. Different regulatory approaches are presented for tackling this issue. 
Chapter seven analyses the current self-regulatory regime of the Antarctic tourism industry, based on interviews with key-stakeholders, using the design principles of Ostrom (2005) for robust common property management institutions. It is argued that although self-regulation has been successful in Antarctica, there is no guarantee for future success.

In chapter eight an integrated scenario analysis is performed for tourism development in Antarctica. Based on a combination of stakeholder perspectives derived from three scenario workshops, available academic literature and documentation, and relevant global scenarios, different future pathways are explored and analysed for implications.

Chapter nine analyses stakeholder interviews on the development and regulation of tourism in Antarctica by linking these to Hunter's (1997) adaptive sustainable tourism concept. The aim of this chapter is to demonstrate the range of perspectives on sustainable tourism in Antarctica and explore the options for governance.

Finally, in chapter ten the main conclusions coming from this thesis will be summarised, reflection will be provided on concepts and methods used in this thesis, and discussion on the prospects for further research. 



\section{Chapter 2}

\section{CONCEPTUAL AND METHODOLOGICAL FRAMEWORK}

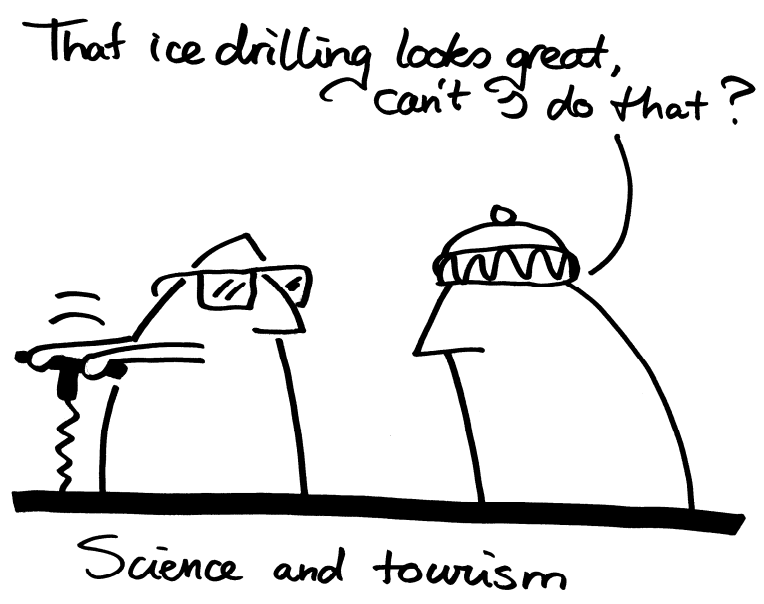




\subsection{Introduction}

Studying the sustainability challenges of tourism in the Antarctic setting requires a conceptual framework that allows us to assess current and future developments, different perspectives of key actors, and governance options. Performing this task is a challenge in itself as sustainable development is a contested concept. It is clear that sustainable development involves finding a balance between economic, ecological and social qualities; but where this balance lays remains as obscure as ever. Further, issues of scale, both temporal and spatial, and questions about responsibility and governance turn sustainable development into a complex concept.

Antarctica provides a unique case to put the sustainable development concept into practice. Because of the relative clearness of tourism activities (compared to destinations elsewhere), the absence of an indigenous human population, and the relatively clear delimitation of the actor communities involved the Antarctic is an interesting study area for such an analysis. The fact that Antarctica is a global common adds to the challenge of finding effective management strategies. In this chapter, key underpinnings of the sustainable development (and sustainable tourism) concept will be introduced as a conceptual basis to identify and understand sustainability challenges of tourism in the Antarctic context.

To address tourism and sustainable development in Antarctica properly it is necessary to design a research approach that fits with the peculiarities of this case, as well as the aims of this research project. The second part of this chapter will introduce the transdisciplinary and integrated research approach that was followed in this study, as well as provide an overview of the research tools and methodologies used.

\subsection{Tourism and Sustainable Development}

\subsubsection{SUSTAINABLE DEVELOPMENT}

The concept of sustainable development was made popular by the famous report of the World Commission on Environment and Development (WCED), also known as the Brundtland Commission (World Commission on Environment and Development, 1987). This report's definition of sustainable development is widely used: "Sustainable development is development that meets the needs of the present without compromising the ability of future generations to meet their own needs" (World Commission on Environment and Development, 1987). While this definition gives some general guidelines, it leaves many issues unresolved and does not provide much guidance for solving concrete dilemmas and making trade-offs. Several dozens, if not hundreds, of other definitions have been proposed, but the vagueness remains (Giddings et al., 2002; Robinson, 2004; Williams and Millington, 
2004). However, a number of common denominators of sustainable development can be derived from the literature, such as the implied balance of economic, ecological and social developments, the achievement of human well-being (i.e. intragenerational equity), and the balance between current and future generations (i.e. intergenerational equity) (Huynen, 2008). The fuzziness of the concept of sustainable development has been identified as a main weakness, but also as one of its major strengths (Burger, 2006). It has allowed sustainable development to emerge as an abstract goal shared by many in society and provides a platform for discussion among groups that perhaps otherwise would not have communicated.

Several broad philosophical communities can be discerned in the sustainability debate. On the one hand, there are those who regard sustainability as an objective biophysical or societal reality: there are certain real and absolute limits to the use of the earths or society's resources and sinks. On the other hand, there are those who regard sustainability as a social construct: what we call sustainable is the result of a value judgment, a trade-off between priorities and interests. The former view of sustainable development is closely linked to the notion of (very) strong sustainability, in which natural capital cannot or only in a very limited way be replaced by human-made capital. The latter view is closely related to the notion of (very) weak sustainability, in which human-made capital (e.g. technology) can be substituted for natural capital in many instances (Robinson, 2004; Williams and Millington, 2004).

The differences between the two views may be partly explained by differences in spatial and temporal scale levels. It is relatively easy to think of the Earth as a closed system, 'only' exchanging (solar) radiation and heat with the universe. The Earth's material resources are limited, so there must also be absolute limits to the use that humankind can make of them. Where exactly these limits are is of course an issue that is surrounded by huge uncertainties. The lower the level of analysis, the more open the systems of concern become, and the more arbitrary their boundaries. As sustainable development is characterised as a process striving towards intra- and intergenerational equity, much room is left for interpretation on how this can be achieved. In addition, we can safely assume that the current generation, in different developmental settings, will prioritise their needs and interests over those in other settings, or even future generations. Speaking of absolute limits, or a universal interpretation, loses its meaning at lower geographical, temporal or functional scales, and as a result there is no way around treating sustainable development as a social construct.

In virtually all real-world applications, then, sustainable development is a concept that must be interpreted and defined by the stakeholders involved. The contested nature of sustainable development is reflected in its normativeness, subjectivity, ambiguity, and complexity (Grosskurth and Rotmans, 2005). Normativeness implies the existence of a norm or a standard, such as the Brundtland norm suggesting that future generations should have the opportunity to fulfil their needs. Subjectivity 
implies that personal convictions rather than facts play a dominant role, as in the answer to the question what constitutes the needs of current and future generations and when they must be considered satisfied. The ambiguity of the concept relates to the fact that there may be conflicts between the economic, environmental and societal goals of sustainable development. Conflicts that cannot be resolved based on the definition alone, as this definition does not give priority to one domain above the other. The complexity of sustainable development is a result of the interplay between processes on multiple spatial and temporal scales and the involvement of multiple actors with varying interests, beliefs and knowledge. Because of the complexity of natural and societal systems and the inherent uncertainties, there is room for multiple perspectives on sustainability issues. It is clear that these characteristics of sustainable development make its use or implementation in different sectors or systems a daunting task (Grosskurth and Rotmans, 2005).

\subsubsection{TOURISM AND SUSTAINABLE DEVELOPMENT}

Tourism has made an early arrival in the sustainable development debate. The World Tourism Organisation (WTO) launched the principle of sustainable tourism as early as in 1988. Sustainable tourism is defined as:

"development (that) meets the needs of present tourists and host regions while protecting and enhancing opportunities for the future. It is envisaged as leading to management of all resources in such a way that economic, social and aesthetic needs can be fulfilled while maintaining cultural integrity, essential ecological processes, biological diversity and life support systems" (WTO, 1993).

Indeed, tourism has often been presented as a potential economic saviour of countries or marginal communities (Garrod, 1998), in particular of developing nations and remote regions. The socio-economic benefits of tourism that are pursued include the generation of foreign exchange, the stimulation of economic growth, the generation of employment and the improvement of regional economic conditions. Also more recently the WTO stated: "sustainable tourism can be one of the few development opportunities for the poor. Let us use it wisely and soon!" (WTO, 2002). A particular attractive feature of tourism is its proclaimed limited negative impact on the environment (Bachleitner and Zins, 1999), especially when compared to other economic sectors. Next to this defensive approach, a literature has developed that stresses the potential positive contributions that tourism can make to the environment and society, for example by increasing the value of natural parks (Dharmaratne et al., 2000) or by creating pride in local heritage (Brown, 1998). However, in the past two decades a growing body of evidence has developed to support the claim that tourism entails negative effects on social structures and cultural systems (Mathieson and Wall, 1982; Sharpley, 1999; Mowforth and Munt, 2000), as well as on the local and global environment (Gössling, 2002). 
The concept of sustainable tourism has not gone unnoticed by the research community; a large number of articles and books on the topic (e.g. Hunter, 1997; Butler, 1999; Sharpley, 2000; Johnson, 2002; Saarinen, 2006) and the emergence of the specialised Journal of Sustainable Tourism illustrate this. Saarinen (2006) argues that similar to the sustainable development literature, research traditions of sustainable tourism range from understanding resource-based limits and activity based limits, to community based tourism. A whole literature on an absolute measure of biophysical carrying capacity developed in the 1970s and 1980s, a concept which was later practically abandoned, largely because of difficulties in making it operational (Lindberg et al., 1997; McCool and Lime, 2001). Activity-based limits to tourism development focus on the operational capacity of the tourism industry in a given destination resulting from business constraints (e.g. access, attraction, market, facilities). Operational capacity is more dynamic and relative; it can be expanded by investment in marketing and infrastructure. Finally, the tradition of community based tourism, or collectively negotiating trade-offs on the local level, has been proposed as a way to overcome difficulties of the previous two traditions with numerous case studies and implementations worldwide. It implies that a balance be struck between economic, ecological and sociocultural objectives of development represented by stakeholders, which clearly involves relations of power and political decision-making (Saarinen, 2006).

Saarinen's research traditions of sustainable tourism are all present in the Antarctic tourism case. Despite a number of attempts, the concept of carrying capacity has only been successfully applied in the Antarctic context on the local level of the landing site (Davis, 1998; Pfeiffer and Peter, 2004; Crosbie, 2005). Natural boundaries of the Antarctic (e.g. the Southern Ocean, the polar climate) present major limits for tourism activity (Landau and Splettstoesser, 2007) but may be overcome as investments are made in transport and accommodation technology (Hall, 1992b; Lamers et al., 2008). The self-regulatory regime of the Antarctic tour operators can be seen as an example of the community-based tourism tradition (Haase et al., 2009), as well as the local agreements between National Antarctic Programmes and tour operators about station visits. Unlike other destinations, the Antarctic tourism case presents a number of peculiarities that require special attention, such as the absence of an indigenous recipient population and a sovereign government. Therefore, three major conceptual dilemmas have been derived from the sustainable development literature, which need to be addressed in the identification of Antarctic tourism sustainability challenges.

\section{Sustaining what?}

The first dilemma relates to the focus, or objective, of sustainable tourism development. Should sustainable tourism be seen as an activity that sustains itself, sustains local communities, or should tourism's role be one of sustaining larger global systems? In other words, should tourism be seen as an end or as a means in the context of sustainable development? And, in the latter case a means to sustaining what? Hunter (1997) and Sharpley (2000) claim that most definitions of sustainable 
tourism, such as the one by WTO, are tourismcentric, focusing on the question how tourism can be developed as to maximise benefits and minimise costs (ecological, social, cultural) rather than how can tourism contribute to the sustainable development of a society. These perspectives represent the concepts of eco-efficiency and eco-effectiveness (Dyllick and Hockerts, 2002; Braungart et al., 2007). The difference also reflects in the continuum between weaker and stronger sustainability. Part of this dilemma is the question to what extent tourism activity is compatible with environmental, economic or societal values and setting a norm of what sustainable development of tourism in a particular context constitutes. Stakeholders in different settings have different perspectives on what the focus of sustainable development should be depending on their interests (e.g. economic growth, environmental quality, social security).

Contributing to society is difficult in a continent that has none (at least not in the classic sense). Nevertheless, priority may be given to economic interests of tourism development in Antarctic gateway ports and also some of the National Antarctic Programmes surely benefit from tourism. In the context of the Antarctic Treaty System economic interests are inferior to a range of other values. The main aim of the 1959 Antarctic Treaty is to ensure peace and to facilitate international cooperation for scientific research (Antarctic Treaty System, 1959). Article 2 and 3 of the 1991 Protocol on Environmental Protection lists the 'values' fundamental to Antarctica that need protection, such as environmental quality (e.g. air, soil, water, ice, flora and fauna), scientific values (e.g. the laboratory function of the ice sheet), and other values (e.g. aesthetic, wilderness and existence values) (Antarctic Treaty System, 1991). In Annex V of the Protocol, historic values are mentioned. In addition, human safety could be seen as a fundamental condition for any type of development in Antarctica. Of these values, many Antarctic policy makers and other stakeholders prioritise environmental quality and safety, but other less tangible values should not be forgotten in the context of sustainable development. One underlying interest could be added: the geopolitical interests of claimant states. Although claims are not valid, claimant states may still undertake actions that reinforce their claim to Antarctic territory and marine space in case the Treaty seizes to exist in the future. Stimulating tourism could be one of these actions.

The meaning of the sustainable development concept has never been thoroughly discussed in the Antarctic context, in neither academic nor political debates. Therefore, framing sustainable development into a narrow concept with clear indicators that can be used to assess the current and future development of tourism in Antarctica is currently considered a bridge too far. We believe that the choice for the sustainable development objective (as a normative concept) is to be made by the competent authorities governing Antarctica, preferably based on a collective debate among stakeholders. In other words, deciding on the objective of sustainable tourism development entails political decision-making, and this is not the task of a researcher. Analysing different perspectives is a researchers' task contributing to decision making for sustainable development. 


\section{Delimitation in space and time}

Closely linked to the main objective of sustainable development is the appropriate level of scale for analysing sustainable tourism development. Giving priority to the viability of local livelihoods requires analysis on a different level of scale, than protecting the global climate system. However, effects of tourism activity can run across spatial and temporal scales, for example in the case of greenhouse gas emissions and the effects of climate change (Gössling, 2002; Amelung, 2006). Nevertheless, studies of sustainable tourism development have been elaborated much more for local destinations than for the world as a whole. Inter-generational equity is a common denominator of sustainable development, which implies taking a longterm perspective of tourism activity. Negative effects of tourism can be transferred to future generations. Issues of both spatial and temporal scale have been largely neglected in studies of sustainable tourism. As the focus of analysis moves beyond the here and now, from the local to the global and from the present to the future, relationships become more abstract and answers further out of reach. Choosing the appropriate scale for analysis, and relating the system of interest to the broader context are important element in sustainability assessments (e.g. Cash et al., 2006; Weaver and Rotmans, 2006; Grosskurth, 2008).

Antarctica, as a tourism destination, poses a major question with regard to the appropriate spatial and temporal focus of analysis. When focusing on the continental scale of Antarctica, tourism volumes remain modest compared to the size of the continent. However, as we have seen in the previous chapter, activities are strongly concentrated in space and time and coincide with science activities of the National Antarctic Programmes (NAPs) and the breeding season of most animal species. In academia, however, most impact assessments have been limited to local effects on individual sites, while Antarctic ecosystems and climate systems are open. The tourism system itself also represents a complex and global industry. In their review of polar tourism research Stewart et al. (2005) have identified this lack of studies focusing on polar tourism in relation to global (environmental) change. The same can be argued for the appropriate temporal scale used in addressing Antarctic tourism. Antarctic tourism studies are undertaken on an ad hoc basis, i.e. small individual projects, scattered across the globe, for periods of just a number of years, without a common research agenda. Also, tourism studies have predominantly taken an historical approach looking back to past developments. Few future oriented studies have been carried out in the mid-1990s (Bauer, 1994; Snyder, 1997), but more recent future studies are lacking.

\section{Governance and control}

Deciding on the goal and appropriate spatial and temporal scale includes decision making, which forms the third dilemma of sustainable tourism. Authorities, institutions and organisations involved in tourism development focus on different dimensions and function on different scales (Cash et al., 2006). Involving the right stakeholders on the right level is an important prerequisite for sustainable development. 
Control over sustainability outcomes can be achieved through different modes of governance ranging from hierarchical governance (i.e. top down approach, vertical relation between actors, decision power with lead actor) to deliberative governance (i.e. bottom up, horizontal relation between actors, decision power shared by multiple actors) (Van Zeijl-Rozema et al. 2009). These modes of governance form the action perspective of sustainable development. On the one end of the continuum management and planning are usually seen as the appropriate instruments to ensure a sustainable tourism outcome and public authorities are held responsible for their implementation (e.g. Pearce, 1981; Mill and Morrison, 1992; Mclntosh et al., 1995). On the other end, it becomes increasingly clear that tourism development is very complex and cannot be easily controlled or planned (Faulkner and Russell, 1997; McKercher, 1999; Russell and Faulkner, 1999;2004). Also, as the influence and capacity of authorities to control developments diminish throughout the world, pressure is mounting on the business community to adopt part of this agenda (Keijzers, 2002). A large share of the corporate sustainability literature is dedicated to the quest for reconciliation of the objectives of making a profit, and of meeting societal requirements (Dyllick and Hockerts, 2002). Locally negotiated forms of community based tourism development (Saarinen, 2006) could be seen as the deliberative mode of governance on the other end of the continuum. Governance for sustainable development therefore implies a collective effort and a joint responsibility of all stakeholders involved (Bastmeijer and Verschuuren, 2005; Van Zeijl-Rozema et al., 2009).

Antarctica and its resources resemble the characteristics of common pool resources and have been categorised as a global common (Cleveland, 1988; Buck, 1998; Joyner, 1998). Common pool resources (CPRs) are natural or manmade resources characterised by high levels of subtractability and non-excludability. The first means that every unit consumed by one individual is subtracted from the resource system and cannot be subtracted by others. Second, it is very difficult to exclude others from using the resource (Ostrom, 2006): CPR are susceptible to free-riding. When CPRs are valuable and no institutional restrictions are in place, individual users have an incentive to appropriate more and more, leading to cumulative effects such as congestion, overuse, and sometimes to the destruction of the resource. For tourism in a global common, this is surely no different. In the previous chapter, we saw that the level of control the ATS can exercise on Antarctic tourism is not necessarily high and may be insufficient for guaranteeing sustainable tourism development. This makes long term private-public partnerships (Hartman et al., 1999), cooperation between a mix of layered institutions (Dietz et al., 2003; Ostrom, 2005), and forms of adaptive co-management (Olsson et al., 2004; Folke et al., 2005) important governance strategies for tackling sustainability challenges. Self-governance of parties in the field will therefore probably always be an important factor in maintaining sufficient control. Extending the ability of formal authorities to control tourism activities through hierarchical regulations is another strategy for sustainable development. 


\subsection{Integrated assessment and transdisciplinary research}

Tourism studies are commonly acknowledged as a separate research domain, which is multidisciplinary by nature. Indeed, we have seen that researchers from a wide range of disciplines have studied aspects of tourism, especially on the destination level. However, the global tourism system, of which Antarctica is part, consists of an intricate system of cause and effect chains running back and forth across spatial and temporal scales and across disciplinary boundaries. As a result of these non-trivial positive and negative feedbacks and the associated nonlinearities, the tourism system cannot be properly understood by deconstructing it into its constituent parts. It is a so-called "complex system" (see e.g. (McKercher, 1999; Amelung, 2006).

Issues of global change and sustainable development pose major challenges for policy and science. Due to the incremental, irreversible and complex character of these issues, the contested nature of concepts (like sustainability), and the large uncertainties involved it is increasingly claimed that new types of knowledge and new ways of knowledge production are needed (e.g. Gibbons et al., 1994; Kemp and Martens, 2007; Ravetz and Funtowicz, 1993). It is argued that the utility of research can be improved by involving relevant stakeholders, contributing practical knowledge and experience, as well as a range of different perspectives (Van Asselt and Rijkens-Klomp, 2002). This transdisciplinary way of knowledge generation has been coined by Gibbons as the shift from mode- 1 to mode- 2 science (Gibbons et al., 1994; Gibbons, 2000). Mode-1 science is entirely academic, mono-disciplinary, and the scientists are mainly responsible for their own professional performance. Mode-2 science is inter- and transdisciplinary: the scientists co-produce knowledge with societal actors (see Table 2.1). The role of the researcher changes from being a "problem-solver" to a "problem-recogniser" or "problem-mediator" (Hisschemöller and Hoppe, 1996). Funtowicz and Ravetz (1994) have called this contemporary scientific practice "post-normal science" (Funtowicz and Ravetz, 1994; Ravetz, 1999).

Table 2.1: Properties of mode-1 and mode-2 science (adapted from Martens, 2006)

\begin{tabular}{|l|l|}
\hline Mode-1 science & Mode-2 science \\
\hline Academic & Academic and societal \\
\hline Mono-disciplinary & Trans- and interdisciplinary \\
\hline Technocratic & Participative \\
\hline Objective & Subjective \\
\hline Certain & Uncertain \\
\hline Predictive & Exploratory \\
\hline
\end{tabular}


These new concepts of knowledge production are problem-focused in a sociopolitical context characterised by disputed values, high stakes and urgent decisions. The concepts have received a variety of criticisms, for example with regard to the implications for quality control and the lack of empirical evidence that these scientific practices are necessarily "new".(see overview by Hessels and Van Lente, 2008; Wickson et al., 2006). Nevertheless, practical approaches to transdisciplinary knowledge production are developed and implemented in research projects (Scholz et al., 2006; Thompson Klein et al., 2001).

Integrated assessment $(\mathrm{IA})$ is a field of research that fits into a trandisciplinary and policy-focused research tradition. Integrated Assessment has been defined as:

"a structured process of dealing with complex issues, using knowledge from various scientific disciplines and/or stakeholders, such that integrated insights are made available to decision makers" (Rotmans, 1998).

Integrated Assessment (IA) aims at generating new perspectives and insights in complex issues by combining knowledge from different sources, including academia, but also stakeholders involved in the issue. IA emerged in response to global environmental problems where the initial aim was to build large computersupported simulation models. Earlier definitions of IA (such as the one above) have focused amongst others on its aim to be relevant for decision-making. Over the last decade, the aim has evolved and become more explicitly focused on supporting the governance of complex societal problems, involving various actors from state, business, and civil society, in the context of sustainable development. As a consequence participatory methods haven gained prominence in IA (Hisschemöller et al., 2001; Kasemir et al., 2003). It is also reflected in the definition of the Integrated Assessment Society (TIAS) that stresses societal learning as a central aim (TIAS, 2009). Therefore, Integrated Assessment will be defined as:

"the scientific 'meta-discipline' that integrates knowledge from various scientific disciplines and other societal sectors about a complex issue, and makes it available for societal learning and decision making to facilitate action towards sustainable development"

Van der Sluijs (2002) notes that an assessment comprises the analysis and review of information derived from research for policy and usually does not involve doing new research. Also, IA should be understood as a research approach or process as opposed to a research methodology as such (Van der Sluijs, 2002). A range of analytical tools and participatory methods can be applied in performing assessments in an integrated way (Rotmans, 1998; Van der Sluijs, 2002). Analytical methods (e.g. model analysis, scenario analysis and risk analysis) are generally adopted from the natural sciences and are aimed at representing and structuring scientific knowledge in an integrated way. Participatory methods originate from the social sciences and are much more diverse, such as focus groups, Delphi methods and policy exercises. 
Participatory integrated assessment (PIA), as these participatory approaches are usually called, aims at the participation of a variety of stakeholders in the research process to enter into a dialogue and to address the uncertainties involved (Kasemir et al., 2003). Although analytical tools and participatory methods are considered to complement each other (Hisschemöller et al., 2001; Van der Sluijs, 2002) combining them in an integrated assessment is not a straightforward process (Grosskurth, 2008). A detailed treatise of individual IA tools, IA frameworks and their applicability goes beyond the scope of this chapter and can be found elsewhere in the literature (De Ridder, 2006; De Ridder et al., 2007).

The more recent concept of Integrated Sustainability Assessment (ISA) has shifted from a linear IA process to a more cyclical transdisciplinary process of scoping, envisioning, experimenting and learning for sustainable development (Weaver and Rotmans, 2006). Sustainability assessments typically consist of different steps and stages, with each stage of the process producing knowledge needed as input for next steps. The following stages have been identified as crucial in sustainability assessments (Weaver and Rotmans, 2006):

- A system of interest, with a clear functional, spatial and temporal boundary, characterised by a persistent problem that gives rise to concern and prompts the need for a prospective policy intervention;

- A sustainability objective, including quality attributes of the system of interests and a set of criteria (or indicators) against which the sustainability of the system of interest can be assessed;

- Integration of the system of interest into the broader socio-ecological system of which it is part to recognise functional relationships and impacts that spill over the system boundaries;

- Recommendations to make the system of interest more sustainable and discussion of the projected impacts of the recommendations as well as the "do-nothing" or "business-as-usual" option.

IA is useful when faced with complex issues, with a high level of uncertainty, such as the future of tourism in Antarctica. The inter- or transdisciplinary research practice needed for addressing sustainability issues is a central tenet of IA, as well as the development of methods and tools for improving the integration of knowledge from various origins. The system dynamic approach of IA, with a keen eye on issues of spatial and temporal scale, is well suited to tackle the complexity in sustainable development. The ambiguity, subjectivity and normative nature of the sustainable development concept can very well be addressed by the IA attention for stakeholder participation and learning, uncertainty, and perspectives (Grosskurth, 2008). The development of the Integrated Sustainability Assessment (ISA) approach has underlined this applicability (Weaver and Rotmans, 2006). 


\subsection{Research approach and methods}

In this thesis a research approach is chosen that fits in the transdisciplinary research tradition and applies, amongst others, a selection of methods from the IA literature. The research addresses sustainability in an explorative way, i.e. we will not use a rigid framework to assess the sustainability of Antarctic tourism but rather explore potential sustainability challenges based on a set of common characteristics. This approach is deemed necessary because of the unresolved status of the sustainability objective in the Antarctic context. At the end of this thesis, we do hope to contribute to the understanding of what sustainable development in Antarctica entails. The thesis does follow the sustainability assessment stages (Weaver and Rotmans, 2006) in the sense that we focus on a clearly defined system of interest with a need for a prospective policy intervention (tourism in Antarctica); integrated in a larger temporal and spatial setting; with the aim to make policy recommendations to improve the sustainability of the system.

Knowledge gaps in addressing strategic sustainability challenges of Antarctic tourism are twofold. Integrative knowledge is needed about the Antarctic tourism system as a whole, with a focus on the future. To fill this gap, a participatory process is designed in which a variety of stakeholders jointly determine the most salient factors in Antarctic tourism development, analyse a set of future scenarios, discuss implications and identify policy options. On the other hand, in-depth (disciplinary) knowledge is needed about crucial parts of the Antarctic tourism system or impact areas where this knowledge is missing from the academic literature. In these cases applicable concepts and methods have been employed from academic fields, such as environmental science and policy studies. In this thesis a combination is made of chapters describing integrative analyses of the Antarctic tourism system (chapters three, eight and nine), as well as chapters providing in-depth analyses using applicable theoretical concepts (chapters four, five, six and seven). The following section outlines the main research methodologies applied in this study. In each of the following chapters of this thesis, theoretical and methodological considerations will be presented in more detail.

\subsubsection{LITERATURE AND DOCUMENT SURVEY}

This research project started with a survey of the Antarctic tourism literature. Aims of the literature survey were to familiarise with the object of research, identify the main challenges, assess the state of existing knowledge, and identify gaps. Different types of documents were collected and analysed. First, there is the academic literature on Antarctic issues (including tourism) originating from different scientific disciplines, such as ecology, environmental sciences, geography, history, anthropology, law, management, and international politics. Literature was collected through the conventional library system and websites, contacts with fellow researchers, and visiting specialised polar libraries abroad, such as the Scott Polar Research Institute at the University of Cambridge in the United Kingdom and the 
University of Canterbury in Christchurch, New Zealand. Second, there is an extensive body of policy papers (working papers and information papers) that are tabled each year at the Antarctic Treaty Consultative Meetings in which current and strategic issues related to Antarctic tourism are addressed. Policy documents are publicly available through the websites of the Antarctic Treaty Secretariat, the organising Treaty Party, or the submitting organisation. References to both academic literature and policy documents can be found in most chapters of this thesis. For the inventories of adventure tourism incidents and permanent tourism facilities, in chapters five and six, reference is also made to a number of Antarctic information databases, such as the invaluable Australian Antarctic Division (AAD) website. For the integrated scenario analysis presented in chapter eight it is necessary to consult a range of global scenario studies. These studies are typically freely available through the websites of the research project or international organisations, such as the United Nations Environmental Programme (UNEP).

\subsubsection{ANALYSIS OF VISITOR DATA}

Factual data of tourism activity and trends in Antarctica were collected from scholarly articles and the websites of organisations, such as the International Association of Antarctica Tour Operators (IAATO). IAATO collects and publishes a range of statistics of both members' and non-members' (if reported) activities, such as visitor numbers per ship, per trip, or landing per site, and nationalities of Antarctic tourists. The IAATO visitor database was started by the US National Science Foundation in the early 1990s and is based on estimates of the numbers of tourists visiting Antarctica from 1965 onwards. Numbers of staff and crew have not been consistently part of the figures, as these numbers have not always been reported. The same is true for land-based tourists and independent expeditions. Therefore, careful interpretation of existing visitor statistics is required. Antarctic visitor data is presented in several chapters of this thesis. For example, chapter three presents a figure detailing trends in visitor numbers for different industry segments, a chart showing trends in tourist ship capacities, and a figure demonstrating trends in spatial distribution of tourist landings in the Antarctic Peninsula. In chapter four, an estimation of $\mathrm{CO}_{2}$ emissions is calculated, based on available data, such as the nationalities of Antarctic visitors and gross tonnage of Antarctic tourist ships.

\subsubsection{PARTICIPATORY METHODS}

The transdisciplinary approach taken in this research project has been implemented through a series of participatory scenario workshops (Greeuw et al., 2000; Alcamo, 2001). Expert knowledge and judgment of the current and future development of Antarctic tourism and its implications were yielded from three stakeholder workshops held in the Netherlands and New Zealand, to which tour operators, expedition staff, policy makers, NGO representatives, managers of science operations and Antarctic researchers were invited. As in the ISA approach presented above, a cyclical process was followed whereby during each workshop research progress was presented and participants were invited to give suggestions 
for improvement. A report providing details on the methodology, process and outcomes was prepared for each workshop. Draft workshop reports were sent back to the participants for comments, revisions and approval before finalisation. In case of workshop results reference will be made to the reports (Haase and Lamers, 2006; Lamers and Amelung, 2006; 2007b), which can be obtained from the project website $^{3}$. Each of the reports lists the stakeholders that participated during the workshops. To maintain the confidentiality of the data, specific ideas or results of the workshops will not be attributed to individual participants. An overview of the workshops is presented in chapter eight.

Scenario workshops played an important role during the first half of this project, when the scope and focus of research were openly discussed with the participants. A limitation of using participatory workshops in a voluntary research project, with no formal policy mandate or clear economic return, is the difficulty of continued commitment of getting relevant stakeholders around the table. In addition, Antarctic tourism stakeholders and experts are sparsely dispersed across the globe and may not be able or willing to participate without being financially compensated for costs. Therefore, scenario workshops were organised in a central location in the Netherlands; a country with a fairly complete group of stakeholders representing most relevant interests. A five-month visit to New Zealand presented an opportunity for organizing a scenario workshop in this Antarctic claimant state with a strong and active interest in Antarctic tourism issues. Workshop results have provided input in chapters three and eight. The scenario workshops have not only yielded in research results but may also have contributed to social learning for sustainable development and raised awareness for future challenges among Antarctic tourism stakeholders.

It is also worth mentioning that parts of this thesis have benefitted substantially from intense participation with Antarctic tourism scholars, beyond the ICIS project team, bringing knowledge and experience from different academic disciplines. Coauthors of earlier published articles upon which chapters of this thesis were based are presented on the cover page of each chapter.

\subsubsection{IN-DEPTH INTERVIEWS}

To obtain insights from key-stakeholders not participating in the workshops, interviews were conducted with international stakeholders and experts in Europe, North America and South America. Among other things, it was considered essential to identify their roles, their ambitions and perceptions of the future. An additional aim of the interviews was to create an alternative set of stakeholder views to which workshop results could be compared. During the interviews a semi-structured interview guideline was used reflecting the issues discussed during the workshops (Neuman, 2003). The interview guideline is included as appendix of this thesis.

\footnotetext{
${ }^{3}$ Check the project website at: http://www.icis.unimaas.nl/projects/atlantis/publications.html
} 
Interviews were audio-recorded, transcribed, and sent back to the interviewees for revisions and approval (Robson, 2001). To maintain the confidentiality of the data, interviewees remain anonymous and a coding system will be used to refer to interviews (for details see chapters seven and nine). In chapter seven, the selfregulatory regime of IAATO was analysed in cooperation with fellow researcher Dr. Daniela Haase of Gateway Antarctica at the University of Canterbury in Christchurch, New Zealand. For that purpose comparable interview material from two studies was combined, resulting in a wider group of interviewees. In chapter seven details are provided. In chapter nine perspectives on a range of strategic future developments and governance options are presented based on the interview round performed by the author.

During a fieldwork expedition to King George Island in January and February 2008, a second, and less comprehensive, round of interviews was organised among base managers and key scientific staff at six research stations, i.e. Base Frei (Chile), Bellingshausen Station (Russia), Base Artigas (Uruguay), Jubany/Dallmann (Argentina/Germany), Arctowski Station (Poland) and Copa Cabana (United States). Aim of the interviews was to generate insight into the different motivations and perspectives of national programmes for their relation to tourism activities. Interviews were conducted together with ICIS colleague Dr. Bas Amelung and audio recorded for accurately capturing the results. The King George Island interviews do not form part of the primary data of this thesis and will only be used as (see chapter three); therefore, no detailed transcriptions were produced.

\subsubsection{OBSERVATIONS AND EXPERIENCES IN THE FIELD}

Besides systematic inventories of factual data and careful interpretations of subjective stakeholder perspectives, this thesis is enriched with the observations and experiences generated over the course of five years of research. It is believed that the special and uncommon nature of both Antarctic tourism operations and policymaking justifies a brief exposition of experiences gained by the author in the Antarctic and during Antarctic decision-making platforms (see box 2.1). Although experiences and personal observations are not part of the primary data collected during this study, they are important for framing the research problem ("putting things in perspective") and thinking about solutions that are in touch with reality ("reality check"). 


\section{ATCM Stockholm (Sweden)}

In June 2005, I attended the Antarctic Treaty Consultative Meeting in Stockholm where I sat in the discussions of the Tourism Working Group. This experience of the Antarctic decision making platform provided a valuable political context for this thesis.

\section{GCAS field camp, Ross Island (Antarctica)}

In December 2005, I gained my first Antarctic field experience as participant of the Graduate Certificate in Antarctic Studies course (GCAS), organised by the University of Canterbury in Christchurch, New Zealand. Part of this summer school programme is a two-week field camp to Ross Island in the Ross Sea region, including visits to Scott Base (NZ), McMurdo station (USA), and various other sites.

\section{Research expedition to King George Island (Antarctica)}

In January and February 2008, a research expedition was organised to King George Island. Several research stations were visited, including Bellingshausen (Russia), Base Frei (Chile), Artigas (Uruguay), The Great Wall (China), Jubany (Argentina), Arctowski (Poland), and Copa Cabana (USA). This expedition provided insights into the relation between tourism operations and the science operations of various nations. During the expedition also valuable lessons were learned regarding logistical challenges of conducting research in Antarctica.

\section{Expedition cruise to the Antarctic Peninsula (Antarctica)}

In March 2009, I joined an 11-day expedition cruise aboard the M/S Aleksey Maryshev to the Antarctic Peninsula organised by Waterproof Expeditions. During this expedition data was gathered (i.e. a tourist experience survey) that is part of a follow-up study and not included in this thesis. However, insightful observations have been made during this tourist cruise of the on-site operations of the tourist industry in Antarctica. 


\section{Chapter 3}

\section{FACING THE ELEMENTS: ANALYSING TRENDS IN ANTARCTIC TOURISM}

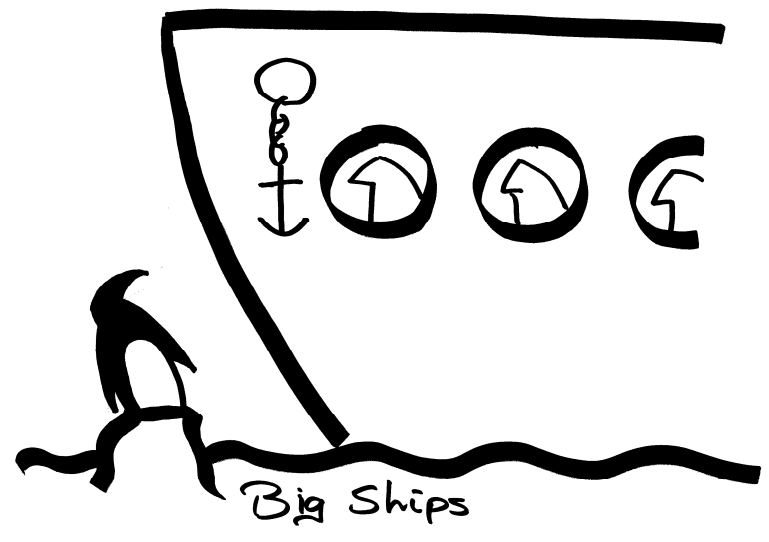

This chapter is based on:

Lamers, M., Haase, D., Amelung, B. (2008) Facing the Elements: Analyzing trends in Antarctic tourism. Tourism Review 63(1): 15-27. 


\subsection{Introduction}

The last two decades have seen a rapid development of tourism in Antarctica with increasing visitor numbers and a diversifying supply of transport modes and activities (see Figure 3.1). Traditional small-ship expedition cruises that include landings are now complemented by cruise-only itineraries without landings for large ships, fly-sail operations, and adventure tourism activities such as kayaking, scuba diving or mountain climbing.

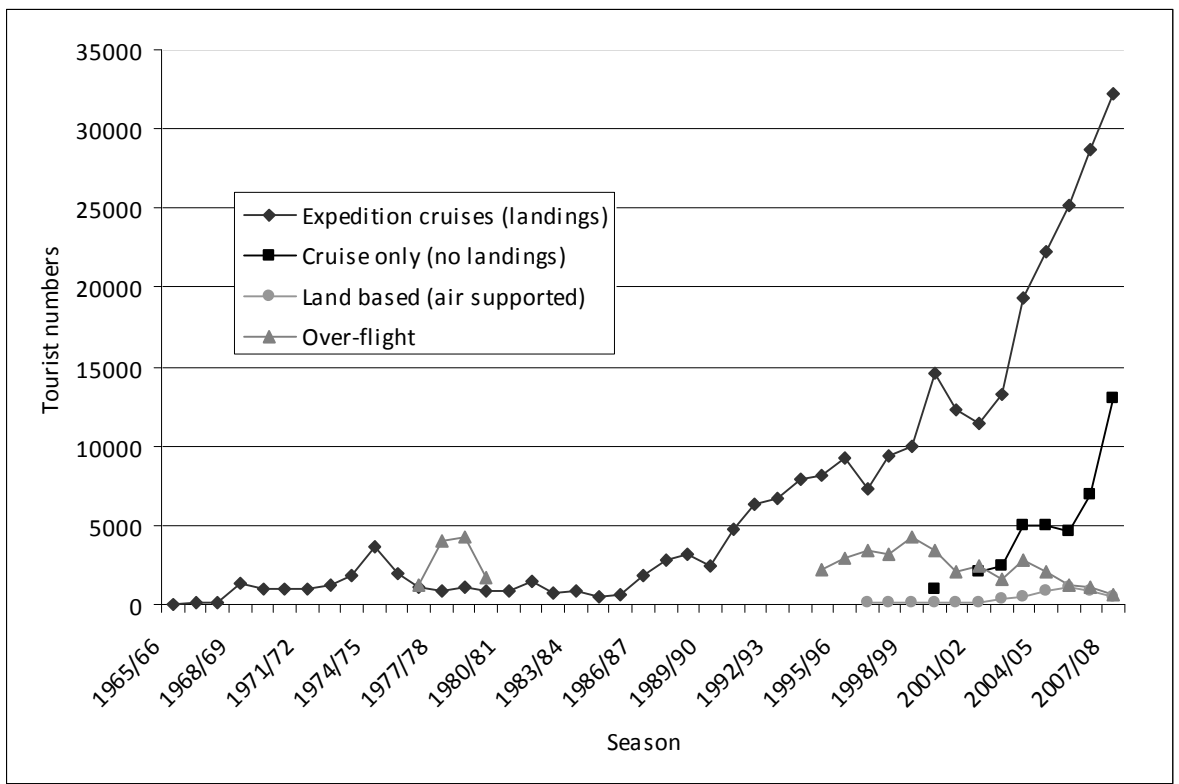

Figure 3.1: Tourists visiting Antarctica in different industry segments 1965-2008 (Headland, 1990; Enzenbacher, 1993; IAATO, 2005b; 2006b; 2007a; 2008b; Headland, 2009)

In view of these developments, tourism management is becoming an increasingly important issue. The current regulatory framework consists of the provisions of the Antarctic Treaty System (ATS) supplemented by external regulations from e.g. the International Maritime Organisation (IMO) and by industry self-regulation through the International Association of Antarctica Tour Operators (IAATO) (Molenaar, 2005). Recent policy discussions at Antarctic Treaty Consultative Meetings (ATCMs) have focused on the need for additional legal instruments and measures, such as site-specific guidelines, to mitigate the effects of tourism (Antarctic Treaty System, 2004; 2005; 2006; 2007b). Some authors (Bastmeijer and Roura, 2004; Molenaar, 2005; ASOC, 2006) argue that, in addition to these rather reactive measures, a more proactive, strategic vision for Antarctic tourism development and regulation is warranted. 
Some of the building blocks needed for such a long-term vision can be provided by integrated scenario analysis (Amelung and Lamers, 2006). Integrated scenarios combine knowledge from a range of disciplines, as well as professional insights, to arrive at a more complete analysis of a system. The scenarios that this chapter relates to are developed in a multiple-stage iterative process (see chapter eight). The first phase consisted of the identification of driving and inhibiting factors for Antarctic tourism development. Past and projected future trends of these factors are analysed in phase two. This chapter reports on these first two phases. The results of the factor analyses will be merged to produce integrated scenarios in stage three. The ultimate goal of this research project is to provide insights for managers and decision makers within the ATS and other relevant institutions.

The central aim of this chapter is to "face the elements" of Antarctic tourism development by exploring how key factors have shaped the past of tourism in Antarctica, and may jointly shape its future. The analysis uses the Recreational Opportunity Spectrum (ROS) approach, developed by Clark and Stankey (Clark and Stankey, 1979) and applied to tourism (Butler and Waldbrook, 1991; Boyd and Butler, 1996), which combines an analytical framework with an action-oriented management perspective, making it suitable for our purposes.

This chapter is organised as follows: Section two describes the data and methodology used and introduces the ROS framework. Section three analyses the past and future trends of the main determinants of Antarctic tourism, including an overview of the components of the Antarctic Tourism Opportunity Spectrum (ATOS). Section four, discusses the implications for different tourism opportunity settings in Antarctica, and section five concludes.

\subsection{Methodological and theoretical considerations}

This analysis of Antarctic tourism trends and their main drivers is based on a thorough literature review, the interpretation of "hard" Antarctic tourism data and "soft" information elicited through a number of stakeholder workshops. The literature review includes an analysis of empirical research studies (e.g. biological and physical impacts of tourism), articles on tourism management and regulation, and policy papers presented at recent ATCMs. Additional literature sources were sought in areas such as climate change, polar logistics, and tourism development. Most of the statistical data on Antarctic tourism development was obtained from IAATO through their website (IAATO, undated), which provides the only detailed publicly available listing of Antarctic tour operator activity from the early 1990s onwards.

Expert knowledge and judgment on the current and future development of Antarctic tourism and its implications were yielded from two stakeholder workshops, in which a wide range of Antarctic tourism stakeholders participated, including tour 
operators and expedition staff, policy makers, NGO representatives, and scientists. Full details on the workshops held in The Hague (Netherlands) on 23 September 2005 and Christchurch (New Zealand) on 7 April 2006 can be found in Haase and Lamers (2006) and Lamers and Amelung (2006).

Upon review of the material obtained, several clusters of key factors determining the future of Antarctic tourism development were identified inductively. Clusters showed close resemblance to the determinants of the factor categories of the Recreational Opportunity Spectrum (ROS) framework developed by Clark and Stankey (1979), and its derivatives. This natural fit convinced us to use this concept for the analysis of our data and to facilitate the assessment of management and policy options later on.

ROS was developed in 1979 to help national park managers in to USA to assess the (potential) qualities of their park for recreational purposes. The concept of a recreation opportunity setting is defined as "the combination of physical, biological, social, and managerial conditions that give value to a place (...). By combining variations of these qualities and conditions, management can provide a variety of opportunities for recreationists" (Clark and Stankey, 1979: 1). Since its conception, the Opportunity Spectrum concept has been applied and adapted to many other settings, including destinations for ecotourism and adventure tourism (Boyd and Butler, 1996; Butler and Waldbrook, 1991) and tourism in the European Arctic (Kaltenborn and Emmelin, 1993). Davis (1999) and Tracey (2001) proposed to do the same for Antarctic tourism, but never proceeded. In this chapter, an Antarctic Tourism Opportunity Spectrum is developed from the application of ROS that resembled the Antarctic case most closely: the Ecotourism Opportunity Spectrum (ECOS), developed by Boyd and Butler (1996).

ECOS was developed as a tool for assessing an area's potential for ecotourism opportunities. Following ROS, care was taken that the factors defining opportunity settings were all observable and manageable, under direct management control, related to recreationists' preferences, and "characterised by a range of conditions" in order to maximise usefulness for managers (Clark and Stankey, 1979). Based on these criteria, Boyd and Butler (1996) identified eight determining factors: access, other resource users, attractions in the region, presence of existing tourism infrastructure, the level of social interaction, the level of skill and knowledge required, the (acceptability of) visitor impacts, and appropriate regulation required to manage the viability of the opportunity and the resource on a long term basis.

In the following section, the ECOS framework is used to structure the presentation of current and possible future development factors in Antarctic tourism. In view of the specific Antarctic conditions, modifications are made to the original ECOS configuration, resulting in an Antarctic Tourism Opportunity Spectrum (ATOS). In the analysis, regular reference is made to contextual developments, i.e. developments beyond the realm of immediate influence of the Antarctic stakeholders, such as 
economic growth, demographics, oil prices, and global terrorism. Strictly taken, these factors are no part of ROS-like frameworks as they are less relevant for operational decision-making. The strategic level of management that our work is directed at requires the inclusion of major contextual factors that represent external and global dynamics.

\subsection{Key factors influencing Antarctic tourism development}

\subsubsection{ACCESS}

Antarctica's remoteness, extreme climatic conditions, and presence of sea and land ice cause major constraints for any type of human activity. Tourists access the Antarctic in two basic steps: by air from their home country to a number of gateway cities in the Southern Hemisphere, and from there by sea or air to a number of Antarctic regions (Amelung and Lamers, 2007). Most tourists visit the Antarctic Peninsula region on ship-based itineraries leaving from gateway cities in Southern Argentina and Chile (see Figure 3.2). Small numbers of tourists and adventurers travel to Antarctica by aircraft from Punta Arenas in Chile and Cape Town in South Africa. Also, a small share of tourists visits the Ross Sea region by ship from Australia and New Zealand. Access is almost completely controlled by professional tour operators, who organise the expedition, determine the schedule, and decide which sites are visited. According to industry representatives, this is a daunting task that involves tremendous operational costs, many constraints and uncertainties (Landau and Splettstoesser, 2007).

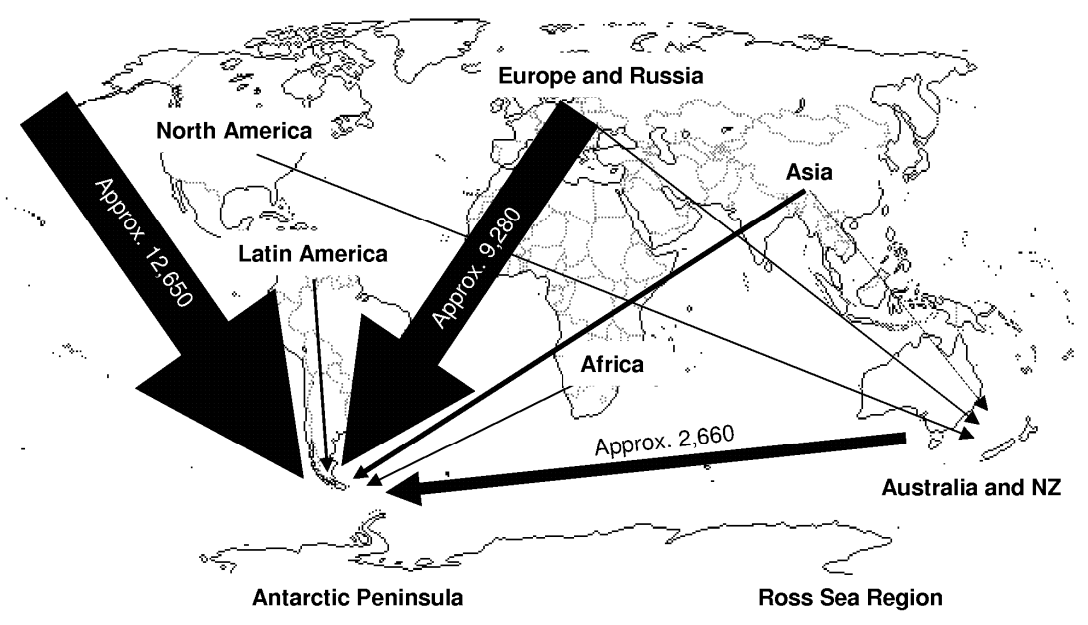

Figure 3.2: Overview of origin and destination of Antarctic tourists during the 2004/05 season (Lamers and Amelung, 2007a) 
In the 1990s, following the collapse of the Soviet Union, the fleet of small passenger ships (< 50 and 51-110 passenger categories) was expanded significantly when Russian research vessels capable of operating in polar waters became available on the free market (Stonehouse, 1994; Cessford, 1997). Over the last few years, cruise-only tourism (large cruise liners making no landings) established itself in Antarctica, and figures and projections indicate that these large vessels are there to stay. In fact, most growth has occurred in the largest ship segment with the number of small ships stabilizing (see Table 3.1). Large cruise vessels travel at higher speeds and cause less turbulence for the passengers than smaller expedition ships when traversing the notorious Drake Passage. Growth in small-scale expedition cruising is expected to stabilise in the coming decade as a result of the limited supply of suitable expedition ships and the cost-effectiveness of building larger vessels (IAATO, 2004a).

Table 3.1: Number of ships active in Antarctic tourism (by passenger capacity), 1990-2006 (IAATO, 1997; 1998; 1999; 2000; 2001; 2002b; 2003a; 2004b; 2005b; 2006b; 2007a; Headland, 2009)

\begin{tabular}{|l|l|l|l|l|l|l|}
\hline Year: & $\begin{array}{l}<\mathbf{5 0} \\
\text { passenger } \\
\text { ships: }\end{array}$ & $\begin{array}{l}\mathbf{5 1 - 1 1 0} \\
\text { passenger } \\
\text { ships: }\end{array}$ & $\begin{array}{l}\mathbf{1 1 1 - 2 0 0} \\
\text { passenger } \\
\text { ships: }\end{array}$ & $\begin{array}{l}\mathbf{2 0 1 - 5 0 0} \\
\text { passenger } \\
\text { ships: }\end{array}$ & $\begin{array}{l}\mathbf{>} 500 \\
\text { passenger } \\
\text { ships: }\end{array}$ & Total: \\
\hline $1989 / 90$ & 1 & 1 & 2 & 0 & 0 & 4 \\
\hline $1990 / 91$ & 1 & 2 & 3 & 1 & 0 & 7 \\
\hline $1991 / 92$ & 2 & 1 & 3 & 3 & 0 & 9 \\
\hline $1992 / 93$ & 2 & 3 & 4 & 3 & 0 & 12 \\
\hline $1993 / 94$ & 1 & 4 & 4 & 1 & 2 & 12 \\
\hline $1994 / 95$ & 5 & 5 & 4 & 1 & 1 & 16 \\
\hline $1995 / 96$ & 6 & 4 & 4 & 0 & 1 & 15 \\
\hline $1996 / 97$ & 5 & 4 & 4 & 0 & 0 & 13 \\
\hline $1997 / 98$ & 3 & 4 & 5 & 1 & 1 & 14 \\
\hline $1998 / 99$ & 4 & 6 & 4 & 0 & 1 & 15 \\
\hline $1999 / 00$ & 6 & 6 & 4 & 0 & 4 & 20 \\
\hline $2000 / 01$ & 6 & 7 & 3 & 1 & 1 & 18 \\
\hline $2001 / 02$ & 6 & 6 & 3 & 1 & 2 & 18 \\
\hline $2002 / 03$ & 8 & 6 & 4 & 1 & 4 & 23 \\
\hline $2003 / 04$ & 5 & 9 & 5 & 2 & 6 & 27 \\
\hline $2004 / 05$ & 6 & 11 & 5 & 2 & 6 & 30 \\
\hline $2005 / 06$ & 9 & 13 & 5 & 3 & 6 & 36 \\
\hline $2006 / 07$ & 7 & 12 & 7 & 5 & 9 & 40 \\
\hline & & & & & & \\
\hline
\end{tabular}

Only a small number of commercial air links have been developed for expedition logistics, adventure tourism, day trips, and over flights. However, National Antarctic Programmes (NAPs) have established air connections between gateway cities and various Antarctic regions and non-governmental operators (mostly independent expeditions) have been allowed to use these air links (IAATO, 2006b). Physical and 
geographical constraints might diminish as infrastructure, logistics and technology improves; for example, the airstrip on King George Island (in the Peninsula region) will be upgraded and become capable of handling larger passenger aircrafts in allweather conditions (Bastmeijer and Roura, 2008).

Infrastructural developments in gateway city ports are believed to greatly influence the opportunities for tourism in Antarctica. Bertram et al. (2007) argue that the increase of ship-based tourism in Antarctica in the last decade can be related to public policy and infrastructural developments in Antarctic gateway cities, particularly Ushuaia. Because of the economic benefits from port charges, airport taxes and expenditure of the undoubtedly affluent visitors, gateway cities have clear reasons for promoting Antarctic tourism in the future.

Increasing global demand for Antarctic experiences constitutes an 'opportunity' for the tour operator to create access, which is influenced by a myriad of contextual factors. Currently, the main Antarctic tourist markets are found in North America, Europe and Australia. Not surprisingly, given the costs involved in Antarctic tourism, these regions also represent some of the richest countries in the world. Demand for Antarctic tourism is expected to increase in these traditional markets as a result of growing media attention, growing affluence, spare time, urbanisation, ageing, and the growing global interest in ecotourism and adventure tourism (WTO, 2001). Further, it is argued that Antarctic tour companies continue to merge or are taken over by larger travel companies with access to extensive resources for marketing Antarctic itineraries. Demand for global tourism products is expected to grow considerably in Russia, China, India and other expanding economies as well. On the other hand, being so energy intensive (e.g. dependence on long haul air travel from Northern Hemisphere societies and shipping), any increase in global energy prices or international greenhouse gas mitigation policy will affect the travel costs and operational costs of Antarctic tour operators (Amelung and Lamers, 2007). Another important contextual factor influencing the access of especially the larger ship-based companies concerns the popularity of other destinations in the region, such as the East and West coast of South America. Since repositioning an empty cruise vessel to the Antarctic is economically unfeasible, cabins have to be sold along the way. Developments in the Arctic region are also believed to be an important factor for providing polar technology, business opportunities during the off-season, and for the promotion of polar destinations in general.

\subsubsection{OTHER NON-TOURIST RESOURCE USES}

The compatibility with other resource uses is considered to be crucial in creating opportunities for recreational and tourism activities (Clark and Stankey, 1979; Boyd and Butler, 1996). In the Antarctic context, scientific activities have clear precedence over the commercial use of Antarctic resources. However, mutual benefits can be derived from the cooperative operations of different users, and pro-active 
management in cases of undesired effects. Moreover, as a result of global developments other industries might become active in the Antarctic in the future.

With regard to tourism development, scientific operations are particularly important as activities tend to occur in the same regions and cooperation with tour operators frequently occurs in the field of transport, facility use, and station visits (COMNAP, 2004; IAATO, 2005c). The attitude of NAPs towards cooperating with tourism varies from station to station (see Box 3.1).

Box 3.1: Motivations of NAPs for relating to tourist activities on King George Island

During the 2008 research expedition to King George Island interviews were conducted with base managers at six research stations operated by six NAPs. At each of the research stations different key motivations were expressed regarding visits of tourist ships and cooperation with tour operators.

\begin{tabular}{|c|c|}
\hline $\begin{array}{l}\text { Showing pres- } \\
\text { ence: }\end{array}$ & $\begin{array}{l}\text { Tour operators for fly-sail operations, evacuations and day-visits frequently use } \\
\text { the Chilean Eduardo Frei station, the Villa las Estrellas and the adjacent aero- } \\
\text { drome. The base manager frankly admitted that if tourism can be used to } \\
\text { strengthen the Chilean territorial claim, Chile would not hesitate to do it. }\end{array}$ \\
\hline Friendship: & $\begin{array}{l}\text { The Russian Bellingshausen station provides accommodation for a tour opera- } \\
\text { tor and space for three basic containers for lodging airborne tourists. The base } \\
\text { manager claimed that in Antarctica friendly cooperation is the key for long- } \\
\text { term maintenance of the research stations. }\end{array}$ \\
\hline Cutting costs: & $\begin{array}{l}\text { The Uruguayan Artigas station has recently built a brand new accommodation } \\
\text { facility for the purpose of lodging scientists and paying airborne tourists. Ac- } \\
\text { cording to the base manager this is a way to retrieve some of the costs of } \\
\text { operating an expensive Antarctic science programme. }\end{array}$ \\
\hline $\begin{array}{l}\text { Breaking the } \\
\text { monotone: }\end{array}$ & $\begin{array}{l}\text { The Argentinean Jubany station hardly gets any visits from tourist ships. Ac- } \\
\text { cording to the base manager tourist visits form a welcome distraction from the } \\
\text { isolated station life as long as it does not interfere too much. Also, ships some- } \\
\text { times bring fresh fruit and vegetables. }\end{array}$ \\
\hline Dependency: & $\begin{array}{l}\text { The Polish Arctowski station receives many ship visits each season and has } \\
\text { constructed a souvenir shop and a tourist walk around the station. According } \\
\text { to the base manager, the Polish programme has to be welcoming to ships } \\
\text { because it has limited logistical capacity in the Antarctic and it therefore de- } \\
\text { pends on tourist ships for transport. }\end{array}$ \\
\hline Legality: & $\begin{array}{l}\text { The United States' Copa Cabana field station receives no visits, as it is located } \\
\text { in an Antarctic Specially Protected Area. }\end{array}$ \\
\hline
\end{tabular}

In some regions, the presence of science programmes provides opportunities (e.g. in the Antarctic Peninsula region), while in other regions tourism developments are discouraged. Besides fruitful cooperation NAPs have raised concerns regarding one-off expeditions, such as private expeditions and yachts, as they demand Search and Rescue (SAR) facilities in case of misadventure (Murray and Jabour, 2004; Lamers et al., 2007). By the same token, increasing numbers of large cruise vessels are a cause for similar concerns as larger groups of tourists are much more difficult to retrieve in case of an accident (ASOC, 2007). 


\subsubsection{ATTRACTIONS IN THE REGION}

According to Boyd and Butler (1996) area-specific characteristics functioning as site attractions constitute an important factor in creating the opportunities sought by different types of visitors. In the case of expedition cruising in the Antarctic, the main attractions are the presence of wildlife (e.g. penguins, seals) at landing sites, the dramatic scenery, heritage sites (featuring remains of whalers' activities, explorer huts and former scientific stations), and sometimes station visits. Most tourist activities are known to concentrate on a limited number of sites in the Antarctic Peninsula (see Figure 3.3 and Figure 3.4). Large-scale cruise operations generally do not land tourists ashore and admire the polar landscape from the ship.

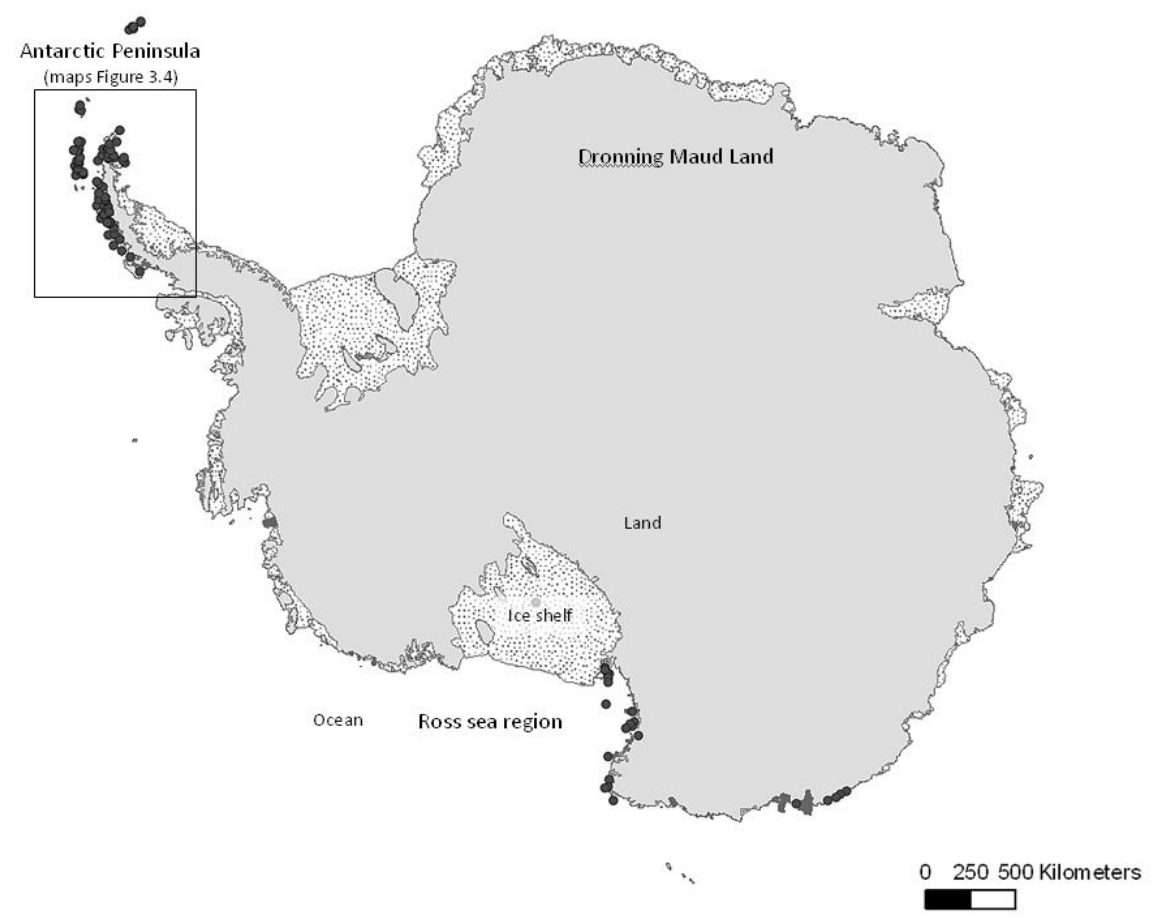

Figure 3.3: Antarctica tourism landing sites used in the $2005 / 06$ season (Olearius, 2007)

It is believed that tourists mainly visit Antarctica because of its reputation as one of the last untouched wilderness areas on earth (Haase and Lamers, 2006; Lamers and Amelung, 2006). Due to contextual factors such as urbanisation, the attraction of Antarctica as a remote and extreme destination will not fade in the future. However, global environmental changes can have a detrimental effect on wildlife populations in fragile Antarctic ecosystems (Crosbie, 2005; Frenot et al., 2005), particularly the Antarctic Peninsula is one of the regions in the world most heavily touched by global warming (Vaughan et al., 2003). 


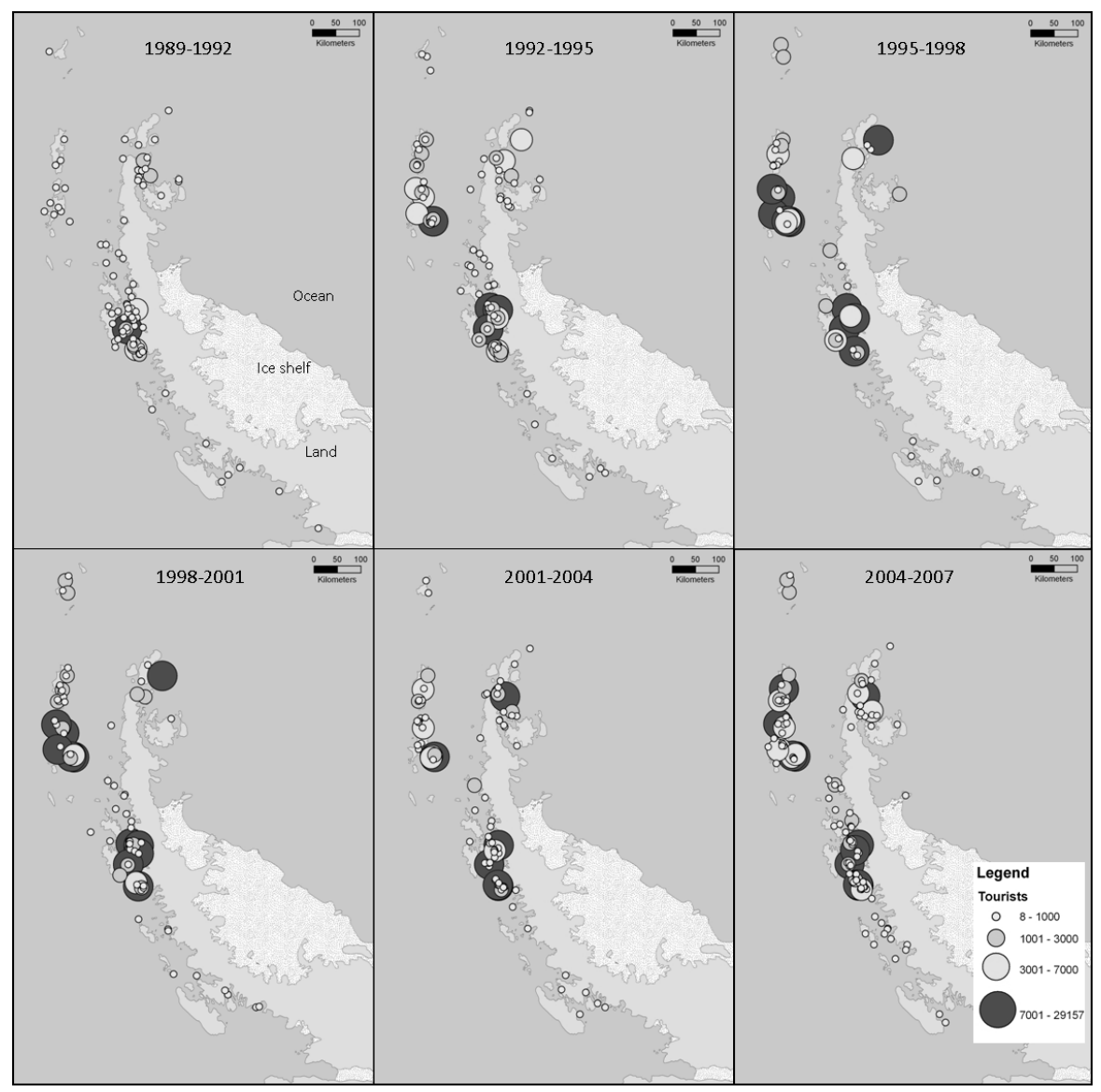

Figure 3.4: Trends in site visitation in the Antarctic Peninsula, 1989-2007 ${ }^{4}$

In recent years, the range of activities undertaken as part of Antarctic tourism operations have greatly diversified and now include kayaking, running marathons, scuba diving, camping, climbing, and helicopter flights as well as a number of others (Bastmeijer, 2003). This diversification of activities reflects the increasing levels

\footnotetext{
${ }^{4}$ Each of the six maps presents the total number of tourists landed at Antarctic Peninsula sites per three consecutive seasons from 1989 to 2007 . The maps show a spatial visitation trend between three main regions of concentration: the South Shetland Islands (upper left concentration), the Northern Peninsula, and the Southern Peninsula. Initial concentration has been on the Southern Peninsula region with other regions receiving more attention as ship numbers increased and itineraries were standardised to manage the flow of traffic (see chapter seven). The maps were created by Götz Olearius of the Geographisches Institut at the RWTH in Aachen as part of his Master thesis on the use of Geographical Information Systems (GIS) in tourism research, co-supervised by the author. For a detailed description of the methods and data used to produce these maps the reader is referred to Olearius' Master thesis (Olearius, 2007).
} 
of specialisation and competition among tour operators globally offering quality ecotourism and adventure experiences (WTO, 2001).

\subsubsection{PRESENCE OF EXISTING TOURISM INFRASTRUCTURE}

In comparison with other tourist destinations in the world, tourist facilities and site modifications are an almost non-existing factor in Antarctica. With the exception of a number of frequently visited landing sites or sites near scientific stations, no clear walking trails are marked or signposted (Crosbie, 2005). The only onsite facilities are a set of containers operated by the Chilean operators Aerovias DAP and a number of visitor centres and tourist gift shops at various scientific stations (Bastmeijer et al., 2008). Nevertheless, infrastructure and facilities for tourism in Antarctica may be established in the future as the industry grows and diversifies. For instance, on a number of sub-Antarctic islands, the option to develop boardwalks is being explored, as they are believed to protect the vegetation and wildlife at frequently visited sites (McKee, 2006). For a more detailed overview and discussion of facilities and infrastructures, see chapter 6 of this thesis.

\subsubsection{OPERATIONAL FACTORS}

ECOS presents the level of social interaction and the level of skill and knowledge as two important factors determining different kinds of tourism opportunities. In the Antarctic, social interaction and the level of skill, knowledge and experience are largely apparent at an operational level, facilitated through the tour operators. Hence, we refer to these factors jointly as operational factors.

Any specific opportunity setting is linked to an expected level of use, for instance, very low expected levels of use in a largely untouched wilderness area. Should the actual level of use exceed the expected level of use, the social carrying capacity is reached and overcrowding is experienced (Clark and Stankey, 1979: 11). Social interaction in Antarctic tourism largely takes place between the tourists travelling in the same group or on the same ship, the crew and expedition staff, and base personnel, with the social carrying capacity being low as intrinsic wilderness values tend to dominate acceptable use of the resources (De Poorter, 2000; Bastmeijer and Roura, 2004; Haase and Lamers, 2006). Since tour operators sell the Antarctic as a pristine and unique destination, interaction between different tourist vessels is kept to a minimum. However, more tour operators are active, and more voyages are organised every season, motivating Antarctic tour operators to collaborate in order to maintain the picture of pristine and untouched wilderness. By means of an integrated ship scheduling system, managed by IAATO, most tour operators maintain the "one ship, one place, one moment" principle, which dictates that individual operators do not interfere with each other in the Antarctic but rather have allotted times for visiting previously specified sites. Besides maintaining the illusion of emptiness, operators also continuously stay in contact to minimise environmental impacts and safety risks by providing backup in case of incidents. 
IAATO has been very successful in developing and enforcing high operational standards as well as convincing tour operators and other actors to join (Molenaar, 2005). For more than a decade, IAATO has managed to anticipate official regulation and solve managerial issues raised by tourism (Landau and Splettstoesser, 2007). However, with new operators with different aims, operational scales, and origins entering the market, pressure on IAATO increases with regard to maintaining its operational standards. Consequently, IAATO has to carefully define its bylaws and guidelines in order to keep everyone on board and avoid free-riding among operators (United Kingdom, 2004a). For a detailed analysis of self-regulation in Antarctic tourism, see chapter seven of this thesis.

Depending on the mode of transport and the activities scheduled, a sufficient level of skill, knowledge and experience is of utmost importance for operating in a continent as extreme and remote as Antarctica. Aside from skills and knowledge for safe and responsible transportation, additional skills are needed for adventure activities and landings as well as for educational programmes scheduled on board. Hiring experienced and qualified staff is considered increasingly problematic, especially for new operators with specialised requirements.

\subsubsection{ACCEPTABILITY OF VISITOR IMPACTS}

In the opportunity spectrum literature, it is acknowledged that "any use creates some impact" (Clark and Stankey, 1979: 13) and argued that it is the duty of the managers to maintain the integrity and quality of the resource. Acceptable levels of impacts describe an appropriate magnitude and environmental value for a specific opportunity setting. The concept of acceptable impacts is of great significance for the Antarctic setting, where emotiveness and sensitivity prevail towards patterns of resource use, crowding, pressures on the environment, or changing habitats (Davis, 1999).

So far, empirical studies have hardly proven observable impacts of tourism visitation (Hofman and Jatko, 2000). Following the Madrid Protocol, IAATO has stipulated that impacts from member companies may not exceed a minor or transitory nature. However, the risks to human safety and the environment can never be totally eliminated. Furthermore, cumulative impacts, which have been neither extensively researched nor subjected to specific and more stringent regulation, may occur at intensely used landing sites. New landing sites are utilised every season (Crosbie, 2005), which may lead to the geographical spread of impacts. Recently, it was argued that environmental impacts that are less easily observable, such as damage to the marine environment (Molenaar, 2005) and greenhouse gas emissions as a result of tourist transport (Amelung and Lamers, 2007), have not been taken into account. Finally, in a region as unique as Antarctica, people might consider tourism to have an impact on the intrinsic value of Antarctica (De Poorter, 2000). These last three types of impacts are not easily observable and are difficult 
to consider in decision-making. For a more in-depth treatise of environmental impacts, see chapter four of this thesis.

\subsubsection{ACCEPTABLE REGULATORY FRAMEWORKS}

Regulation and management of an opportunity setting may be indispensable where the natural character and integrity of a resource have to be assured. The latter is of great significance for the Antarctic with environmental principles enshrined in the ATS in form of the Environmental Protocol. In addition to the regulations imposed by the ATS, external regulatory frameworks, such as the self-imposed rules and guidelines of IAATO, constrain opportunities for tourism in Antarctica. In these paragraphs, we will briefly describe the regulatory framework of the ATS.

Many authors have argued that the current level of formal ATS regimentation is not sufficient, as it seems to lag behind the level of growth and diversification that Antarctic tourism has experienced over the last decade (Scott, 2001; Bastmeijer and Roura, 2004; Molenaar, 2005; Amelung and Lamers, 2006). The ATS is characterised by a lack of undisputed sovereignty and not every nation in the world is a party to the Antarctic Treaty, making it difficult to effectively regulate global tourism activities (Beck, 1990; Richardson, 2000; Molenaar, 2005). A major criticism of the ATS relates to the fact that it does not represent a single, unified, comprehensive regime including real restrictions (Bastmeijer and Roura, 2004; Molenaar, 2005), but a rather fragmented collection of recommendations, measures, resolutions and decisions which leave some significant loopholes (Molenaar, 2005: 31). Within the ATS there are considerable national differences and inconsistencies with respect to the implementation of regulatory procedures (Kriwoken and Rootes, 2000; Richardson, 2000).

Nevertheless, the Environmental Protocol requires that tourism activities are prenotified and that an environmental impact assessment is filed. Tour operators are advised to follow a range of guidelines (most of which were developed by IAATO). Acquiring insurance and back-up planning has become mandatory and site-specific guidelines are being developed to minimise the impacts on frequently visited landing sites and improve onsite management. A more recent discussion is the adoption of precautionary restrictions on particular tourism developments, such as permanent land-based tourism facilities and infrastructure (Bastmeijer and Roura, 2004). Chapter nine discusses the attitudes and perspectives of stakeholders towards Antarctic tourism policy.

\subsubsection{OVERVIEW}

The factor areas and external factors, discussed above, jointly determine the future development of tourism in Antarctica. These key factors shape the Antarctic Tourism Opportunity Spectrum (ATOS) and are schematically presented in Figure 3.5, which captures the dynamic nature of Antarctic tourism development. ATOS represents the "window of opportunity" for various actors in the Antarctic, including 
tour operators and policy makers. In the following discussion, we will mainly focus on the future opportunities of ATOS for different types of tourism operations.

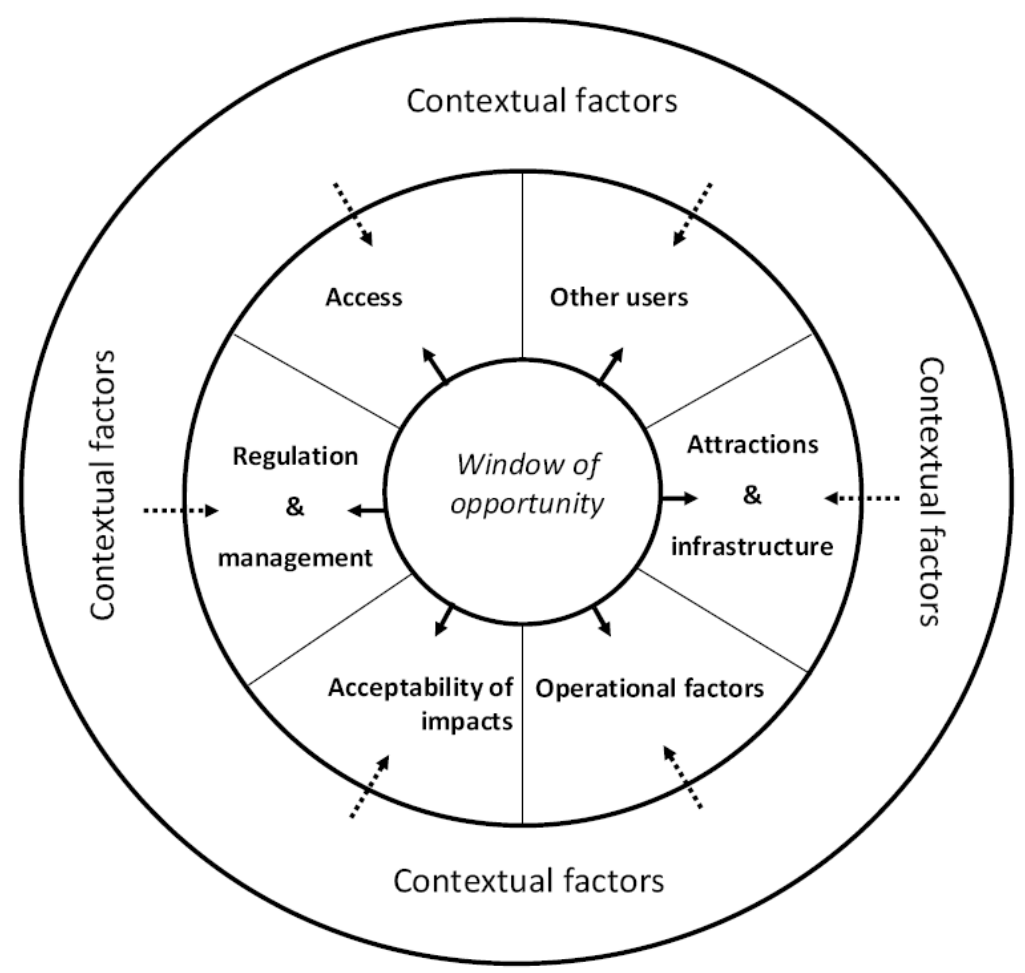

Figure 3.5: The integrated nature of the Antarctic Opportunity Spectrum (ATOS)

\subsection{Future opportunities and trends in Antarctic tourism}

Developments in sub-sectors of ATOS will influence the window of opportunity for Antarctic tour operators. It is also likely that this window is larger than is currently exploited, either because of lack of awareness or because of perceptions of risk and ethical considerations. Until recently the opportunities for tourism in Antarctica were largely organised and managed towards (smaller scale) sea-borne expeditionstyle cruises and niche tourism products, while latterly, the market has been supplemented by operators focusing on economies of scale (e.g. large cruise liners). In Table 3.2, the future opportunities for both operational strategies are summarised under influence of the factors discussed. 
Table 3.2: Future opportunities for small scale and large scale Antarctic tourism operations

\begin{tabular}{|c|c|c|}
\hline Factor: & $\begin{array}{l}\text { Small scale operations } \\
\text { (niche markets) }\end{array}$ & $\begin{array}{l}\text { Large scale operations } \\
\text { (economies of scale) }\end{array}$ \\
\hline $\begin{array}{l}\text { 1) Access } \\
\text {-Remoteness and extremeness } \\
\text {-Availability of suitable ships } \\
\text {-Ship building } \\
\text {-Availability of aircraft } \\
\text {-Global environmental change } \\
\text {-Infrastructural development } \\
\text {-Compatible with global routes } \\
\text {-Information channels/media } \\
\text {-Marketing resource }\end{array}$ & $\begin{array}{l}\text { Major constraint } \\
\text { Stagnation: limited supply } \\
\text { Decrease: less cost-beneficial } \\
\text { Increase } \\
\text { Not known } \\
\text { Increase } \\
\text { Increase } \\
\text { Increase } \\
\text { Increase }\end{array}$ & $\begin{array}{l}\text { Major constraint } \\
\text { Increase: relative large supply } \\
\text { Increase: more cost-beneficial } \\
\text { No real opportunity } \\
\text { Not known } \\
\text { Increase } \\
\text { Increase } \\
\text { Increase } \\
\text { Increase }\end{array}$ \\
\hline $\begin{array}{l}\text { 2) Other users: science } \\
\text {-Logistical cooperation } \\
\text {-Infrastructure sharing } \\
\text {-Facility sharing and visits }\end{array}$ & $\begin{array}{l}\text { Increase } \\
\text { Increase } \\
\text { Increase }\end{array}$ & $\begin{array}{l}\text { No real opportunity } \\
\text { Increase } \\
\text { No real opportunity }\end{array}$ \\
\hline $\begin{array}{l}\text { 3) Attractions/activities } \\
\text {-Available landing sites } \\
\text {-Wildlife } \\
\text {-Dramatic scenery } \\
\text {-Heritage sites } \\
\text {-Adventure activities }\end{array}$ & $\begin{array}{l}\text { Increase: exploration } \\
\text { Increase/growing challenge } \\
\text { Increase } \\
\text { Increase } \\
\text { Increase }\end{array}$ & $\begin{array}{l}\text { No real opportunity } \\
\text { No real opportunity } \\
\text { Increase } \\
\text { No real opportunity } \\
\text { Limited opportunity }\end{array}$ \\
\hline $\begin{array}{l}\text { 4) Tourist infrastructure } \\
\text {-Logistical infrastructure } \\
\text {-Accommodation facilities }\end{array}$ & $\begin{array}{l}\text { Not known } \\
\text { Increase }\end{array}$ & $\begin{array}{l}\text { Major constraint } \\
\text { Major constraint }\end{array}$ \\
\hline $\begin{array}{l}\text { 5) Operational factors } \\
\text {-Interaction in the field } \\
\text {-Qualified staff and crew } \\
\text {-IAATO self-regulation }\end{array}$ & $\begin{array}{l}\text { Increase/growing challenge } \\
\text { Growing challenge } \\
\text { No real constraints }\end{array}$ & $\begin{array}{l}\text { Increase/growing challenge } \\
\text { No real constraints } \\
\text { No real constraints }\end{array}$ \\
\hline $\begin{array}{l}\text { 6) Acceptability of impacts } \\
\text {-Environmental impacts } \\
\text {-Human safety } \\
\text {-Intrinsic value }\end{array}$ & $\begin{array}{l}\text { Stagnate: low acceptance } \\
\text { Increase: higher acceptance } \\
\text { Growing challenge }\end{array}$ & $\begin{array}{l}\text { Increase: higher acceptance } \\
\text { Stagnate: low acceptance } \\
\text { Growing challenge }\end{array}$ \\
\hline $\begin{array}{l}\text { 7) Regulation } \\
\text {-Antarctic Treaty System }\end{array}$ & No real constraints & No real constraints \\
\hline
\end{tabular}

Table 3.2 suggests that the opportunities for operators at both ends of the spectrum are increasing. Growth trends in the larger ship segments indicate that shifts in the market are underway and that access for larger scale tour operations is improving. Moreover, the cruise industry has recently identified Antarctica as an important growth destination (Budget Travel Online, 2005). Cost-effectiveness in operations, economies of scale in shipbuilding, and growing demand for comfortable cruising as a result of an ageing and affluent population in traditional markets and the development of new markets, are creating a momentum for larger scale operations in the Antarctic. 
As tourism develops, some operators will continue to specialise and focus on specific niche markets, such as small groups, high-quality information, luxury, adventure, resulting from opportunities provided by infrastructural developments, cooperation with other users, and global demand for special interest tourism products. In other words, high-quality niche products provide opportunities for small-scale operators to remain active in an industry where economies of scale and efficiency are increasingly dominating. The improvement of air access is most likely to provide initial opportunities for smaller scale operations but, as time goes by, these operations might increase in scale. As a result, visitor numbers are likely to continue growing in the future as will the diversity of tourism products and operations.

Much depends on the acceptance of visitor impacts by various stakeholder groups and the resulting regulatory and managerial developments. As more and larger tour operators enter the market with increasingly different aims and activities, it becomes more difficult for IAATO to self-regulate. At the same time, a loosening grip on the behaviour and operational standards of tour operators will expand the opportunities for any of the abovementioned trends. Clark and Stankey (1979) argue for consistency of settings in any tourism opportunity spectrum. In other words, settings of different factor areas need to develop alongside to safeguard opportunities and controlled development. In this chapter, we present a similar argument. As tourism in Antarctica develops as a result of any of the key factors analysed in the previous section, constraints in the form of regulations and restrictions have to be set if the current balance, i.e. current level and style of tourism operations, is to remain. ATOS can provide assistance towards active management of Antarctic tourism and regulatory options, for instance identifying locations or activities with specific restrictions or science operators who wish to gain understanding about the influence of their activities on tourism.

\subsection{Conclusion}

Tourism has grown rapidly over the past two decades and diversified in different market segments in terms of both, transport types and activities. Our analysis has shown that the development of tourism in Antarctica is the result of a range of factors, each with their own direction, belonging to six tangible factor areas: factors influencing access, other resource related users, attractions and activities, operational factors, acceptable impacts, and regulation and management frameworks. Factors influencing access, such as logistical and infrastructural developments, prove to be particularly important, which is no surprise in a region as remote as Antarctica. Related to this, the compatibility with science operations can provide both opportunities and limit actions for tourism development. Each of the factor areas is influenced by a range of contextual factors that occur on a global scale, out of reach of the Antarctic institutions and regulatory bodies (e.g. energy prices, climatic changes, etc). These factors are joined in the Antarctic Tourism Opportunity Spectrum and collectively define the opportunities for tour operators to organ- 
ise tourism itineraries in Antarctica. Overall, the resulting ATOS has proven to be a useful framework to assess the window of opportunity for tourism in the Antarctic and discuss future trends.

With regard to future opportunities and trends, we conclude that there are more opportunities than those currently exploited. An increasing operational scale, increasing efficiency and continuous innovation and diversification, drives Antarctic tourism development. Therefore, we expect to see more and larger cruise liners entering Antarctic waters, air-cruise operations and land-based tourism developing, and niche operations offering various activities, from more adventurous to more luxurious. In the absence of extensive sovereign governance in Antarctica, the tourism industry has taken on the ambitious role of being both organiser and manager of Antarctic tourism. Future developments may entail unacceptable levels of impact, undermine the position of the industry association, and jeopardise selfregulation. Therefore, we recommend that both the industry and regulators within the ATS follow a cautious approach in the development of Antarctic tourism, taking into account potential future impacts. 



\section{Chapter 4}

\section{THE ENVIRONMENTAL IMPACTS OF TOURISM IN ANTARCTICA: A GLOBAL PERSPECTIVE}

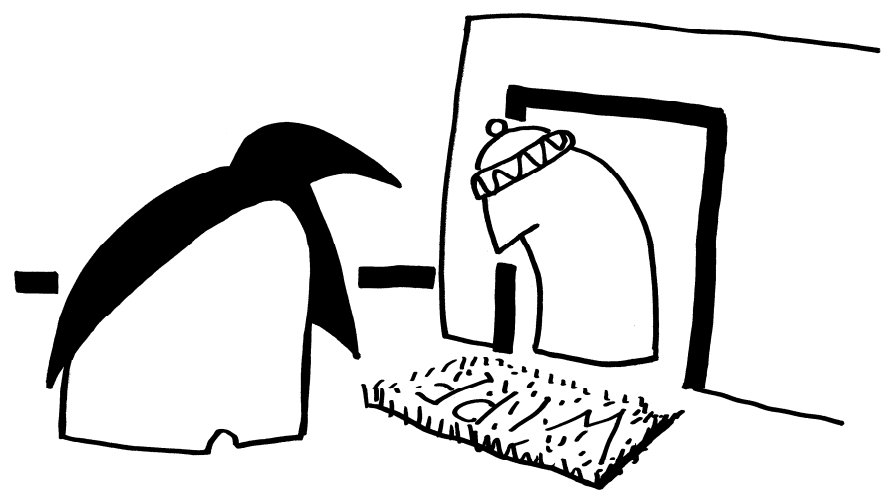

This chapter is based on:

Lamers, M., Amelung, B. (2007) The Environmental Impacts of Tourism in Antarctica: A global Perspective. In: Peeters, P. (ed.) Tourism and Climate Change Mitigation. Methods, greenhouse gas reductions and policies. NHTV Academic Studies No. 6, Breda. Pp: 51-62.

Amelung, B., Lamers, M. (2007) Estimating the Greenhouse Gas Emissions from Antarctic Tourism. Tourism in Marine Environments 4(2-3): 121-133. 


\subsection{Introduction}

Although tourist numbers have grown rapidly over the past two decades, Antarctic tourism volumes remain modest compared to the size of the continent. However, activities are strongly concentrated in space and time. Most tour operations take place in the Antarctic Peninsula area, because of its geographical proximity and absence of sea ice (Stonehouse and Crosbie, 1995). Biodiversity is relatively high in this area, in particular around the ice-free landing sites used by tourists. Arrivals are clustered in the short Antarctic summer season of about four months (Cessford, 1997), coinciding with the science activities of the National Antarctic Programmes (NAPs) and the breeding season of most penguins, seabirds and seals.

Tour operators and policy makers recognised the (potential) environmental impact of tourism in Antarctica in an early stage. In 1991, the Protocol on Environmental Protection of the Antarctic Treaty was adopted (and ratified in 1998), which regulates all human activities in Antarctica, including tourism. Around that same time, the International Association of Antarctica Tour Operators (IAATO), the Antarctic tourism industry association, introduced a range of environmental procedures and standards for its member companies. In more recent years, tourism appeared on the agendas of the Antarctic Treaty Consultancy Meetings (ATCMs) several times, resulting in a number of tourism-related measures, such as site-specific guidelines for several frequently visited tourist landing sites (Bastmeijer and Roura, 2004).

In academia, a range of empirical studies have appeared since the early 1990s about the desirability, implications and manageability of tourism in the fragile, pristine and extreme Antarctic environment. The impact assessments among these studies have been limited to local effects, i.e. those directly affecting Antarctica itself. This chapter argues that the scope of assessments should be widened. Tourist trips to and in Antarctica have prominent global impacts, in addition to the local ones. Antarctica is a very distant destination, in particular for the majority of tourists that come from the Northern Hemisphere (see Figure 3.2). The long-haul air travel and Antarctic cruises result in probably large, but unknown volumes of greenhouse gas emissions. The aim of this chapter is to produce an estimate of these emissions. But first, an overview of the environmental impacts of tourism in Antarctica identified in the literature so far is provided in the next section.

\subsection{The environmental impacts of tourism in Antarctica}

In the Antarctic tourism context, De Poorter (2000) defined the concept of 'environmental impact' as "the result of an environmental component being exposed to an output from an activity." Environmental components can be physical (land, water, air), biological (flora, fauna), and non-material (values). Outputs can take vari- 
ous forms, such as emissions, trampling, noise, and the visual presence of people. Only impacts to the physical and biological environment are addressed in this section.

Rubbish disposal and littering are among the most direct and visible effects of tourism. This visibility may partly explain the considerable academic interest for these impacts (see e.g. Hall, 1992b; Hall and Johnston, 1995; Hall and Wouters, 1995; Mason and Legg, 1999; De Poorter, 2000; Hofman and Jatko, 2000; Bastmeijer and Roura, 2004; Molenaar, 2005). Cumulative impacts on frequently used sites may be more difficult to monitor and control. Such impacts may take place at or near landing sites, through damage to unique geomorphologic features, 'souveneering', footpath erosion, and soil erosion (see e.g. Hall, 1992b; Stonehouse, 1994; Hall and Johnston, 1995; De Poorter, 2000; Bastmeijer and Roura, 2004). The marine counterpart of this type of terrestrial impact is the damage that ships cause to the marine environment by anchoring in frequently visited places (De Poorter, 2000; Hofman and Jatko, 2000; Molenaar, 2005). In addition to the mechanical damage done to marine and terrestrial environments, tourism also impacts on the environment through emissions to water, air and soil. Hall (1992b), Hall and Johnston (1995), Bastmeijer and Roura (2004), Molenaar (2005) report on the pollution of marine and coastal regions through oil and fuel spills and sewage dumps, whereas Bastmeijer (2004), De Poorter (2000), Hall (1992b), Hofman and Jatko (2000a), and Molenaar (2005) report on the contamination of the atmospheric and terrestrial environment with particulates and chemicals emitted by ships and aircraft.

Tourism influences the Antarctic ecosystem in a number of ways. First of all, the contamination, littering and damage that tourist activities bring about may have an impact on organisms. Stonehouse (1994), Hall and Johnston (1995), Hall and Wouters (1995), Cessford (1997), Mason and Legg (1999), Hofman and Jatko (2000a), De Poorter (2000), Bastmeijer and Roura (2004), and Molenaar (2005) report on the damage done to vegetation, such as mosses and lichen, through trampling or vehicles. Second, the mere presence of tourists is sometimes enough to disturb wildlife and modify wildlife behaviour (Stonehouse, 1994; Naveen et al., 2000; Pfeiffer and Peter, 2004). Finally, 'stowaways' may be transported by the ships and aircraft used by tourism operators to transport tourists to the Antarctic. Hall (1992b), Hall and Johnston (1995), De Poorter (2000), and Frenot et al (2005) discuss the risks of introducing exotic flora and fauna as well as animal and plant diseases.

So far, scientific assessments of the impact of tourism have not revealed major environmental impacts or changes caused by tourism (Hofman and Jatko, 2000). In 1994, Stonehouse (1994: 209) concluded that "preliminary results suggest that the number of tourists currently deployed, and under the gentle but strict codes of practice prevailing, have very little immediate impact on ecosystems at many of the sites they visit." This does not mean that tourism development is harmless, however. For a start, tourism has grown substantially since 1994 and is expected to continue growing in the future. Furthermore, the cumulative impact of tourism is 
not well understood. Researchers have only started to come to grips with this concept and realise its implications (De Poorter, 2000; Hofman and Jatko, 2000; Bastmeijer and Roura, 2004). In addition, most research has focused on the impacts on terrestrial animal life, whereas the impacts on the marine environment received much less attention. The picture is thus far from complete.

One of the main omissions may be the lack of a global perspective. The environmental impact assessments of tourism have so far focused on the impacts in Antarctica itself. Even the work on atmospheric pollution is limited to emissions in the Antarctic region. This local focus is in stark contrast with recent academic insights that suggest that the bulk of global tourism's environmental impact is associated with (origin-destination) transport (Gössling, 2002). Transport contributes to a range of problems, of which climate change may be the most important. The objective of this chapter therefore is to make an initial calculation of the volume of greenhouse gases emitted by Antarctic holidaymakers.

\subsection{Methods and data}

In recent years, several inventories have been made of tourism-related greenhouse gas emissions, with scopes ranging from the global (e.g. Gössling, 2002), to the national (Becken, 2002; Becken and Simmons, 2002 for New Zealand), and local levels (e.g. Gössling et al., 2005 for Amsterdam and the Rocky Mountain National Park). In these studies, emissions were estimated using bottom-up or top-down methods, or a combination of both. Bottom-up approaches start from the emission properties of individual facilities, motor vehicles, aircraft or ships and arrive at macro-scale results through aggregation. Top-down approaches start from macrolevel statistics and use average emission coefficients to calculate total emissions. In this chapter, bottom-up techniques are used where possible, complemented by top-down methods where low-level data are missing.

Tourism in Antarctica is atypical in many respects, one of them being the virtual absence of permanent land-based facilities for tourism (Splettstoesser et al., 2004). To date, the accommodation capacity on the continent is limited to a few tented camps and small-scale accommodations at research stations. The bulk of tourism takes place on ships, which unite all three traditional components of tourism: transport, accommodation and activities. Tourists fly from their country of origin to the so-called 'gateway cities' in South-America, Australia, and New Zealand, where ships pick them up. A minority of tourists engage in land-based tourism or overflights. In attempt to follow this reality as much as possible, the inventory of greenhouse gas emissions is made up of four compartments: origin-destination (OD) transport, (expedition) cruises, overflights, and land-based expeditions. Calculations are based on data for the Antarctic season of 2004/05. The scope of the study is limited to tourists reported by IAATO, and does not encompass staff and crew members and the small minority of tourists not reported by IAATO. 


\subsubsection{TRANSPORT TO AND FROM THE GATEWAY CITIES}

The continent of Antarctica is very remote, and poorly connected to the international transportation networks. There are only a handful of entry points, usually called gateways, including Ushuaia in Argentina, Punta Arenas in Chile, and Christchurch (Lyttleton) in New Zealand. Ushuaia is the main 'hub' for ship-born tourism, while Punta Arenas is the main basis for tourism air connections to Antarctica. These gateway cities usually have air connections with only a handful of other airports, typically located in the same country or in a neighbouring nation. The large majority of international tourists therefore change flights at a large international airport: Buenos Aires, Santiago de Chile and Auckland for connections to Ushuaia, Punta Arenas and Christchurch respectively. In this chapter, the simplifying assumption is therefore made that passengers travel to the gateway cities in two stages: from the home country to the hub airport in the gateway country, and from that hub to the gateway city. Since the individual flight plans are unknown, all passengers are assumed to depart from the largest airport in their respective home countries. In the absence of information about the technical specifications of the individual aircraft used, a fixed coefficient linking distances to emissions is used. The resulting emission estimates are cast into $\mathrm{CO}_{2}$-equivalent emissions by multiplying them by a correction factor to take into account that non-carbon coproducts of burning fossil fuel at great heights are responsible for most radiative forcing.

Following Gössling et al. (2005) and Watterson et al. (2004) a detour factor is applied to correct for the fact that actual flight distances are usually longer than the minimum Great Circle distances. The estimate of total emissions from transport to and away from the gateway cities is now given by:

$E=I \cdot C \cdot \sum_{i, j=1}^{n, m} P_{i, j} \cdot\left(D 1_{i, j}+D 2_{j}\right)$

in which $\mathrm{E}$ stands for the amount of $\mathrm{CO}_{2}$ emissions, I denotes the emission intensity, i.e. the amount of emissions per passenger kilometre, $\mathrm{C}$ denotes the detour correction factor, $\mathrm{P}$ represents the number of tourists per country of origin, D1 denotes twice the distance from the airport in the home country to the hub in the gateway country, D2 denotes twice the distance from this hub to the gateway city airport, $i$ and $n$ identify the source countries, and $j$ and $m$ identify the gateway cities.

Data on the number of tourists and their nationalities are retrieved from the IAATO website (http://www.iaato.org). The distances between two airports are calculated as Great Circle distances using the web-based Great Circle Mapper tool (gc.kls2.com). A detour correction factor of 1.05 is used, as suggested by Gössling et al. (2005) for long-haul air travel. An emission intensity factor of $0.14 \mathrm{~kg} / \mathrm{pkm}$ is used, as suggested by Gössling et al. (2005) for long-haul air travel. An equivalence factor of 2.7 is used to compensate for non-carbon emissions, following Penner et al. (1999). 
To fill in equation 1, a list of gateway cities and countries of origin must be composed. Tourists visit Antarctica from a range of gateway cities. For ship-based tourism by far the most important of these is the port of Ushuaia in Argentina. In addition, a small number of tourists travelling to the Ross Sea region make use of gateway cities in New Zealand and Australia, mostly Christchurch (Lyttleton) in New Zealand. In South America, tourists engaging in land-based tourism depart from the city of Punta Arenas, but these are relatively few, and this city is located close to Ushuaia. In the analysis, the number of gateway cities is therefore limited to the largest gateways of the two main Antarctic tourism regions, i.e. Ushuaia and Christchurch. Origin-destination transport related to overflights is not considered, as this information is not available. Given the brevity of an overflight experience, we assume that most passengers will probably be Australian citizens. Also, international passengers probably do not perceive the overflight as the principal activity of their visit. Therefore, it is not fair to attribute emissions caused by international origindestination transport to Antarctic tourism. Emissions caused by domestic tourists are assumed to be small enough to be ignored.

In the season 2004/2005, close to a hundred countries were represented in the Antarctic tourist population (IAATO, 2005). Many of these national group categories consisted of one or just a few individuals, while the largest delegation (that of the USA) consisted of more than 11,000 visitors. The 21 countries that were the source of more than 100 tourists each covered almost $97 \%$ of all tourists. In the calculations, only these countries are considered individually; the remaining $3 \%$ are assumed to travel from a hypothetical country that is located at the average distance of the first 21 countries.

\subsection{2 (EXPEDITION) CRUISES}

The ships used for tourism in the Antarctic vary widely in size, with capacities ranging from approximately 50 to 1,300 passengers. Some of the ships were built for tourism purposes, but many others were originally constructed and used as expedition ships or icebreakers. As a result, fuel use and emissions also differ greatly between ships. To take some of this diversity into account, without knowing the technical details of all individual ships, a linear relationship is assumed between fuel use at maximum power and gross tonnage, as suggested by Trozzi and Vaccaro (1998). Actual fuel use depends on the 'mode' a ship is operating in; in 'hotelling' mode much less fuel is used than in cruise mode. It is common practice in the Antarctic cruise business to unload and load ships in one day (IAATO, 2005a). Therefore it is assumed that in each trip a minimum of one day is spent in 'hotelling mode'. The estimate of total emissions from (expedition) cruising is now given by:

$$
E=I \cdot F_{m p} \cdot\left(U_{c} \cdot S_{c} \cdot(T-1)+U_{h} \cdot\left(S_{h} \cdot(T-1)+1\right)\right)
$$

in which $E$ stands for emissions, $I$ is the emission intensity, i.e. the amount of emissions per $\mathrm{kg}$ of fuel, $\mathrm{Fmp}$ represents daily fuel use at maximum power, $\mathrm{U}$ denotes fuel used for cruising (c) and hotelling (h) as percentages of maximum fuel use, $T$ 
represents trip duration, $\mathrm{S}$ represents the share of trip time spent on cruising (c) and hotelling $(\mathrm{h})$, and $\mathrm{Sc}+\mathrm{Sh}=1$.

In this chapter, an emission coefficient of 3.2 is used, as suggested by Trozzi and Vaccaro (1998). This coefficient closely resembles the $0.859 \times 44 / 12$ estimate proposed by Watterson et al. (2004) for jet fuel. Fuel use by ships is typically expressed in tonnes of fuel per day used at maximum power. Retrieving technical specifications for all ships involved was beyond the scope of this chapter. Instead, estimations for fuel use were retrieved from Trozzi and Vaccaro (1998). Based on regression analyses including hundreds of ships, they estimated the empirical relationship between gross tonnages and daily fuel use for a range of ship categories. It is assumed here that the equation that Trozzi and Vaccaro derived for passenger ships is an acceptable estimation of the fuel use of the Antarctic tourism fleet:

$F=16.904+0.00198 \cdot G T$

in which $\mathrm{F}$ is fuel consumption at maximum power in tonnes per day, and GT stands for gross tonnage. The names of all ships used for Antarctic cruising in the season of 2004/05 are available from IAATO (2005a). Information on their gross tonnage was retrieved from dedicated websites ${ }^{5}$. For each ship, maximum daily fuel use was estimated using equation 3 .

According to Trozzi and Vaccaro (1998), ships in cruising mode operate at $80 \%$ of maximum power, while ships in hotelling mode operate at $32 \%$ of maximum power. No information was found on the relative share of time that is spent on cruising and hotelling respectively during cruise expeditions. Ship-borne tourism comes in two basic flavours: expedition cruises that include landings, and cruiseonly trips. In the 2004/05 season, four ships were used for cruise-only trips, while twenty-seven were used for expedition cruises, excluding sailing vessels and small yachts (IAATO, 2005a). Cruise ships are assumed to operate in cruise mode continuously, except for the day of loading and unloading, so that $\mathrm{Sc}=1$ and $\mathrm{Sh}=0$. According to Carey (2005), expedition cruises make an average of two landings per day of three hours each. Based on this empirical observation, it is assumed that expedition cruise ships operate in cruise mode for $75 \%$ of time, and in hotelling mode for $25 \%$ of time, excluding days that are used for loading and unloading. The duration of all individual trips by all individual ships in the 2004/05 season is documented by IAATO (2005a).

\subsubsection{LAND-BASED ACTIVITIES}

Land-based tourism, serviced by aircraft, comprises a minor share of Antarctic tourism. Two IAATO member companies conduct land-based tourism activities from Punta Arenas, namely Antarctic Logistics and Expeditions (ALE) and Aerovias DAP. Land-based expeditions to the Antarctic continent are risky and require ex-

\footnotetext{
${ }^{5}$ For example: http://www.kreuzfahrt-w.de
} 
tensive preparation, and implementation of stringent safety measures. The USbased organisation ALE takes care of the logistical side of all or most land-based tourist expeditions. In its Multi-Year Application to the US Environmental Protection Agency, ALE reports on the environmental impact of their activities, including $\mathrm{CO}_{2}$ emissions (ALE, 2003). In the 2003 report, ALE (2003) projected its emissions for the 2003/04 season at 1801 tonnes. The bulk of these emissions (1783 tonnes) were attributable to air transport, i.e. flights between Punta Arenas and the Antarctic field camp at Patriot Hills. These figures were calculated based on the prospect of handling 100 tourists on 7 flights in the 2003/04. In reality, ALE had a total of 119 clients in 2003/04, and 190 clients and 14 flights in 2004/05. In the absence of more recent information, proportionality was assumed between the increase in demand and the increase in emissions. For the flight components, an equivalence factor of 2.7 is used to compensate for non-carbon emissions, following Penner (1999).

Operating from Punta Arenas, the Chilean Aerovias DAP conducts tourist day flights and two-day trips to King George Island for land-based activities. In the 2004/05 season, it transported a total of 657 tourists on 29 flights (IAATO, 2005b) using two relatively small aircraft: a King Air 200b (King Air) with a capacity of 12 for small groups, and a De Havilland DHC-7 (Dash 7) with a capacity of 54 for larger groups. In the absence of information about the number of flights each of these planes made, a hypothetical configuration was established of 21 King Air flights and 8 Dash 7 flights, with a total capacity of 684 passengers. Watterson et al. (2004) provide the following equations linking fuel use to distance flown:

$F_{K A}=(7.33+0.392 \cdot 2 D) \cdot C$ for the King Air and

$F_{D 7}=(-0.135+1.05 \cdot 2 D) \cdot C$ for the Dash 7

in which $F$ is the amount of fuel used in $\mathrm{kg}, \mathrm{D}$ is the distance flown, and $\mathrm{C}$ is the detour correction factor. The itinerary from Punta Arenas to King George Island and back corresponds with a distance of $1,255 \mathrm{~km}$ one way. A detour factor of 1.05 is used, as suggested by Gössling et al. (2005). Emissions are calculated from the amount of fuel used, using the coefficient provided by Watterson et al. (2004). An equivalence factor of 2.7 (Penner et al., 1999) is used to compensate for noncarbon emissions.

\subsubsection{OVERFLIGHTS}

Tourist overflights are made from two different gateway cities. The Australian tour operator Croydon Travel and airline Quantas organise overflights from different Southern Australian cities to East-Antarctica and back, using Boeing 747-400 aircraft. IAATO (2005b) reports on the number of passengers taken, the number of flights made, and the flying time. Croydon/Qantas performed a total of 4 overflights with a Boeing 747-400, carrying a total of 1,568 passengers. According to 
their report ${ }^{6}$, a distance of some $11,000 \mathrm{~km}$ is covered per trip, using 150 tonnes of fuel. An estimate of the $\mathrm{CO}_{2}$ emissions resulting from Croydon/Quantas overflight activities is produced using the coefficients suggested by Watterson et al. (2004). Overflights are also organised from Punta Arenas by LanChile with Boeing 737-200 aircraft. IAATO reports on the number of passengers taken, the number of flights made and the routes flown (IAATO, 2005b). LanChile performed a total of 9 overflights with a Boeing 737-200, carrying a total of 462 passengers. In the absence of specific information on the Boeing 737-200 in Watterson et al. (2004), the equation of fuel use as a function of distance for the Boeing 737-100 is taken instead: $F_{737-100}=(241+2.75 \cdot D) \cdot C$

in which $\mathrm{F}$ is the amount of fuel used in $\mathrm{kg}, \mathrm{D}$ is the distance flown, and $\mathrm{C}$ is the detour correction factor. The route taken during the Lanchile overflights is: Punta Arenas $\rightarrow$ King George Island $\rightarrow$ Deception Island $\rightarrow$ O'Higgins $\rightarrow$ Marambio $\rightarrow$ Punta Arenas (IAATO, 2005b), which, corrected for detours with the usual factor of 1.05 , corresponds to a distance $D$ of $3,288 \mathrm{~km}$ per flight. Again, a detour factor of 1.05 is used, as suggested by Gössling et al. (2005). Emissions are calculated from the amount of fuel used, using the coefficient provided by Watterson et al. (2004). The equivalence factor of 2.7 (Penner et al., 1999) is also used here to compensate for non-carbon emissions.

\subsection{Results}

The total flight volume related to travelling to and from the gateway cities by air is estimated at 728 million passenger kilometres $(\mathrm{pkm})$, of which 713 million pkm are linked to Ushuaia/Punta Arenas and 15 million pkm to Christchurch. Total $\mathrm{CO}_{2}$ emissions (pkm x emission coefficient) are estimated at 90 thousand metric tonnes. Multiplying total $\mathrm{CO}_{2}$ emissions by the higher forcing potential at cruising altitude yields an estimate for total emissions of 243 thousand metric tonnes of $\mathrm{CO}_{2}$ equivalents.

In absolute terms, tourists from the United States are the dominant factor in passenger kilometres and emissions. This is a result of relatively large numbers of tourists and moderate travel distances. Tourists from other countries (in particular Japanese travelling to South America and Europeans travelling to New Zealand), however, are more energy-intensive in relative terms. Estimated emissions by Japanese tourists travelling to Ushuaia are almost twice as high as emissions by their American counterparts (14.32 tonnes versus 7.34 tonnes per capita). Average per capita emissions for travelling to Ushuaia and Christchurch are similar, at 8.58 and 8.48 tonnes per capita respectively. Detailed results per nationality are presented in Table 4.1 (Ushuaia/Punta Arenas) and Table 4.2 (Christchurch).

\footnotetext{
${ }^{6}$ Http://www.avweb.com/news/features/187317-1.html
} 
Table 4.1: Estimated passenger kilometres and $\mathrm{CO}_{2}$ emissions resulting from travelling to and away from the South American gateway cities (Ushuaia, Argentina), season 2004/05

\begin{tabular}{|c|c|c|c|c|c|}
\hline Country (airport code) & Pax & $\begin{array}{l}\text { Pkm } \\
\text { (1000s) }\end{array}$ & $\begin{array}{l}\mathrm{CO}_{2} \\
\text { (tonnes) }\end{array}$ & $\begin{array}{l}\mathrm{CO}_{2}-\mathrm{eq} \\
\text { (tonnes) }\end{array}$ & $\begin{array}{l}\mathrm{CO}_{2} \text {-eq } \\
\text { per capita } \\
\text { (tonnes) }\end{array}$ \\
\hline USA (ATL) & 11,224 & 245,014 & 30,510 & 82,376 & 7.34 \\
\hline UK (LHR) & 3,835 & 108,408 & 13,387 & 36,146 & 9.43 \\
\hline Germany (FRA) & 3,243 & 94,166 & 11,620 & 31,374 & 9.67 \\
\hline Australia (SYD) & 2,347 & 69,687 & 8,594 & 23,204 & 9.89 \\
\hline Canada (YYZ) & 1,425 & 33,821 & 4,199 & 11,338 & 7.96 \\
\hline Japan (NRT) & 740 & 32,096 & 3,925 & 10,596 & 14.32 \\
\hline Netherlands (AMS) & 614 & 17,777 & 2,194 & 5,923 & 9.65 \\
\hline Switzerland (ZRH) & 494 & 14,158 & 1,748 & 4,719 & 9.55 \\
\hline New Zealand (AKL) & 315 & 8,390 & 1,038 & 2,802 & 8.90 \\
\hline Spain (MAD) & 329 & 8,575 & 1,062 & 2,866 & 8.71 \\
\hline France (CDG) & 287 & 8,091 & 999 & 2,698 & 9.40 \\
\hline South Africa (JNB) & 250 & 5,501 & 685 & 1,849 & 7.40 \\
\hline Mexico (MEX) & 230 & 4,699 & 587 & 1,584 & 6.89 \\
\hline Italy (FCO) & 190 & 5,381 & 664 & 1,794 & 9.44 \\
\hline Austria (VIE) & 183 & 5,447 & 672 & 1,813 & 9.91 \\
\hline Belgium (BRU) & 151 & 4,334 & 535 & 1,445 & 9.57 \\
\hline Norway (OSL) & 144 & 4,426 & 545 & 1,472 & 10.22 \\
\hline Sweden (ARN) & 138 & 4,326 & 533 & 1,438 & 10.42 \\
\hline Argentina (EZE) & 131 & 646 & 91 & 244 & 1.87 \\
\hline Ireland (DUB) & 119 & 3,336 & 412 & 1,112 & 9.35 \\
\hline Chile (SCL) & 102 & 748 & 100 & 269 & 2.64 \\
\hline Other (n/a) & 901 & 23,469 & 2,905 & 7,844 & 8.69 \\
\hline Total & 27,392 & 702,496 & 87,005 & 234,906 & 8.58 \\
\hline
\end{tabular}


Table 4.2: Estimated passenger kilometres and $\mathrm{CO}_{2}$ emissions from travelling to and away from the New Zealand/Australian gateway cities (Christchurch, New Zealand), season 2004/05

\begin{tabular}{|c|c|c|c|c|c|}
\hline Country (airport code) & Pax & $\begin{array}{l}\text { Pkm } \\
\text { (1000s) }\end{array}$ & $\begin{array}{l}\mathrm{CO}_{2} \\
\text { (tonnes) }\end{array}$ & $\begin{array}{l}\mathrm{CO}_{2} \text {-eq } \\
\text { (tonnes) }\end{array}$ & $\begin{array}{l}\mathrm{CO}_{2} \text {-eq } \\
\text { per capita } \\
\text { (tonnes) }\end{array}$ \\
\hline USA (ATL) & 158 & 4,570 & 553 & 1,494 & 9.46 \\
\hline UK (LHR) & 96 & 3,850 & 465 & 1,256 & 13.08 \\
\hline Germany (FRA) & 32 & 1,273 & 154 & 415 & 12.97 \\
\hline Australia (SYD) & 113 & 690 & 86 & 233 & 2.06 \\
\hline Canada (YYZ) & 21 & 644 & 78 & 211 & 10.03 \\
\hline Japan (NRT) & 6 & 120 & 15 & 39 & 6.58 \\
\hline Netherlands (AMS) & 18 & 714 & 86 & 233 & 12.93 \\
\hline Switzerland (ZRH) & 10 & 402 & 49 & 131 & 13.11 \\
\hline New Zealand (AKL) & 44 & 69 & 10 & 26 & 0.59 \\
\hline Spain (MAD) & 0 & 0 & 0 & 0 & $\mathrm{n} / \mathrm{a}$ \\
\hline France (CDG) & 15 & 607 & 73 & 198 & 13.20 \\
\hline South Africa (JNB) & 5 & 136 & 16 & 44 & 8.89 \\
\hline Mexico (MEX) & 2 & 49 & 6 & 16 & 8.05 \\
\hline Italy (FCO) & 8 & 322 & 39 & 105 & 13.13 \\
\hline Austria (VIE) & 5 & 195 & 24 & 64 & 12.74 \\
\hline Belgium (BRU) & 3 & 120 & 14 & 39 & 13.03 \\
\hline Norway (OSL) & 3 & 113 & 14 & 37 & 12.28 \\
\hline Sweden (ARN) & 1 & 37 & 5 & 12 & 12.16 \\
\hline Argentina (EZE) & 1 & 23 & 3 & 8 & 7.62 \\
\hline Ireland (DUB) & 2 & 79 & 10 & 26 & 12.96 \\
\hline Chile (SCL) & 0 & 0 & 0 & 0 & $\mathrm{n} / \mathrm{a}$ \\
\hline Other (n/a) & 10 & 315 & 38 & 103 & 10.28 \\
\hline Total & 553 & 14,328 & 1,738 & 4,690 & 8.48 \\
\hline
\end{tabular}


Ships burnt an estimated 53,020 tonnes of fuel during the 2004/05 season, encompassing 44,550 tonnes by expedition cruises and the remaining 8,470 tonnes by cruise-only ships (see Table 4.3). Total $\mathrm{CO}_{2}$ emissions are estimated at 169,666 tonnes. The 27 expedition cruise ships account for close to 85 percent of these emissions, whereas the four cruise-only ships are responsible for the remaining 15 percent. Average per capita emissions are 6.16 tonnes per passenger, but this ratio varies widely, from 2.09 tonnes per passenger for the Alexander Humboldt to 22.63 tonnes per passenger for the Spirit of Enderby. Average per capita emissions for expedition cruise ships are almost 20 percent higher than for cruise-only ships.

The ALE emissions for the 2004/05 season were estimated at 3,423 tonnes of $\mathrm{CO}_{2}$, an increase of $90 \%$ with respect to the projected emissions for 2003/04. Expressed in terms of $\mathrm{CO}_{2}$ equivalents to take account of the large contribution of air transport, total ALE emissions are estimated at 9182 tonnes (see Table 4.4). Emissions produced by the two DAP airplanes are estimated at 139 tonnes of $\mathrm{CO}_{2}$ in 2004/05, which is equivalent to 375 tonnes of $\mathrm{CO}_{2}$ equivalents when correcting for the greater contribution to radiative forcing at greater heights.

For the Croydon/Qantas overflights, total $\mathrm{CO}_{2}$ emissions are estimated at 1,890 tonnes (5,102 tonnes of $\mathrm{CO}_{2}$ equivalent); an average of 472 tonnes per flight. The nine LanChile flights resulted in an estimated total of 263 tonnes of $\mathrm{CO}_{2}$ emissions (710 tonnes of $\mathrm{CO}_{2}$ equivalent). Total $\mathrm{CO}_{2}$ emissions related to overflights in the $2004 / 05$ season are thus estimated at some 2,153 tonnes $\left(5,812\right.$ tonnes of $\mathrm{CO}_{2}$ equivalent).

All in all, tourism in Antarctica produced an estimated 264 ktons of $\mathrm{CO}_{2}$ in the season 2004/05 (see Table 4.5). Origin-destination air travel and cruises dominate emissions, accounting for almost $90 \%$ of total amounts. Cruises are the single largest source of $\mathrm{CO}_{2}$ emissions, causing around two thirds of these emissions. Air transport is most important in terms of radiative forcing $\left(\mathrm{CO}_{2}\right.$-eq emissions) as a result of non-carbon impacts. Air travel contributes close to 60 percent of the estimated total of 425 ktons of $\mathrm{CO}_{2}$-equivalents. In per capita terms this total boils down to an average of 15 tonnes of $\mathrm{CO}_{2}$-equivalents per tourist trip. This figure excludes overflights and tourists travelling with DAP, because the country of origin of these tourists is not known or the origin-destination transport can in all fairness not be attributed to Antarctic tourism. The per capita emissions of land-based tourism are close to 50 tonnes per tourist, including transport between the gateway cities and Antarctica. 
Table 4.3: Fuel use for ships used for cruise tourism in the season 2004/05

\begin{tabular}{|c|c|c|c|c|c|c|}
\hline Ship name & Pax & Tonnage & $\begin{array}{l}\text { Daily fuel } \\
\text { use } \\
\text { (t) }\end{array}$ & $\begin{array}{l}\text { Fuel } \\
\text { use } \\
\text { (t) }\end{array}$ & $\begin{array}{l}\mathrm{CO}_{2} \\
\text { (t) }\end{array}$ & $\begin{array}{l}\mathrm{CO}_{2} \\
\text { per } \\
\text { capita (t) }\end{array}$ \\
\hline Akademik loffe & 865 & 6,450 & 29.68 & 2,164 & 6,924 & 8.01 \\
\hline Akademik S. Vavilov & 739 & 6,450 & 29.68 & 1,811 & 5,796 & 7.84 \\
\hline Akademik Shokalskiy & 303 & 1,753 & 20.37 & 1,271 & 4,068 & 13.43 \\
\hline Alexander Humboldt & 281 & 12,500 & 41.65 & 183 & 586 & 2.09 \\
\hline Andrea & 521 & 2,632 & 22.12 & 1,245 & 3,983 & 7.64 \\
\hline Bremen & 651 & 6,752 & 30.27 & 1,489 & 4,766 & 7.32 \\
\hline Clipper Adventurer & 732 & 5,750 & 28.29 & 1,602 & 5,127 & 7.00 \\
\hline Discovery & 1,496 & 20,186 & 56.87 & 1,253 & 4,011 & 2.68 \\
\hline Endeavour & 765 & 3,132 & 23.11 & 1,419 & 4,540 & 5.93 \\
\hline Explorer & 1,013 & 2,398 & 21.65 & 1,666 & 5,332 & 5.26 \\
\hline Explorer 2 & 1,524 & 12,500 & 41.65 & 2,924 & 9,357 & 6.14 \\
\hline Grigoriy Mikheev & 413 & 2,000 & 20.86 & 1,464 & 4,684 & 11.34 \\
\hline Hanseatic & 716 & 8,378 & 33.49 & 1,443 & 4,617 & 6.45 \\
\hline Kapitan Klebnikov & 457 & 12,288 & 41.23 & 3,066 & 9,812 & 21.47 \\
\hline Le Diamant & 356 & 8,282 & 33.30 & 429 & 1,373 & 3.86 \\
\hline Marco Polo & 3,129 & 22,080 & 60.62 & 2,384 & 7,628 & 2.44 \\
\hline Nordnorge & 2,730 & 11,386 & 39.45 & 3,333 & 10,664 & 3.91 \\
\hline Orion & 652 & 4,050 & 24.92 & 1,124 & 3,595 & 5.51 \\
\hline Orlova & 1,170 & 4,251 & 25.32 & 1,940 & 6,207 & 5.30 \\
\hline Polar Pioneer & 536 & 2,140 & 21.14 & 3,058 & 9,785 & 18.26 \\
\hline Polar Star & 762 & 3,500 & 23.83 & 1,803 & 5,769 & 7.57 \\
\hline Professor Molchanov & 476 & 1,753 & 20.37 & 1,693 & 5,417 & 11.38 \\
\hline Professor Multanovski & 443 & 1,753 & 20.37 & 2,081 & 6,658 & 15.03 \\
\hline Saga Rose & 499 & 24,474 & 65.36 & 643 & 2,058 & 4.12 \\
\hline Spirit of Enderby & 96 & 1,764 & 20.40 & 679 & 2,172 & 22.63 \\
\hline Ushuaia & 664 & 2,802 & 22.45 & 1,781 & 5,699 & 8.58 \\
\hline Vistamar & 539 & 7,500 & 31.75 & 603 & 1,931 & 3.58 \\
\hline All expedition cruise & \multicolumn{3}{|l|}{22,528} & 44,551 & 142,559 & 6.33 \\
\hline Amsterdam & 2,618 & 61,000 & 137.68 & 4,384 & 14,028 & 5.36 \\
\hline Crystal Symphony & 705 & 51,044 & 117.97 & 1,642 & 5,255 & 7.45 \\
\hline Insignia & 669 & 30,277 & 76.85 & 1,008 & 3,227 & 4.82 \\
\hline Royal Princess & 1,032 & 30,200 & 76.70 & 1,436 & 4,595 & 4.45 \\
\hline All cruise-only & 5,024 & & & 8,470 & 27,105 & 5.40 \\
\hline Total cruises & 27,552 & & & 53,021 & 169,664 & 6.16 \\
\hline
\end{tabular}


Table 4.4: $\mathrm{CO}_{2}$ emissions from ALE operations, projected by ALE for the 2003/04 season, and estimated for the 2004/05 season. Source: based on ALE (2003)

\begin{tabular}{|l|l|l|l|l|}
\hline & \multicolumn{2}{|c|}{$\mathbf{C O}_{\mathbf{2}}$ emissions (tonnes) } & \multicolumn{2}{l|}{$\mathbf{C O}_{2}$-eq emissions (tonnes) } \\
\hline & $\mathbf{2 0 0 3 / 0 4}$ & $\mathbf{2 0 0 4 / 0 5}$ & $\mathbf{2 0 0 3 / 0 4}$ & $\mathbf{2 0 0 4 / 0 5}$ \\
\hline $\begin{array}{l}\text { Air Transport north } \\
\text { of 60ㅇ }\end{array}$ & 394 & 749 & 1,064 & 7,126 \\
\hline $\begin{array}{l}\text { Air Transport south } \\
\text { of 60ㅇ }\end{array}$ & 1,389 & 2,639 & 3,750 & 2021 \\
\hline Land Transport & 15 & 29 & 15 & 29 \\
\hline Gas Combustion & 3 & 6 & 3 & 6 \\
\hline Total & $\mathbf{1 , 8 0 1}$ & $\mathbf{3 , 4 2 3}$ & $\mathbf{4 , 8 3 2}$ & $\mathbf{9 , 1 8 2}$ \\
\hline
\end{tabular}

Table 4.5: Overview of total estimated $\mathrm{CO}_{2}$ emissions resulting from Antarctic tourism in the 2004/05 season

\begin{tabular}{|l|l|l|l|}
\hline Activity & $\mathrm{CO}_{2}$ (tonnes) & $\mathrm{CO}_{2}$-eq (tonnes) & $\begin{array}{l}\text { CO} \text {-eq per } \\
\text { capita (tonnes) }\end{array}$ \\
\hline OD Transport - South America & 87,005 & 234,906 & 8.58 \\
\hline OD Transport - NZ/Aus & 1,738 & 4,690 & 8.48 \\
\hline Expedition cruises & 142,559 & 142,559 & 6.33 \\
\hline Cruise-only & 27,105 & 27,105 & 5.40 \\
\hline Land-based - ALE & 3,423 & 9,182 & 48.32 \\
\hline Land-based - DAP & 139 & 375 & 0.57 \\
\hline Overflights - Qantas & 1,890 & 5,102 & 3.25 \\
\hline Overflights - Lanchile & 263 & 710 & 1.54 \\
\hline Total & $\mathbf{2 6 4 , 1 2 2}$ & $\mathbf{4 2 4 , 6 2 9}$ & \\
\hline Total (excl. overflights and DAP) & $\mathbf{2 6 1 , 8 3 0}$ & $\mathbf{4 1 8 , 4 4 2}$ & $\mathbf{1 4 . 9 7}$ \\
\hline
\end{tabular}

\subsection{Discussion}

In this chapter, the total contribution of Antarctic tourism to greenhouse gas emissions was estimated at 425 ktons of $\mathrm{CO}_{2}$-equivalents for the season 2004/05. In absolute terms, this contribution is negligible, because visitation levels are relatively low. More meaningful comparisons can be made based on the emissions per visit. The 15 tonnes of emissions produced during the typical two-week holiday of an Antarctic tourist equal the emissions produced by the average European in seventeen months time. In 2000 per capita $\mathrm{CO}_{2}$-equivalent emissions amounted to 10.5 tonnes for the EU-25, 24.5 tonnes for the USA, 1.9 tonnes for India and 5.6 tonnes for the world as a whole (Baumert et al., 2005). 
Tourism is known to be an energy-intensive sector in general (Gössling et al., 2005), and Antarctic tourism belongs to the most energy-intensive segments. Average per capita emissions for Antarctic tourists are more than three times as high as those for visits to the Seychelles (4.76 tonnes of $\mathrm{CO}_{2}$-eq per capita), and forty-three times as high as the per capita emissions of a visit to the Rocky Mountains ( 0.35 tonnes of $\mathrm{CO}_{2}$-eq per capita), as documented in Gössling et al. (2005). These differences may be explained by the absence of an Antarctic home tourism market, the dependence on long haul transport for origin-destination transport, and the considerable emission levels of expedition ships and cruise-liners. The results are even more flagrant when put in the perspective of sustainable energy use. If the world would aim to prevent dangerous climate change by stabilising $\mathrm{CO}_{2}$ concentrations at twice the pre-industrial level - i.e. at 550 parts per million (ppmv) - and the world's population at 10 billion, the average emissions budget per capita would amount to 2.2 tonnes of $\mathrm{CO}_{2}$-equivalents per year by 2100 (IPCC, 2001). One trip to Antarctica would then eat up seven person years of carbon budget.

Tourism is sometimes considered an important vehicle for promoting the need for the preservation of the Antarctic wilderness. This 'ambassadorship' (Maher et al., 2001; Powell et al., 2008) of tourists comes at a large cost, however. Greenhouse gas emissions from tourism aggravate the problem of climate change, of which Antarctica itself is a major 'victim'. The Antarctic Peninsula has witnessed an increase in average annual temperature of $3^{\circ} \mathrm{C}$ since the $1940 \mathrm{~s}$, causing the disintegration of ice-shelves, and creating opportunities for the success and distribution of exotic species (Crosbie, 2005). Labelling Antarctica as an ecotourism or sustainable tourism destination (Stonehouse, 1994; Splettstoesser et al., 2004) may well be misplaced.

Sustainable development is not only about environmental concerns; it implies a balance between the social, ecological and economic aspects of societal performance. The concept of eco-efficiency captures some of the trade-offs involved. Gössling et al. (2005) calculated a global average eco-efficiency of $1.18 \mathrm{~kg}$ of $\mathrm{CO}_{2}$ equivalent emissions per euro of value added for 1999, and a sustainable ecoefficiency of $0.24 \mathrm{~kg} \mathrm{CO}$-eq/ $€$. To achieve these ratios, the average trip to Antarctica would have to yield $€ 12,700$ and $€ 62,400$ respectively, much more than the US\$3,000-US\$5,000 tourists paid for a typical Antarctic holiday in 1998/99 (Bauer, 2001), excluding the $€ 1,000-2,000$ plane ticket.

The emissions inventory presented in this chapter should be treated as a rough estimate, given the many uncertainties involved. The most salient ones in the current inventory are probably the technical properties of the ships and airplanes involved tourists' flight itineraries, and the contribution of non-carbon emissions. Differences in energy-efficiency are probably most noteworthy for ships. Technical properties were available for just a handful of ships, so that no meaningful Antarctica-specific averages or estimates could be derived for fuel use. Instead, an equation was used that linked fuel use to gross tonnage. Trozzi and Vaccaro specifically 
derived this equation for passenger ships, but the high intercept suggests that the ships included in their sample were generally larger than the ones used for expedition cruising in the Antarctic. Emissions may therefore have been overestimated for smaller ships. Our analysis suggests that large vessels are more eco-efficient than smaller vessels, but this proposition needs to be investigated in more detail. A fact that may support this finding is that most ships used for tourism purposes were never built with a keen eye on energy efficiency. The vital characteristic of these former expedition ships was reliability, to be able to survive in the harsh polar conditions. In addition to safety issues, energy efficiency may be a more important issue for the latest generations of large cruise-only ships.

In the case of aircraft, standard coefficients for emissions per passenger kilometre were used, because detailed information about individual aircraft used and occupancy rates were lacking. If tourists travelling to Antarctica systematically used more (or less) energy-efficient aircraft or aircraft with higher (or lower) occupancy rates, emissions may have been overestimated (or underestimated). The assumption that all tourists travelled from the largest airport in their home country to the gateway cities almost certainly represents an underestimate of real emissions. It is very likely that in many cases itineraries were more complex, including additional stop-overs and domestic flights. The role of non-carbon emissions is still heavily debated. It is clear that they have an impact, but the magnitude of these impact is disputed, as well as the linear relationship that is generally assumed between carbon and non-carbon emissions (Peeters et al., 2007).

It is very likely that overall emissions were underestimated in this study, because the scope was limited to tourists, and only those reported by IAATO. Staff, crew, and non-reported tourists were not taken into account. This latter category is probably relatively small, but the former two are very significant, because Antarctic tourism is a labour-intensive industry. It has been estimated that in the 2004/05 season a total number of 46,031 people were landed in Antarctica (including crews and guiding staff), while only approximately 23,000 of these were tourists (ASOC, 2006). Although many of these crew and staff members made repeated visits in one season, the emissions related to their origin-destination transport make a significant contribution to the underestimation. Also, emissions from inflatable boats, helicopter operations, repositioning the ship between the North and the South, business travel, and so on were not included. Together these non-accounted emissions are probably larger than the margin of error in our calculations.

\subsection{Conclusion}

In this chapter an inventory was made of the greenhouse gas emissions produced by tourism to and in Antarctica. The local environmental impacts of tourism in Antarctica have long been recognised, and addressed in (self)regulatory measures. The global environmental impacts of visiting Antarctica, however, have been sys- 
tematically overlooked in environmental impact assessments. As it turns out, this is a serious omission. The long distances travelled, the large aircraft used, and the safety measures taken result in an impressive amount of emissions of close to 15 tonnes of $\mathrm{CO}_{2}$-equivalents per typical tourist trip, including transport to and from the gateway cities. This is extremely high even for an energy-intensive industry such as tourism. For comparison: the average trip to the long-haul destination of the Seychelles produces a third of this amount, and it takes the average inhabitant of the EU-25 around 20 months to emit it. Total emissions added up to some 0.4 Mtonnes of $\mathrm{CO}_{2}$-equivalents in the season 2004/05, which is a moderate amount in the grand scheme of things, but only because the number of arrivals is still limited.

Our results provide a strong case for including global greenhouse gas emissions in any future environmental impact assessments of Antarctic tourism shipping and aviation, such as the ones performed to meet the requirements of the various domestic implementations of the Environmental Protocol to the Antarctic Treaty. Without a doubt, this can be done in a more sophisticated way than the analysis shown here. In particular, our method for calculating emissions from (expedition) cruises is very crude, as it does not take the wide variety in ships into consideration. Studies that are more accurate would require improved data availability of ship-based emissions. The emissions of origin-destination air travel clearly goes beyond the regulatory scope of the ATS and illustrate the global interdependencies of Antarctic tourism.

A fundamental question remains: is there a long-term future for Antarctic tourism? In the absence of a domestic market, trips to the South Pole region unavoidably imply long-haul travel. To make matters worse, the Antarctic tourism industry is currently extremely dependent on visitors from the Northern Hemisphere. To compensate for the large distances travelled, large efficiency gains in air travel are required, and these are not in sight for the next few decades. In addition, Antarctica and other long-haul destinations are vulnerable to any policies that would lead to substantial increases in transport costs. One such potential policy measure is the introduction of a tax on jet fuel, which has been proposed by the former French president Chirac. Albeit taking place in a distant location, Antarctic tourism is very strongly connected to global developments. 



\section{Chapter 5}

\section{ADVENTURE TOURISM AND PRIVATE EXPEDITIONS IN ANTARCTICA: CONCEPTUALISING THE RISKS}

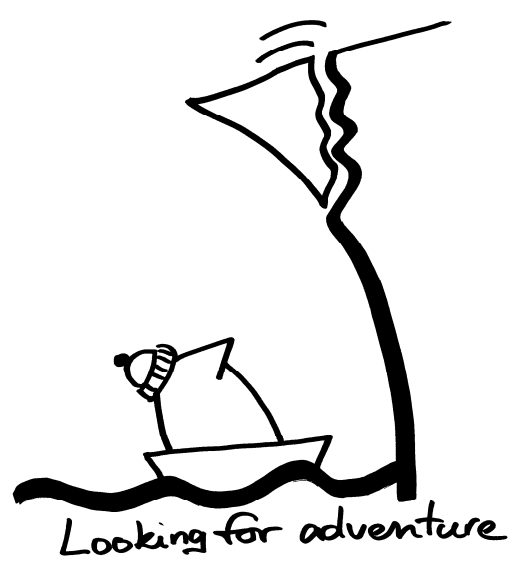

This chapter is based on:

Lamers, M., Stel, J.H., Amelung, B. (2007) Antarctic Adventure Tourism and Private Expeditions. In: Snyder, J., Stonehouse, B. (eds.) Prospects for Polar Tourism. CABI: Wallingford. Pp: 170-187. 


\subsection{Introduction}

Tourist arrivals in Antarctica have sharply increased over the last decade. Modern transport technologies have improved the accessibility of this remotest of continents, creating new opportunities for both commercial and private expeditions. As a result, the portfolio of tourism activities has gradually become more diverse; a broad range of market segments is now catered for, including luxury tours and adventure tourism. The classic Antarctic expedition cruises involving small to medium sized ships and inflatable boat landings are now complemented by, for example, eclipse-viewing trips reported by the Antarctic Non-government Activity Newsletter (ANAN, 2003: 96/05, 95/01), fly-sail cruises, overflights, and cruises on very large cruise liners, as well as by land-based adventurous activities, such as mountain climbing, cross-country skiing and marathon running (IAATO, 2004b). The trend towards diversification has given rise to concerns about the desirability and appropriateness of certain tourist activities in an Antarctic setting. In policy circles, adventure tourism has become a catchall term for all insufficiently prepared trips to the Antarctic. There is thus a lack of clear terminology and definition, which hampers the identification, analysis and possible solution of any tourism-related problems in Antarctica (Murray and Jabour, 2004). However, terminology is just one side of the issue. Key concepts in understanding the commotion around adventure tourism are risk and impact, and these are only loosely linked to tourism typologies. This chapter explores the risks of adventure tourism in Antarctica and their determinants. The implications of our findings are discussed with an eye on future developments and governance.

\subsection{Adventure tourism in Antarctica}

The process of negotiating and ratifying the Environmental Protocol in the 1990s temporarily reduced attention on tourism, but the issue re-emerged on the agenda of the first Antarctic Treaty Consultative Meeting (ATCM) of the new millennium (ASOC, 2001). Since then the discourse has focused on specific and technical issues, such as ship sizes, site-specific guidelines, cumulative impacts, and 'adventure tourism'. The Council of Managers of National Antarctic Programs (COMNAP) and the International Association of Antarctica Tour Operators (IAATO) have recently addressed this latter issue. Various policy documents report on incidents involving adventure tourists that required intervention from the National Antarctic Programs (NAPs) in terms of search and rescue (SAR), medical support, accommodation and transportation (COMNAP, 2002). Such assistance is typically very expensive and risky, and disruptive for the stations' usual activities. Its effects on science programmes that may have taken years of planning cannot be easily undone by financial compensations of the direct costs incurred (Chiang, 2000; ANAN, 2003: 95/03). 
The financial and operational consequences of several serious incidents have given adventure tourism a negative connotation in policy circles and raised questions about its desirability and options for regulation. Some NAPs have even established stringent policies regarding station visits and services such as accommodation, food, and fuel. At some frequently visited stations, adventure tourists are informed upon arrival that they are basically entitled to nothing, a point confirmed in many written accounts by adventure tourists. However, in practice, such hostility hardly ever leads to serious conflicts; the station personnel often seem happy to have guests, and treat them hospitably. Nevertheless there have been serious conflicts between NAPs and adventure tourists, up to the highest political and diplomatic levels (New Zealand and United States, 2004).

The Environmental Protocol currently regulates activities in Antarctica from an environmental perspective by demanding initial environmental assessments and notifications. However, since its adoption, some Treaty Parties and authors have expressed concerns about its limitations in regulating tourism (Richardson, 2000). COMNAP has stated that 'high risk adventure tourism' often cannot be regulated within this environmental legal framework, since risks to the environment are generally considered low in this type of tourism. As a consequence, parties do not have legal powers to require adventurers to undertake contingency planning or carry insurance to cover SAR costs in case of emergency (COMNAP, 2002; 2003). Meanwhile IAATO has made it very clear that its member organisations do not cause any problems (IAATO, 2003b): all are subject to a list of strict personal, financial and operational requirements. Furthermore, IAATO members have been called in where necessary to rescue independent adventure tourists in difficulties.

In the academic literature, the significance and scope of the notion of adventure tourism are heavily debated. The many definitions differ in focus, depending on the research context (Swarbrooke et al., 2003). Many definitions stress tourist motivation as a distinguishing factor: adventure tourism is distinguished from other types of tourism by differences in the participants' intent. For our purpose, the relevance of these types of definitions is limited, because they are unrelated to the risks and impacts that are imposed on others.

A very general observation about adventure tourism is that it entails an interaction between a participant and the environment, in which the outcome is uncertain (Hall, 1992a; Priest, 2001; Swarbrooke et al., 2003). The inherent uncertainty often translates into risks for participants. In the Antarctic context, these risks are amplified by the continent's inhospitable climate and general lack of facilities.

Paradoxically, these very uncertainties and real or perceived risks are among adventure tourism's main attractors - very different from scientific activities and mainstream tourism in Antarctica, where intentions are to exclude or avoid as many risks as possible. The role of risk may well constitute one of the main distinctive features of adventure tourism. 
Adventure tourism in Antarctica can be characterised as a broad spectrum of selfinitiated or commercially provided journeys, or single activities, with a challenging or innovative nature, to or within the Antarctic continent. In the following sections, we discuss activities that match these general characteristics. An important distinction is made between commercially provided adventure tourism activities and those that are independently pursued. Specifically, IAATO member companies organise various types of adventure tourism and support private expeditions in terms of transport and backup. A distinction is also commonly made between shipbased and land-based adventure tourism. We discuss below (1) ship-based tourism, consisting of activities in the coastal zones that are operated from tourist ships; (2) land-based tourism, involving activities away from the coasts, operated from tented camps serviced by aircraft, and ( 3 ) forms of adventure tourism that do not belong to either category, for example independent adventurers arriving by private boats or aircraft.

\subsubsection{SHIP-BASED ADVENTURE TOURISM}

Ship born tourism has a history of decades in the Antarctic. The Antarctic coastal zones are now sailed for tourism purposes by a variety of ship types and sizes, from small yachts and expedition ships to sailing-ships and cruise liners. Most ships visit the Antarctic Peninsula for traditional activities, such as zodiac cruising and wildlife viewing. New generations of travellers show a keen interest in more active elements. As a result, the range of activities has broadened over the past decade to include sea kayaking, scuba diving, snorkelling, ice camping, and climbing (IAATO, 2002a). In general, most of these additional adventure activities are organised from the smaller ships (i.e. yachts and some of the expedition ships).

According to IAATO (2003b), the passengers participating in these ship-based adventure packages account for less than $0.5 \%$ of all tourists travelling to Antarctica. Based on this statement, the number of adventure tourists can be estimated at 120 for the $2003 / 2004$, and at 150 for the $2004 / 2005$ season.

IAATO members that organise these new activities have developed guidelines and operating procedures for passengers, staff and crew (ANAN Archive, 2002: 77/08) that address the activities' specific risks. Prior to any trip, tour operators screen the passengers for physical and mental competence, and for experience in the particular sports involved. In addition, participants are required to declare in writing that they accept the risks involved in the activity. Appropriate and qualified staff facilitates the activities (IAATO, 2003b). IAATO ensures that member companies are well insured and that they are capable of dealing with incidents without much reliance on facilities and support from uninvolved national programs. The network of IAATO member companies active in the Antarctic region and the pre-established contacts with NAP's anticipates this need. Despite safety regulations, fatal incidents have occurred among scuba divers (IAATO, 2003a; 2005b). 


\subsubsection{LAND-BASED ADVENTURE TOURISM}

Land-based tourism activities rely on air links for transportation into and out of the Antarctic interior. Currently, two commercial airlines are operational. The Adventure Network International/Antarctic Logistics and Expeditions (ANI/ALE, formerly Adventure Network International), registered in the United States, has been operating in Antarctica for seventeen consecutive seasons. From Punta Arenas and Cape Town ANI/ALE services several tented camps and landing strips in Antarctica. The Chilean Aerovias DAP is an airline with a long history of flying between Punta Arenas and King George Island in the Antarctic Peninsula. DAP operations are limited to station visits and fly-sail operations, and are thus of little interest to us $^{7}$. As a result, our overview is limited to the ANI/ALE activities.

ANI/ALE was established by the late Gilles Kershaw, a well-known Antarctic pilot and one of the pioneers of landing a wheeled aircraft on natural blue-ice fields. Blue-ice runways were vital in the establishment of ANI/ALE because it opened up the Antarctic interior and created opportunities for adventurers and even NAPs (Swithinbank, 1998a). Another important factor has been the small but steady market of mountaineers and polar adventurers desiring to go to the Antarctic interior. Initially these adventurers were mostly the world's top mountaineers climbing Antarctica's tallest mountain, the Vinson Massif, as part of the seven highest summits on each continent. Later these adventurers also included South Pole crosscountry skiers using kites and sledges, mountaineers climbing the numerous unclimbed peaks, and single activities such as skydiving.

Private expedition teams are constantly in search of innovative and challenging activities. As a result, the composition of private groups varies widely, as do the activities and locations chosen. ANI/ALE provides services such as transport, contingency planning, SAR services, and medical evacuations. Typically, mountain climbers and South Pole skiers only use the transport and rescue services. In addition, ANI/ALE organises a number of land-based adventure activities and less demanding packages. The adventure packages include skiing trips to the South Pole, mountaineering trips and marathons. The less demanding packages include the South Pole fly-in, the Emperor penguin trip, and small scale activities around the tented camp, such as driving snowmobiles and short skiing trips. Finally, besides supporting private expeditions and operating their own tourist itineraries ANI/ALE provides logistics and back up support for several tourist vessels and NAPs in Antarctica.

Adventure tourism in the Antarctic interior is a very small niche market. Contrary to the general belief, average growth rates are not high either, as Figure 5.1 shows. Nevertheless, the trend has been upwards over the last few years, interrupted only

\footnotetext{
${ }^{7}$ During the King George Island research expedition in 2008 it became clear that besides day-visits and overnight stays DAP is involved in other activities as well, for example camping and marathons.
} 
by a dip in 2003/2004 when operations were limited as ANI was taken over by ALE. Figure 5.1 must be interpreted cautiously as a significant share of the passengers does not seem to qualify as adventure tourist. Arguably, the only real adventure tourists are the ones that take part in private expeditions, mountaineering activities and ANI/ALE's own adventure tourism activities. These visitors and adventurers are independent and self-reliant part of the expedition, or move away from the base camps into difficult terrain, with or without experienced guides. People in the category of 'other passengers' did not perform any of the adventurous activities described above, but were visitors participating in the less-demanding packages, ANI/ALE personnel and other unspecified passengers.

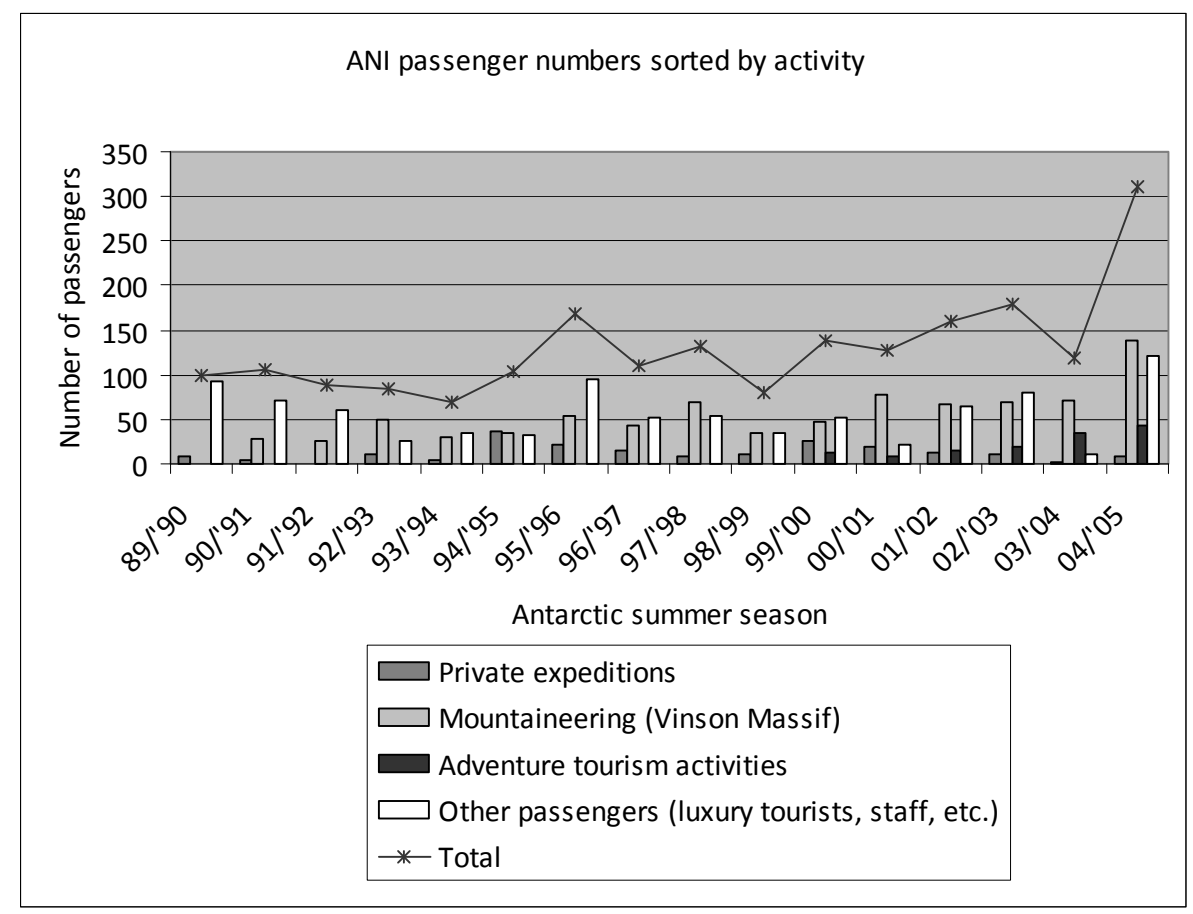

Figure 5.1: Numbers of ANI passengers per austral season, 1989-2005 (Swithinbank, 1989; 1990; 1992a; 1992b; 1993; 1994; 1995; 1996; IAATO, 1997; Swithinbank, 1997; IAATO, 1998; Swithinbank, 1998b; IAATO, 1999; Swithinbank, 1999; IAATO, 2000; Swithinbank, 2000; IAATO, 2001; 2002b; 2003a; 2004b; 2005b).

Being a founding member of IAATO, ANI/ALE applies stringent requirements to its own trips and the private expeditions it supports. These requirements relate to client acceptance, risk management (including appropriate insurance in case of an emergency); environmental impact assessment for the proposed journey; permission from the relevant national government departments; the quantity of food that is taken and the caloric value of each meal; information on the route taken and the 
equipment used (camping, communication, medical); experience of team members in polar regions and with the proposed activity; and back up planning in case of technical problems. As an extra safety measure, ANI/ALE automatically dispatches an aircraft to pick up expedition teams if no communication can be established for 48 hours (IAATO, 2003b).

In 1997, the only fatal incident happened within the operational history of ANI/ALE. On the first Antarctic skydive attempt above the South Pole, three of the participants died when their parachutes failed to open (IAATO, 1998). It was argued that despite significant polar experience in the group, they lost their sense of perception looking down on the white expanse of the icecap. Further, no emergency deployments were in place (Chiang, 2000). This expedition resulted in an incident that triggered a discussion about the appropriateness of skydiving in Antarctic. In spite of this, another skydiving expedition (the Millennium Expedition 1999/2001) was organised by a Russian polar outfitter in 2001; no major problems occurred. Nevertheless, ANI/ALE has declared that it will not organise any further skydiving activities in Antarctica ${ }^{8}$.

\subsubsection{OTHER FORMS OF ADVENTURE TOURISM}

There is more to adventure tourism than the activities conducted and supported by IAATO member companies. In the history of Antarctic adventure tourism there have been cases of NAPs supporting private expeditions in terms of transport, food and other services. In fact, the first private expeditions and adventure tourism programs were a direct spin off from large-scale governmental expeditions, involving the same people and using the routes and experiences gained (Swithinbank, 1998a). There are numerous examples of private mountaineering and skiing expeditions that were supported in terms of logistics and backup by NAPs. These services were either voluntarily granted to adventure travellers or provided in cases of emergency.

Also, more recently private adventurers sometimes try to make arrangements with NAPs to arrange particular services to cut the costs of their expeditions. Some NAPs have protested against these 'hopping and shopping' practices and established stringent permit requirements, regulations for station visits or called for improved communication between the NAPs. However, the negative attitude towards Antarctic tourists is not shared by all NAPs (IAATO, 2003b).

Recently, Antarctic Logistics Centre International $(A L C I)$ started operating a new air link between Cape Town and Dronning Maud Land (DML). While initially intended as a transport link for NAPs operating in the DML area, several reports show that paying passengers have been taken on board. Moreover, several proposals exist for

\footnotetext{
${ }^{8}$ Personal communication with David Rootes (2005).
} 
mountaineering expeditions (ANAN Archive, 2001: 83/01, 61/01) ${ }^{9}$. ALCl has not provided any information on the exact passenger numbers that have been carried to and from the Antarctic and their operational procedures (IAATO, 2003b). In the 2004/05 season the Uruguayan national programme has reported to have taken paying passengers on their operational flights to Artigas station on King George Island (Uruguay, 2005). Paying tourists can provide a welcome source of income for NAPs with limited budgets.

In addition, personnel of national programs are known to participate in mountaineering and skiing activities (Murray and Jabour, 2004), and may sometimes even attempt to traverse the icecap (ANAN Archive, 2001: 41/02). No official statistics are available for these activities, so that the scope and nature of these arrangements are difficult to assess.

A final group of travellers are the so-called 'one-off' adventurers. These independent groups or individuals rely on their own transport into the Antarctic Treaty area. Their means of transport include privately owned or rented yachts and aircrafts. For these one-off expeditions the challenge typically lies in 'getting there', rather than in performing particular activities in Antarctica. Because of the independent nature of these activities, statistics are hardly available. It is very difficult to estimate how many travellers are involved, what activities are carried out, where travellers are located, what kind of equipment is used and how well trips are planned. In fact, such information is gathered only when an accident occurs.

\subsection{Recent incidents that have caused concern}

Chiang (2000) reports that, from 1979 to 2000, twenty-six incidents have been recorded in adventure tourism expeditions that have caused policy-makers to express concern for the development and effects of adventure tourism: in Chiang's view, the number of such incidents is growing. Murray and Jabour (2004) in contrast reject this focus on adventure tourism by pointing to the notion's fuzzy definition. We approach the issue by discussing the main factors involved in incidents recorded during five recent seasons 2000-2005 (Table 5.1).

Coinciding with general visitation patterns, most of the incidents occurred in the Antarctic Peninsula and in the area around the geographical South Pole. The Peninsula is relatively easily accessible, while the South Pole is attractive because of its mythical qualities. Most of the incidents with private aviators happened near the airstrips of research stations. Incidents also occurred in other locations, such as the ANI/ALE's Patriot Hills camp, and Marion Island, off the coast of DML. Remoteness is a key risk factor in Antarctica. The Russian party of seventeen in 2002, and other

\footnotetext{
${ }^{9}$ See also: http://www.thepoles.com/news.php?id=14115
} 
smaller groups would have been in serious trouble had they not ended up near a station or ship. Good information on the environmental conditions and the available infrastructure are also vital, as the incidents of Henri Chorozs and Stephen Thomas show.

Table 5.1: Incidents during Antarctic adventure tourism expeditions in 2000-2005 that have caused concern.

\begin{tabular}{|c|c|}
\hline Season & Incidents \\
\hline $2000 / 01$ & $\begin{array}{l}\text { In } 2001 \text { Rolf Bae and Eirik Sonneland, two Norwegian adventurers, arrived at Scott } \\
\text { Station (New Zealand) after a } 2.900 \mathrm{~km}, 107 \text { day, unsupported skiing trek from Troll } \\
\text { Station (Norway) in Dronning Maud Land to Ross Island. Bae and Sonneland started } \\
\text { off after wintering at Troll Station with no formal arrangements on transport, or } \\
\text { SAR. They were not able to communicate their circumstances and position because } \\
\text { of failing communication equipment. Furthermore, they surprised everyone by } \\
\text { taking off for Ross Island after arriving at the South Pole, since this was not in their } \\
\text { initial plans. They arrived at Ross Island with little food and were accommodated } \\
\text { and fed at Scott Station. They were able to leave Antarctica on a tour vessel (ANAN } \\
\text { Archive, 2001: 41/02). } \\
\text { In the same season, two Australian adventurers Peter Bland and Jay Watson ran into } \\
\text { difficulties in an attempt to cross the Antarctic Peninsula after Bland was injured in } \\
\text { an avalanche. Despite the negative advice while obtaining permits from by the } \\
\text { Australian authorities, Bland and Watson chartered a private yacht and set off for } \\
\text { the Peninsula. The activities involved in this Antarctic Peninsula trek included kayak- } \\
\text { ing, mountain climbing and skiing. It took the combined efforts of the yacht's crew, } \\
\text { a nearby tour ship and the Chilean national program to save Bland in a very difficult } \\
\text { and dangerous rescue attempt. Bland and Watson had no official permit for their } \\
\text { expedition and no formal SAR plan (ANAN Archive, 2001: 41/01). }\end{array}$ \\
\hline $2001 / 02$ & $\begin{array}{l}\text { In } 2002 \text { a group of Russian government officials and tourists traveling with Cerpolex, } \\
\text { a French company, were stranded for two days at the South Pole because their } \\
\text { aircraft failed to start. They were accommodated and catered for at Amundsen- } \\
\text { Scott Station (USA) and eventually flown out at their own expense (ANAN Archive, } \\
2002: 79 / 05 \text { ). In 2005, their aircraft, an Antonov -3, was successfully recovered by } \\
\text { combined efforts of the USA and Russia. }\end{array}$ \\
\hline $2002 / 03$ & $\begin{array}{l}\text { In } 2002 \text { the French pilot Henri Chorozs made an unexpected emergency landing on } \\
\text { Marion Island (off the coast of DML) in an attempt to become the first to fly around } \\
\text { the world via both poles in a single-engined aircraft. After a hard landing, Chorozs } \\
\text { was quickly pulled from his aircraft by a South African rescue team. He stayed at } \\
\text { Marion Island (South Africa) for ten days, then was transported off the island by a } \\
\text { French naval vessel (ANAN Archive, 2002: 88/01). } \\
\text { In early } 2003 \text { a UK-registered helicopter crashed into the ocean near the South } \\
\text { Shetlands in the Antarctic Peninsula. The Chilean navy rescued two British pilots } \\
\text { from a life raft. Apparently the British authority was not aware of this expedition } \\
\text { prior to the incident (ANAN, 2003: } 93 / 03 \text { ). } \\
\text { A few days later a scuba diver died while making a check dive with the Netherlands- } \\
\text { based tour company Oceanwide Expeditions. The victim was part of a group of nine } \\
\text { Latvian scuba divers on board the tourist vessel Gregory Mikheev. Despite the re- } \\
\text { suscitation attempts by the ship's doctor and the help offered by a nearby Brazilian } \\
\text { research ship; he died (ANAN 2003: } 91 / 02 \text { ). }\end{array}$ \\
\hline
\end{tabular}




\begin{tabular}{|c|c|}
\hline Season & Incidents \\
\hline $2003 / 04$ & $\begin{array}{l}\text { British pilot Polly Vacher had to abort her attempt to cross the Antarctic by aircraft } \\
\text { because of bad weather conditions. She had made several arrangements with the } \\
\text { national programs of New Zealand and the UK and a tourist vessel for services } \\
\text { (ANAN Archive, 2002: 64/11). The expedition was cancelled (IAATO, 2004b: 21). } \\
\text { Australian aviator Jon Johanson landed at Ross Island after having become the first } \\
\text { person to fly across the South Pole in a homemade aircraft. He had no fuel left to } \\
\text { return to New Zealand and eventually got a refill from the Vacher expedition's fuel } \\
\text { dump that was stored at McMurdo station (USA) (New Zealand and United States, } \\
\text { 2004) (IAATO, 2004b). } \\
\text { British helicopter pilots Jennifer Murray and Colin Bodill planned to circle both poles } \\
\text { when their helicopter crashed near Patriot Hills. They were rescued by ANI/ALE } \\
\text { according to their contingency plans (IAATO, 2004b). }\end{array}$ \\
\hline $2004 / 05$ & $\begin{array}{l}\text { In early 2005, UK sailor Stephen Thomas died after falling into a crevasse near Port } \\
\text { Lockroy in the Antarctic Peninsula. Thomas and his crew reached Antarctica by } \\
\text { private yacht after having previously sailed to the Arctic region. Despite his consid- } \\
\text { erable experience in mountaineering, Thomas was unaware of the specific Antarctic } \\
\text { conditions. He was retrieved by his yacht crew and examined by a medical doctor on } \\
\text { a nearby cruise ship and pronounced dead (BBC News, 2005; IAATO, 2005c). }\end{array}$ \\
\hline
\end{tabular}

Incidents occurred in expeditions of varying group composition, and of varying physical and mental abilities, and levels of experience. Aviators usually travelled alone, whereas the land-based activities that failed both consisted of parties of two or more. Adventure tourists travelling with established companies were typically better prepared for the conditions in the Antarctic interior than the members of one-off expeditions. In 2005, Stephen Thomas was well prepared for crossing the Southern Ocean in his yacht, but not for trekking on the islands of the Peninsula. However, even experienced trekkers, aviators, and sailors can underestimate the dangers of the Antarctic environment, or be simply overwhelmed by them.

The incidents occurred with a broad range of activities, including cross-country skiing, kayaking, scuba diving, mountain climbing and aviation. For some expeditions, trekking across a part of the continent is the main challenge, whereas for others this challenge lies in simply 'getting there'. In 2002, a Russian group managed achieved this latter objective, but had paid insufficient attention to the issues of 'staying there', and 'getting away if something goes wrong'. Between 2002 and 2004, adventures took on the new challenge of flying around the world over the poles in their own aircraft. The competitive spirit made adventurers rush their preparations, and consequently many failed.

Activities by IAATO member companies are well organised from a perspective of safety regulations and minimising risk and uncertainty for third parties. Nevertheless, incidents have occurred lately, such as the Polar First expedition in 2004 and 
the Oceanwide Expeditions diving incident in 2003. Because of elaborate contingency planning and pre-arranged back up no request for help from external parties was needed. Most of the other activities were not announced to other parties in the Antarctic before it was too late. In the case of Bae and Sonneland in 2001, no incident occurred but third parties were worried because of the unexpected behaviour of the adventurers and the lack of pre-arranged back up. In other cases, assistance was requested from scientific stations and tourist ships nearby. These interventions are known to be costly and to incur additional risks upon the rescue personnel, but so far, the impacts have not been estimated quantitatively.

Despite the lack of back up plans and SAR contracts, most of the parties managed to obtain a permit from their respective national authorities. Exceptions are Bland and Watson in 2001, who required a permit but set off without one, and the two British helicopter pilots in 2003, who did receive a permit but from the Chilean authorities through established contacts. Obviously, it is very difficult to manage and control travellers arriving in the Antarctic by their own means of transport. However, by making the issuing of permits conditional upon the development of contingency plans, the impacts of accidents can be limited. The SAR and insurance contracts guarantee that the costs of any emergency operation can be recovered.

A number of risk determinants emerge from the above analysis of the incidents. First of all, the level of risk depends on the activity that is being undertaken, i.e. the physical and mental challenge that the activity demands or the innovative nature of the activity. Extraordinary single activities, such as scuba diving have risk profiles that differ from journeys or expeditions venturing deep into the continent. Remoteness composes a second risk factor. In contrast to mainstream tourism, adventure activities are typically set in remote and exotic places, in this case the Antarctic polar environment (Swarbrooke et al., 2003). Remote polar environments can pose great risks, such as crevasses, unreliable weather conditions, especially when the tourist vessel, tented camp or other human environment is far away. A third determinant of the level of risk is the nature of the participants. These adventurers can be solo adventurers or groups, endowed with different levels of experience regarding the activity or the environment, and with different physical and mental abilities. Typically, adventure tourists have to perform at the very limits of their capabilities in order to succeed. The fourth element is organisation. Adventure tourism can take the form of a self-initiated, independently organised expedition or a commercially offered tourist itinerary. In the first category the expedition members are responsible for possible financial, environmental and safety risks. In the second category commercial tour companies provide an adventure experience for paying clients, manage the risks that are involved and carry the responsibility of the outcome. In practice, many expeditions are combinations of these two extremes, with commercial tour operators taking care of just a few aspects of the otherwise private expeditions. 
Figure 5.2 is a graphical representation of the four factors that together determine the level of risk associated with a particular activity, i.e. activity (what), environment (where), participants (who), and planning (how). Ewert and Hollenhorst (1989) and Weber (2001) propose that the final level of risk depends on the interplay between individual attributes (e.g. experience and skill) on the one hand, and activity and environment attributes on the other. Bentley and Page (2001) contend that a single risk factor rarely leads to an accident or crisis situation; usually combinations of multiple factors create the conditions in which a mishap can occur. If the four factors are not well balanced, relatively small injuries (like a cut) can lead to a chain reaction of other mishaps or incidents. Our analysis also points at the importance of proper management and organisation, and at the desirability of being independent from third parties for assistance. Examples of private expeditions and adventure tourism activities show that mishaps do not necessarily have to lead to incidents involving third parties, if sufficient contingency plans are in place.

Figure 5.2: Risk determinants in Antarctic adventure tourism

\begin{tabular}{|c|c|}
\hline $\begin{array}{l}\text { Pre-planning factors: } \\
\text { Finance } \\
\text { Institutional planning: e.g. permits, IEE } \\
\text { Equipment: e.g. clothing, food } \\
\text { Transport } \\
\text { Contingency planning: e.g. SAR, insurance }\end{array}$ & $\begin{array}{l}\text { Traveler/group factors: } \\
\text { Competence: } \\
\text { Physical abilities } \\
\text { Mental abilities } \\
\text { Experience } \\
\text { Group composition: } \\
\text { solo or group } \\
\text { Guides }\end{array}$ \\
\hline $\begin{array}{l}\text { Activity type: } \\
\text { Journey: } \\
\text { e.g. trekking, climbing, skiing, flying, sailing } \\
\text { Single activities: } \\
\text { e.g. skydiving, marathon, scuba diving, kayaking }\end{array}$ & $\begin{array}{l}\quad \text { Environmental factors: } \\
\text { Natural environment: } \\
\text { e.g. land/water, crevasses, climate, biodiversity } \\
\text { Human environment: } \\
\text { e.g. facilities (camp or ship), research stations, } \\
\text { other travelers/groups }\end{array}$ \\
\hline
\end{tabular}

\subsection{Policy development}

Following discussions on tourism at the ATCMs of Warsaw (2002) and Madrid (2003), an Antarctic Treaty Meeting of Experts on Tourism and Non-Governmental Activities (ATME) was organised in Norway in 2004. Concerning adventure tourism, 
the meeting yielded two types of proposals. The first was the adoption of additional guidelines and requirements for organisers of activities within the ATCP's national permit systems - guidelines that would increase self-sufficiency and mitigate human risks (United Kingdom, 2004b; United States, 2004). The second was to improve the exchange of information and the coordination of activities between different ATCPs and stakeholder groups. The idea behind this proposal is that a centralised and open database of tourist activities and non-governmental expeditions would take away much of the uncertainty that surrounds adventure tourism (COMNAP, 2004; New Zealand and United States, 2004; United Kingdom, 2004c). Further, 'hopping and shopping' practices for permits and support of adventurers should be identified and targeted.

In response to the ATME proposals, at the 2004 ATCM in Cape Town, a resolution and a measure were adopted containing new guidelines for tourist activities. First, Resolution 4 was adopted on 'Guidelines on Contingency Planning, Insurance and Other Matters for Tourist and Other Non-governmental activities in the Antarctic Treaty Area'. This resolution was strengthened by a measure agreed upon with immediate voluntary effect under the same title and contents (Antarctic Treaty System, 2004). Major elements in these guidelines are contingency plans, including SAR, medical provisions, insurance and liability issues. In addition, two resolutions were adopted to cope with the uncertainty aspect and the lack of information about activities taking place in the Antarctic Treaty Area: Resolution 3 on 'Tourism and Non-governmental Activities: Enhanced Co-operation Amongst Parties'; and Resolution 5 on the 'Establishment of an inter-sessional contact group to improve exchange of information between Parties.'

Will these measures that were agreed upon at the Cape Town ATCM solve the problem of risk management in Antarctic adventure tourism? So far, policy decisions only include recommendations for ATCPs and voluntary measures. Moreover, it may still be easy for adventurers to find gaps in the regulatory systems, especially by establishing contacts and arranging support in countries with different permitting systems. In addition, private adventurers from non-Treaty countries do not have to keep to these rules.

Remarkably, policy proposals and agreed measures focus solely on the preplanning phase of the risk determinant model, i.e. making sure that adventurers depart well-prepared, self-sufficient, well-insured and that ATCPs, NAPs and other stakeholders are well-informed. The analysis has shown that the pre-planning phase, especially contingency planning and back up, is of crucial importance for the success or failure of a private expedition or adventure tourism itinerary. Although important, the analysis has also shown that not all risks can be anticipated, especially since vital information on the harsh and unreliable environmental conditions are generally missing. Moreover, earlier we learned that adventurers might be deliberately seeking these risks in their expeditions. 
The risk determinant model proposes a number of other strategies to mitigate human risks in Antarctica. An important role in checking permits and contingency plans, providing information about local environmental risks, and informing third parties, could be allocated to the Antarctic gateway cities, especially with regard to 'one-off' yachting trips or expeditions involving aircraft. Further, one could think of closing parts of the Antarctic continent for particular types of adventure that are not considered suitable because of ecological vulnerability, high human risk, scientific research, or the impossibility of possible SAR or medical evacuations in case something goes wrong. One could think of the establishment of a 'dead zone' similar to that at Mount Everest. On the other hand, evidence from the Himalaya shows decades of high-risk activities with significant cumulative impact in remote and cold climates. Another logical improvement in mitigating human risk is the establishment of permanent rescue facilities in the areas where most of the activities take place, in this case the Peninsula. On the other hand, much resistance exists for the establishment of permanent land-based tourism infrastructures in Antarctica. There is no consensus so far on this issue.

Risks involved in adventure tourism and private expeditions depend to a very large extend on the characteristics and prior experiences of the individual. It proves to be very difficult to assess whether an adventurer is well prepared, especially for policy executers who have never been to the Antarctic, or participated in similar activities. A possible way to overcome this problem is to review permit applications by a variety of experienced experts. Another option is to have the right to refuse a permit if an adventurer has caused problems in the past. One could also think of arrangement whereby one-off expeditions are obligatory to collaborate with a certified, well-established company. This, on the other hand, would stimulate the creation of monopolies in the Antarctic tourism industry.

Finally, the skydiving incident described earlier has triggered a discussion about the appropriateness of particular activities in the Antarctic. Some activities or developments could be considered in conflict with intrinsic Antarctic values, such as the designation of Antarctica as a wilderness. One can think of the use of motorised vehicles, or adventure activities that are not considered 'Antarctic', such as bungee jumping, paintball or even 'extreme ironing' (a fairly new phenomenon whereby participants try to iron under extreme conditions, and provide photographic evidence $\left.{ }^{10}\right)$. A possible policy option could be to ban those activities that are jeopardising the Antarctic intrinsic values, despite the level of pre-planning, commercial involvement, or experience of participants.

We must understand that adventure tourism does not develop in isolation. Rather, it is related to and co-evolves with other issues, such as the growth of commercial tourism, scientific programmes (such as the International Polar Year in 2007/08),

\footnotetext{
${ }^{10}$ For example see: http://www.extremeironing.com
} 
and the creation of land-based facilities (see for example New Zealand 2004, which argues for a prohibition of the development of land-based tourism facilities. It is thought that such facilities have irreversible environmental effects and creates possibilities for tourism development, including adventure tourism). Also involved are newly established air links (for example the recently established Cape TownDronning Maud Land link (DROMLAN), and an air link currently under consideration by the Australian Antarctic Division); the establishment of an environmental liability regime; raising of awareness among adventurers and yachting people who may not fully appreciate the climatic and other dangers (ANAN Archive, 2002: 82/07), and the role of gateway city harbours and airports (ANAN Archive, 2002: 82/04). These interdependencies should be acknowledged, and merit more detailed investigation.

Incidents are also not exclusive to adventure tourism. In recent years, we have seen a series of ship-based incidents involving tour operations that can be categorised as "regular" (see box 5.1). It remains unclear what causes these incidents (e.g. failing ship technology, human mistake, poorly charted waters) and what can be done about it. It is clear that Antarctic shipping policy could benefit from further investigation into risk determinants.

Box 5.1: Recent incidents with expedition cruise ships 2006-2009 (ASOC, 2009b)

Cruise tourism vessel the Ocean Nova grounded on 17 February 2009 in Marguerite Bay near Argentina's base San Martin. All passengers were transferred to nearby tourist ships and the Ocean Nova was eventually refloated without spillage of fuel.

The Ushuaia grounded on 4 December 2008 at the entrance of Wilhelmina Bay near Cape Anna in the NW Antarctic Peninsula. The ship had punctured fuel tanks with a capacity of $55 \mathrm{~m} 3$ of Marine Gas Oil (MGO). According to industry sources only a small amount of fuel leakage took place and an oil spill barrier was deployed.

The Explorer sank off King George Island, South Shetland Islands, on 24 November 2007, after a collision with ice. All on board were rescued. At the time of sinking, the Explorer is estimated to have been carrying $210 \mathrm{~m} 3$ of D.M.F.O., oils, lubricants and petrol. While most of the fuel may still be contained in the vessel, some fuel has spilt and what is left in the wreck will eventually be discharged into the marine environment.

On December 30, 2007, the Fram lost power and drifted along the Antarctic Peninsula coast for several hours after having collided with an iceberg.

The Nordkapp grounded at Deception Island on 31 January 2007. The accident resulted in the spillage of marine diesel into the marine environment and resulting environmental damage.

The Lyubov Orlova grounded at Deception Island on 15 November 2006. It is believed that the rescue call was made 15 hours after the vessel grounded, at which time no MAYDAY call was raised. The Lyubov Orlova was towed off the sandbank, a process that took 3 hours to complete. 


\subsection{Conclusion}

Currently, adventure tourism and private expeditions in Antarctica are a very small niche market. Just several hundreds of adventurers take part in them annually, and the number of problematic expeditions is limited to just a few per season. One may wonder whether adventure tourism and private expeditions are a problem at all, with such small numbers of participants and incidents. Yet, with an eye on the improving accessibility of Antarctica and the trend towards increased diversification, adventure tourism may be at the eve of a period of rapid growth. The level of attention that adventure tourism gets from policy-makers may seem unjustified at first sight, but warranted from a longer-term perspective, particularly in view of the slowness of Antarctic decision-making processes on tourism.

Murray and Jabour (2004) claim that independent expeditions have quite wrongly been depicted as the opposites of mainstream, organised tourists and other (primarily scientific human operations in Antarctica. We must acknowledge that these well-established Antarctic institutions also once started as adventurous expeditions, including risks and incidents. In fact the numerous incidents in the mainstream ship-based sector could be see as a reinforcement of their claim. The adventure spirit has been intrinsically part of Antarctica from the moment humans have set foot on the continent. The series of recent incidents in "regular" shipbased tourism (e.g. the sinking of the $M / S$ Explorer) illustrates that risks are not exclusively related to industry segments (see box 5.1). The above-mentioned risk model could just as well apply to the operation of mainstream forms of tourism. Adventure tourism and private expeditions highlight the uncertainty of possible outcomes in Antarctic tourism activities and the unpredictable course of its development. Further, independent expeditions benefit the Antarctic community by introducing creative innovations in polar technology, transport, and geographical knowledge. As a result, the industry believes that adventure tourism should have a place in Antarctica, provided that it is organised properly (IAATO, 2003b).

The management of tourism activities in Antarctica is largely left to the tourism sector. The IAATO network issues guidelines and procedures to tackle any problems in a technical way. As a result, fundamental decisions about Antarctic tourism, such as structural limitations, or its moral implications, are left untouched. More and more authors claim that the pace and direction of the current tourism trends call for the development of a more proactive and comprehensive policy (Bastmeijer and Roura, 2004). In the previous section, we have seen that for adventure tourism plenty of management and policy options are available. However, diverging interests regarding tourism on the short term may hamper consensus building on the longer term. In order to create such a proactive comprehensive tourism policy a common future vision between the different stakeholder groups and the ATCPs is required. 


\section{Chapter 6}

\section{PERMANENT LAND-BASED FACILITIES FOR TOURISM IN ANTARCTICA: THE NEED FOR REGULATION}

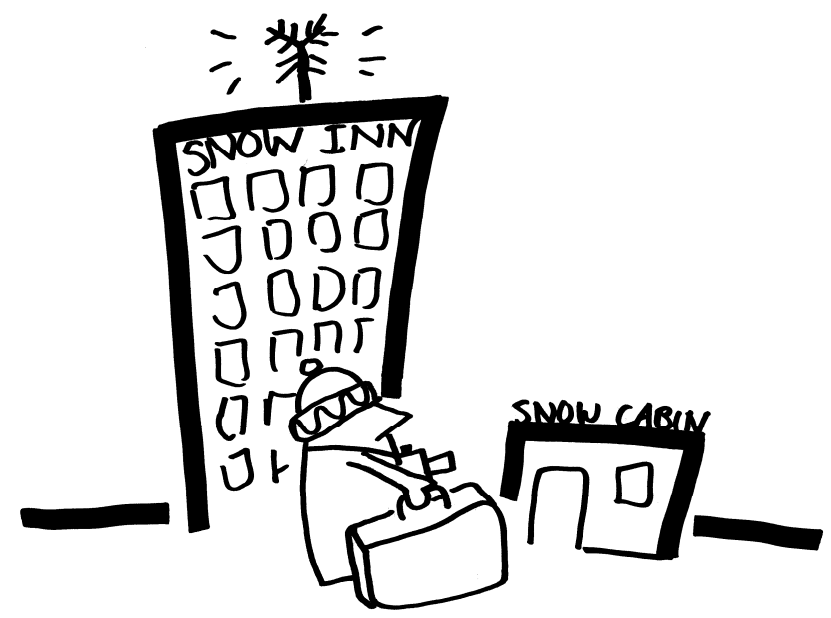

This chapter is based on:

Bastmeijer, K., Lamers, M., Harcha, J. (2008) Permanent Land-based Facilities for Tourism in Antarctica: The Need for Regulation. Review of European Community and International Environmental Law (RECIEL) 17(1): 84-99. 


\subsection{Introduction}

One of the issues that have received much international attention since 2004 is the possible future development of permanent land-based facilities and infrastructures for tourism. Although the scale of such facilities is currently limited, the interest in the issue is understandable in view of the fast developments in the Antarctic tourism industry. Currently only two IAATO companies are categorised as land-based operators, making use of seasonally removable tented camps and existing facilities at scientific research stations. Together their operations consist of some 1,000 passengers but their activities range considerably, from one-day organised station visits to independent crossings of the Antarctic ice cap. Increasing scale, efficiency and diversification of the tourism industry, as well as the potential implications of permanent land-based tourism, have urged a number of Consultative Parties to the Antarctic Treaty to propose a prohibition on the development of such facilities. However, so far, no consensus has been reached on the adoption of restrictive measures.

The international debate raises many questions regarding the feasibility and desirability of permanent facilities and infrastructures for tourism in Antarctica. Unfortunately, the discussions are not based on clear definitions, inventories of existing facilities, potential future developments and arguments for and against these developments. A clear overview and comparative analysis of the various management options is also missing. This chapter aims to contribute to the collection of such information. Based on a definition of permanent land-based facilities for tourism (section 2), an inventory is made of past and present existing Antarctic tourism facilities as well as a number of proposals for such facilities (section 3). Next, the debate within the ATS on the issue since 2004 is summarised (section 4), followed by a discussion of arguments for and against permanent tourist facilities in Antarctica (section 5). A number of policy options will then be discussed for consideration by the ATS (section 6). Finally, conclusions will be drawn (section 7).

\subsection{Definition of permanent land-based facilities for Antarctic tourism}

For the purpose of this chapter, we define land-based tourism as tourism that makes use of facilities located on or connected to Antarctic land or ice. Land-based tourism requires transportation of tourists to Antarctica by ship or aircraft, but must be distinguished from ship-based tourism (using the ship as the 'hotel' of the Antarctic visitor) and tourist overflights (where no landings are made). Land-based tourism includes not only the visitors that pay for their travel and stay but also the accompanying staff and crew (ASOC, 2006). Members of staff and crew are likely to 
have similar environmental impacts and enjoy the same legal status as the rest of the visitors.

A facility is generally defined as "something that makes an action, operation, or course of conduct easier' or 'something [...] that is built, installed, or established to serve a particular purpose" (Merriam-Webster, 2007). For the purpose of this article, we focus on human-made facilities in the Antarctic that serve or support tourism, for instance, as a place where tourists can overnight or as a place to be visited by tourists during the day (e.g. visitor centre, historic site or museum). A place that has a different primary purpose (e.g. scientific research) but facilitates tourism and facilities that support logistic activities related to tourism also fall within the definition as used for our discussion. Furthermore, the term facility as used in this article includes facilities and infrastructures on land, but also facilities connected to land, such as hotels built on floating platforms. However, we exclude from our definition management facilities that have the sole purpose of preventing damage to the ecosystem by (high) visitation (e.g. boardwalks).

It may be argued that, in the Antarctic context, no human-made facility can be considered permanent, as all buildings and structures are subject to high levels of erosion and entropy. Moreover, the Protocol states that everything brought to the continent should be removed after usage (Antarctic Treaty System, 1991). In this chapter, land-based facilities are considered permanent if they are intended to continue or persist over a period of time, at least longer than one Antarctic season. This is not to say that facilities or infrastructures are permanent in the sense that they are static, i.e. without experiencing fundamental or marked change (MerriamWebster, 2007). For instance, our definition includes also seasonal campsites that continue operating for a number of consecutive years or store facilities in Antarctica during the Antarctic winter. In the inventory of existing and planned facilities below, such facilities will be categorised as 'semi-permanent'.

Thus, for the purpose of this chapter, permanent land-based tourist facilities include all human-made structures on or connected to Antarctic ground or ice with the purpose or function of serving Antarctic tourism for a time period of more than one Antarctic summer season.

\subsection{Permanent facilities for tourism in Antarctica and future trends}

\subsubsection{OVERVIEW OF EXISTING AND PLANNED FACILITIES}

Only a few facilities are known to have been erected on Antarctic land or ice with the specific purpose of supporting tourism. However, there are examples of buildings that originally had another purpose, which received a tourist function later in time. Furthermore, there are facilities that support tourism, while their primary 
function is different. In Tables 6.1 and 6.2 below, a categorised inventory is provided of all these facilities that currently exist. Although this article focuses on facilities that support tourism, other categories of permanent structures for nonscientific purposes are also included. The categorisation is based on several practical criteria, i.e., the owner or operator of the facility (governmental or nongovernmental), the nature of the facility (permanent or semi-permanent) and the current primary purpose of the facility (e.g. science or tourism support). Table 6.1 relates to non-governmentally operated facilities. Table 6.2 presents governmentally operated facilities.

The overview shows that in 2007 a relatively limited number of permanent Antarctic facilities with a non-scientific primary purpose are maintained and that most of these facilities (e.g. E-Base and Villa Las Estrellas) are attached to or in close range of facilities and infrastructure maintained by national Antarctic programmes (NAPs). Even in the case of operating semi-permanent tented camps near blue-ice runways (e.g. Patriot Hills and Blue-One), close cooperation with NAPs is necessary (Swithinbank, 1998a).

\subsubsection{POSSIBLE FUTURE DEVELOPMENTS}

The limited number of existing permanent tourist facilities in Antarctica and their close links with NAPs raise the question of whether such facilities are likely to further develop in the near future. To start with, it should be noted that the Greenpeace World Park Base was operated entirely independently from governmental support and influence. It may be true that this base (and perhaps the same holds for E-Base and the Chilean hostel) provided very basic accommodation for only a few visitors and would not meet the needs of many present-day travellers; however, the facility proves that it is feasible to realise and maintain a facility without the support of NAPs.

During the international debates at the ATCMs on the issue, IAATO has questioned the need to take management action because the development of serious proposals for permanent tourism facilities was considered unlikely (IAATO, 2006c). Undoubtedly, the financial costs for developing a comfortable tourist facility in Antarctica on a sound commercial basis would be tremendous. However, a number of examples exist of commercially oriented proposals that never materialised but provide valuable insight into the feasibility of permanent land-based tourism facilities. The most striking and comprehensive proposal was the one for a 'US\$ 200 million tourist centre to be built in Australia's pristine Antarctic,' known as 'Project Oasis' (Simpson, 1989). This project related to a three-capsule resort, planned near the Australian Davis station, including 'an aircraft facility, visitor education and research centres, accommodation, hospital, search and rescue services and Antarctic Treaty related organisation facilities' (Rohde, 1990). 
Table 6.1: Non-government operated permanent facilities for tourism

\begin{tabular}{|c|c|}
\hline Category: & Cases: \\
\hline $\begin{array}{l}\text { 1. Non- } \\
\text { governmentally } \\
\text { operated perma- } \\
\text { nent facilities with } \\
\text { a primary tourism } \\
\text { purpose }\end{array}$ & $\begin{array}{l}\text { E-base was established in } 2006 \text { near Bellingshausen Station (Russia) at King } \\
\text { George Island by 2041, an NGO founded by polar explorer Robert Swan. E-base } \\
\text { is described as a sustainably built and run facility that functions as an education } \\
\text { centre (Bastmeijer and Roura, 2008); } \\
\text { The Chilean air carrier Aerovias DAP is known to organise day trips and over- } \\
\text { night trips to King George Island using basic lodging facilities installed between } \\
\text { Villa las Estrellas, a facility run by Chile as part of Base Frei, and the Russian } \\
\text { Bellingshausen Station. The infrastructure includes } 5 \text { containers located on a } \\
\text { site covering } 0.1 \text { hectares. Each container is } 6 \text { m. long, } 2 \text { m. wide and } 2.5 \text { m. } \\
\text { high, made of metal similar to the other facilities present in the area. All con- } \\
\text { tainers are mounted on skids so they can be easily set up and removed. The } \\
\text { facility is also used, on a commercial basis, to host National Antarctic Programs } \\
\text { personnel passing through Fildes Peninsula on their way to/from KGI (Baraona, } \\
\text { 1999; DAP, 2008); } \\
\text { Proposed but not established: Lars Erik Lindblad's } 1974 \text { plan for leasing Cape } \\
\text { Hallett Station in the Ross Sea region (capacity: } 60 \text { people) (Lamers, 2006); } \\
\text { Proposed but not established: Rhode and partners } 1989 \text { Project Oasis for es- } \\
\text { tablishing a joint science and tourism facility in the Vestfold Hills (capacity: } 344 \\
\text { tourists/70 scientists/174 staff) (Rohde, 1990). }\end{array}$ \\
\hline $\begin{array}{l}\text { 2. Non- } \\
\text { governmentally } \\
\text { operated semi- } \\
\text { permanent facili- } \\
\text { ties with a primary } \\
\text { tourism purpose }\end{array}$ & $\begin{array}{l}\text { Annually erected tented camps near continental blue-ice runways operated by } \\
\text { private companies for the purpose of tourism and other non-governmental } \\
\text { activities. Examples include: Patriot Hills (ALE/ANI) and Vinson Massif base } \\
\text { camp (ALE/ANI), and Dronning Maud Land (ALCI). Seasonal tented camps are } \\
\text { included in this table because of their persistent presence (Patriot Hills was } \\
\text { established in the } 1986 / 87 \text { season) and the fact that equipment and material } \\
\text { are usually stored at these sites during the austral winter (Kershaw, 1998; } \\
\text { Swithinbank, 1998a). }\end{array}$ \\
\hline $\begin{array}{l}\text { 3. Historical huts } \\
\text { and monuments, } \\
\text { maintained by } \\
\text { NGOs }\end{array}$ & $\begin{array}{l}\text { Many examples exist of historical huts and monuments established by early } \\
\text { explorers and scientific expeditions that are currently managed by non- } \\
\text { governmental Antarctic heritage organisations, such as the Discovery Hut, Cape } \\
\text { Royds, and Port Lockroy. }\end{array}$ \\
\hline $\begin{array}{l}\text { 4. Art projects, } \\
\text { resulting in the } \\
\text { establishment of } \\
\text { permanent facili- } \\
\text { ties }\end{array}$ & $\begin{array}{l}\text { Proposed but not established: Art project proposal, developed in Germany, } \\
\text { which would result in the 'installation of a sculpture of bronze in Antarctica for } \\
\text { an unlimited time period'. The German competent authority denied a permit } \\
\text { for this activity, which decision was confirmed by the Administrative Court of } \\
\text { Berlin (Neumann and Bunge, 2006). }\end{array}$ \\
\hline $\begin{array}{l}\text { 5. Other non- } \\
\text { governmentally } \\
\text { operated perma- } \\
\text { nent facilities }\end{array}$ & $\begin{array}{l}\text { World Park Base was established on Cape Evans, Ross Island by Greenpeace } \\
\text { International and ran from } 1987 \text { to } 1992 \text {. The main purpose of this facility, } \\
\text { which was crewed by four people, was to 'monitor human activities in the } \\
\text { surrounding area [...]; carry out a modest programme of scientific research; } \\
\text { and draw public attention to the future of the continent, in particular to gener- } \\
\text { ate opposition to the minerals convention' (Greenpeace, 1994; Roura, 2007). }\end{array}$ \\
\hline
\end{tabular}


Table 6.2: Government operated permanent facilities for tourism

Category:
1. Governmentally
operated perma-
nent facilities with
primary tourism
purpose

2. Governmentoperated permanent facilities with a scientific purpose providing lodging services for tourists

3. Governmentoperated permanent facilities or infrastructure with a primary scientific purpose and limited visitor services (other than lodging)

4. Other permanent facilities or structures

\section{Cases:}

Hotel Estrella Polar was established on King George Island by Chile in 1982 providing basic lodging for visitors, including tourists. Visits to the facility terminated when the Chilean Air Force declined to carry passengers on official flights (Headland, 1994). The hotel is no longer in use for commercial tourism, but it does provide accommodation for people who come to Antarctica on invitation from the National Air Force. The hotel is listed as one of the available facilities at Villa Las Estrellas. It is labelled as a 'Hostería' (a hostel) close by the airstrip, with a capacity of approximately 80 guests, which is normally used by national and foreign scientific personnel.

The Uruguayan National Programme transports and accommodates between 20 and 50 paying visitors at their Artigas Station in King George Island to recover some of the station's operating costs. In terms of capacity, it is stated that a maximum of 20 passengers are taken per trip, with no more than four trips per season. The Uruguayan Antarctic Institute advertises tourist activities at the Artigas station under the concept of 'scientific tourism' (Uruguay, 2005);

Proposed but not established: It is reported that in 1991 Argentina received a request from Holiday Inn to build a hotel at Base Esperanza in the Antarctic Peninsula (White, 1994);

Proposed but not established: In 1999, the Chilean Enterprise 'Antex Polux Chile' agreed with Russian authorities that a part of the Bellinghausen Station (King George Island) would be turned into a hostel to accommodate a maximum of 40 tourists over 3 nights at a time. The project was subjected to an initial environmental evaluation and approved by the National Commission for the Environment. However, the project was not implemented (Chanceaulme, 1999).

Numerous scientific stations maintain gift shops or postal services for government personnel, scientists and tourists, including: Palmer Station (USA) and Scott Base (New Zealand);

Some scientific stations maintain small-scale visitor centres as part of their stations to welcome tourists while minimizing disruption of scientific activities, including Henryk Arctowski Station (Poland) (Donachie, 1994);

Airfields, churches, driveways or pathways, jetties, wharves, and the like can be found at many continental and peninsula sites used by both government operators and tour operators (IAATO, 2006c).

Sculpture garden at the Australian Davis Station. According to the website of the Australian Antarctic Division, 'The sculpture garden is envisaged to be an ongoing enterprise, with additional contributions from inspired expeditioners.' The website also states that additional sculptures are subjected to environmental assessment requirements, among other things (AAD, 2008).

Further, as shown in Tables 6.1 and 6.2, plans were made for the commercial exploitation of (parts of) the existing stations of Cape Hallett in the Ross Sea region, and Bellingshausen in the Antarctic Peninsula region. The proposals were not implemented for different reasons, including denial of the issuance of leases or cooperation contracts with the respective NAP and the economic feasibility of the pro- 
ject (such as balancing the developmental, operational and maintenance costs against the limited operational season) (Lamers, 2006).

In the future, however; the balance between costs and profits may be different due to new technologies and the increased demand for Antarctic land-based tourism. Opportunities for developing permanent tourist facilities are determined by factors of both supply and demand (Lamers et al., 2008). Figure 3.1, in chapter three, shows that there has been a substantial increase of Antarctic tourist numbers since the beginning of the 1990s. It is likely that this demand for Antarctic tourism products will continue to grow in the traditional Antarctic tourism markets (i.e., North America, Europe and Australia), because of growing affluence, aging populations, and increasing awareness of Antarctica as a tourist destination. In addition, growing affluence as a result of economic developments in other parts of the world may create new markets for Antarctic experiences (e.g. India and China). The WTO has projected growth in all global tourism market segments important for the Antarctic tourism industry, including nature-based tourism, adventure tourism and cruise tourism (World Tourism Organisation, 2001).

The key factor for all commercial developments of permanent facilities is securing long-term air access. Since passenger vessels already combine transport, accommodation, catering and activities, there is no need to develop permanent tourist facilities for the sustained success of this industry segment ${ }^{11}$. In other words, the discussion on permanent tourism facilities is inseparable from the issue of commercial air access. With the exception of air operations by US-based ALE/ANI to several continental destinations, and the Chilean company Aerovías DAP providing services from Punta Arenas to King George Island, air access is largely controlled by NAPs. Constructing a reliable infrastructure for commercial air access and operating passenger aircraft will be an expensive and difficult project, highly dependent on available technology, weather conditions, and cooperation with NAPs. However, a company like ALE/ANI has proven that non-governmental air access is feasible and can hardly be considered a one-off exercise ${ }^{12}$. Moreover, from several Antarctic gateway cities, governmental projects for establishing or extending air access with Antarctica are currently being undertaken, such as between Hobart (Australia) and Casey Station, and between Punta Arenas (Chile) and King George Island (Bastmeijer and Roura, 2008). Other air connections have also been used to transport private expeditions and adventure tourism groups to offset some of the costs, such as the air link operated between Cape Town (South Africa) and Novolazarevskaja, in Dronning Maud Land. Whether more non-governmental or tourism operators will be able to gain air access, e.g. by building facilities or using facilities owned by NAPs, remains to be seen.

\footnotetext{
${ }^{11}$ Exceptions to this statement could include jetties, harbours, and Search and Rescue (SAR) facilities.

12 The private company Antarctic Logistics and Expeditions (ALE), which purchased the company Adventure Network International (ANI), has operated in the Antarctic at least since the 1986-1987 season. For more information see chapter five of this thesis.
} 


\subsection{The international debate}

The question of whether the establishment of (semi-)permanent tourist facilities in Antarctica is desirable is certainly not 'new' to the ATS. Already during the negotiations of the Protocol in 1990, this issue received attention. It was stated that "consideration was also given to the convenience of carrying out tourist activities by maritime means. This would avoid the proliferation of terrestrial support infrastructure in Antarctica" (SATCM, 1990). Shortly after the Protocol was signed, Recommendation XVI-13 was adopted, which states that "an informal meeting of the Parties be convened with a view of making proposals to the XVIIth Consultative Meeting on the question of a comprehensive regulation of tourist and nongovernmental activities in Antarctica" (Antarctic Treaty System, 1991). In the Recommendation a number of issues were listed that would require attention, including the 'number of tourists/carrying capacity, permanent infrastructure for tourists, concentration/dispersal of tourist activities and access to unexplored areas.' Although the issue of tourism management has been discussed during the ATCM since the beginning of the 1990s, these more fundamental strategic issues were not discussed until 2004.

The issue of (semi-)permanent facilities for tourism in Antarctica was put on the agenda of the Antarctic Treaty Meeting of Experts on Antarctic Tourism in Norway (March 2004) by New Zealand. At that meeting, New Zealand proposed to prohibit the establishment of such facilities. The proposal was subjected to a comprehensive debate but the experts expressed different views on the desirability of a prohibition.

Since the Norwegian expert meeting, which was a very good initiative for strengthening the international debate on Antarctic tourism matters, the issue of permanent tourist facilities in Antarctica has been one of the central items on the agenda of the Tourism Working Group at the ATCM. The issue was generally discussed at the XXVIIth ATCM (Cape Town, May/June 2004) and in increasing detail and intensity at the XXVIIIth ATCM (Stockholm, 2005) and the XXIXth ATCM (Edinburgh 2006). Through papers and interventions, various ATCPs have advocated a prohibition of permanent facilities for tourism in Antarctica. It was argued that the establishment of such facilities:

- $\quad$ is inconsistent with the designation of Antarctica as a "natural reserve, devoted to peace and science" in Article 2 of the Protocol and the environmental principles of Article 3 of the Protocol, including the obligation to protect Antarctica's wilderness values (New Zealand, 2005);

- will "inadmissibly erode and restrict the research privilege", laid down in the Antarctic Treaty and the Protocol (Germany, 2005); and

- may cause difficult and sensitive discussions between states and other stakeholders on legal issues (sovereignty, jurisdiction and private owner- 
ship) and these discussions may "severely test the ATS framework" (New Zealand, 2005).

In view of these arguments and the developments in Antarctic tourism, some of the papers stressed that measures should be taken before it is too late. It was also stressed that the ATS has the responsibility to keep track of the self-regulatory system of IAATO (Australia, 2005).

However, some parties were not convinced of the need to adopt the proposed measure (Antarctic Treaty System, 2005; 2006; 2007b):

- Some questioned the inconsistency of (semi-)permanent facilities with the provisions of the Protocol;

- Others questioned the hierarchy between science and tourism, or stressed that - given the fact that governments share the coastal areas of Antarctica with the tourist industry - this industry should not be discriminated against elsewhere in Antarctica;

- $\quad$ Some parties "believed that these activities could be controlled through existing instruments such as Environmental Impact Assessment procedures" (Antarctic Treaty System, 2005);

- Various parties questioned the unclear scope of proposed management measures, particularly because terms such as 'semi-permanent', 'facility' or 'infrastructure' may be the subject of different interpretations.

During the debates at ATCMs, IAATO expressed the view that the development of serious proposals for such facilities should be considered unlikely. IAATO also argued that there are already structural facilities in Antarctica to support tourism and suggested that tourism may help ATCPs in funding the cost of scientific research and logistics.

This diversity of views prevented the ATCMs in 2005 and 2006 from reaching consensus on a legally binding measure on the issue. The less sensitive path of adopting a non-legally binding instrument (a resolution) could not be achieved either. At the XXIXth ATCM, the United Kingdom proposed to adopt a resolution on "Limiting Permanent Non-Governmental Infrastructure in Antarctica", and although the meeting appeared to be close to consensus, the resolution was not adopted.

The discussion was continued during the XXXth ATCM (New Delhi, 2007). The basis for the discussion was again a paper proposed by New Zealand to adopt a resolution that would recommend the governments of the ATCPs to "endorse the concept that all tourism activity is guided by the principle that tourism should have no more than a minor or transitory impact on Antarctica" (New Zealand, 2007). This proposal might seem to be an easy one to agree upon, but it became the subject of a lengthy debate. Many ATCPs supported the New Zealand proposal, but the US could not agree with the use of terminology - a common characteristic for the 
instrument of environmental impact assessment - for setting normative standards. Argentina did not support the proposal either and explicitly "reserved its right to install at any time interpretative centres for tourists with some lodging capacity in any of its bases" (Antarctic Treaty System, 1991). Discussions in a contact group and informal consultations resulted in a new resolution that was adopted by the ATCM as Resolution 5 (Antarctic Treaty System, 2007b). In this resolution, the Parties are recommended to "discourage any tourism activities which may substantially contribute to the long-term degradation of the Antarctic environment and its dependent and associated ecosystems" (Antarctic Treaty System, 2007b). This general policy statement could receive the agreement of each ATCP, but given the vague and general terminology, it is highly uncertain whether this statement regulates in any way the issue of permanent land-based tourism facilities in Antarctica.

\subsection{Review of arguments}

The above summary of the international debate shows that the discussion is complex; statements at the ATCM by ATCP representatives and observers refer to the relationship between science and tourism, to potential financial or economic advantages, and environmental concerns as well as political considerations. In general, the discussions at the ATCM are characterised by a rich exchange of views and arguments. However, arguments have not been thoroughly discussed and balanced and, so far, the discussion has centred around the arguments for and against a prohibition of permanent tourism facilities. In this section, we take a more comprehensive examination of the arguments for and against the (further) development of permanent tourism facilities in Antarctic and to discuss these arguments in more detail. This overview may not be exhaustive and it should be stressed that the authors do not agree with all arguments to the same extent; it is primarily an inventory, based on the literature, international debate and factual information available.

\subsubsection{ARGUMENTS IN FAVOUR OF PERMANENT TOURIST FACILITIES IN ANTARCTICA}

\section{Benefits for tourists}

The people benefiting most from the development of permanent tourist facilities would probably be the tourists, especially groups that do not have the physical capacity or time to embark on rough and long ship itineraries. Further, permanent tourist facilities would cater to those groups that want to be involved in land-based activities, such as cross-country skiing and visiting wildlife colonies. Cooperation between science programmes and tour operators may have additional benefits from the perspective of education of visitors, the diffusion of Antarctica's intrinsic values, and the creation of Antarctic ambassadors, through involvement of tourists in science or conservation projects. 
Legitimacy of tourism under the Antarctic Treaty System

Currently, tourism in the Antarctic is unambiguously permitted under the rules of the Antarctic Treaty System. In fact, the provisions of the Treaty establishes (without being explicit on this) a three-fold scheme to regulate activities conducted

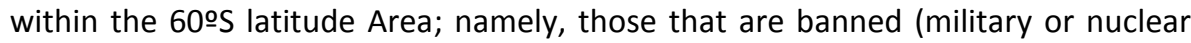
operations), those that are favoured and take precedence over other activities (scientific research), and, finally, those that are neutral, limited by the 'peaceful purposes' requirement (Antarctic Treaty System, 1959). Further, under the Protocol, tourist activities are explicitly considered as part of Antarctic nongovernmental activities, which activities are not prohibited as long as they are conducted in a manner consistent with the principles and other provisions of the Protocol (Antarctic Treaty System, 1991).

Consequently, for permanent tourist facilities to be regarded as prohibited, it is necessary to establish that such facilities are inconsistent with the principles or other provisions of the Protocol. Certain authors have advocated this view as they considered permanent tourist facilities to implicitly contradict the precautionary principle incorporated in the Protocol (Germany, 2005). Discussions at the XXVIIIth ATCM clearly showed that these views were not supported by all ATCPs.

Furthermore, during international debates at the ATCMs, certain ATCPs stated that the issue of permanent land-based facilities for tourism in Antarctic has been sufficiently addressed by the provisions of the Protocol on environmental impact assessment (EIA). IAATO also stresses this argument:

"Any construction activity undertaken by a commercial company organised in a Treaty State would most likely need to undertake an environmental assessment, probably at the level of a CEE [Comprehensive Environmental Evaluation]. There would be ample opportunity for States to comment on the structure during review by the CEP [Commission on Environmental Protection]. The relevant State would also likely apply permit or authorisation procedures according to its national laws" (IAATO, 2006c).

\section{Considerations of a political nature}

It is clear that some claimant states have developed their policies and programmes with a view to strengthening their interests in the white continent (see section 2), and that involvement in tourism plays a key role in such a strategy. For instance, Argentina's National Policy on the Antarctic sets out among its priorities "the improvement of the connection between Patagonia and Argentinean Antarctica, through the development of suitable infrastructure to guarantee due support to expeditions, national or foreign, governmental or private, scientific or commercial" (Genest, 2004). Additionally, the Argentinean Dirección Nacional del Antártico (National Antarctic Directorate) conducts the "collaboration with official agencies and private organisations that promote tourism in the Antarctic"' (Argentinean 
Government, 1969). In turn, Chile's National Policy on the Antarctic sets forth as part of its objectives "the protection and strengthening of Chile's rights on the Antarctic, supported by clear geographical, historic and juridical grounds; the advertising of Chile as a gateway country, and the promotion of controlled tourism in Antarctica" (Chilean Government, 2000). The development of permanent tourist facilities could well fit within this strategy (White, 1994).

\section{The industry in perspective}

According to Bauer, human activity in the Antarctic uses $0.005 \%$ of the continent's area (705 km2 of 14,000,000 km2) and $0.25 \%$ of Antarctica's ice-free area (705 km2 of $284,000 \mathrm{~km} 2$ ) (Bauer, 2001). He explains that this is the spatial impact of all human activities, which may roughly be divided into science and tourism; the former being accountable for the $99.48 \%$, and the latter for the remaining $0.52 \%$. Furthermore, it has been stated that no significant impact on wildlife has been found as a result of tourism activities. Therefore, it could be argued that, even when construction of durable infrastructure to support tourism activities poses a delicate matter, to infer from this that the whole continent's pristine condition would be at stake does not sound proportionate.

\section{Economic benefits for different stakeholders}

A modus vivendi of mutual support has evolved between tourism, science, and managers of NAPs, for example, with regard to search and rescue operations, which IAATO as well as certain other stakeholders consider a desirable phenomenon (COMNAP, 2004; IAATO, 2006c). Should tourist facilities be developed in the future next to scientific stations, all parties might benefit from synergy and economy of scale. For instance, the Uruguayan Antarctic science programme has adopted a model through the implementation of a visitor scheme allowing for direct support of research work by visitors (Uruguay, 2005). Cooperation may also have financial benefits, e.g. through cost-sharing of infrastructure. Furthermore, if tourists (directly or through their operators) pay an amount of money for staying at or near to the station, tourism may contribute to the funding of scientific research $^{13}$. It is clear that having a souvenir shop in a scientific station near a popular landing site could generate a substantial amount of cash $^{14}$. IAATO has suggested this 'partnership' at one of the ATCM debates on permanent land-based facilities for Antarctic tourism. Another benefit could be the maintenance of unused facilities and infrastructures by tour companies at no cost, which would otherwise have to be removed at high costs, and would thereby lose their geopolitical function.

\footnotetext{
${ }^{13}$ According to a survey conducted by COMNAP, 6 out of 22 respondent stations provided accommodation for private activities in the Antarctic (COMNAP, 2004).

${ }^{14}$ During the 2006-07 Antarctic season, 17,183 visitors landed near the former British research base Port Lockroy; the Chilean research base Gonzales Videla received 5,937 visitors; the American base Palmer Station received 4,537 visitors; and the Polish base Arctowski received 4,362 visitors. It is known that at all these sites there are souvenir shops. See http://www.iaato.org (accessed 3 October 2007).
} 
Other stakeholders than NAPs could also generate economic benefits of permanent tourist facilities in Antarctica. First of all, multinational tourism companies willing to invest in an Antarctic land-based tourism project would most likely benefit. As we have shown earlier, the development of land-based facilities and infrastructure would entail tremendous construction and operational costs ${ }^{15}$. Successful enterprises would therefore need to generate enough income to at least meet the costs, but carefully balancing costs and benefits are part of any investment or development project.

Besides directly involved Antarctic stakeholders, gateway countries are believed to benefit substantially from the Antarctic tourism traffic passing through their cities (Bertram et al., 2007). It is argued that the increase of tourism in Antarctica in the last decade can be related to public policies and infrastructural developments in Antarctic gateway cities, particularly in South America. Because of the economic benefits from port charges, airport taxes and expenditure of undoubtedly affluent visitors, these gateway cities and possibly governments at a higher level have obvious reasons for promoting Antarctic tourism in the future, including land-based tourism.

\subsubsection{ARGUMENTS AGAINST PERMANENT TOURIST FACILITIES IN ANTARCTICA}

\section{Potential Impacts on the Environment}

Environmental impacts for permanent land-based tourism facilities and infrastructures may be similar to its scientific counterparts, and dependent on a range of factors, including the eco-efficiency of construction technology and operation, the scale of the facility, the nature of the site, the activities undertaken, and the environmental management practices. However, given the higher throughput of visitors in order to make permanent land-based tourism economically feasible, operations will most likely result in higher levels of transport emissions, waste production, water use, energy use, and intensified local onshore activities. This might give rise to increased pressure on the Antarctic flora and fauna (e.g. through increasing competition with wildlife for ice-free areas) and long lasting effects on highly sensitive ecosystems (Germany, 2005). As the number of tourists visiting the Antarctic will substantially increase if land-based facilities are further developed, concerns with respect to cumulative impacts will increase (New Zealand, 2004a). This is all the more true as tourist activities tend to concentrate in the Antarctic Peninsula region. Furthermore, the risk of introducing diseases, micro-organisms and/or nonnative species of plants and animals is likely to increase (Frenot et al., 2005), not only because the number of persons visiting the Antarctic will increase, but also

\footnotetext{
${ }^{15}$ An indication could be the recently developed Belgian station. According to a presentation by J. Berte and $A$. Hubert, a construction budget (based on state of the art technology) of $€ 6.4$ million was used (construction and equipment). The base would be operational at $€ 1$ million per year (Berte, J. and $A$. Hubert, 2006).
} 
because the actual presence on land and ice will substantially increase. This problem has not been extensively researched nor is it completely understood, but it is likely to occur at intensively used land-based sites. In addition, the development of land-based tourism will most likely lead to more flight connections and thereby more greenhouse gas emissions, as well as a range of other kinds of environmental feedback or impact that we may currently not be aware off (Amelung and Lamers, 2007).

\section{Loss of Wilderness}

Wilderness has been defined from different perspectives. In the literature, the term wilderness "has been thought of both as a real place and as an experience" (Aplet et al., 2000). In respect of Antarctica, Keys describes Antarctic wilderness values as follows:

"Antarctic wilderness values include those of remoteness, few or no people, an absence of human made objects, traces, sounds and smells, and untraveled or infrequently travelled terrain. This implies remoteness from permanent or semipermanent habitation (not merely an absence of it), an absence of related human artefacts (e.g. tracking) and disturbance and an absence of motorised transport" (Keys, 1999).

Based on this definition, most of the Antarctic must be considered wilderness with the exception of, in particular, the areas where research stations are located (Codling, 2001).

The Protocol is one of the very few international conventions that give a legal status to 'wilderness values': according to Article 3, the "protection of the Antarctic environment and dependent and associated ecosystems and the intrinsic value of Antarctica, including its wilderness and aesthetic values [...] shall be fundamental considerations in the planning and conduct of all activities in the Antarctic Treaty area" (Antarctic Treaty System, 1991). This unique provision receives little serious attention during the international debates on Antarctic management and the implementation of the Protocol (Bastmeijer, 2005), let alone in preparing environmental impact assessments (Bastmeijer and Roura, 2008). Nonetheless, in view of this provision and the fast increase in tourism, state parties to the ATS should think about the future of Antarctica: should Antarctica be preserved as a 'wilderness' in which permanent human infrastructure may only be established where there is a pressing need (for example infrastructure needed for essential scientific research that cannot be conducted elsewhere)? Or is there space for further human development and should Antarctica be considered as an 'international park' in which comparable to other regions of the world - various values and functions are balanced, for instance, through a spatial planning system?

This question is of a similar character to the question on the acceptability of mineral resource exploitation that was discussed during the 1980s (Scott, 2001). 
Shortly after the decision of Australia and France not to sign and ratify the Convention on the Regulation of Antarctic Mineral Resource Activities (CRAMRA), a representative of WWF stated:

"As well as being amazingly beautiful, with spectacular land and ice formations, the Antarctic is the only part of the world that has never been permanently inhabited by people. When you consider the devastation that human beings have inflicted over almost all of the rest of the planet, from polluted rivers and seas to degraded forests, from overcrowded cities to the loss of topsoil, then the fact that there remains a continent almost as large as South America which so far is very little affected by human activities, is important to us emotionally and spiritually, as well as scientifically" (Philips, 1990).

This understanding may well constitute the basic drive for adopting a policy to protect Antarctica as a wilderness. This would imply the adoption of a tourism policy that prevents the establishment of permanent facilities for tourism in Antarctica and would codify the current situation in which ships may be considered as the 'visitor centres' and 'hotels' for the tourists that want to visit the Antarctic (Bastmeijer, 2007).

\section{Different kind of tourists visiting the Antarctic}

Permanent tourist facilities in Antarctica and improved air transportation of visitors may lower the price of Antarctic visits (Hemmings, 2000). Lower prices in combination with more comfortable facilities may not only substantially influence the number of Antarctic visitors, but also the kind of tourists that visit the Antarctic. As noted above, today's Antarctic tourism is primarily ship-based and most tourists appear to have a special interest in nature and the special values of Antarctica and do not mind travelling two to ten days by ship to see the first iceberg or penguin. In the future, it may be persons who are not really interested in such values at all (Hummel, 1994). This may also lead to the development of different types of activities that may be characterised as 'anywhere' activities such as casinos, high-grade restaurants, shopping and other vicarious experiences. All this would substantially increase the other concerns discussed in this subsection and, even if stricter regulations were adopted, the enforcement of such regulations would be difficult.

\section{Potential conflicts between tourism and scientific research activities}

At the ATCMs it has often been stated that the development of permanent tourist facilities in Antarctica is likely to jeopardise the privilege of scientific research under the ATS. For instance, from the perspective of logistics and safety, it is likely that facilities for tourism are planned in close range of research stations and related facilities. The above overview of existing facilities supports this suggestion. Consequently, if land-based tourism increases, it is likely that tensions between tourism and scientific research and logistic activities will increase as well, e.g. through disturbance of research activities. The Protocol is clear that, in case of competition 
between tourism and scientific research, the latter should receive priority: "Activities shall be planned and conducted in the Antarctic Treaty area so as to accord priority to scientific research and to preserve the value of Antarctica as an area for the conduct of such research" (Antarctic Treaty System, 1991). The second part of this provision is relevant for this discussion as well: with the increase of land-based tourism, tourist numbers will increase as well the use of infrastructure and transport (e.g. motor vehicles such as snowmobiles). Consequently, there is a risk that pristine areas will be visited, which may limit the scientific values of such sites in the shorter or longer term.

The increasing risk of legal conflicts regarding sovereignty, jurisdiction and property rights

In order to prevent conflict between claimant and non-claimant states, the Treaty froze the assertions of sovereignty rights over the Antarctic (Antarctic Treaty System, 1959). Earlier, we saw that claimant states might have an interest in strengthening their interests in Antarctica by developing permanent tourist facilities. Nonclaimant states, on the other hand, centre their national policies on scientific themes, making fewer references to tourism. If private enterprises are not prevented from establishing additional permanent facilities on Antarctic land or ice, demands for recognition and enforcement of property or usufructuary rights by tourist companies or other stakeholders would be likely to occur. This would surely exacerbate the differences between claimant and non-claimant states, as well as among claimant states (New Zealand and Australia, 2006). This could cause serious pressure on the ATS.

The risk of legal conflicts on jurisdictional issues will also increase. The only clear rule of jurisdiction within the Antarctic Treaty concerns observers, scientific personnel and accompanying staff, all of whom are subject to the law of their own country (Antarctic Treaty System, 1959). Otherwise, the Treaty calls on parties to harmonise their positions, since national legislation differs from one country to another in terms of the basis for asserting jurisdiction. Because essential obligations of the Protocol (e.g. EIA, waste management) explicitly refer to all activities that are subject to the report obligation of Article VII(5)(a) of the Treaty, it has been argued that, in implementing the Protocol, Contracting Parties should address their implementing legislation to their nationals, expeditions organised and/or departing from their territory and their ships and aircraft involved in Antarctic expeditions (Bastmeijer, 2002). However, research on domestic Antarctic legislation clearly shows that this interpretation has not determined state practice as the jurisdictional scope of domestic laws differs substantially. These differences as well as the overlap of applicable domestic laws in concrete situations result regularly in questions and debates on which an ATCP is responsible for applying the ATS provisions. If in the future permanent tourism facilities were to increase, it is very likely that the increased number of seasonal visitors, and the need for permanent staff at camp sites, hotels, ports and airfields will immediately lead to conflicts over jurisdiction (New Zealand, 2005). 


\subsection{Management options for consideration}

Taking into account the discussions above, this section provides a brief inventory of management options for the ATCM to address the issue of permanent tourist facilities in Antarctica. Depending on how the various arguments for and against are balanced and which arguments are emphasised, options may be based on various factors, such as the type of operator (governmental or private), the location of the facility (e.g. near research stations or in pristine areas) and the size of the facility and expected environmental impacts.

\subsubsection{OPTION I: NO ADDITIONAL MANAGEMENT MEASURES}

With this option, governmental and private operators would have the possibility to establish new permanent facilities for tourism in Antarctica, as long as they are subjected to applicable requirements of domestic law, e.g. the law implementing the Protocol. In certain ATCPs, competent authorities have the power or obligation under domestic law to refuse authorisation for such initiatives, but in others, this may be different. The legislation of certain ATCPs does not provide the government with the discretionary power to refuse authorisation if the more specific provisions (e.g. the provisions implementing the annexes to the Protocol) are respected (e.g. the USA). Consequently, with this option, the development of (new) permanent tourist facilities in Antarctica depends on domestic law and policy. This option provides space for the potential advantages of permanent facilities for tourism discussed in subsection 6.1 above, but the concerns discussed in subsection 6.2 are not addressed.

\subsubsection{OPTION II: CODIFICATION OF THE IAATO BYLAWS}

When considering regulation of permanent tourist facilities in Antarctica, governments should ask the question of whether and to what extent the issue has been addressed by the private sector itself. Particularly for Antarctic tourism issues, this is important as it is broadly recognised that this sector has established a strong system of self-regulation. Most of the tour operators active in the Antarctic cooperate under the umbrella of IAATO. Although much work of IAATO has been focused on ship-based tourism, more recently a new bylaw has been adopted that is of particular relevance for land-based tourism. Article II, Section E of the IAATO bylaws states: "Members of IAATO subscribe to the principle that their planned activities will have no more than a minor or transitory impact on the Antarctic environment" (IAATO, 2008a). This section was included in IAATO's bylaws in 2004 and is one of the examples of a management measure taken by the industry that goes beyond the obligations of the Protocol and illustrates at least to a certain degree the pro-active approach by the IAATO member organisations.

As discussed in section 4 above, at the XXXth ATCM (2007) New Zealand proposed to adopt this norm as a (non-legally binding) ATS component through a resolution. In the view of New Zealand, this "would provide reassurance to members of the 
public and to the wider international community that the ATCM is alert to the risks posed by the rapid expansion and diversification of tourism and other nongovernmental activities in Antarctica" (New Zealand, 2007).

The question is what the exact consequences of this option would be. For instance, the phrase 'no more than a minor or transitory impact' is derived from Annex I of the Protocol and establishes the threshold for the most comprehensive level of Environmental Impact Assessment: a Comprehensive Environmental Evaluation (CEE). In practice, CEEs are only required for major projects, such as the establishment of new research stations. It could therefore be argued that the bylaws do not apply to facilities on land that may easily be removed (e.g. facilities for camping during the summer season) or even to floating hotels. Furthermore, it may be questioned whether wilderness values are taken into account when assessing the impact level in an EIA process. If this is not the case, it could be argued that a permanent hotel in an area with low biodiversity and little scientific value, or near an existing facility, will not cause more than minor or transitory impact. This approach is not unlikely in view of the current EIA practice, in which wilderness values receive very little attention (Bastmeijer and Roura, 2008).

\subsubsection{OPTION III: FULL PROHIBITION OF NEW PERMANENT FACILITIES}

A strict approach would be to adopt a full prohibition of any new permanent tourist facilities in Antarctica, regardless of whether facilities have governmental or private operators. This option would fit best when future tourism facilities are considered to be threatening the stability of the ATS and when emphasizing the value of Antarctica as one of world's last wildernesses. Taking into account Antarctica's designation as a nature reserve, devoted to peace and science (Article 2 of the Protocol), a policy might be adopted that any permanent structural human facility in Antarctica is only allowed for extraordinary societal needs and under the condition that alternatives are not available. Under this policy, the establishment of a new scientific research station would be acceptable if the research needs could otherwise not be met, but permanent facilities for tourism should not be authorised in view of the lower societal interests and because sufficient alternatives are available (ship-based tourism). It is clear that with this option, achieving the potential advantages would not be compromised, while the concerns would be addressed most adequately.

\subsubsection{OPTION IV: PROHIBITION OF NEW PERMANENT FACILITIES EXCEPT IN THE DIRECT SURROUNDINGS OF SCIENTIFIC RESEARCH STATIONS WITH THE APPROVAL OF ATCPS}

An option in between options I and II and option III is a restricted state authorisation system, whereby both governmental and privately operated facilities would only be allowed in the direct surroundings of existing scientific research stations. Further, explicit authorisation by one or more ATCP governments would be obligatory. The restriction in respect of location would limit adverse impacts on Antarctic wilderness values and on the potential values of existing pristine areas for (future) 
scientific research. Environmental concerns would be limited through effective cooperation on environmental issues with the station management, which should be the subject of the conditions for authorisation. Depending on the size and intensity of the activities, the number of stakeholders involved and the specific characteristic of the location, the designation of the area as an Antarctic Specially Managed Area under Annex $V$ to the Protocol could be considered.

\subsection{Conclusion}

Antarctic tourism activities are broadly recognised as "human activities that offer both threats and benefits to Antarctic conservation" (Philips, 1990). It may be argued that there should be opportunities for people to experience the Antarctic and to enjoy its beauty and relatively untouched environment, but the rapid developments in Antarctic tourism raise various concerns regarding environmental impacts, human safety and other issues. So far, Antarctic tourism has primarily been ship-based, but this may change in the near future. As shown in section 4, permanent tourism facilities in Antarctica, supported by NAPs, are already increasing as well as the collective use of infrastructure by NAPs and private operators. In view of developments in the Antarctic tourism industry (e.g. increase of operators and ships, stricter regulation of ship-based tourism over the years) and certain global developments (e.g. the worldwide increase of interest in nature based tourism and the fast growth of new markets) it is likely that land-based tourism in Antarctica will further develop (France, 2004).

It has been advocated that permanent tourist facilities in the Antarctic conflict with Article 3 and other provisions of the Protocol, but this is an interpretation that is not generally shared by all ATCPs. Currently, the ATS instruments do not prohibit the establishment of new permanent facilities for tourism. For instance, EIA is a valuable instrument to ensure that potential environmental impacts of activities are reported and taken into account in the decision making process on such activities; however, the Protocol does not provide clear normative guidance on whether the activity should be authorised.

It is our view that the counterarguments and related concerns in respect of permanent facilities for tourism are more convincing than the arguments in favour of such facilities. Future development of permanent land-based facilities creates clear risks for the ATS objectives. These objectives are in the interest of all mankind, while most of the benefits of permanent tourism facilities focus on individual interests. Timely regulatory action fits well in the pro-active approach that has been characteristic for the ATS (e.g. prohibitions on commercial sealing (1972) and commercial mining (Article 7 of the Protocol) before such activities were initiated). The more permanent facilities for tourism are established, the more difficult it will be to agree on regulatory measures, particularly in view of the potentially high commercial interests involved and the 'permanent' character of the activities. Furthermore, 
the many decades of ship-based tourism activities to the Antarctic make clear that restricting or even prohibiting permanent facilities for tourism does not close the Antarctic to tourists. Therefore, the issue requires explicit regulation by the ATCM. The concerns are too serious to depend solely on the policy of the industry, developed by IAATO. Furthermore, in view of the likeliness of future developments, such regulatory action should be taken in the short term.

In respect of the most favourable options for regulation, different views can lead to different management options. Those in favour of a full prohibition would consider the issue of permanent facilities for tourism a fundamental policy issue that directly touches upon the future of Antarctica. In certain other parts of the world, wilderness protection may be difficult, for instance because this would unreasonably limit development opportunities for local communities; however, in the absence of permanent human habitation in the Antarctic, the international community has a unique opportunity (one might call it a 'luxury') to protect this wilderness in its (almost) purest form. It is true that some small portions of Antarctica have already lost their wilderness character, but this is not a good argument to continue a policy that is characterised by a slow but steady degradation of untouched nature (De Poorter, 2000). In view of the influences of mankind on the rest of our planet, the international community should take this opportunity. One of the components of such an 'Antarctic Wilderness Policy' would be to prevent permanent facilities for tourism and to keep tourism ship-based.

Those in favour of a state-authorisation system would stress that a full prohibition might not be acceptable to a number of ATCPs, at least not in the short term. Moreover, the state-granted scheme as discussed above would work as a de facto prohibition of any new permanent tourism facility outside the areas of existing scientific stations, while the requirement of governmental authorisation and the possibility to attach conditions to such an authorisation provide opportunities to promote sustainability. ${ }^{16}$ Finally, such a system would build toward the funding of science by tourism, which is perfectly consistent with the consideration of science as a paramount value within the ATS.

The primary aim of this contribution was to provide the international community with relevant information to continue the debate. With the adoption of Resolution 5 (2007), the ATCPs agreed to "discourage any tourism activities which may substantially contribute to the long-term degradation of the Antarctic environment and its dependent and associated ecosystems" (Antarctic Treaty System, 2007b). Given the likelihood of future initiatives for establishing new permanent land-based facili-

\footnotetext{
${ }^{16}$ Certain concerns would require further consideration. For instance, questions arise regarding the numbers of tourists that may visit the facility each season and the activities they undertake. Furthermore, the option might be considered controversial from a sovereignty point of view; for instance, ATCPs may consider sponsorship by a claimant state as an initiative to strengthen the sovereignty claim, which could create tensions between governments.
} 
ties for tourism in Antarctica and the serious concerns discussed above, the ATCPs should take responsibility and start the discussion on what this resolution exactly means in respect of permanent facilities for tourism. 


\section{Chapter 7}

\section{SELF-REGULATION IN ANTARCTIC TOURISM: EXPLORING THE INSTITUTIONAL ROBUSTNESS}

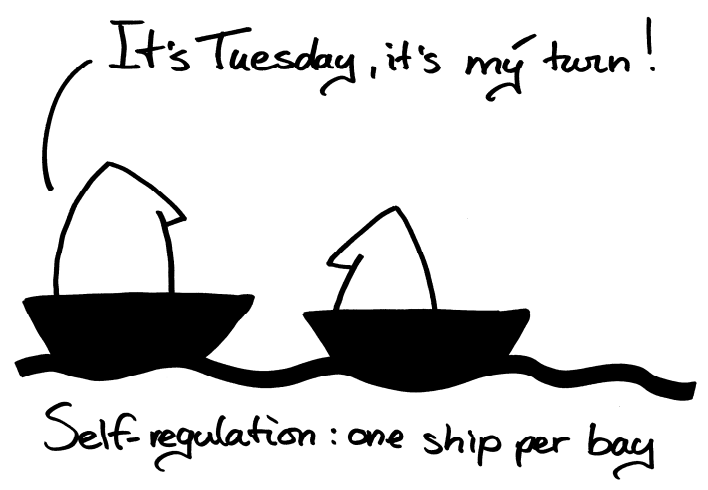

This chapter is based on:

Lamers, M., Haase, D., Amelung, B. (2009) Self-regulation in Antarctic tourism: exploring the conditions for success and failure. In: Lakhsmi, L. (ed.) Tourism and Law: Cross Country Perspectives. Hyderabad: Amicus Books. Pp: 69-99.

Haase, D., Lamers, M., Amelung, B. (2009) Heading into uncharted territories: Exploring the institutional robustness of self-regulation in the Antarctic tourism sector. Journal of Sustainable Tourism17(4): 411-430. 


\subsection{Introduction}

Key selling points of tourism in Antarctica and other remote areas are their pristine wilderness, unique and undisturbed wildlife, and dramatic landscapes. These attractions can be qualified as 'commons' (Healy, 1994; Briassoulis, 2002; Healy, 2006), implying that their use is subtractable and non-exclusive. The level of enjoyment that a tourist gets out of visiting Antarctica diminishes as the number of other tourists increases. The presence of other tourists makes the area less pristine, disturbs the wildlife, and spoils the landscapes. Avoiding this by excluding 'others' from enjoying the commons is very difficult, if not impossible. On the contrary, more and more people visit the area, seeking to (privately) enjoy the same attractions, thereby further reducing their quality. Apart from impacts on tourism itself, Antarctic ecosystems as well as the research activities of the national programmes may be affected by increased visitation. So far, no major biophysical impacts of tourism in the Antarctic have been determined (Hofman and Jatko, 2000; Naveen et al., 2001; Pfeiffer and Peter, 2004), but monitoring programmes are far from comprehensive, and there are concerns about potentially cumulating impacts.

The issue of the commons is by no means unique to Antarctic tourism. It is a major factor behind the general tendency of tourism to "kill the goose that lays the golden eggs" (Glasson et al., 1995). In destinations around the world, tourism inevitably reduces the quality of many attractions, be they natural, cultural or social. This common observation has led to all kinds of proposals to limit the number of tourists or the growth of tourism in destinations. A whole literature on carrying capacity developed in the 1970s and 1980s, a concept which was later practically abandoned, largely because of difficulties in determining carrying capacity in practice (Lindberg et al., 1997; McCool and Lime, 2001). The issue of dealing with the commons as tourist attractions and avoiding their demise also resonates in the current debate on sustainable tourism (Hunter, 1997; Butler, 1999; Sharpley, 2000; Briassoulis, 2002; Johnson, 2002; Saarinen, 2006).

Taking an even broader perspective, the issue of the commons is a key challenge for sustainable development. Commons are at the heart of many of the world's most pressing problems, including climate change (the atmosphere as a commons), deforestation (land as a de facto commons) and overfishing (fish as a commons). A large literature has been dedicated to the tendency of commons use to end in tragedy. Olson (1965) claimed that no self-interested person would contribute to a public good, unless the number of individuals participating was small and there was coercion or some other incentive to make individuals act in their common interest. This argument, also known as the 'zero-contribution thesis' was adopted in the Tragedy of the Commons theory developed shortly afterwards (Hardin, 1968). Hardin attributed the demise of common pool resources to a constant tension between rational individual behaviour and rational group behaviour. When a group of 
individuals is confronted with controlling a shared resource, individual group members have an incentive to increase their use of the resource, because they can keep the additional benefits to themselves, while sharing the costs of resource degradation with the other group members.

Hardin concluded that resource degradation might be prevented by securing private ownership or state-enforced rules for the use of commons (Hardin, 1968). Both are no option in the Antarctic, where no state has exclusive sovereign authority. A number of authors (Feeny et al., 1990; Ostrom, 1990; 2005) have increasingly challenged Hardin's view on the inevitability of tragedy, opening up new avenues for sustainable management of the commons. Ostrom et al., (1999) stated that although some tragedies have occurred, in many cases self-organised groups of individuals successfully governed common pool resources over many years.

Antarctic tourism management presents a clear case of successful self-organisation, driven by the clear collective interest of users in maintaining the quality of the key attractions. The majority of Antarctic tour operators are organised under the umbrella of the International Association of Antarctica Tour Operators (IAATO). This self-regulatory organisation has played a major role in achieving the tour operators' relatively strong record in terms of safety and environmental sensitivities (Splettstoesser, 2000; Splettstoesser et al., 2004; United Kingdom, 2004a). IAATO has put a consistent and practical set of guidelines into place, and is widely commended by various Antarctic Treaty Consultative Parties (ATCPs) for the results that have been achieved (Bastmeijer and Roura, 2004; Haase et al., 2007). Successful as IAATO may be, its achievements are no guarantee for future excellence. The Antarctic community has relied heavily on self-regulation by the tourism industry, but this strategy entails significant risks. Internal factors such as diverging interests among IAATO members, and non-compliance by individual entrepreneurs, may upset the current equilibrium. External factors, such as new environmental or safety regulations, may be equally challenging. Thinking about the future of tourism management in Antarctica thus raises the question of how robust IAATO as a self-regulatory framework is.

A well-established benchmark against which to test this robustness is provided by Ostrom (1990; 1998; 2000; 2005), who developed a set of design principles for setting up robust institutions to manage common pool resources. This article explores the robustness of IAATO by examining its strengths and weaknesses using Ostrom's set of design principles. These design principles are presented in the next section of this article, following the discussion of the methods used for data collection. The resulting assessment of the strengths and weaknesses of Antarctic tourism self-regulation provides the main focus of this chapter. Based on information about the development of Antarctic tourism as well as the status of industry selfregulation, Ostrom's (2005) institutional design principles will be applied to the IAATO case in order to discuss trends in Antarctic tourism and their consequences for collective action. 


\subsection{Data and analytical framework}

An assessment of the strengths and weaknesses of Antarctic tourism self-regulation requires in-depth factual knowledge about the functioning of the self-organised resource user group of tour operators and its regulatory context. It also requires broad knowledge of the perspectives of key stakeholders on what IAATO is, could be and should be. The academic Antarctic tourism literature and Antarctic Treaty System (ATS) documents provide a wealth of information, but they lack crucial insights, in particular on decision-making processes, and subjective viewpoints.

Complementary to the literature analysis, qualitative data were therefore obtained through semi-structured stakeholder interviews. Interview participants were selected through an initial analysis of relevant policy and operational documents and according to references and recommendations by the Antarctic community and the participants themselves. Due to the focus of the interviews on operational and selfregulative aspects of Antarctic tourism, the majority of the interview participants selected were representatives of the Antarctic tourism sector. Table 7.1 illustrates the composition and affiliation of the interview participants.

Altogether, 33 interviews were conducted by the three authors with 29 keystakeholders. Four stakeholders were interviewed twice on the issue by two different authors. In accordance with human ethics regulations and in order to maintain the confidentiality of the data, the identity of the interviewees will be protected and a coding system has been used, as identified in Table 7.1. All interview participants are reputable and knowledgeable Antarctic tourism stakeholders with a function directly related to Antarctic tourism, regulation or monitoring. The quality of the information provided in the interviews was cross-checked with other interviews, available documents and literature. The stakeholder interviews were conducted between January 2006 and February 2008 and generally lasted between 45 and 90 minutes.

Despite utilising a general topic guide to sustain a focus on the current state, the anticipated future development and a range of regulatory and operational aspects of Antarctic tourism, the interviews followed an open, and free-flowing conversational pattern. The issue of robustness of the self-regulatory regime was explicitly part of the interview guidelines of all three interviewers. With the permission of the participants, all interviews were recorded and transcribed in their entirety. The participants were given the chance to review the transcripts prior to their analysis. An iterative and modified constructivist grounded-theory approach as suggested by Pidgeon and Henwood (2004) guided the analysis of the interviews with themes and categories both prescribed by the topic guide used during the interviews and emerging from the data evaluating the performance of self-organisation. 
Table 7.1: Categorisation and coding of the interviews

\begin{tabular}{|c|c|c|c|c|c|}
\hline Coding & Category & Characteristics & Position & Int* & Date \\
\hline 01 & Organiser & $\begin{array}{l}\text { Ship-based with land- } \\
\text { ings (<200 pax.) }\end{array}$ & Director & $\mathrm{DH}$ & $1-5-2006$ \\
\hline $\mathrm{O} 2$ & Organiser & $\begin{array}{l}\text { Ship-based with land- } \\
\text { ings (<200 pax.) }\end{array}$ & $\begin{array}{l}\text { Co-owner and expe- } \\
\text { dition leader }\end{array}$ & $\mathrm{DH}$ & $28-4-2006$ \\
\hline $\mathrm{O} 3$ & Organiser & $\begin{array}{l}\text { Ship-based with land- } \\
\text { ings (<200 pax.) }\end{array}$ & $\begin{array}{l}\text { Co-owner and expe- } \\
\text { dition leader }\end{array}$ & $\mathrm{DH}$ & $26-4-2006$ \\
\hline $\mathrm{O} 4$ & Organiser & $\begin{array}{l}\text { Ship-based with land- } \\
\text { ings ( }<200 \text { pax.) }\end{array}$ & $\begin{array}{l}\text { Sales and marketing } \\
\text { manager }\end{array}$ & $\begin{array}{l}\mathrm{DH} \\
\mathrm{ML}\end{array}$ & $\begin{array}{l}30-4-2006 \\
16-6-2007\end{array}$ \\
\hline 05 & Organiser & $\begin{array}{l}\text { Ship-based with land- } \\
\text { ings (200-500 pax.) }\end{array}$ & $\begin{array}{l}\text { Expedition leader/ } \\
\text { lecturer/scientist }\end{array}$ & $\mathrm{DH}$ & $27-4-2006$ \\
\hline 06 & Organiser & $\begin{array}{l}\text { Ship-based with land- } \\
\text { ings (<200 pax.) }\end{array}$ & $\begin{array}{l}\text { Expedition leader/ } \\
\text { lecturer/scientist }\end{array}$ & $\mathrm{DH}$ & $26-4-2006$ \\
\hline 07 & Organiser & Industry association & $\begin{array}{l}\text { Upper-level repre- } \\
\text { sentative }\end{array}$ & $\begin{array}{l}\mathrm{DH} \\
\mathrm{ML}\end{array}$ & $\begin{array}{l}23-12-2006 \\
7-6-2007\end{array}$ \\
\hline 08 & Organiser & $\begin{array}{l}\text { Ship-based with land- } \\
\text { ings (<200 pax.) }\end{array}$ & $\begin{array}{l}\text { Co-owner and expe- } \\
\text { dition leader }\end{array}$ & $\mathrm{DH}$ & $2-11-2006$ \\
\hline 09 & Organiser & $\begin{array}{l}\text { Ship-based with land- } \\
\text { ings (<200 pax.) }\end{array}$ & Lecturer/scientist & $\mathrm{DH}$ & $14-12-2006$ \\
\hline 010 & Organiser & $\begin{array}{l}\text { Ship-based with land- } \\
\text { ings (<200 pax.) }\end{array}$ & $\begin{array}{l}\text { Sales and marketing } \\
\text { manager; lecturer }\end{array}$ & $\mathrm{DH}$ & $7-3-2007$ \\
\hline 011 & Organiser & $\begin{array}{l}\text { Ship-based with land- } \\
\text { ings (<200 pax.) }\end{array}$ & $\begin{array}{l}\text { Expedition leader/ } \\
\text { lecturer/scientist }\end{array}$ & $\begin{array}{l}\mathrm{DH} \\
\mathrm{ML}\end{array}$ & $\begin{array}{l}10-3-2007 \\
27-11-2006\end{array}$ \\
\hline 012 & Organiser & $\begin{array}{l}\text { Ship-based with land- } \\
\text { ings (> } 500 \text { pax.) }\end{array}$ & Expedition leader & $\begin{array}{l}\mathrm{DH} \\
\mathrm{ML}\end{array}$ & $\begin{array}{l}25-4-2006 \\
22-6-2007\end{array}$ \\
\hline 013 & Organiser & $\begin{array}{l}\text { Ship-based with land- } \\
\text { ings (<200 pax.) }\end{array}$ & Director & $M L$ & $12-6-2007$ \\
\hline O14 & Organiser & $\begin{array}{l}\text { Tour agent of Antarctic } \\
\text { cruises }\end{array}$ & Director & BA & $19-2-2008$ \\
\hline
\end{tabular}

* Interviewer represented by initials 


\begin{tabular}{|c|c|c|c|c|c|}
\hline Coding & Category & Institution & Position & Int* & Date \\
\hline M1 & Monitor & Environmental NGO & $\begin{array}{l}\text { Former representa- } \\
\text { tive }\end{array}$ & $\mathrm{DH}$ & $25-4-2006$ \\
\hline M2 & Monitor & Environmental NGO & Representative & $\mathrm{DH}$ & $3-5-2006$ \\
\hline M3 & Monitor & Environmental NGO & Representative & $\mathrm{DH}$ & $12-4-2006$ \\
\hline M4 & Monitor & University & $\begin{array}{l}\text { Antarctic tourism } \\
\text { researcher }\end{array}$ & ML & 6-6-2007 \\
\hline M5 & Monitor & University & $\begin{array}{l}\text { Antarctic tourism } \\
\text { researcher }\end{array}$ & ML & $8-6-2007$ \\
\hline M6 & Monitor & NAP & $\begin{array}{l}\text { Environmental } \\
\text { officer ( USA) }\end{array}$ & ML & $14-6-2007$ \\
\hline M7 & Monitor & NAP & $\begin{array}{l}\text { Logistical director } \\
\text { (USA) }\end{array}$ & ML & $14-6-2007$ \\
\hline R1 & Regulator & ATCP government & $\begin{array}{l}\text { Upper-level repre- } \\
\text { sentative (Germany) }\end{array}$ & $\mathrm{DH}$ & $13-1-2006$ \\
\hline R2 & Regulator & ATCP government & $\begin{array}{l}\text { Upper-level repre- } \\
\text { sentative (USA) }\end{array}$ & $\mathrm{DH}$ & $28-4-2006$ \\
\hline R3 & Regulator & ATCP government & $\begin{array}{l}\text { Upper-level repre- } \\
\text { sentative (USA) }\end{array}$ & $\mathrm{DH}$ & 3-5-2006 \\
\hline R4 & Regulator & ATCP government & $\begin{array}{l}\text { Upper-level repre- } \\
\text { sentative (USA) }\end{array}$ & ML & $13-6-2007$ \\
\hline R5 & Regulator & ATCP government & $\begin{array}{l}\text { Upper-level repre- } \\
\text { sentative (Chile) }\end{array}$ & $\begin{array}{l}\mathrm{ML} \\
\mathrm{BA}\end{array}$ & $15-1-2008$ \\
\hline R6 & Regulator & ATCP government & $\begin{array}{l}\text { Upper-level repre- } \\
\text { sentative (Argentina) }\end{array}$ & $\begin{array}{l}\mathrm{ML} \\
\mathrm{BA}\end{array}$ & $18-2-2008$ \\
\hline R7 & Regulator & Antarctic Treaty System & $\begin{array}{l}\text { Upper-level repre- } \\
\text { sentative }\end{array}$ & $\begin{array}{l}\mathrm{ML} \\
\mathrm{BA}\end{array}$ & $19-2-2008$ \\
\hline R8 & Regulator & Antarctic Treaty System & $\begin{array}{l}\text { Upper-level repre- } \\
\text { sentative }\end{array}$ & $\begin{array}{l}\mathrm{ML} \\
\mathrm{BA}\end{array}$ & $19-2-2008$ \\
\hline
\end{tabular}

* Interviewer represented by initials

A systematic assessment of tourism self-organisation in Antarctica requires an analytical framework, a set of criteria against which performance can be evaluated. A conceptualisation is needed of what constitutes a robust system for selforganisation and collective action when dealing with commons. Developing such a conceptualisation is at the heart of Elinor Ostrom's extensive academic work. Observing that in many cases, individual users manage to restrict themselves and share the benefits of the resource through collective action (Ostrom, 2006), she set out to find the determinants of success. The result was laid down in a set of design principles (Ostrom, 1990; 2000; 2005) that are important for enduring and robust institutions. Ostrom's design principles for robust institutions governing common pool resources (see Box 7.1) were derived from extensive, long-term studies spanning more than a decade and scrutinised during colloquiums, mini-conferences and 
working group meetings at the Workshop in Political Theory and Policy Analysis, an interdisciplinary research centre based at the University of Indiana (WPTPA, 2008).

Box 7.1: Design principles for robust common pool regimes (Ostrom, 2005: 259)

\section{Clearly defined boundaries}

The boundaries of the resource system and the individuals or households with rights to harvest resource units are clearly defined.

\section{Proportional equivalence between benefits and costs}

Rules specifying the amount of resource products that a user is allocated related to local conditions and to rules requiring labour, materials, and/or money inputs.

\section{Collective-choice arrangements}

Many of the individuals affected by harvesting and protection rules are included in the group who can modify these rules.

\section{Monitoring}

Monitors, who actively audit biophysical conditions and user behaviour, are at least partially accountable to the users and/or are the users themselves.

\section{Graduated sanctions}

Users who violate rules-in-use are likely to receive graduated sanctions (depending on the seriousness and context of the offense) from other users, from officials accountable to these users, or from both.

\section{Conflict-resolution mechanisms}

Users and their officials have rapid access to low-cost, local arenas to resolve conflict among users or between users and officials.

\section{Minimal recognition of rights to organise}

The rights of users to devise their own institutions are not challenged by external governmental authorities, and users have long-term tenure rights to the resource.

\section{Nested enterprises (for resources that are parts of larger systems)}

Appropriation, provision, monitoring, enforcement, conflict resolution, and governance activities are organised in multiple layers of nested enterprises.

Extensive empirical studies of the institutional arrangements employed by successful self-organised common pool systems, as discussed by Ostrom et al. (1992), Ostrom and Gardner (1993), Ostrom et al. (2002), form the backbone of Ostrom's theory. Local specificities should always be taken into consideration, including local complexities within communities and the dynamic nature of environments (Mehta et al., 2001; Steins, 2001; Cleaver, 2002). However, numerous insightful applications of Ostrom's theory in conjunction with other common pool resource regimes, including Antarctic resources, serve as evidence that Ostrom's design principles are generic enough to justify their application as the analytical framework for the Antarctic tourism case. 


\subsection{Tourism regulation in Antarctica}

Antarctica, or more precisely the area south of $60^{\circ} \mathrm{S}$ Lat., is considered an international common (Buck, 1998), or global common (Joyner, 1998), and is governed by 28 ATCPs within the realm of the ATS (Joyner, 1994). Annual Antarctic Treaty Consultative Meetings (ATCMs) facilitate the discussion among the ATCPs of areas of concern and the development of policy agreements, for which consensus is required. Within the ATS, tourism is largely regulated by the Protocol on Environmental Protection to the Antarctic Treaty (Protocol), which governs all human activities in the Antarctic Treaty area. An important issue for tourism providers is the Protocol's requirement for environmental impact assessments to be made for any Antarctic activity originating from Treaty nations. In recent years, a number of voluntary and binding measures were added to the catalogue of tourism regulations through the ATS on issues such as pre-trip and post-trip notification, compulsory contingency planning and insurance, and site guidelines for visitors (Antarctic Treaty System, 2004; Molenaar, 2005; Antarctic Treaty System, 2007b; Haase, 2008).

Despite the progress made, Antarctic tourism regulation by the ATCPs has been considered weak. The decision making and implementation process is arguably too slow to deal with the dynamic tourism industry (Bastmeijer and Roura, 2004). Many regulations specifically applying to Antarctic tourism are not legally binding. Those that are binding are implemented through the domestic legislation of individual ATCPs, leaving much room for national translation and interpretation (Kriwoken and Rootes, 2000; Bastmeijer, 2003). In addition, the rules cannot be policed and enforced effectively in the field (Tracey, 2001; Molenaar, 2005), and they do not apply to operators from Third Party states. For an in-depth treatise of the legal and jurisdictional peculiarities, the reader is referred to elsewhere in the literature (Beck, 1990; Richardson, 2000; Bastmeijer, 2003; Hemmings and Roura, 2003; Bastmeijer and Roura, 2004; Molenaar, 2005).

In several respects, the lack of regulation is of no advantage to the tourism industry; for a proper functioning of the business, some coordination is needed. Unlikely as it may sound for this vast continent, Antarctic tourism struggles with congestion. Due to the harsh climate, tourism activities are confined to a relatively short period of the year, largely running from November to March, and concentrated around a limited number of landing sites. In search of attractions, such as interesting geological and historical features, research stations and wildlife, which are within easy distance from South America, ship-based tourism is centred around the Antarctic Peninsula region (Enzenbacher, 1992; Hughes and Davis, 1995; Cessford, 1997; Mason and Legg, 1999). Out of all available sites at the Antarctic Peninsula, fewer than ten are visited by more than 10,000 people each year (IAATO, 2008b). 
To avoid having several ships at the same place at the same time, activities need to be coordinated. Consequently, an important aspect of IAATO's general policies is the coordination of operator activities in accordance with the one ship, one place, one moment principle (IAATO, 2006a). A web-based ship scheduler is utilised to coordinate the itineraries of individual operators in such a way that interference and the visible lining up of vessels at landing sites are avoided. Several months in advance, tour operators are required to enter their schedules online, and under consideration of site-specific aspects such as the environmental sensitivity and existing site-specific guidelines, landing sites are allotted on a first-come, firstserved basis. Although at present, there is no requirement for non-members to notify their Antarctic itineraries, IAATO tries to encourage these operators to enter their itineraries in the ship scheduler as well, in order to achieve smooth cruise operations without overlaps at landing sites. Other motives for coordination are the protection of tourism resources, and safety concerns. Arrangements for mutual assistance between tour operators in cases of emergency provide additional security, on top of the extensive preparation and ample experience that each individual tour operator needs to operate in the harsh Antarctic conditions. Recent experience with near-disasters, e.g. the grounding of the M/S Nordkapp (Norway, 2007) or the sinking of the $M / S$ Explorer (Stewart and Draper, 2008), has revealed that such arrangements are no luxury. The same holds for arrangements to maintain the integrity of the key attractions for tourism in Antarctica, such as rules for waste disposal, and for the interaction with wildlife.

When tourism to Antarctica took off in the late 1980s, tour operators had good reasons to organise themselves, coordinate travelling schedules, and institutionalise best-practice guidelines (Splettstoesser, 2000; United Kingdom, 2004a). In 1991, seven tour operators founded the IAATO in order to advance and promote safe, environmentally sound and responsible travel to Antarctica (Splettstoesser, 2000). A further, rarely cited reason for the establishment of IAATO in the early 1990s was the 'friendly coercion' of US-based tour operators by the U.S. National Science Foundation to be organised and have a central communication point (M6, 2007; 07, 2006; R1, 2007).

Over the years, IAATO has grown to a total of 102 members from a wide range of countries, although most of the tour operators are based in affluent Western countries in Europe and North America (IAATO, 2007b; 2008c). Given the unpredictability of the Antarctic climate, seasonal plans and schedules must always be complemented with day-to-day communication between operators. IAATO therefore established guidelines for such communication, which are considered to be of utmost importance $(06,2006 ; 2007)$. Other guidelines introduced by IAATO relate to practical aspects of tourist management such as briefings, a reiteration of the importance of environmentally sound behaviour, debriefings, and a high guide-passenger ratio (1:20). In order to remain members in good standing in the eyes of their peers, IAATO members voluntarily impose upon themselves stringent codes of conduct and guidelines for visitors and operators in the Antarctic. Although no 
regular internal review processes are in place for full IAATO members, compliance with existing guidelines, which have been developed from best practices, is ensured through self-monitoring and peer pressure (04, 2006; 05, 2006). These guidelines aim at guiding behaviour by providing instructions and the reasoning behind these instructions (Mason and Legg, 1999), a strategy which has been commended by Johnston (Johnston, 1997). The resulting operational rules are institutionalised in the bylaws of the association. Detailed accounts of the rules and guidelines are given elsewhere and will not be recounted in detail here (Splettstoesser and Folks, 1994).

Faced with a rapid development of Antarctica as a tourism destination and the increasing numbers of operators including the Antarctic in their itineraries, it is necessary to question whether IAATO will be able to maintain its positive record in terms of self-regulating the use of the Antarctic tourism resource. Ostrom et al. (1999) argued that the greater the number of participants controlling a common pool resource, the more difficult it would be to effectively self-regulate resource use. Does IAATO have the capability to counterbalance the organisational, monitoring and compliance problems associated with an increasing number of participating tour operators so that joint benefits continue to outweigh membership costs? To shed some light on this question, the following section discusses the main vulnerabilities and strengths of IAATO within the framework of Ostrom's design principles for robust institutions.

\subsection{The robustness of the Antarctic tourism self-regulatory regime}

\subsubsection{WELL-DEFINED BOUNDARIES}

Despite various definitions of the continent in the geophysical, biological or geopolitical sense, the physical boundaries of the Antarctic resource system are generally well accepted (Buck, 1998). Antarctica possesses a strong natural boundary, its geophysical isolation, which can be considered as a barrier of entry. Antarctic tourism businesses and impacts can be traced across the globe, so are the regulatory institutions that directly or indirectly steer Antarctic tourism development (Molenaar, 2005). However, when analysing Antarctic tourism regulation it is sensible to apply the legal and geopolitical boundary of $60^{\circ} \mathrm{S}$ Lat. of the Antarctic Treaty System. As Antarctic tourism is often regarded as a wilderness experience (Cessford, 1997; Davis, 1999; Maher et al., 2001), the main resource utilised by Antarctic tour operators is wilderness space. Here, the quality of space is of utmost importance along with a clear preference for easily accessible sites with abundant wildlife, historic monuments or research stations (Cessford, 1997; Mason and Legg, 1999). In order to protect space, or the right to use space for their members, IAATO advocates the one ship, one place, one moment principle as described previously. Nonetheless, operators remark that getting the favoured popular slots is becoming increasingly problematic, especially for larger vessels that have a limited number of sites that can be visited $(012,2007)$. Therefore, it would be advisable to give larger 
vessel operators a head start in the process of reserving slots at certain landing sites (Ibid). Another pertinent question arises - what will happen if high-quality space becomes scarce relative to the number of vessels active in the Antarctic? The current trends of rapidly increasing visitor numbers (Bastmeijer, 2003; Hemmings, 2004; Molenaar, 2005) as detailed in Figure 3.1 indicate that such a scenario may not be totally inconceivable.

Ostrom (2005) stressed that defining the boundaries of groups of users clearly in order to be able to deal with free-riding would be as important as defining the boundaries of the resource system itself. With respect to Antarctic tourism, the clear delineation of user groups and the excludability of non-members are very tricky. Two main resource governance regimes with different levels of decisionmaking power coexist for Antarctic tourism. The ATCPs govern all aspects of human activities (for members from the Treaty nations) south of $60^{\circ} \mathrm{S}$ Lat., and IAATO selfgoverns the activities of Antarctic tourism operators. Both regimes are applicable only to members or, in the case of the ATS, to Treaty nations, allowing nonmembers to use the Antarctic resource pool freely without legal hindrance (Molenaar, 2005). This non-excludability of non-members constitutes a great legal and political challenge which might even gain in significance once technological advancement results in diminishing the importance of the natural barrier as a 'gatekeeper' to the Antarctic.

To complicate the case, looking at Antarctica as a single resource unit is problematic. It is far too complex and large to allow its meaningful resource management as a single unit. Therefore, it might be useful to create boundaries for smaller manageable resource units (e.g. Antarctic regions or individual landing sites) in order to facilitate improved governance of the system. This idea of zoning has been advocated for Antarctica or other regions (Tangley, 1988; Page and Dowling, 2002; Gill, 2004; Haase, 2008) and may allow for the creation of 'no-go zones', besides the existing ASPAs and SSSIs, that could be turned into sanctuaries for wildlife. Zoning allows for targeted and site-specific management that takes into consideration the specific characteristics and ecological significance of a diverse set of smaller geographical areas. In the Antarctic context, the importance of micro-management through zoning is currently demonstrated by the development of a growing number of site specific guidelines (see ATS Resolutions 5 [2005], 2 [2006] and 1 [2007] (see respectively Antarctic Treaty System, 2005; 2006; 2007b).

\subsubsection{PROPortional equiValenCe BetWeen Benefits AND COSTS}

The main direct costs incurred by IAATO members are represented by the membership fees consisting of an annual due for IAATO members and, if applicable, passenger fees (IAATO, 2008a; 010, 2007; 011, 2007). Generally, IAATO members apply the user-pays principle and pass the cost of an IAATO membership on to the tourists. Furthermore, all costs related to an IAATO membership application, including the provision of passage for an observer, have to be covered by the tour 
operator. According to the IAATO bylaws, to be accepted as a member, a company must support IAATO's objectives; abide by the association's bylaws and the provisions of the ATS; be active in operating tours to Antarctica at least once every three years; and be accepted by two-thirds of IAATO members in good standing (IAATO, 2008a). In addition, on one of their Antarctic itineraries, associate members applying for (full) membership have to carry an observer, typically an IAATO outsider and Antarctic tourism expert, whose report needs to be submitted to the membership body. The observer's report will then be circulated and reviewed by IAATO members in good standing, and a vote will be passed during an AGM.

Additional membership costs include travel, accommodation, subsistence and other expenses linked to the attendance of AGMs as well as the time that has to be set aside for AGMs and for committee work. The time necessary for these tasks depends on the degree of involvement of the respective operators in the decisionmaking processes. Time also has to be reserved for administrative work in conjunction with IAATO membership requirements. Examples include regular communication with the executive committee, developing detailed itineraries for activities in the upcoming season and providing these itineraries to IAATO and other members by means of a web-based ship scheduler, and reporting back on last season's activities and any experienced or observed problems (O2, 2006; 03, 2006; 04, 2006). Finally, costs could attach to constraints in resource use imposed by IAATO guidelines through the previously mentioned one ship, one place, one moment principle (IAATO, 2006a) or by operating self-sufficiently in the wilderness.

IAATO membership includes a range of intangible benefits. IAATO is acknowledged as an association that promotes and practices environmentally sound tourism in the Antarctic creating a positive pubic image (Splettstoesser, 2000). IAATO also represents the interests of tour operators at international meetings, and in particular at ATCMs, where IAATO can provide its expertise and influence decision-making (Herr, 1996; Murray and Jabour, 2004). In addition, IAATO members benefit from sharing information, jointly filing permits and EIAs in some Treaty countries, and the preference that some ATCPs give to IAATO tour operators for station visits and landings on national territory. For instance, British stations and sub- Antarctic Islands only accept visits by IAATO members (United Kingdom, 2004a).

Consistently increasing membership numbers over the years (IAATO, 2007b; 2008c) are an indication that most tour operators perceive the benefits of being a member of IAATO as outweighing the costs. This being said, free-riding continues to present a challenge, particularly as IAATO tries to include non-members in their ship scheduling system such that non-members benefit from the same high-quality resource use without visual disturbance by other vessels.

Until recently, two US-based large-vessel operators, Orient Lines and Discovery World Cruises, organised Antarctic cruises outside the IAATO framework. Both companies operated vessels with a capacity of more than 500 passengers, although 
Orient Lines capped the number of passengers for their Antarctic itinerary at a maximum of 500, and fall outside IAATO's category of ship-based tourism with landings. They included landings in their itineraries, but aside from that they largely operated in accordance with IAATO's general principles and policies and had experienced expedition leaders $(012,2006,2007)$. Recently, Orient Lines has left the Antarctic tourism market by selling the M/S Marco Polo. Discovery World Cruises apparently plan to apply for IAATO membership, a move that has been anticipated for some time by IAATO tour operators (O2, 2006; 03, 2006; 010, 2007; 012, 2006; $012,2007)$. Despite the reduction in the number of non-member operators, there is concern among IAATO members that free-riders may adversely impact their reputation and degrade the environment as their activities cannot be adequately monitored $(06,2006)$. Moreover, potential non-members cannot be excluded from enjoying the utilisation of the resource. Apart from these large-vessel operators, the non-IAATO Antarctic tourism sector is dominated by small yachts and other organisers of small-scale polar expeditions from various countries.

\subsubsection{COLLECTIVE-CHOICE ARRANGEMENTS}

As a self-organised institution, IAATO was founded on the principles of participatory decision-making. Facilitated through committee work, IAATO guidelines and policies are developed in consultation with the membership body. Decision-making is finalised during the AGMs, when members vote on proposed guidelines, rules or recommendations. Members are encouraged to participate in committees and contribute to policy-making directly, but in this regard individual involvement and initiatives differ among the individual members $(02,2006)$.

Over the years, the development and wide application of a set of practical operational codices and guidelines have proven IAATO's adaptive capacity and high levels of participation. To give one example, in recent years, as a result of growing number of larger tourist vessels (i.e. carrying more than 400 passengers) with the desire to conduct landings, the bylaws were adjusted with the ships' size limits for landings being set to 500 passengers (IAATO, 2002c). Although such adaptations have been criticised for being a relaxation of the operational standards, they are an indication of IAATO's capacity to respond to changing conditions and structure of the tourism industry. Increasing numbers and types of operators involved in decisionmaking within IAATO are believed to make collective decisions more and more difficult (M3, 2007). IAATO may again be forced to adapt its bylaws and guidelines to emerging conditions, and such adaptations are unlikely to result in improvements to IAATO's environmental standards. Strict guidelines will have to be loosened to guarantee a continuously high level of inclusiveness among Antarctic tour operators. As operational rules have been developed by the 'older' generation of member companies, new entrants might not share the same norms, which may cause a transmission failure from one generation of tour operators to the next. As a result, both new and old participants might see membership costs exceeding the benefits and decide to terminate their membership. 


\subsubsection{MONITORING, GRADUATED SANCTIONS AND CONFLICT RESOLUTION}

IAATO maintains two different approaches to monitoring. On an internal level, members monitor fellow members continuously (Haase et al., 2007). Any infringements or problems are reported to the Executive Committee and subsequently to the other members, who decide on appropriate actions. Secondly, specific and external monitoring is required when operators apply for (full) membership, as explained previously.

From an institutional perspective, this monitoring system works well as various IAATO members have attested. IAATO members attempt to remain in good standing and want to adhere to the rules that have been decided on collectively (010, 2007). The love for the Antarctic that many of the current operators express (Haase et al., 2007), and the wish to keep the environmental standards up (Richardson, 2000), propel them towards institutionalised cooperation and coordination. Personal communication, peer pressure and the aforementioned dedication to remain members in good standing also aid the resolution of conflict and decrease the likelihood of conflicts arising. As long as IAATO members describe the internal monitoring process as "looking out for each other" $(04,2006)$ rather than a necessary evil, it seems to be a stabilising factor which aids institutional robustness. The alignment of goals among IAATO members, a belief in joint benefits and mutual trust allow for simplified and low-cost sanctioning systems to be applied. To be reprimanded by a group of peers represents a considerable penalty to tour operators. The intrinsic motivation to maintain a good reputation adds a new dimension to an otherwise indiscriminative sanctioning system, which utilises a probationary rule as the main punishment for misconduct. When found to transgress the bylaws, any member can be reprimanded by the membership body and can be put on probation or be expelled (IAATO, 2008a). This implies that environmental infractions, (as well as not paying membership fees), can result in probation (IAATO, 2006a; 2008a; 010, 2007). When put on probation, members will lose all membership rights, including the use of the IAATO logo, but will maintain their duties.

Although members have reportedly been reprimanded (Haase, 2008) or put on probation, this rule did not have to be used often $(010,2007)$. Even when this rule is enforced, a probation will become public only indirectly (e.g. through the respective company itself or through the members' directory on the IAATO website). Aside from probation, negative reporting can be considered a sanction in its own right, thus creating a system of subtly graduated sanctions. For example, based on reports by the expedition leader and ice master member (7 Seas Consulting, 2007; KZ Expedition Consulting, 2007), at the 2007 AGM a company was thoroughly interrogated about its garbage disposal procedures in the Southern Ocean during the 2006/7 operating season. As it could not be established beyond doubt whether IAATO rules or international law had been transgressed, the member company in question was not officially put on probation but was reprimanded and required to carry an observer on board for a cruise in the $2007 / 08$ season (Haase, 2008). 
Regarding monitoring, sanctioning and internal conflict resolution, IAATO exhibits the characteristics of a fairly stable institution that has been able to design, solidify and extend shared norms and visions through committee work and at AGMs. The AGMs provide a regular platform for the resolution of conflict between members, which decreases the necessary amount of monitoring and sanctioning. Increasing numbers and types of operators may necessitate the development of a greater number of site guidelines and operational rules. One of the interviewees observed that if more comprehensive guidelines were to be implemented, a continuous, independent, professional monitoring system would have to be established (M4, 2007). The monitoring system should employ a range of professional observers upon whose assessment decisions for policy and dispute resolution could be based. An institutionalised monitoring system would detach itself from the current basis of judgement that compares individual operators' opinions against each another. However, such a system would be costly and extremely difficult to establish under the current institutional arrangements (M4, 2007). Furthermore, an increasing number of operators joining IAATO will affect the interaction of members within the organisation. In several publications, Ostrom $(2005 ; 2006)$ stressed the importance of face-to-face communication for reaching agreements at limited costs. A growing and more diverse group of members will complicate the facilitation of direct communication to resolve conflict and may reduce the chances to come to mutual understanding (Ostrom et al., 1999).

\subsubsection{MINIMAL RECOGNITION OF RIGHTS TO ORGANISE}

An observation by Johnson and Libecap (1982) as cited in Ostrom (2005: 268) reads:

"When external governmental officials presume that only they can make authoritative rules, then it is difficult, but not impossible, for local users to sustain a selforganised regime"

In the Antarctic tourism context, the lack of undisputed sovereignty (Polk, 1998) pre-empts a strong, unilateral and comprehensive governance regime. Despite a strong reliance on industry self-regulation for aspects of Antarctic tourism (Molenaar, 2005), many ATCPs aim at exclusivity regarding governance over Antarctica and possess the ultimate responsibility for regulating tourism in the Treaty area for signatory states. Notwithstanding the applicability of the Antarctic Treaty only to signatory states, the ATCPs have the means to give official legitimacy to the guidelines and rules that IAATO establishes. At the moment, the ATCPs recognise IAATO only in relative terms. They respect IAATO's efforts to ensure operator compliance with ATS mechanisms (Richardson, 2000), but do not grant any official power to IAATO (Haase et al., 2007). Although some state that self-regulation should be embraced as long as the net-effect is in line with the ATS requirements (R4, 2007), many ATCP representatives claim that the responsibility for tourism 
regulation ultimately lies in their hands and not in the hands of the tourism industry (R5, 2008; R6, 2008, R7, 2008; R8, 2008).

The lack of true recognition in terms of legitimate sanctioning powers has been lamented by some tour operators (Haase et al., 2007; 08, 2006), and can be viewed as a destabilizing factor. Moreover, power imbalances and asymmetries between the ATCPs and IAATO may complicate cooperation and the exchange of information in the future. Molenaar (2005) recognised this asymmetric power relationship and suggested that a strong role of IAATO in the realm of Antarctic tourism regulation was preferable, but could be sustained only if the ATCPs grant IAATO a more official, for instance advisory, role within the ATS. Some of the interviewees proposed that the relationship between IAATO and ATCPs could be improved by setting up a tourism commission consisting of representatives of both groups (07, 2007; M3, 2007).

Recent developments at ATCMs indicate a move towards a greater recognition of IAATO's rights and achievements. The ATCPs have now formally acknowledged a range of IAATO guidelines by adopting them as resolutions (Antarctic Treaty System, 2007a). An example is Resolution 4 (2007), which formalises that national governments should discourage or decline to authorise tour operators that use vessels carrying more than 500 passengers from making any landings in Antarctica (Antarctic Treaty System, 2007a: 26). Resolution 4 (2007) further encourages a guide-to-passenger ratio of 1:20 while onshore and restricts the numbers of passengers landing at a site to no more than 100 at any one time ${ }^{17}$. As with many ATS instruments, most tourism resolutions have a hortatory character and cannot guarantee congruent application or sanction non-compliance, a complication which has been lamented by researchers (Richardson, 2000; Bastmeijer and Roura, 2004). Nonetheless, the adoption of these mechanisms is to be commended as they represent a step in the right direction.

\subsubsection{NESTED ENTERPRISES}

Antarctica is a complex, large-scale resource system. Currently, nested enterprises, as defined by Ostrom (2005), are not developed to a great extent. Antarctic governance is polycentric in the sense that there are several entities responsible for managing specific aspects of human activities in Antarctica, but these entities remain rather separate instead of being organised in multiple layers of nested enterprises. The main reason for this is the lack of official recognition discussed in the previous section. A number of authors argue that a comprehensive approach to governing Antarctic tourism is needed (Bastmeijer and Roura, 2004; Molenaar, 2005), in which fragmented policies from different levels (e.g. IMO regulations, ATS regulations, IAATO regulations) are integrated and clear roles are defined for each

\footnotetext{
${ }^{17}$ During the 2009 ATCM in Baltimore these operational standards were codified in a binding Measure (Personal communication with Kees Bastmeijer, 2009).
} 
of these institutions. ATCPs would be wise to clearly define the playing field for organisations such as IAATO to self-organise under their supervision. That way, ATCPs could make effective use of IAATO's knowledge, experience and networks while reducing costs. Another reason for ATCPs to clearly define their position to self-regulatory organisations, such as IAATO, is that it creates clarity for potential additional self-regulatory organisations that might become active in the future. It is not inconceivable that other types of resource users (or even tour operators) set up their own self-organised systems. The latter almost happened around the turn of the century, when IAATO refused to allow large ships (larger than 500 passengers) to become IAATO members (M4, 2007). When it was suggested that these largevessel operators could start an association of their own, IAATO changed their mind.

An accreditation scheme has been suggested as a way to improve the nested character of the ATS and IAATO (Molenaar, 2005; R7, 2008): that way ATCPs would have to define the criteria that tour operators have to abide by to be accredited to operate in the Antarctic Treaty area. Nonetheless, nested systems are not easy to realise in the Antarctic context because of, among others, financial reasons (R7, 2008). However, the uniqueness of the Antarctic wilderness constitutes a considerable value for tourists, which provides opportunity for financing the regulatory schemes both of IAATO and of the ATS.

\subsection{Discussion and conclusion}

Tourism in Antarctica is growing and diversifying into an expanding range of industry segments and niche products (Enzenbacher, 1992; Bastmeijer, 2003; Stewart et al., 2005). Antarctica's key tourist attractions are commons, the consumption of which by one tourist diminishes their value to another. Hardin's (1968) two solutions to the 'commons problem', i.e. privatisation and nationalisation of the commons, are impossible in the Antarctic context, making the continent a prime candidate for experimentation with alternative forms of management. Ostrom's work has opened pathways to new solutions encouraged by examples of successful management of common pool resources all over the world (Ostrom 1990; 2005; 2006; Ostrom and Gardner 1993; Ostrom et al. 1992; 1999). The relevance of alternatives to Hardin's (1968) suggestions may stretch well beyond Antarctica, as commons are crucial for tourism (especially cruise tourism) around the world, and governments lose power to business and civil society in many places.

In Antarctica, the tourism industry has seized the initiative in managing the commons. Over the last 17 years, industry self-regulation through IAATO has been a success, which is reflected in its growth and increasing international influence. Institutionally, IAATO has developed and evolved as well. For instance, an Environ- 
mental Officer joined the Executive Committee in September $2005^{18}$; the existence and work of standing committees reflect the growing complexity of the organisation; and amendments to rules and regulations as well as the development of new guidelines hint at active learning and a maturing governance system.

The increasing complexity of IAATO's internal organisation may introduce existential challenges to the current self-regulatory system, such as fundamental incompatibilities between the interests of different (types of) IAATO members. This raises the question of how robust IAATO's system of self-regulation is. Can it stand the test of time? This question was approached by evaluating IAATO's performance against Ostrom's design principles for robust institutions for the management of commons. The analysis revealed a number of strengths and weaknesses.

The strengths of IAATO are related primarily to the proportional benefits that an IAATO membership creates for tour operators in managing wilderness space, and especially prime wilderness space. In addition, the administrative service offered, the positive reputation IAATO has gained and IAATO's participatory collective decision-making arrangements represent important benefits to tour operators. Ostrom et al. (1999) argued that for self-organised institutions to be successful the benefits perceived by resource users have to be greater than the costs attributed to collective action and any restrictions imposed on resource use. Currently, for Antarctic tour operators, the joint benefits of imposing restrictions, e.g. upon the accessibility of the resource or modes of use, in order to maintain the quality of the resource, outweigh the costs of self-organisation and of operational limitations and thus provide the foundation of a robust institution.

Weaknesses inherent in the self-regulatory system are mainly related to the nonexcludability of other resource users (the free-riding potential), the enormous scale of the resource pool and the uncertain position of IAATO within the ATS. The interaction with external users and official authorities is not organised very well at the moment $(07,2007)$. Arenas in which to resolve conflict are largely absent due to the geopolitical peculiarities of the ATS. Conflicts with ATCPs may be addressed at the ATCMs, but doing so is unlikely to result in any radical changes as influence and decision-making power ultimately rest with the ATCPs. The lack of conflictresolution mechanisms and nested enterprises is related to the uncertain position of IAATO within the ATS but may also result from the relatively limited number of violations and internal conflicts experienced by IAATO to date, as mentioned in numerous stakeholder interviews. Yet, these accounts have to be considered with some caution, as IAATO would have no interest in putting conflicts and violations into the public domain.

\footnotetext{
${ }^{18}$ Personal communication with Kim Crosbie (2008).
} 
So far, IAATO has been capable of accommodating the diverging interests of a growing number of tour operators in one institutional structure and adapt to a changing environment. IAATO's adaptive capacity along with the benefits perceived by tour operators of collectively managing the Antarctic tourism resource qualifies IAATO as a robust institution (Ostrom, 2005). However, this does not guarantee that IAATO will indefinitely be able to maintain its current level of robustness. IAATO has managed to successfully self-organise and self-regulate every aspect of Antarctic tourism over which it exercises full control. Nonetheless, there are developmental factors that lie outside IAATO's control, such as the rapid growth and diversification of Antarctic tourism observed over the past two decades. Many interviewees, including operators, monitors and regulators, believe that diverging interests, inside and outside the association, will put pressure on this voluntary regime. The fact that the ATCPs animatedly discuss the development of further tourism regulation might change the status quo.

It is very likely that Antarctic tourism regulation will continue to rely heavily on selfregulation in the future. At the moment, much of the impetus towards environmentally sound tourism regulation comes from the self-regulatory regime. The lack of regulatory support through the ATS weakens the self-regulatory framework and affects its robustness. If, due to external, destabilising pressures, more operators decide to act outside the self-regulatory system, the lack of ATS support may ultimately lead to its demise. Trustworthy partnerships, accreditation schemes and professional monitoring are some of the suggestions made by the interviewees to improve ATS support and recognition of IAATO. Some countries, such as the United Kingdom, who started granting permission to visit Antarctic stations only to IAATO members, point the way in this respect. Overall, addressing upcoming questions as they arise rather than strategically, Antarctic tourism regulation is still largely piecemeal.

With this article the authors hope to contribute to the institutional development of the Antarctic tourism regulatory regime. Robust and adaptive governance regimes are an essential element for sustainable tourism in one of the world's last great wildernesses. In the light of recent developments in Antarctic tourism, what is needed now is the integration of policy and tourism management approaches, an array of possible future scenarios, as well as research into operator and tourist compliance. Additional research is needed to identify and assess options for effectively regulating Antarctic tourism in the future. Embracing an environmental imperative as reflected in stakeholder interviews and the literature (Riddle, 1998; Summerson and Riddle, 2000; Hemmings, 2004; Enzenbacher, 2007; Snyder, 2007; Scully and IAATO, 2008), the ultimate objective when regulating Antarctic tourism should be to maintain the integrity of the Antarctic environment in the future. Therefore, one should ask "what-if" questions before they turn into "why" questions and pro-actively investigate design parameters for appropriate regulatory tools. 



\section{Chapter 8}

\section{BUSINESS AS (UN)USUAL: AN INTEGRATED SCENARIO ANALYSIS OF ANTARCTIC TOURISM}

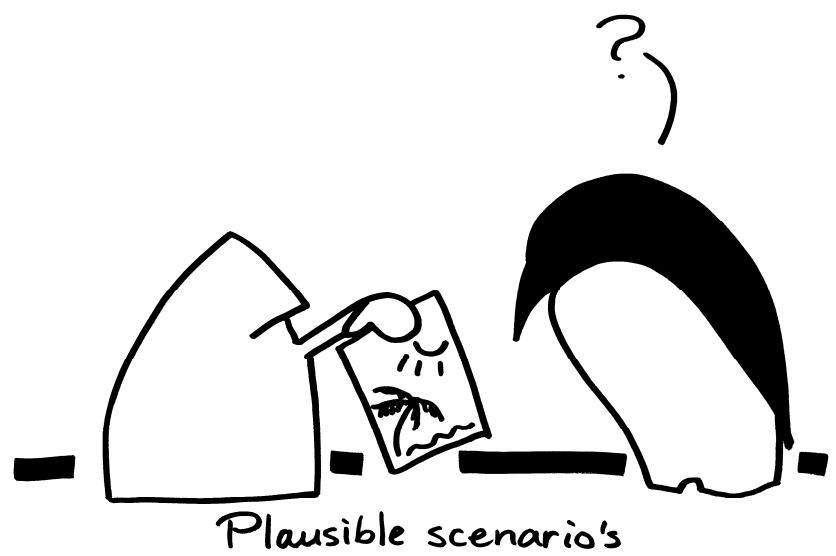

This chapter is based on:

Lamers, M., Amelung, B., Stel, J.H. (in press) Business as (un)usual: An integrated scenario analysis of Antarctic tourism. In: Hall, M. and Saarinen, J. (eds.) Tourism and Change in Polar Regions: Climate, Environment and Experiences. London: Routledge.

Amelung, B. and Lamers, M. (2006) Scenario development for Antarctic tourism: Exploring the uncertainties. Polarforschung 75(2-3): 133-139. 


\subsection{Introduction}

In 1775, after a three year unsuccessful search for the Antarctic continent, Captain James Cook concluded: "I can be bold to say, that no man will venture farther south than I have done, and that the land which may lie to the south will never be explored" (as cited in Fogg, 1992; Landis, 2001). Being an explorer from the preindustrial age, James Cook could not have known that the technological and economic developments that followed in the next 225 years would prove his prediction wrong. Future forecasts are always informed about what we know about the present and coloured by the position and opinion of the predictor. Predicting the future of a continent is difficult, including Antarctica. Despite the fact that this most remote and isolated continent on the planet has always been relatively untouched by human developments.

The last two decades have seen a rapid development of tourism in Antarctica with increasing visitor numbers, from a few hundred to around 45.000 (IAATO, 2008b), and a diversifying supply of transport modes and activities. It has been argued that in recent years operational strategies in Antarctic tourism have been increasingly dominated by economies of scale, in addition to the traditional niche tourism products (Lamers et al., 2008). Antarctica is a special tourism destination for a number of reasons, i.e. the extreme climatic and weather conditions, the short four to five month season, the unique ecosystems and wildlife populations, the inexistence of an indigenous population, the sparse human (infra)structures, the relatively limited human activities, and the successful tailor-made international governance system. These characteristics are often considered intrinsically connected to the Antarctic continent, unchangeable, and independent from external globalisation processes. If these inherent Antarctic conditions remain untouched remains to be seen and cannot be guaranteed.

In view of the developments, many stakeholders and academic authors are becoming concerned about Antarctic tourism. Recent policy discussions at Antarctic Treaty Consultative Meetings (ATCMs) reflect these concerns and focus on the need for additional legal instruments and measures, such as site-specific guidelines and shipping standards, to mitigate some of the negative effects of tourism. A range of authors (Bastmeijer and Roura, 2004; Molenaar, 2005; Amelung and Lamers, 2006; ASOC, 2006) argue that, in addition to the rather reactive measures, a more proactive long term tourism policy is needed, based on a strategic vision on Antarctic tourism. Recently, the tourism industry and a number of Antarctic Treaty Parties have taken up this idea of a strategic tourism policy vision (Antarctic Treaty System, 2008; Scully and IAATO, 2008; United Kingdom, 2008). The development of consistent and plausible scenarios for tourism in Antarctica could play an important role in this policy process. 
The future of Antarctic tourism has been systematically studied only a few times before (Bauer, 1994; Snyder, 1997; Bauer, 2001). Only once this has led to the drafting of a diverse set of scenarios (Snyder, 1997), unfortunately without receiving much attention from policy makers and the tourism industry. In many articles, conference presentations, and workshop reports on Antarctic tourism loose snapshots of future visions are given. Visions are usually focused on single issues, such as the growing numbers of tourists or visitor sites, the increasing ship sizes, the creation of land-based tourism facilities and infrastructures, and forms of government supported tourism (Kershaw, 1998; Landau, 2000). Many of these visions fail to reach beyond the parameters of the current situation: the "business-as-usual" of the expedition cruise industry. In many future visions a moral judgment is included, reflecting stakeholder interest or personal opinion. Different recent development pathways, or single future issues, have never been jointly considered in a consistent way.

The aim of the research presented in this chapter is to develop and analyse Antarctic tourism scenarios based on a combination of future storylines developed during three participatory future workshops and a range of global scenarios. Integrated scenarios combine insights at various levels of scale, from a range of sources, to arrive at a more complete analysis of a system's future than can be achieved by singular disciplinary approaches or individual opinions. Integrated scenario analysis can provide a valuable tool in the development of a broadly supported long term Antarctic tourism policy. Cooks error demonstrates the necessity to create a diversity of future visions that go beyond the "business-as-usual" of tourism business in an unusual part of the world.

In the next section, we introduce the concept of integrated scenario analysis and elaborate on the methodological considerations involved in developing them. Section three presents the results of our study: analysis of four groups of scenarios. In section four a brief exposition is provided of the responses given by participants during the scenario workshops. In section five the validity and implications of the results are discussed. Section six concludes this chapter.

\subsection{Theoretical and methodological considerations}

\subsubsection{INTEGRATED SCENARIO ANALYSIS}

Integrated scenario analysis is a well-established tool to explore the implications of a large range of possible developments (Ringland, 1998; Greeuw et al., 2000b). Scenarios can be defined as "coherent descriptions of alternative hypothetical futures that reflect different perspectives on past, present and future developments, which can serve as a basis for action" (Van Notten et al., 2003). The creation of a diverse set of plausible scenarios discovers the uncertainties that are inherent in future studies, so that these can be addressed by policy or management. In addition, the use of scenarios allows the effectiveness of policy measures and other 
plans to be 'tested' under a variety of circumstances. Scenarios can be developed as a desktop exercise, but if time and money allow it is often recommendable to develop them in a participatory way to benefit from the knowledge, know-how, creativity and perspectives of a broad range of stakeholders; as well as stimulate social learning between different stakeholders (Alcamo, 2001).

Scenarios are used in a variety of ways and for a range of purposes. Scenarios can be categorised according to the project goal, the process design and the scenario content (Van Notten, 2005). In relation to the goal of the scenarios, a distinction is made between exploratory and pre-policy scenarios. Whereas exploratory scenarios are aimed at such ends as learning and investigating the interaction of societal processes, pre-policy scenarios have a strong normative aspect, in that they examine alternative paths to the future that vary according to their desirability. The design of the scenario development process can range from intuitive to analytical. Intuitive designs strongly depend on qualitative insights, while analytical approaches regard scenario development as a quantitative modelling exercise. The third dimension of scenarios refers to the level of complexity of their content. While simple scenarios may be limited to extrapolations of isolated trends, complex scenarios take a web of interrelated causes and effects into account. Exploring the many facets of tourism development, capturing different perspectives and opinions, and social learning are key components of the current research project. Therefore the scenarios developed in this project can be characterised as exploratory, intuitive, and complex (Amelung and Lamers, 2006).

Integrated participatory scenario development has been used in a number of scientific projects, most notably VISIONS - "Visions for a sustainable Europe" (Rotmans et al., 2000) and MedAction - "Policies for land use to combat desertification" (Kok et al., 2006). In the VISIONS project, scenarios were developed for Europe by integrating scenarios for three European regions. In the MedAction project, a similar methodological approach was applied at the Mediterranean scale level with regard to the problem of desertification. Typically, scenario processes consist of a number of steps:

- The identification of factors, actors and sectors important to the issue at hand;

- The elicitation of a wide range of possible landmark events in the future by using brainstorming techniques;

- The combination of trends, landmark events, and possible actor behaviour into 'snippets' or strings of events (storylines) that emphasise the relationships between a limited number of factors;

- The elaboration and recombination of storylines into full-blown scenarios;

- Discussion of the set of scenarios with the stakeholders, resulting in a set of modified scenarios; and

- Exploration of the opportunities and challenges that these scenarios pose to stakeholders, and identification of strategies to take advantage of them, adapt or mitigate them. 
The same steps were followed in this project. Figure 8.1 represents the different steps and shows the iterative nature of the scenario development and analysis process.

Figure 8.1: Steps in the scenario process

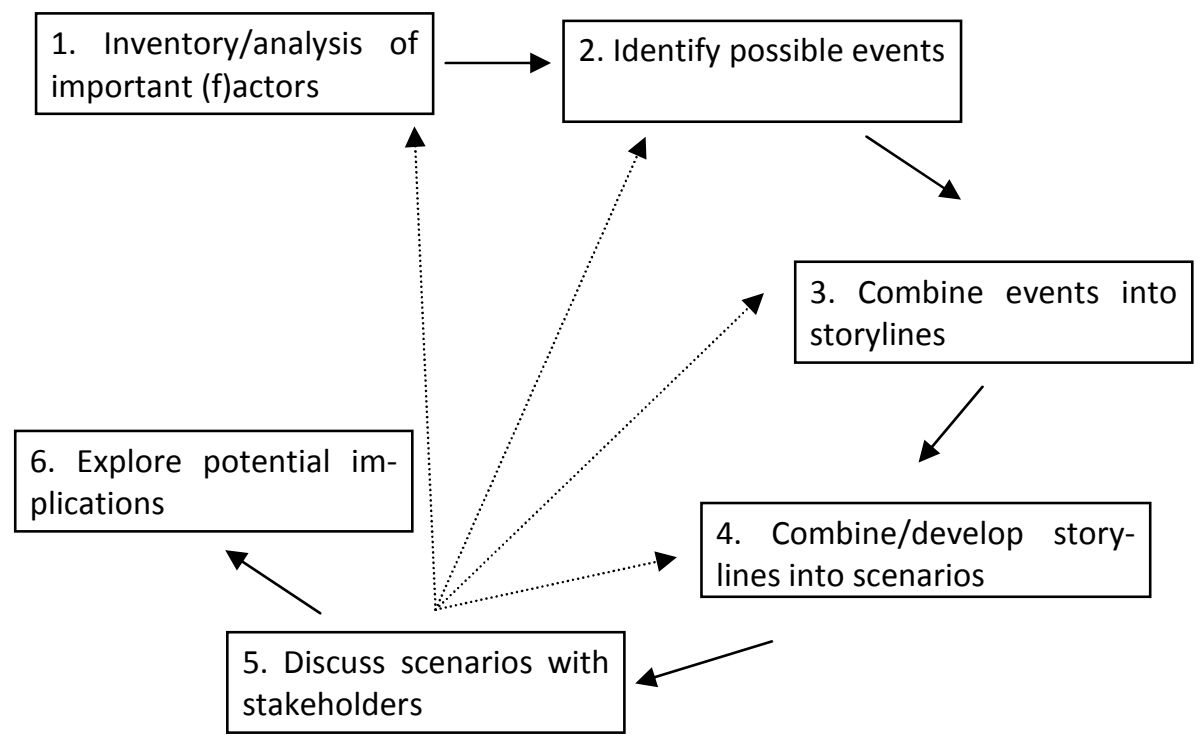

\subsubsection{DATA COLLECTION}

The material upon which the analysis of this chapter is based has been elicited during three future workshops and a literature review (see Table 8.1). Expert knowledge and judgment of the current and future development of Antarctic tourism and its implications resulted from three stakeholder workshops, including tour operators and expedition staff, policy makers, NGO representatives, managers of NAPs and Antarctic researchers, held in the Netherlands and New Zealand. Invitations to the workshop were sent out with a few months notice, accompanied by Antarctic tourism factsheets and (for the two later workshops) draft scenarios. A report providing details on the methodology, process and outcomes was prepared for each workshop. Draft workshop reports were sent back to the participants for revisions and consent before finalisation. In presenting workshop results reference will be made to the reports, which can be obtained from the authors (Haase and Lamers, 2006; Lamers and Amelung, 2006; 2007b).

Splitting up the scenario space can be done with the scenario axis technique (Van 't Klooster and Van Asselt, 2006). This technique defines a two-dimensional space made up of all plausible combinations of values that two influential and uncertain factors can assume within the time frame considered (Bischop et al., 2007) The greater the uncertainty, the larger the scenario space is, and the more room for 
distinct scenarios there will be. The selection of the defining factors is usually the result of the first phase in the scenario development process, when the key factors, actors and sectors are identified. The factor analysis performed in this study resulted in the conceptualisation of the Antarctic Tourism Opportunity Spectrum (ATOS) (see Figure 3.5). The model provides an integrated view on the factors that determine the opportunities for Antarctic tourism development, i.e. accessibility, other resource users, existence of tourist infrastructures, facilities and attractions, operational factors, acceptability of impacts, and regulation and management.

\begin{tabular}{|c|c|c|c|}
\hline Date: & Country: & Objectives of the workshops (scenario step): & \#: \\
\hline $\begin{array}{l}\text { Sept. } 29 \\
2005\end{array}$ & The Netherlands & $\begin{array}{l}\text { Identify important development factors (1) } \\
\text { Brainstorm of possible future events (2) } \\
\text { Develop future storylines in small groups (3) }\end{array}$ & 17 \\
\hline $\begin{array}{l}\text { April } 6 \\
2006\end{array}$ & New Zealand & $\begin{array}{l}\text { Identify important development factors (1) } \\
\text { Discuss draft future scenarios, assess feasibility and } \\
\text { desirability in small groups (5) } \\
\text { Identify policy, industry and NGO responses (6) } \\
\text { Address future challenges and concerns (6) }\end{array}$ & 21 \\
\hline $\begin{array}{l}\text { Sept. } 23 \\
2006\end{array}$ & The Netherlands & $\begin{array}{l}\text { Discuss draft future scenarios, assess feasibility and } \\
\text { desirability in small groups (5) } \\
\text { Explore implications for policy, identify policy solutions } \\
\text { (6) } \\
\text { Address future challenges and concerns (6) }\end{array}$ & 12 \\
\hline
\end{tabular}

\# Number of participants

Table 8.1: Overview of scenarios workshops

\subsubsection{INTERNAL AND CONTEXTUAL DEVELOPMENT FACTORS}

Just looking at factors internal to the Antarctic tourism system was not considered enough. Figure 3.5 indicates that contextual factors, such as global developments, influence the internal factors opportunities for future tourism development in Antarctica. To enlarge our understanding of global drivers and constraints a number of global scenario studies were analysed. However, a consistent set of global tourism development scenarios are also non-existent, with the exception of the twenty year projection of the World Tourism Organisation (WTO, 2001) and conceptual scenarios that do not provide practical insight (Weaver, 2000). Therefore, different sets of more general global scenarios were identified suitable for our purpose. Three criteria were used to select global scenarios: the scenarios need to be state of the art and recent; the scenarios need to provide a description of global developments, and the scenarios need to be relevant for Antarctic tourism. Based on these criteria two sets of scenarios were selected: the Global Environmental Outlook 4 (GEO4) scenarios of the United Nations Environmental Programme (UNEP, 2007) and the Millennium Ecosystem Assessment (MEA) scenarios (Carpenter et al., 2005). The Millennium Ecosystem Assessment presents four con- 
sistent global scenarios focused on the implications for ecosystems, and ecosystem services. GEO4 presents four global scenarios in which different interests are dominant, i.e. markets, policy, environment and sustainability.

In the MEA tourism and recreation, related issues are mainly used to illustrate possible implications for local ecosystems and in none of them implications for Antarctic, or polar ecosystems are included. The GEO4 scenarios contain a section describing the Polar Regions in which implications for the Antarctic Treaty System, climate changes, fisheries and wildlife are detailed. Overall, limited attention is given to either tourism or Antarctica, but both scenario studies provide important contextual input. Following Huynen who performed an integrated scenario analysis for globalisation and health, the global scenarios were clustered into four main scenario themes (Huynen, 2008). The four scenario themes differ along the lines of geographical orientation (i.e. globalisation versus fragmentation) and ethical orientation (i.e. market versus environment). An overview of the main characteristics, differences and similarities are given in table 8.2.

\begin{tabular}{|c|c|c|}
\hline Scenario theme & Variation in scenario outcome & Scenarios \\
\hline \multirow[t]{2}{*}{$\begin{array}{l}\text { 1. Globalisation } \\
\text { with a market } \\
\text { focus }\end{array}$} & $\begin{array}{l}\text { Low mitigation capacity of economic and } \\
\text { technological development; social and } \\
\text { environmental problems largely remain or } \\
\text { increase. }\end{array}$ & -Markets First (MF-GEO4) \\
\hline & $\begin{array}{l}\text { High mitigation capacity of economic and } \\
\text { technological development; social and } \\
\text { environmental problems largely decrease. }\end{array}$ & $\begin{array}{l}\text {-Global Orchestration (GO- } \\
\text { MEA) }\end{array}$ \\
\hline \multirow{2}{*}{$\begin{array}{l}\text { 2. Globalisation } \\
\text { with an environ- } \\
\text { mental focus }\end{array}$} & $\begin{array}{l}\text { Rapid progress towards sustainability; } \\
\text { wider-ranging societal transformation. }\end{array}$ & -Sustainability First (SuF-GEO4) \\
\hline & $\begin{array}{l}\text { Slow progress towards sustainability } \\
\text {-policy-driven approach with mixed results } \\
\text {-green technologies but neglect of social } \\
\text { issues. }\end{array}$ & $\begin{array}{l}\text {-Policy First (PF-GEO4) } \\
\text {-TechnoGarden (TG-MEA) }\end{array}$ \\
\hline $\begin{array}{l}\text { 3. Fragmentation } \\
\text { with a market } \\
\text { focus }\end{array}$ & $\begin{array}{l}\text { Threats of global terrorism, growing in- } \\
\text { come disparity, global migration, forces } \\
\text { wealthy nations to take protective meas- } \\
\text { ures and secure national resources. }\end{array}$ & $\begin{array}{l}\text {-Security First (SeF-GEO4) } \\
\text {-Order from Strength (OS- } \\
\text { MEA) }\end{array}$ \\
\hline $\begin{array}{l}\text { 4. Fragmentation } \\
\text { with an environ- } \\
\text { mental focus }\end{array}$ & $\begin{array}{l}\text { Human societies will focus more on learn- } \\
\text { ing about survival and adaptation to major } \\
\text { socio-ecological changes on the local level. }\end{array}$ & -Adapting Mosaic (AM-MEA) \\
\hline
\end{tabular}

Table 8.2: Global scenarios generally clustered by theme (adapted from (Huynen, 2008)

The ATOS model of Figure 3.5 functioned as a conceptual framework for the assessment, whereby changes for a range of development factors were analysed under influence of the global scenarios. The storylines developed and revised by Antarctic tourism stakeholders during the three workshops were coupled with the global scenarios, leading to four scenario groups (see Table 8.3). These scenario 
groups $(\mathrm{S})$ results in a matrix in which the relations are indicated on a five point scale from very negative relation (--), to neutral (+/-), to very positive relation (++). The storyline material from the workshops was used to analyse and flesh up this conceptual frame. In the following paragraphs, we will summarise the results of this exercise.

\begin{tabular}{|c|c|c|c|c|}
\hline FACTOR CATEGORY & S 1. & S 2. & S 3. & S 4 . \\
\hline 1) Accessibility factors & ++ & + & - & $+/-$ \\
\hline -Availability of expedition cruise ships & + & + & - & $+/-$ \\
\hline -Availability of large cruise liners & ++ & + & ++ & -- \\
\hline -Availability of infrastructure for air links & ++ & - & + & $+/-$ \\
\hline -Occurrence of information/media attention & ++ & + & - & -- \\
\hline -Ability of tourists to cover travel costs & ++ & + & - & $+/-$ \\
\hline 2) Relations with other users & ++ & + & - & + \\
\hline -Occurrence of logistical cooperation & + & $+/-$ & -- & ++ \\
\hline -Compatibility of tourism with other users & $+/-$ & ++ & -- & + \\
\hline 3) Presence of key attractions & ++ & - & + & - \\
\hline -Availability of interesting sites/wildlife & - & + & -- & ++ \\
\hline -Occurrence of adventure activities & + & + & $+/-$ & ++ \\
\hline 4) Presence of on-site facilities & ++ & - & + & $+/-$ \\
\hline -Availability of accommodation & ++ & - & + & $+/-$ \\
\hline -Occurrence of on-site managing facilities & + & -- & $+/-$ & + \\
\hline 4) Operational factors & $+/-$ & ++ & -- & + \\
\hline -High number and diversity of operations & ++ & + & - & + \\
\hline -Availability of quality staff and crew & - & + & -- & ++ \\
\hline -Level of self-regulation among operators & $+/-$ & ++ & -- & ++ \\
\hline 5) Acceptability of impact & ++ & - & ++ & -- \\
\hline -Occurrence of environmental impact & ++ & - & + & $+/-$ \\
\hline -Occurrence of human risk/SAR incapability & ++ & - & + & $+/-$ \\
\hline -Erosion of intrinsic value & ++ & - & ++ & $+/-$ \\
\hline 6) Regulation & - & ++ & -- & $+/-$ \\
\hline -Comprehensiveness of ATS regulation & - & ++ & -- & $+/-$ \\
\hline
\end{tabular}

Table 8.3: Scenario matrix defining some of the main differences between the scenarios 


\subsection{Four Antarctic futures}

\subsubsection{THE SKY IS THE LIMIT: GLOBALISATION WITH A MARKET FOCUS ${ }^{19}$}

In the GO-MEA and MF-GEO scenarios, the focus is largely global with commercial interests prevailing over other issues. In the GO-MEA scenario the tourism industry is mentioned as a victim of ecosystem degradation resulting from activities of other industries, as well as one of the culprits, especially in coastal regions. Industrialised lifestyles are promoted through travel and tourism and air travel becomes highly affordable for middle-income citizens around the world. Technological innovation, economic growth and urbanisation are very high in these scenarios. Invasive species and infectious diseases are affecting global tourism mobility. The GO-MEA and the MF-GEO differ in their elaboration of the role of global political cooperation and the scenario outcome.

Figure 8.2: The sky is the limit (@ZwaarWater) ${ }^{20}$

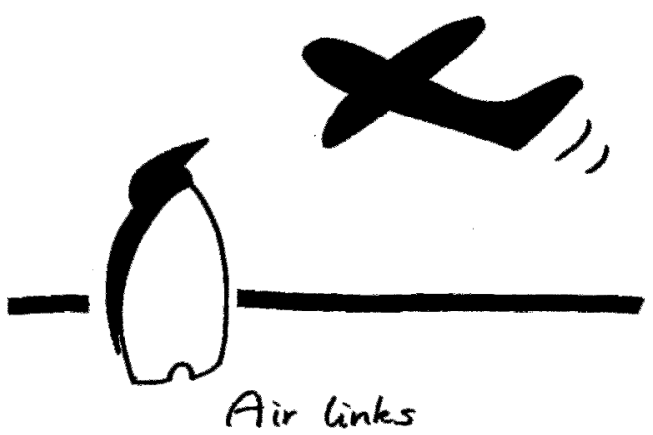

Conditions described in this scenario group provide excellent prospects for global tourism developments, including Antarctic tourism. Access will greatly improve as a result of growing global affluence, improved information and communication technology, affordable long haul travel, and improved infrastructure and transport technology. New tourist generating markets will be developed, including South America, China, India and Russia. Market forces will slowly open up the Antarctic for fisheries, mineral exploitation, and an increasing diversity of tourism ventures. A number of National Antarctic programmes privatise their infrastructures, making it easier for tour operators to acquire access to accommodation and air strips. Larger scale operations, such as cruise liners and large expedition ships, will eventually

\footnotetext{
${ }^{19}$ This scenario is based on the following storylines: "SOS Antarctica" (Lamers \& Amelung, 2006), "Increasing interest/high risk and incidents" (Haase \& Lamers, 2006), "The sky is the limit" (Lamers \& Amelung, 2007b).

${ }^{20}$ Cartoons presented in this chapter were created for this project by Esther Mosselman (http://www.zwaarwater.nl). Copyright of these cartoons remains with ZwaarWater, Amsterdam.
} 
prevail over smaller scale expedition cruise vessels. Small ships simply turn out to be less economical to build and operate in the Antarctic Peninsula. Land-based tourists will be catered in a series of eco-lodges, based on high environmental standards, and transported from and back to the South American continent by aircraft and ferries. On King George Island a passenger handling facility will be developed to organise the transfers. A wide range of adventurous and experiential tourist products is developed. Alongside cooperative corporate players, increasing numbers of private actors will be active beyond effective legal control, such as yachts and adventurers. Niche tourism operators will venture deeper into the Antarctic wilderness, while the opportunities for land-based tourism will increase because of the presence of new commercial resource users and available polar technology. Intrinsic Antarctic wilderness values will further erode as a consequence as the Antarctic is increasingly seen as a resource for man. Cumulative impacts are increasingly detectible on landing sites and near facilities due to larger scale operations. The current self-regulatory system will be overwhelmed and different industry segments will establish their own cooperative associations to guarantee safety and minimise environmental degradation. The changing scale and structure of the industry increases the risk of incidents and resulting impacts. Because of increasing human activities, the search and rescue capabilities within the Peninsula region will also develop substantially. On the longer term, climatic changes start to affect the Antarctic Peninsula more seriously, resulting in biodiversity loss and invasive species. Nevertheless, the acceptability of impact will be higher as a result of other industries with enormous impacts. The growing and diverging interests of different stakeholder groups creates increasing difficulties for the Antarctic Treaty System to come up with restrictive and binding measures to regulate tourism. Global commercial interest will gradually increase the number of members of the ATS; however, the tourism debate is pushed to the background. It is estimated that by 2030 approximately 250,000 tourists will visit Antarctica.

\subsubsection{BUSINESS AS (UN)USUAL: GLOBALISATION WITH AN ENVIRONMENTAL FOCUS ${ }^{21}$}

Three scenarios have been categorised under this theme, i.e. PF-GEO, SuF-GEO and TG-MEA. In these scenarios a globalisation trend is combined with a strong role of government to safeguard social and environmental quality, based on more equitable values and in some cases supported by new institutions. Global companies that pre-empt sustainability policies are seen as role models. Partnerships of business, NGOs and governments result in initiatives worldwide for the conservation of ecosystems and wildlife. Urban environments are reorganised to create more green spaces. Technological innovations will facilitate global travel and communication for civil society, global companies and organisations. A global climate policy is adopted that strongly mitigates greenhouse gasses and slows down the warming trends in the Polar Regions.

\footnotetext{
${ }^{21}$ This scenario is based on: "Polar Profit" (Lamers \& Amelung, 2006), "Increasing interest/low risk and incidents" (Haase \& Lamers, 2006), Business as Unusual (Lamers \& Amelung, 2007b).
} 


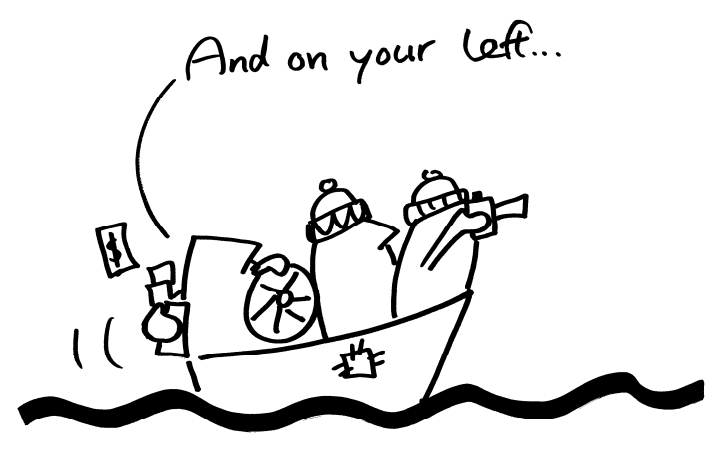

Both global tourism and the Antarctic environment will continue to bloom under this scenario. The media attention for climate change and polar science continues to keep the Antarctic on the radar screen of many consumers in the world. Economic growth in most Antarctic tourist generating markets will continue steadily. Tourist numbers will continue to grow as the global consumer becomes aware of Antarctic tourism products but activities will be more constrained and carefully controlled. Rising oil prices and a global climate change policy will contribute significantly to the travel costs of long haul tourists and mitigate some of the demand for Antarctic travel. Most consumers are put off by rising costs but a fair share is willing to pay for an unusual Antarctic experience. The Antarctic Treaty System recognises its responsibility in environmental protection and establishes high environmental and safety standards for both the tourism industry and national programmes

The modus operandi of the tourism industry will remain largely ship based and cooperation among operators will remain an important value. The fleet of current expedition cruise ships will be replaced by purpose built polar vessels with high eco-efficiency. The tourist industry will continue to diversify into different shipbased products and small-scale land-based activities. Further, cruise-only itineraries will develop alongside expedition cruising. Impacts of tourism remain fairly low as a result of pro-active management guidelines and effective emergency response. Pressure on industry self-regulation is mounting but through supporting policies of the ATS it remains an important vehicle for control in the field. Part of the revenues generated by tour companies are contributed to a fund managed by the ATS for monitoring impacts on Antarctic ecosystems and conservation projects. Antarctic tourists are increasingly seen as ambassadors for Antarctic conservation. The role of ATS policy increases with active monitoring programmes and strategic policies, enforced by a combination of industry self-regulation and government observers. By 2030 , around 150,000 tourists visit Antarctica. 


\subsubsection{Cold hostage: FragmentATION With A MARKET FOCUS ${ }^{22}$}

In the SeF-GEO and OS-MEA scenarios, the world becomes compartmentalised resulting from an inward and nationalistic focus in response to threats of global terrorism, migration from developing countries, and resource protection. The liberal democratic nation is considered the best protection against these threats and wealthy nations are securing their natural resources and citizens from outside influences by closing the borders. National security measures in the rich countries will not be beneficial for the global tourism industry, because of reduced mobility and degradation of natural attractions due to lack of funds. A new world order arises of three blocs: the Americas, Europe and Africa, and Asia.

Figure 8.4: Cold Hostage (@ZwaarWater)

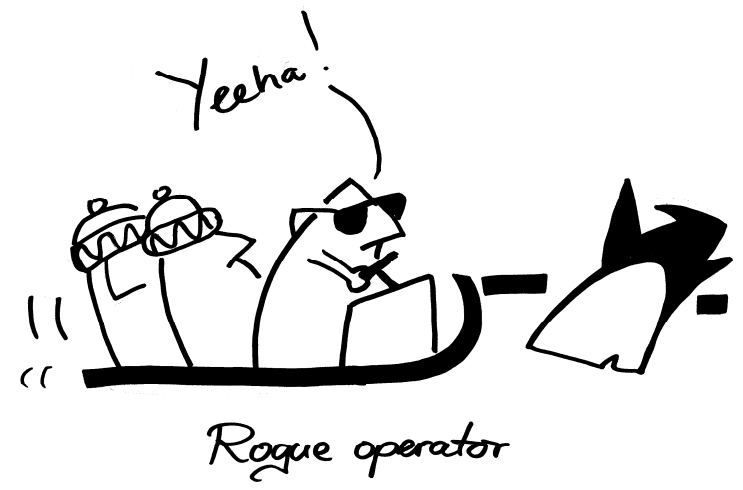

In the first decade tourist numbers and diversity of activities will further increase to 100,000 by 2015 . Large global cruise companies are buying out smaller expedition cruise operators. Eventually smaller vessels disappear from the scene and are being replaced by larger and more luxurious cruise vessels. A growing number of large cruise ships start making landings and omit the self-regulatory framework of the industry association. This leads to increased risks for environmental impact and safety risks. During the second decade access to Antarctica will decline as a result of rising fuel costs and national protection measures by some of the claimant gateway states. Antarctic Treaty Parties start grappling with the enormous resources that are stored in the Antarctic, including oil and fresh water. A number of large multinationals, including a few tourism companies, manage to secure access by negotiating with the respective governments. This has major implications for the Antarctic Treaty System that eventually collapses under the rivalry between claimant states, and between claimant and non-claimant states. This whole develop-

\footnotetext{
${ }^{22}$ This scenario is based on: "Negotiation" (Lamers \& Amelung, 2006), "High environmental awareness, low risk and incidents" (Haase \& Lamers, 2006), "Go large, go small, or go home" (Lamers \& Amelung, 2007b).
} 
ment will lead to a major media campaign of environmental NGOs. Fishing and mineral exploitation takes off leading to permanent infrastructures and residence of workers. Tourism companies will be given certain sectors of the Peninsula region where they can undertake their activities without disturbance from the other resource users. Other resource uses will prevail over tourism activities in terms of economic power. However, elite groups from the rich northern countries will most likely continue to be interested by Antarctic niche tourism products, such as smallscale land-based activities or expedition cruising. Permanent residence in the Antarctic becomes status for some of the worlds wealthiest. Due to the presence of more exploitative industries, the acceptability of impacts will increase. By 2030, around 75,000 tourists are visiting Antarctica.

\subsubsection{SPECIAL INTEREST TOURISM: FRAGMENTATION WITH AN ENVIRONMENTAL FOCUS ${ }^{23}$}

In the AM-MEA scenario, human societies will focus more and more on learning about human survival and adaptation to major socio-ecological changes on the local level. On the one hand, trade barriers will increase. On the other hand, information and communication barriers will disappear as a result of innovations in information technology. The role of civil society grows and the emergence of partnerships between NGOs and industry, and NGOs and governments.

Figure 8.5: Special interest tourism (@ZwaarWater)

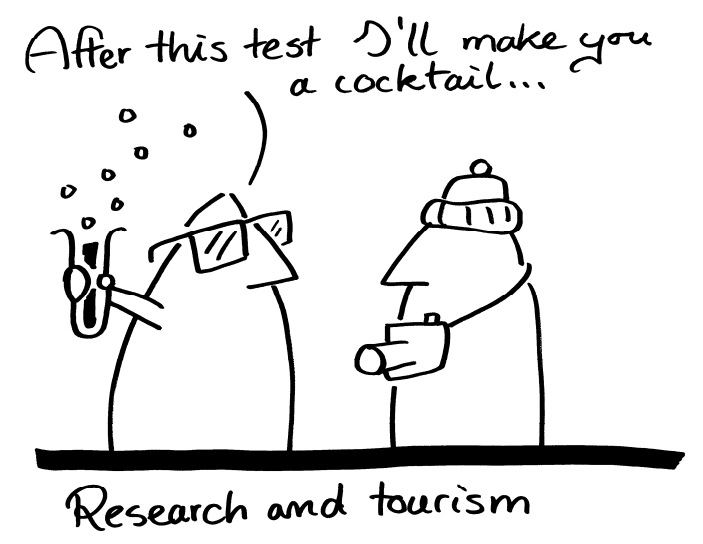

In this scenario, Antarctic issues, including tourism, will continue in its current state without much influence from global drivers. Tourist numbers will initially grow to 60,000 by 2015 , slowly balance out and decline in the years after. No major investments are made in tourism infrastructure and logistics. The main operational modus remains a combination of small-scale ship-based and land-based activities. Media attention for Antarctica will fade. In addition, for some countries Antarctic

${ }^{23}$ This scenario is based on: "Special interest tourism" (Lamers \& Amelung, 2007b). 
science will seize to exist, as nations are more focused on regional cooperation. For the science programmes that stay, cooperation with tour operators is essential to secure affordable and effective logistics. Smaller-scale Antarctic tourism niche products, both ship-based and land-based, will increase the prices significantly and will be affordable only for rich and purist travellers. As no major international regulatory efforts are made, self-regulation will be the key, with a continued important role for an industry association in managing tourism and other non-governmental activities. By 2030, around 50,000 tourists are visiting Antarctica.

\subsection{Stakeholder responses}

The scenario analysis in the previous section consists of a treatise of possible future developments. The aim was to formulate these scenarios as neutral as possible. During the second Dutch workshop and the New Zealand workshop participants were asked to comment on the consistency of storylines and suggest improvements. These improvements were subsequently incorporated in following drafts of the scenarios. Besides the quality of the scenarios itself, participants were asked to provide their views on the plausibility and the desirability of the scenarios, and suggest policy options to steer the scenarios into a more desirable outcome. Since the analysis in section 8.3 represents a synthesis of a range of storylines developed by Antarctic tourism stakeholders as well as global scenarios based it is difficult to discuss participants' responses per scenario group in detail. In the following paragraphs we will outline the main results of these sessions (Haase and Lamers, 2006; Lamers and Amelung, 2006; 2007b). An overview of stakeholder responses to individual storylines per scenario group is provided in Table 8.4.

Table 8.4: Overview of responses per scenario group

\begin{tabular}{|c|c|c|c|c|}
\hline $\begin{array}{l}\text { Response } \\
\text { category }\end{array}$ & Scenario 1 & Scenario 2 & Scenario 3 & Scenario 4 \\
\hline Plausibility & Plausible & Fairly plausible & Partly plausible & Fairly plausible \\
\hline Desirability & Undesirable & Fairly undesirable & Undesirable & Partly desirable \\
\hline $\begin{array}{l}\text { Policy op- } \\
\text { tions }\end{array}$ & $\begin{array}{l}\text {-Prohibition of } \\
\text { land-based facili- } \\
\text { ties; } \\
\text {-Cap tourist } \\
\text { numbers; } \\
\text {-Long term moni- } \\
\text { toring; } \\
\text {-Establishing } \\
\text { zones }\end{array}$ & $\begin{array}{l}\text {-Intensified dia- } \\
\text { logue between } \\
\text { actors; } \\
\text {-Cap tourist } \\
\text { numbers and ship } \\
\text { sizes; } \\
\text {-Increase moni- } \\
\text { toring effort } \\
\text { financed by levy } \\
\text { system; } \\
\text {-Discourage air } \\
\text { links }\end{array}$ & $\begin{array}{l}\text {-Reinforce the } \\
\text { ATS: increasing } \\
\text { signatories } \\
\text {-Increase ATS } \\
\text { responsibility: } \\
\text { Annex to the } \\
\text { Protocol } \\
\text {-Restrict ship size } \\
\text { and numbers of } \\
\text { ships } \\
\text {-Establish zones }\end{array}$ & $\begin{array}{l}\text {-Strict (binding) } \\
\text { guidelines for } \\
\text { activities } \\
\text {-Establishing } \\
\text { zones }\end{array}$ \\
\hline
\end{tabular}




\subsubsection{PLAUSIBILITY}

Overall, draft scenarios were qualified as plausible to fairly plausible. In almost all of the scenarios growth of different variables is mentioned, such as tourist numbers, ship numbers, ship sizes, business sizes. Growth is generally seen as inevitable during both workshops. Remarkably enough, under the given assumptions, the most extreme storyline ("The sky is the limit") was considered most plausible during both workshops. The other scenarios, on the other hand, received more criticism from the participants. In fact, growth rates portrayed in storylines were in many cases seen as being too modest. For example, during the second Dutch workshop tourist numbers in 2015 for the "Business as unusual" storyline were considered too low and adjusted from 65,000 to 120,000 . In terms of the changing form of tourism in the various scenarios, it was argued that a continued diversification of industry segments, logistical modes and activities is most plausible. Different segments of the industry would be working merely next to each other, as opposed to replacing (outcompeting) each other. For example, the development of permanent land-based facilities and infrastructure was seen as fairly plausible. It was also remarked that such as development would be difficult, due to high development costs and the strong resistance of several ATCPs.

\subsubsection{DESIRABILITY}

Although fairly plausible, most storylines were generally not considered desirable by the workshop participants. The growing scale and form of tourism activities were anticipated to lead to major impacts for the environment, risks for human safety and implications for science programmes. "The sky is the limit" was not considered desirable due to vast scale of Antarctic tourism developments that are assumed, which would be posing major impacts. Together with the "Cold Hostage" scenario, it was also considered undesirable because of the inability of the regulatory system to control tourism developments, and the major transition both scenarios imply in the way the Antarctic continent and human activities are perceived. Particularly the development of land-based tourism is seen as undesirable in both scenarios. The "Business as unusual" scenario, which assumes a sustainable environmental outcome, was not considered desirable because of the sheer number of tourists visiting Antarctica. The "Special interest tourism" scenario was considered not necessarily undesirable, if negative impacts from activities can be sufficiently mitigated. The development of tourist air links was not considered desirable, as it implies the construction of facilities.

Overall, the workshop participants pointed to the degradation of Antarctic ecosystems and the loss of unique wilderness values as important reasons for this assessment. Concern was also raised about potential conflicts between different users of the Antarctic. Interesting regions and sites for tourism can also be sites of importance for scientific research and essential habitats for wildlife or other ecosystem functions. Increasing tourism activities might lead to the unfortunate demise of others. An important observation from the New Zealand workshop is that 
future perspectives of stakeholders (e.g. tour operators, NAPs, Antarctic Treaty Parties, and NGOs) may not be as uniform as one might expect. The relative clarity and coherence that currently characterises these stakeholder groups may very well dissolve in the future, contributing to an additional level of uncertainty (Haase and Lamers, 2006). For example, the ability of tour operators to self-organise the various development strands raised in the scenarios was questioned (see also chapter seven). It was felt that it seems as if they try to cater for everybody operating in the Antarctic, resulting in a lack of clarity about what their position is. This might lead to difficulties in the future with an ever-growing diversity of operator's needs. For example, the emergence of more than one self-regulatory organisation is generally seen as very plausible. It depends on the standards set by, and the enforceability of, the ATS whether this would be desirable or not.

Several of the scenarios were considered not compatible with the Environmental Protocol and regarded as a failure of the ATS to control tourism (or human activities in general) and damaging the legitimacy of the ATS. It was stressed during both workshops that perhaps the largest challenge of future tourism is political. Participants mention that claimant states tend to see tourism either as an opportunity or as a threat. It is believed that in some of the scenarios the conflict between states that want to discourage further tourism development and states with a growing tendency to become tour operators themselves would certainly aggravate.

\subsubsection{POLICY RESPONSE}

Various policy responses were identified as an appropriate way to steer the development in a more acceptable direction and to mitigate some of the expected negative effects (see table 8.4). Overall, participants supported the ongoing development and monitoring of site-specific guidelines by IAATO and ATCPs. This way, on the short term, cumulative impacts on frequently visited landing sites can be managed in a non-binding way. It was argued that the ATS should take more responsibility in setting standards for tourism operation. It was felt that a good start would be to codify important non-binding bylaws of IAATO into binding measures (see chapter seven). In 2007 at the ATCM in New Delhi a start was made by codifying a range of bylaws by means of a non-binding resolution. During the 2009 ATCM in Baltimore, the same operational rules were adopted by the ATCPs by means of a binding Measure. Participants of the workshops urged the ATS to take a more proactive approach towards Antarctic tourism. One way of doing that is by developing a strategic vision on tourism in Antarctica on the desirable and undesirable aspects of future development. Zoning instruments were suggested in nearly all of the scenario discussions as a useful way to manage the growth and diversity of tourism in a limited number of suitable areas. At the same time, areas can be set aside to safeguard wilderness values and prevent disturbance of ecosystems and scientific research activities. In addition, for several of the scenarios restrictive policies are proposed on tourist numbers, ship numbers, ship sizes, and restrictions on the development of permanent land-based facilities (see Table 8.4). It is further argued 
that in order to administer restrictive measures a more comprehensive legal structure would be desirable, such as a Tourism Convention or an Annex to the Protocol (see also Haase, 2008).

\subsection{Discussion}

The history of Antarctic tourism cannot be seen as a linear trend but is characterised by unpredictable feedback effects, events and incidents (McKercher, 1999; Russell and Faulkner, 2004). Nobody could foresee the surge in availability of icestrengthened vessels for the tourism market after the collapse of the Soviet Union. It is widely attested that the availability of ships has been driving the development of tourism in the 1990s. Tour operators and policy makers have been confronted with accidents, causing impacts for science programmes or Antarctic ecosystems, such as the sinking of the Bahia Paraiso in 1989. The recent sinking of the $M / S$ Explorer has instigated a discussion about the future of tourism in Antarctica (Scully and IAATO, 2008). Nobody knows what might happen if a large cruise liner would sink in the Antarctic, or if it is possible to stop a large international hotel chain from building a hotel in the Antarctic (see chapter six). Like Captain James Cook, we will probably never be able to fully understand the scale of consequences of these uncertain discontinuities (Van Notten, 2005). Nevertheless, through scenario analysis we can start to identify important future challenges and uncertainties.

The different scenario outcomes presented in section 8.3 emphasises the fact that Antarctic tourism is not a closed regional system, but a global industry influenced by contextual developments. This makes the Antarctic tourism system volatile for global change, such as economic growth or decline, water and energy shortages, climate change, and climate change mitigation policies (Amelung and Lamers, 2007). GEO4 scenarios even suggest that global drivers could eventually collapse the Antarctic Treaty System. Biological invasions and the spread of disease (Frenot et al., 2005), might have a great influence on the destiny of Antarctic tourism development. Growing affluence (in all scenarios), growing world populations, ageing (in all scenarios), and technological innovations are believed to drive this growing demand. It is generally expressed that in terms of potential tourist demand the limits have not been reached, both in the traditional and in potentially new Antarctic tourist markets. The supply side of tourism is also highly influenced by contextual factors, such as corporate take-overs, marketing, energy prices, and media attention. It has to be noted that besides opportunities, contextual factors can also lead to major constraints for tourism development. Examination of the annual IAATO seasonal outlook indicates that the current global economic recession is a good example of this (IAATO, 2009).

Nevertheless, a prominent feature in most scenarios is the increase in tourist arrivals. This resonates in the observation that workshops participants often suggested that storylines were not extreme enough in terms of the form and rate of expected 
tourism development under given assumptions. However, the growth rates vary substantially between the scenarios. It is also uncertain whether expected growth leads to an increased concentration of activities in current hotspots or a spread of activities over the Antarctic region. Many participants expressed their concern for cumulative impacts resulting from tourism growth or catastrophic incidents. These concerns are also articulated by stakeholders and academic authors independent from the workshops (ASOC, 1999; 2008). Increased tourism activities in the Antarctic in combination with global environmental change (e.g. climatic changes, invasive species) may cause multiple stressors for ecosystems and major uncertainty in terms of effects.

Growth does not necessarily mean more of the same. The nature or form of tourism activities and tourism logistics in Antarctica vary substantially between the scenarios; from medium sized expedition vessels to large cruise liners and from ship-based to land-based tourism, serviced by air links. A general tendency is that more multinational tourism companies are active in the Antarctic. Smaller scale niche markets may develop offering adventure tourism activities or special interest activities, such as yachts. If new forms of tourism entail negative impacts for Antarctic ecosystems, wilderness values or scientific research is uncertain and cause for concern. For example, it was suggested that different forms and larger scale tourism activities might bring tourists and tour operators that are not as dedicated to the ecological integrity of the Antarctic as the present ones. This observation is also found in the literature (Hummel, 1994), and highlights the potential need for future visitor management (Page, 2003).

Some of the scenarios allude to the inherent tensions in the structure of the tourist industry by featuring 'rogue entrepreneurs' that upset the self-regulatory system or work outside of ATS regulations (Molenaar, 2005). Strict self-regulation measures increase the incentives for tour operators to withdraw from IAATO or to refrain from joining in the first place (see chapter seven). The scenarios address the challenge of self-regulation to maximise compliance, while minimising the risk of defection.

Stakeholder responses to the scenarios generally suggest that a more active involvement by the Antarctic Treaty System is warranted, starting with the development of a strategic vision on tourism in Antarctica (Bastmeijer and Roura, 2004; United Kingdom, 2008). Scenario development can support this process, by exploring salient uncertainties and incorporating a broad range of stakeholders and perspectives. Scenarios provide a framework for discussing the implications of a wide range of plausible future developments and the effectiveness of different responses to address them. The "what-if" exercises that are made possible by scenarios do not decrease the fundamental uncertainties in any way, but they allow policy-makers and stakeholders to explore and prepare for a wide range of eventualities (Greeuw et al., 2000; Swart et al., 2004). Taking into account our shortsightedness regarding the future and the rapidly changing Antarctic tourism scope urges 
for regular future assessments if we want to safeguard a proactive policy for Antarctic tourism.

Scenarios remain stereotypical depictions of the future. In fact, multiple scenarios could be occurring at the same time depending on your perspective. The main purpose of scenario discussions is to exchange and learn from each other's perspectives. During the scenario workshops, in which a variety of stakeholders participated, there was a remarkable consensus among participants about the desirability of future tourism developments. Storylines were developed and analysed on the collective level of the workshop participants instead of the individual or sectorlevel interests of a particular stakeholder. Many important issues in the development of Antarctic tourism can potentially be anticipated using scenarios, but we have to acknowledge that simultaneously many factors remain uncertain and unexplained. The global scenarios, particularly the GEO4 scenarios, used in this study were designed to address trends in issues of poverty and inequalities of resource access. In many global scenarios, human societies are facing major problems whereby tourism, especially to destinations like Antarctica, would be the last thing on people's minds. This study could have benefited enormously from a consistent and plausible set of global tourism scenarios, but this is currently missing from the literature. We feel that developing and analysing global tourism scenarios would be worthwhile and certainly be a research recommendation coming from this study.

\subsection{Conclusion}

The integrated scenario analysis described in this chapter shows that the future of Antarctica is very open and holds many uncertainties and strategic challenges regarding the development of tourism. We believe the global scenarios analysed in the previous section have proven valuable in the context of Antarctic tourism for analysing uncertainties and risks that might become more prominent in the future. Such uncertainties include the rate of tourism development, the development of land-based tourism infrastructures and air travel, the appearance of rogue operators, and the robustness of industry self-regulation and the ATS.

The integrated scenario analysis also elicited stakeholder perspectives on these future challenges of those participating in the workshops. Many of the developments described in the scenarios were assessed both as plausible and undesirable. Participants clearly stressed the need for strengthening existing policies and developing additional policies responding to the issues raised by the scenario analysis. The ATS is currently exploring ways to address many of the risks and changes presented in this chapter in the form of a strategic vision for Antarctic tourism. In the next chapter, we will present a more elaborate examination of perspectives on Antarctic tourism governance and potential policy options. 
Policy makers and other stakeholders have to realise that change is underway: scenarios can be used to anticipate to changing conditions. Scenario analysis can assist in the development of a strategic vision and a proactive approach by setting policies and limits that will safeguard intrinsic Antarctic values and ecosystems for future generations. 


\section{Chapter 9}

\section{SUSTAINABLE TOURISM IN ANTARCTICA? PERSPECTIVES, POLICIES AND PROSPECTS}

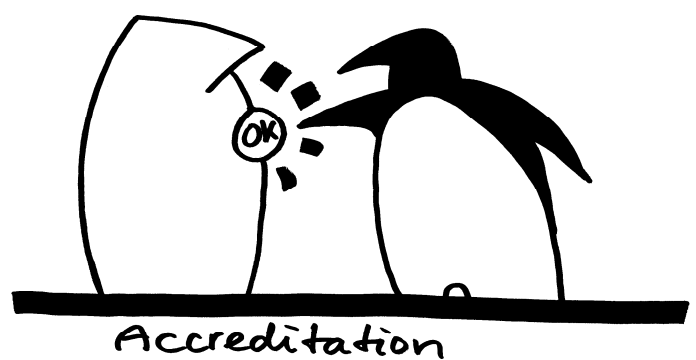

This chapter is based on:

Lamers, M., Amelung, B. (submitted). Sustainable development of tourism in Antarctica: conceptualization, perspectives and ways forward. In: Grenier, A. and Muller, D. Polar Tourism: A Tool For Regional Development? Montreal: Les Presses de l'Université du Québec (PUQ). 


\subsection{Introduction}

In the previous chapters, a number of potential impacts have been explored relating to future tourism on the environment, on human safety, on corporate and state governance structures, and on intrinsic wilderness values. Integrated analyses of opportunities and constraints, development trends and plausible future scenarios have offered a more thorough understanding of where tourism could be heading. The growth and diversification of tourism in Antarctica has triggered concerns about the sustainability of this development. In a number of chapters, different perspectives have been discussed relating to the sustainability challenges posed by tourism development. To close the circle of this investigation we will link these challenges to the perspectives of a wider group of present Antarctic stakeholders.

Recent policy discussions at Antarctic Treaty Consultative Meetings (ATCMs) reflect a range of concerns and focus on the need for additional instruments and measures to mitigate some of the negative effects of tourism, such as site-specific guidelines and shipping standards. Recently, the tourism industry and a number of Antarctic Treaty Parties have taken up this idea of a strategic tourism policy vision in which fundamental issues can be clarified (Antarctic Treaty System, 2008; Scully and IAATO, 2008; United Kingdom, 2008). Through this vision, the focus of sustainable tourism development in Antarctica can be determined and policies can be developed to deliver this vision. Some recent work has been done on stakeholder perspectives on the compatibility of science and tourism (Stewart et al., 2006) and on the effectiveness of the current regulatory system (Haase et al., 2007). A similar perspective based analysis has never been performed in using the sustainable development concept.

This chapter aims to contribute to the development in Antarctic tourism policy. It addresses the following question: How do perspectives of different Antarctic tourism stakeholders link with the concept of sustainable tourism, and what are the implications for tourism governance? By presenting interview material, the perspectives of different stakeholders on these policy challenges are analysed leading to recommendations for Antarctic tourism policy.

\subsection{Methodology}

\subsubsection{DATA}

A perspective-based assessment of Antarctic tourism policy requires in-depth knowledge about the tourism industry and its activities, as well as the regulatory context. It also requires broad knowledge of the perspectives of key stakeholders. The academic Antarctic tourism literature and Antarctic Treaty System (ATS) documents provide a wealth of information, but they lack crucial insights, in particular 
on stakeholder perspectives of emerging strategic issues. Complementary to the literature analysis, qualitative data was therefore obtained through stakeholder interviews. A total of seventeen interviews were conducted with international stakeholders and experts in Europe, North America and South America. During the interviews, a semi-structured interview guideline (see appendix of this thesis) was used reflecting emerging strategic issues in Antarctic tourism, such as the increasing scale of industry, new forms of tourism, the compatibility with activities of other user groups and intrinsic Antarctic values, and the options for future governance. Interviews were audio-recorded, transcribed, and sent back to the interviewees for revisions and approval. To maintain the confidentiality of the data interviewees remain anonymous and a coding system will be used to refer to interview results (for details see Table 9.1).

Table 9.1: Overview of interviewees

\begin{tabular}{|l|l|l|l|}
\hline Coding & Category & Profile & Date \\
\hline O1 & Organiser & Sales/marketing director of cruise company (<200) (USA) & $16-06-2007$ \\
\hline O2 & Organiser & Upper-level representative of industry association (USA) & $07-06-2007$ \\
\hline O3 & Organiser & Expedition leader of cruise company (<200) (Netherlands) & $27-11-2006$ \\
\hline O4 & Organiser & Expedition leader of cruise company (> 500) (USA) & $22-06-2007$ \\
\hline O5 & Organiser & Director of cruise company (<200) (Canada) & $12-06-2007$ \\
\hline O6 & Organiser & Director of Antarctica cruise agent company (Argentina) & $19-02-2008$ \\
\hline M1 & Monitor & Antarctic tourism researcher and penguin expert (UK) & $06-06-2007$ \\
\hline M2 & Monitor & Antarctic tourism researcher and university lecturer (UK) & $08-06-2007$ \\
\hline M3 & Monitor & Environmental officer for NAP (USA) & $14-06-2007$ \\
\hline M4 & Monitor & Logistical director for NAP (USA) & $14-06-2007$ \\
\hline M5 & Monitor & Environmental officer for NAP Argentina) & $18-02-2008$ \\
\hline M6 & Monitor & Antarctic legal expert from (Netherlands) & $18-02-2005$ \\
\hline R1 & Regulator & Antarctic policy maker from USA & $13-06-2007$ \\
\hline R2 & Regulator & Antarctic policy maker from Chile & $15-01-2008$ \\
\hline R3 & Regulator & Representative of Antarctic Treaty System (Netherlands) & $19-02-2008$ \\
\hline R4 & Regulator & Representative of Antarctic Treaty System (Argentina) & $19-02-2008$ \\
\hline R5 & Regulator & Antarctic policy maker (UK) & $14-04-2005$ \\
\hline
\end{tabular}

\subsubsection{ASSESSMENT FRAMEWORK}

To analyse the stakeholder interviews an assessment framework is needed that encompasses a wide range of perspectives on development and regulation of tourism. As shown in chapter two, sustainable development is a contested notion, characterised by normativeness, subjectivity, ambiguity and complexity (Grosskurth and Rotmans, 2005). As a result, there is much room for interpretation and multiple perspectives on sustainability issues. A useful model has been developed by Hunter (1997), for analysing interpretations of tourism development within the 
weaker and stronger sustainability continuum. Weaker sustainability is humancentred, focusing on efficient resource use (i.e. conservation) and relying on technological innovations for meeting sustainability standards. Stronger sustainability is eco-centred, focusing on absolute limits of resource use (i.e. preservation) and relying on policy restrictions and changing human demands for meeting sustainability standards (Robinson, 2004; Williams and Millington, 2004).

Characteristics of each of the two sides of the continuum focus on different objectives and can be justifiably used by stakeholders in different contexts. Hunter (1997) defines four basic interpretations of sustainable tourism, whereby the first interpretation is focused towards weaker and the fourth interpretation towards stronger sustainability:

- Sustainable development through a "tourism imperative" is heavily skewed towards the fostering and development of tourism: environmental and social concerns are much less pressing. Tourism could contribute to sustainable development in destinations where it could replace or preempt economic activities that are heavily degrading the environment and contributing little to the livelihood of local communities.

- Sustainable development through "product-led tourism" focuses on developing new and maintaining existing tourism products, with environmental and social concerns being important as long as they sustain these products. This approach is most easily justified in tourist destinations that have become heavily dependant on tourism income.

- Sustainable development through "environment-led tourism" prioritises environmental concerns over marketing opportunities. The aim would be to promote types of tourism, which specifically rely on the maintenance of a high quality natural environment. Regulation and encouraging the greater use of waste-free technologies by tourism businesses are important.

- Sustainable development through "neotenous tourism" actively and continuously discourages the development of tourism on ecological grounds. The aim would be to keep tourism to juvenile stages of tourism development.

Depending on the interests of stakeholders, these four basic orientations of tourism development and policy may be deemed acceptable or unacceptable in the eyes of stakeholders. Applying this adaptive conceptualisation, allows for a more thorough understanding of different perspectives on sustainable tourism policy and potential governance options.

In embedding this model into the tourism literature Hunter also refers to (sub)Antarctic tourism literature (Hall and Wouters, 1994; Sanson, 1994), but only in explaining the third and fourth perspective category. On first glance, these two orientations fit most naturally to the Antarctic tourism case with its reliance on 
unspoilt wilderness (see chapter seven). Since permanent human population is absent in Antarctica, tourism's contribution to a sustainable local livelihood or economy is less pertinent (Molenaar 2005). The goal of sustainable development in Antarctica, including the role of tourism, is therefore less focused on human development than in other destinations. However, the perspectives of the stakeholders that are present in Antarctica do include elements of the first two orientations on the role of tourism in meeting present and future generation human needs (World Commission on Environment and Development 1987). The absence of sovereign government over local and regional territories makes the Antarctic tourism case even more different from other tourism destinations. Tourism policy of the ATS is focused primarily on setting environmental and safety requirements under which tourism operations are allowable, and not on stimulating tourism development (or specific tourism products) through subsidies or tax policies. For individual ATCPs or NAPs, however, this can be different (see chapter six). An important question is to what degree we can formally control, regulate and restrict tourism development (see chapter two). To what degree are we dependent on the benevolence of stakeholders to cooperate?

In the following section, different stakeholder perspectives on the sustainability objective of tourism in Antarctica will be presented, largely following Hunter's model. Section four will present stakeholder perspectives on the capability of the current regulatory regime to control tourism development; section five presents the views of the interviewees on a number of policy directions. Based on this analysis of perspectives section six explores the prospects for sustainable Antarctic tourism, and section seven concludes this chapter.

\subsection{Perspectives on sustainable Antarctic tourism}

Protection of the Antarctic environment and ensuring human safety are claimed to be a key principles of tourism development of all interviewees (United Kingdom 2009). The designation of Antarctica as a nature reserve through the Environmental Protocol and the common interest of all stakeholders to maintain the remote and pristine condition of Antarctica makes that, in general, this is not surprising. Nevertheless, there are notable differences in the way the interviewees interpret these objectives and see the role of tourism in relation to these principles.

\subsubsection{A TOURISM IMPERATIVE}

The first perspective in Hunters model prioritises the development of tourism over other types of human development or resource uses to pre-empt developments that are potentially worse and prevent detrimental impacts arising from it. In this perspective, the advantages of tourism development are seen as a ground for stimulating tourism development. As noted, the extent to which tourism activities, or other human activities, contribute towards the local community is less prominent. Nevertheless, views fitting this perspective do exist. The question is to what 
degree activities are beneficial to the international community. Interviewees with perspectives that fit in this category perceive tourism largely as an innocent and harmless activity, especially when compared to other potential human activities in the Antarctic such as mining, oil and gas exploration. Active encouragement to create viable and sustained economic activity through policy is seen as not necessary; but tourism is seen as an activity that should not be restricted as it raises public awareness and contributes to the protection of Antarctica.

"The ideal state in 25 years (...) is for tourism to be the most important thing going on in the Antarctic, along with science of course. For tourism to be the only industry there. That the continent is kept for peace and science. Do you want to ensure peace? Bring more tourists" $(05,2007)$.

It has been argued that tourism plays an important watchdog role in the Antarctic $(05,2007)$, and has democratised Antarctic issues by making them visible for world's tax paying citizens. Related to this watchdog role is the claim that visitors of the Antarctic may become active in protecting the continent, the surrounding Southern Ocean and its marine life, from negative impacts caused by human activity. Some claim that the clean up of many Antarctic research stations was partly fuelled by reports and photographs of influential tourists of environmental degradation around scientific stations (Times Online, 2003). Lars Lindblad, the first expedition cruise operator, famously quoted: "You can't protect what you don't know" (Landau, 2001; Maher et al., 2001). It is argued that tourism creates a critical mass of ambassadors for the Antarctic that are more aware and will become active in Antarctic conservation (Powell et al., 2008).

The Antarctic Treaty System has been designed for maintaining peace and the conduct of scientific research; therefore science is generally seen as having priority over other human activities (Hemmings and Roura, 2003). In addition, the societal relevance of science is considered to be greater than that of tourism (R1, 2007). Although this prerogative is accepted by almost everyone, tourism operations have been compared on several occasions with science operations and ranked superior in terms of environmental impact and environmental management practices (Headland, 1994; Riffenburgh, 1998). Many interviewees consider the environmental performance of tourism better than science operations (02, 2007; 06, 2008), for example in the case of preventing introductions of invasive species through boot washing. Differences can be explained by the permanent land-based presence of science operations, the considerably longer duration of stay, and the more direct interaction with the physical and natural environment. Despite that tourism and science are inherently different activities; it is widely believed that they should be held to the same environmental and safety standards. Tour operators tend to use some of the more notorious cases of environmental degradation of NAPs as a reference to proof the quality of environmental management undertaken by the current generation of tour operators. 
"What we see is that many people equate the increase in numbers of tourists with environmental impacts. They think that going ashore is a bad thing. It is nothing compared to National Programmes people driving up and down the road in big trucks at King George Island" (02, 2007).

The interview material contains several examples of views that fit into this first orientation in which tourism developments are justified by replacing or preempting activities that are considered devastating for the resource or environment. Interviewees perceiving tourism as a relative innocent industry, as performing a watchdog role and a creator of ambassadors for protecting the Antarctic environment against other current and potential activities that are seen as more destructive (e.g. science, fisheries, mining, hydrocarbons extraction) fit into this category. Chapter eight demonstrates that future resource exploitation would not be inconceivable. Our material suggests that tour operators predominantly express these views.

\subsubsection{PRODUCT LED-TOURISM}

The second perspective in Hunter's model regards the development of existing and new tourism products as sustainable in cases where the local community has become dependant on it for its income. The fact that an indigenous human population is non-existent does not mean that host and recipient communities do not exist for Antarctic tourism. Communities living in the tourism gateway cities (particularly those in South America), the scientific and logistic communities of NAPs present at Antarctic research stations, people working at NGOs looking after Antarctic biodiversity or heritage sites, the community of tour operators and those employed by tourism companies do benefit from the development of tourism.

The compatibility of tourism with science activities is a highly contested topic. It is feared by some of the interviewees that increased tourist visits to scientific research stations may interfere with research activities (M1, 2007; M4, 2007). On the other hand, NAPs also benefit from tourism visitation, by selling souvenirs, providing logistical services or even accommodation (see chapter three and six). Opinions range widely regarding the desirability of some of these science-tourism interdependencies. According to some of the interviewees close cooperation between science and tourism operators should be discouraged as it blurs the line between activities and it changes the palette of interests of NAPs (M2, 2007; M4, 2007). This could have implications for policy-making. NAPs that are dependent on expedition cruises for their logistics would not likely be in favour of restricting this activity; NAPs that are financially dependent on accommodating airborne tourists will not likely be in favour of a prohibition of land-based tourism. Others argue that there is nothing wrong with this dependency on mutual services $(02,2007 ; 05,2007$; $M 1$, 2007). In several cases tourism is providing direct income for the conservation of Antarctic heritage sites and biodiversity, such as the albatross $(06,2008)$. 
"We live in a world of science budget cuts. (...) There are many countries that cannot afford science. So if there is a way that tourism and science can work together, and it's not going to affect the integrity of Antarctica, the wildlife, and there is away to cooperate, it is fine" $(02,2007)$.

At the same time particular segments of the industry have needs of their own. The expedition-cruise segment, for example, is in need of landing sites to visit and scenic areas to cruise around. Popular tourist spots, such as the Lemaire Channel or Deception Island, have already been reported as congested in the peak of the season. The scheduler system of IAATO has been developed to deal with this issue (see chapter seven). Especially for larger expeditions cruise ships it is difficult as they are not able to cruise everywhere and land at all possible sites. With the increase of larger tourist ships (see chapter three and eight), scheduling itineraries could become more difficult. It has been suggested that larger vessels should be scheduled first; leaving the rest of the sites for the smaller ships that can land anywhere (O4, 2007). Also, cruise operations in Antarctica are much more reliant on cooperation with competitors than elsewhere in the world. For example, tour operators are dependent on each other and on NAPs in case of emergency. It is stated that with the influx of new cruise operators coming from other parts of the world a lot of effort goes into informing them about the special Antarctic requirements and conditions $(02,2007)$. Corporate take-overs might also be affecting the values that are considered important by yesterday's and today's generation of tour operators (M2, 2007). The help of the ATS and Treaty Parties is needed in this $(02,2007)$.

The role and interests of gateway cities present another example of dependency in the development of Antarctic tourism. According to some of the interviewees, Ushuaia has developed into the main gateway port for Antarctic tourism due to favourable tax policies and infrastructural developments (M5, 2008; R4, 2008). The direct and indirect economic benefits for Ushuaia resulting from catering and accommodating the affluent Antarctic tourists are considered considerable (Bertram et al., 2007).

\subsubsection{ENVIRONMENT-LED TOURISM}

The third perspective of tourism development prioritises forms of tourism that minimise impacts and maintain high environmental standards. Environmental quality is renowned and accepted without exception by all the interviewees as the leading principle for sustainable future tourism activities. This is not surprising as environmental quality is a central objective of the Environmental Protocol and in the general interest of all current stakeholders (see chapter seven). Despite this consensus, different stakeholders can find different viewpoints on issues such as the collection of scientific evidence and the interpretation of the rules.

Impact assessments of Antarctic tourism have revealed little evidence of environmental impacts (Stonehouse and Crosbie, 1995; Hofman and Jatko, 2000; Naveen 
et al., 2000; Stewart et al., 2005; Snyder and Stonehouse, 2007), although there are a few exceptions (Pfeiffer and Peter, 2004). Some of the tour operators refer to this lack of scientific evidence in justifying their activity $(02,2007 ; 05,2007)$. Scientific evidence and monitoring are important ways to generate a more objective judgement. At the moment an oil spill resulting from a grounded ship or a ship wreck at the bottom of the Bransfield Strait is considered harmless by some $(R 3,2008)$ and a major concern to others (ASOC, 2008). Another example is the assertion of IAATO that by means of the 'one place, one ship, at one time approach' and the development of site-guidelines, only 'minor or transitory impacts' are guaranteed (O2, 2007), which is a legal standard set by the Environmental Protocol. This claim has been criticised by others arguing that this statement is deceiving and not based on scientific evidence $(R 2,2008)$.

There may be lacunas in our knowledge of impact due to a limited research effort (M2, 2007). Particularly the fast increase of Antarctic tourism in combination with other factors, such as climate change, result in major uncertainties about potential future impacts, including cumulative impacts (M4, 2007). When focusing on Antarctica as a whole, many interviewees claim that tourism volumes remain modest compared to the size of the continent (R3, 2008; O2, 2007; O5, 2007). However, interviewees are concerned with the growing number of sites used by tourism (R4, 2008; M2, 2007), and the ecological integrity of frequently visited landing sites (O3, 2006; M1, 2007; M4 2007; 01, 2007; 02, 2007; 06, 2008). Through the development of site-specific guidelines for several frequently visited sites (Bastmeijer and Roura, 2004), the ATS is trying to tackle this issue in cooperation with the tourism industry. Some interviewees indicate that it is not clear whether landing sites are the only probable areas of impact and argue for comprehensive monitoring and more research (M1, 1007; M2, 2007; M4, 2007). For example, in chapter four it was demonstrated that the global impacts of Antarctic tourism are potentially substantial.

Impacts can also be the result of incidents. Safety risks are inherent to human activities in a remote destination like Antarctica (03, 2006; 05, 2007). Sufficient preparation, insurance, and contingency planning, but also quality equipment, information and experience, are generally seen as crucial factors in minimising risks (see chapter five). Still, certain activities may be more likely to cause danger for tourists, or the activities of other parties in the area. Support staff of national programmes have been called in on the rescue of expedition cruise ships (Stewart and Draper, 2008) and one-off (or independent) expeditions (e.g. aviators, yachtsmen, and cross-continent skiers). Large-scale operations (such as large cruise ships) are a cause of concern for stakeholders, because of the lack of capacity in the region to respond in case of an incident. An incident of a large cruise ship can potentially cause many victims, environmental damage, and pressure for the Antarctic Treaty System (R1, 2007; R2, 2008; R3, 2008; R6, 2005). Others argue that companies operating larger ships are much safer because of better technology and higher safety standards (02, 2007; O6, 2008). 


\subsubsection{NEOTENOUS TOURISM}

Uncertainty on potential impacts of future tourism development might urge some stakeholders to advocate for a precautionary approach; which would be largely in line with the perspective of sustainable development through neotenous tourism. In this fourth perspective of Hunter's model, tourism development is actively discouraged or restricted based on safeguarding the ecological integrity or wilderness values. Also, as groups of tourists increasingly visit areas where scientific research is conducted and new unexplored parts of the Antarctic, the scientific value (laboratory function) of these places diminishes (M2, 2007). Tourism activities impinging on intrinsic wilderness and existence values are recognised by a number of interviewees (O3, 2006; 05, 2007; M6, 2005; M1, 2007; M2, 2007).

"I think that my top concern would be that the intrinsic scientific value of the Antarctic would be compromised with Antarctic tourism that is not managed properly. One has to really look at what Antarctica has to offer to mankind (...). The value of having this place in the world without human activity is at the risk of being lost" (M2, 2007)

It is argued that these intangible or immeasurable values should be considered in the authorisation of activities or the setting of norms and standards (M6, 2005). For example, land-based tourism infrastructures and facilities, large cruise liners, air links, and certain types of adventure sports have been identified as developments that would not be compatible with Antarctic values (O3, 2006; 04, 2007; 05, 2007; $M 2,2007 ; M 6,2005)$. Opinions on the likelihood of the development of permanent facilities for tourism in the near to distant future differ greatly, ranging from those believing that this is a logical next step (O3, 2006; O6, 2008; M1, 2007; M2, 2007), to those believing that this will never materialise $(02,2007 ; 05,2007, M 4,2007$; $M 5,2008)$. Finding consensus on restrictions regarding tourist numbers, ship numbers, ship sizes or the development on land-based tourism would be difficult without a scientific ground.

Based on the scale of the potential effects a proactive and precautionary approach is advocated by some, despite the contested views on the likelihood of this development. Corporate take-overs and increasing scale of businesses operating in Antarctica could also lead to a situation whereby operational standards may erode $(02,2007)$. Another spin-off is that different types of tourists will visit Antarctica that might not be interested in Antarctic wilderness (M6; 2005). For example, expedition leaders and lecturers stress some of the difficulties of dealing with groups of tourists from newly industrialised countries with a very different concept of nature or biotic rights $(04,2007 ; M 1,2007)$. Dealing with these groups, and ensuring that tourist behaviour meets the codes of conduct set out by IAATO and the ATS, requires additional attention, as direct communication is often difficult due to language. 
The point we want to make here is that stakeholder groups, i.e. the organisers, monitors and regulators of Antarctic tourism, have different perspectives on what constitutes sustainable development and of the role tourism plays in this. It is argued that the lack of clarity on this common policy objective obstructs the formulation of policy. Perspectives are not necessarily right or wrong; they each contribute valuable pieces of the puzzle and merely reflect different interests in the development of tourism. The perspectives presented are not exclusive; points of view of individual interviewees may very well be categorised in different perspectives. Understanding differences in perspectives can help focusing discussions on the development of a strategic vision and the formulation of a shared policy objective.

\subsection{Perspectives on tourism governance}

The level of control the regulatory regime can exercise on different forms and volumes of tourism activity in parts of Antarctica provides a crucial component of sustainable tourism development. Perspectives on what constitutes acceptable tourism regulation in the Antarctic diverge widely among stakeholders and are related to the discussion of the main policy objective discussed in the previous section. The question of acceptable regulation can roughly be divided into two parts: the capability of the ATS to deal with tourism, and the need for additional regulation. Further, there is the relation between formal regulation of the ATS and self-regulation of the tourism industry.

\subsubsection{ATS TOURISM REGULATION}

It is argued by some that the existing ATS governance system is appropriate in dealing with tourism; a more comprehensive legal construct is not considered to be needed (R1, 2007; 05, 2007). The Environmental Protocol is seen as the main instrument for regulating human activities; what is really lacking is a standardised interpretation of the regulations set out by the Environmental Protocol (O2, 2007; $M 3,2007)$. In addition, the way the Protocol is implemented differs from country to country (R5, 2005; M6, 2005). It is argued that binding regulations that have been approved by the ATS have not been implemented yet. Implementation of these regulations (e.g. Measure 4 of 2004, the Liability Annex to the Protocol of 2005) into the domestic legislation of the ATCPs would already mean a big improvement in the capability of the regulatory system (R1, 2007; R3, 2008).

On the other hand, many of the interviewees, including several tour operators, believe that more regulation is needed to adequately manage tourism in the future. Besides the wish for stricter regulations, interviewees also point to the inability of the ATS to reach consensus, to implement, and to enforce restrictive policies (M1, 2007; M5, 2008; R3, 2008; R4, 2008).

"I have always believed that forbidding tourism is a bad thing, for two reasons. The first is: tourism also has positive aspects. The second is: we do not have the means 
to regulate tourism. We can only do that through the tourism industry. There is, also in the future, no chance that we would have an adequate system of park rangers and patrol ships to control activities in Antarctica" (R3, 2008).

Several other interviewees remark that it is not a question of ATS capability, but more an issue of political will of the ATCPs to really address the issue (M2, 2007). A central question in striving for additional governance instruments is how to finance it. It has been claimed that the ATS has evolved from an initial small consortium of countries with a strong interest in Antarctica and a considerable investment in scientific research, into a larger group of countries with a more marginal interest and investment. This entails an inherent danger, especially now stricter regulations are increasingly considered needed, as well as the costs associated with these regulations (R3, 2008; M5, 2008).

A range of structural problems of the capability of the ATS to deal with tourism is identified in the previous chapters of this thesis. Knowledge and experience of tourism operations is believed to be lacking with policy makers involved in the ATCM tourism discussions, which hampers decision-making $(02,2007 ; M 2,2007)$. Proposals for tourism (and other) activities are assessed on a one by one basis. It is insufficiently known if some other country is allowing the same activity in the same place at the same time. It is argued that ATCPs have to communicate more closely in allowing access and issuing permits (M5, 2005; R5, 2005). According to one interviewee, the ATS has been designed to control scientific activities operated by NAPs and not for controlling commercial activities like tourism (M1, 2007). Following the above discussion on the compatibility and interdependency of science and tourism operations, the issue arises if the different sets of rules should apply to both types of users. There seems to be a consensus among the interviewees that although the two activities are inherently different in nature the same standards should be applied. It could very well be that because of inherently different activities, different sets of rules have to be drafted for these groups to meet the same standards. Another structural problem of the ATS is the incapability of dealing with activities organised from non-signatory states (M4, 2007). For example, several interviewees mention rumours concerning large cruise operators from non-Treaty countries planning to organise trips to Antarctica in the future (M3, 2007; M5, 2008).

The ATS is based on a deliberative mode of governance (Van Zeijl-Rozema et al., 2009). The Antarctic Treaty stipulates that ATCPs have to collectively agree on policy during ATCMs. Several of the interviewees expressed the wish for a more hierarchical governance approach of the ATS to facilitate a more swift response and increase the adaptive capacity in decision-making and the ability to enforce regulations. Despite the doubts of the feasibility of such an approach, several suggestions are made in this direction. A few interviewees argue that tourism regulation should be strengthened by developing a more comprehensive legal instrument, such as an Annex to the Environmental Protocol (M6, 2005) or a Tourism Convention (M1, 
2007). In the case of regulating fisheries the CCAMLR convention was established. Tourism could be regulated in a similar way, modelled on the CCAMLR approach (M1, 2007). Both ideas have been circling around the academic literature and policy arenas for years but no consensus exists on any of the options (Molenaar, 2005).

Another way of improving the role of the ATS in the regulation of Antarctic tourism is to establish a commission with representatives of the main tourism countries, reporting to the ATS (M1, 2007; $M 2,2007)$. A team of trained observers could be working for this tourism commission (M2, 2007). This way the ATS could effectively develop their own vision of tourism that is not aligned with industry interests. The tourism industry would benefit from a more effective working relation with the ATS. Disadvantage would be the political discussion about who would have to be in this commission and how to finance its activities.

\subsubsection{RELATION ATS - IAATO}

Industry self-regulation is generally seen as a successful way to overcome some of the described problems. At the same time it is recognised by almost all interviewees that the collective and voluntary nature of an industry association also makes it vulnerable. The vulnerability is a cause for concern given the responsibility it carries over an increasingly complex industry. IAATO has taken the lead in many practical and operational interpretations of the Environmental Protocol (O2, 2007; O5, 2007) and suggesting policy solutions, for which the ATS should be thankful (M1, 2007). In recent years, a range of IAATO bylaws have been codified, first into a non-binding resolution and later in a binding measure. This is a very useful way of ensuring that these rules, that are practiced by the majority of the companies anyway, have to be followed by all companies (R3, 2008). According to some interviewees IAATO guidelines should be carefully examined before adoption as standards of the international community (R2, 2008; M1, 2007; M5, 2008). Some question the appropriateness of the industry's leading role in policy setting (M2, 2007). Others claim that the ATS should also take its responsibility in tourism regulation by collecting statistics; engaging in monitoring and observer schemes, and setting the standards for operations (M1, 2007; M2, 2007; M5, 2008; R1, 2008; R2, 2008).

"I think that it is important that we see both tourists and scientists as visitors of Antarctica for whom the same standards apply. For enforcing these rules we need the cooperation of the tour operators (...). I do think that the basis for cooperation lies with the Treaty Parties. At the moment IAATO has a leading role in collecting statistics and supervision of tourism, but in my view that would have to become the role of the Parties" (R3, 2008).

It is stressed by some of the operators that a more formal working relationship, or partnership, should be built between IAATO and the ATS (O2, 2007; 05, 2007). There is a great interdependency of the ATS and IAATO when it comes to tourism 
regulation. Tourism is developing in such as way that we cannot rely on regulation debates once a year at the ATCM. Therefore maintaining strong ties between the ATS and self-regulatory regimes, like IAATO, is an important vehicle for robust governance and in need of improvement (O2, 2007; see also chapter seven).

\subsection{Perspectives on policy instruments}

In the previous section it was demonstrated that there is a general tendency towards improving elements of the regulatory regime that improve control, particularly regarding the enforcement of regulation and the monitoring of potential impacts. Hunter argues that by means of a range of regulatory and market based policy instruments ("sticks and carrots") the behaviour of tour operators and tourists can be influenced to minimise negative impacts (Hunter, 1997). A range of policy instruments are, or have been, discussed in the academic and political debates on Antarctic tourism regulation. In this section, we will briefly discuss different stakeholder perspectives on these instruments.

\subsubsection{PORT STATE CONTROL}

Extending existing port state controls in the gateway cities has been suggested both in the academic and political debate (Vicuna, 2000; ASOC, 2003). Apart from the type and level of port state control, opinions differ largely about the appropriateness of this regulatory option. Some argue that it makes sense to build on existing institutions present in Antarctic gateway cities to improve control of vessels travelling south $(05,2007)$. Others point to the geopolitical difficulties of this option (R1, 2007; M3, 2007). Since all major gateway ports are located in claimant states, both claimant and non-claimant states would be concerned that extended controls could be used to strengthen territorial claims of Antarctica. Also, port state controls are considered not effective for managing tourism as the control is gone when ships or aircraft leave the (air)port (O2, 2007; M1, 2007). Further, gateway cities are believed to benefit enormously of Antarctic tourism, so it can be questioned to what degree they can be convinced to undertake activities that counteract their interest (M1, 2007). Nevertheless, (air)port state control can be instrumental in checking yachts and other types of one-off activities for having obtained the right permits and carrying sufficient documentation on site guidelines, protected areas, and general codes of conduct (M6, 2005).

\subsubsection{ACCREDITATION}

Setting up a certification system for tourism operators has been suggested as a way to guarantee safe and sound industry standards (Australia, 2004a), as well as to formalise the relation between IAATO and the ATS (Molenaar, 2005). An accreditation scheme could create another quality check for tour companies to take (M4, 2007), besides finding an ice-strengthened ship, hiring staff, obtaining insurance, etc. $(05,2007)$. The idea of accreditation is not viewed upon with much enthusiasm 
by the interviewees. There has been extensive debate between Treaty Parties and the tourism industry on the content, the organisation and the development of a certification system (United Kingdom, 2005), without a satisfactory outcome (M3, 2007). The IAATO membership requirements are already by some of the operators as a practically functioning system of certification; setting up an accreditation scheme would pose a large investment in time and money without having significant additional value $(02,2007)$.

\subsubsection{GOVERNMENT OBSERVERS AND MONITORING}

The option of sending government observers on tourist ships also seems contested. Some states, predominantly claimant states (New Zealand, 2004b), regularly send government observers on ships of companies operating from their country. Some interviewees consider it a useful way to generate insight in onsite tourism practices $(04,2007)$ and a responsibility of Treaty Parties with tour operators active in Antarctica to do so $(M 5,2008)$. Many interviewees remark that it is an expensive way of control that can only be effective if observers are trained and well-equipped to perform the job (O2, 2007; O5, 2007; M1, 2007; M2, 2007; M3, 2007). Another way of generating knowledge and establishing ground for policy decisions is by setting up an independent monitoring system. Monitoring programmes have been developed by NGOs (Naveen et al., 2000; Naveen et al., 2001), and some of the NAPs (Australia, 2004b). So far, monitoring is performed on a voluntary basis and consequently far from comprehensive (M1, 2007). Up to now, no agreed approach and scheme for environmental monitoring of non-governmental activities exists (Australia, 2004b). Opinions differ on who should be paying for a more comprehensive monitoring scheme: the tourists (M1, 2007; M2, 2007) or the ATCPs (O2, 2007).

\subsubsection{ZONING INSTRUMENTS}

Zoning instruments can be used to assign appropriate activities to particular areas and limit access to others (Hunter, 1997) and are commonly applied and studied in tourism management (Page, 2003). Zoning is reviewed by most of the interviewees, as a useful type of policy instruments for regulating future tourism development. Antarctic tourism has increased both in terms of operational scale (e.g. size of ships), and the level of activity at different spatial scales. For example, tourism activities have especially grown at the regional scale of the Antarctic Peninsula, at the sub-regional scale (Argentina, 2006), and at the scale of individual landing sites (Crosbie, 2005). Zoning instruments function as a way of compromise between different development objectives of users, whereby activities can be allowed in some areas, while other areas can be closed. The Antarctic Special Protected Areas (ASPAs), Sites of Special Scientific Interest (SSSIs) and Antarctic Special Managed Areas (ASMAs) instruments of the Environmental Protocol are already existing zoning instruments that can be used to fence off or manage tourist activity near research stations or particularly vulnerable sites. The non-binding site guidelines allow certain levels of visitation and therefore function as a zoning instrument for 
larger ships $(04,2007)$. It is reported that operational zones are already in place as there is a limited number of places where you can land tourists as well as IAATO zones for specific activities $(02,2007)$. So far, zoning instruments have not been applied on larger spatial scales than individual sites. France (2005) has introduced the idea of additional zoning instruments through the establishment of Sites of Special Tourism Interest (SSTI), without much response. It has also been proposed to apply the existing ASPA and ASMA zoning instruments on larger spatial scales, such as sub-regions or regions (ASOC, 2008). Some of the interviewees argue that if zoning were to be extended it would have to be backed up with monitoring data or scientific evidence $(02,2007 ; M 2,2007)$.

\subsubsection{SPECIFIC RESTRICTIONS AND PROHIBITIONS}

Some of interviewees argue for limits on the number of tourists or ships visiting the Antarctic continent per annum (M1, 2007; R4, 2008), or on the size of the ships used $(R 3,2008)$. Most of the interviewees raising this issue immediately add that setting a tourist cap would be difficult because of political will and the difficulties of enforcing it (M5, 2008; R4, 2008). Countries might not want to limit economic activities if the ground for it is arbitrary; a demonstrable scientific underpinning of cumulative impact would be needed. Operators generally argue that a cap is not necessary, as the boundaries of entry are high, providing sufficient limits to the industry (O2, 2007; 05, 2007; 06, 2008).

A prohibition on land-based tourism facilities and infrastructure has been suggested a few years ago (New Zealand, 2005), and has been debated in ATCMs ever since (see chapter six). The previous section has shown that the opinions of interviewees regarding the feasibility of large-scale land-based tourism differ considerable. Nevertheless, most of the interviewees considered such developments unacceptable. In terms of regulation, opinions differ on what needs to be done. According to some the discussion has been closed with the adoption of Resolution 4 in 2007 (R1, 2007; R2, 2008), while others qualify this policy solution as too weak and vague (R3, 2008; M5, 2008).

Some interviewees mention specific proscriptions and restrictions that are necessary for safe shipping in Antarctic waters, such as compulsory ice-classes, minimal seasons of experience for captains sailing in Antarctic waters and ice-pilots (O4, 2007; M5, 2008; R5, 2005). It is not clear to what degree the ATS should take the responsibility for Antarctic shipping regulations, or what level of responsibility the IMO has in principle. The ATS has started to address the issue of shipping in Antarctic ice-covered waters some years ago, by asking for advice from the IMO (ASOC, 2009b). Given the recent shipping incidents, the ATS should find the right balance between a swift policy response, and policy back up from the IMO that would guarantee world coverage. 


\subsection{Towards sustainable tourism?}

The ATS has been a stable institution over the past fifty years and successful at addressing upcoming challenges in a proactive way. In the context of commercial activities, such as fisheries and mineral resource extraction, a comprehensive regulatory system was set in place before activities commenced (Scott, 2001; Molenaar, 2005). Regarding tourism a range of regulatory weaknesses have been identified. Tourism policies have typically been ad hoc and reactive, targeting individual expeditions per season rather than clusters of activities for a number of years and often responding to concrete incidents and plans (Kriwoken and Rootes, 2000; Hemmings and Roura, 2003; Bastmeijer and Roura, 2004). At the same time, change is on the horizon. Some have argued that comprehensive regulatory efforts should be made for tourism (Hall, 1992b; Davis, 1999), for example based on the CCAMLR system developed for fisheries. Tourism is believed to be the most important debate occurring in the ATS at this moment $(R 3,2008)$. Following the previous sections of this chapter, a number of strategic questions arise: Is the ATS robust enough to stand the test of future tourism? Is the ATS regime adaptive enough to anticipate to tourism development, and to what degree can we rely for the sustainability on the tourism industry to self-regulate? What can we do to steer towards sustainable development?

In the previous sections, we have seen that although environmental quality and human safety are recognised as general principles, the interpretation of these principles in terms of future scale, form and control of tourism development in Antarctica are contested. Some of the operators see tourism as a harmless activity that creates ambassadors for Antarctic conservation against more devastating activities that Antarctica might face in the future. The second perspective sees tourism as a potential source of income for other local stakeholders, such as NAPs. In both perspectives, policies for Antarctic would not go beyond creating a level playing field by backing up self-regulatory operational standards. According to the third perspective, tourism is allowable as long as there are no environmental impacts or other types of negative effects, such as risks for human safety. Policies should merely focus on mitigating unacceptable levels of proven impacts. Those who want to establish a more objective judgement of impacts would argue for the creation of an independent monitoring programme. Demonstrable negative impacts can be minimised by setting conditions under which tourism activities can be approved, for example through a zoning system or an accreditation scheme. The fourth perspective sees tourism activities as a threat to intrinsic wilderness and scientific values and urges for a precautionary approach. According to this perspective, particular forms of tourism (e.g. land based tourism), scales of operation (e.g. large cruse liners), or volumes of tourists should be prohibited or restricted. It should be noted that perspectives on the role of tourism and the preferred management style are not exclusive and can be combined, for example by setting up a comprehensive zoning system in which a different approach is chosen for different regions. 
Here it is argued that without a clear tourism policy objective it will be very difficult to agree on a set of policy instruments. The creation of a collective vision on the acceptable volume and form of tourism should therefore be made top priority in the ATS tourism debate to clarify these issues. Recently concrete initiatives have been taken towards this objective. Based on an initiative of the United Kingdom, an inventory was made of vision statements of a range of ATCPs and organisations, including a list of general principles (United Kingdom, 2009). An adapted version of these principles was adopted at the 2009 ATCM in Baltimore by means of nonbinding Resolution 7 (Antarctic Treaty System, 2009). Although these principles are too general to settle the issues discussed in this chapter or this thesis, they do provide a useful reference document for ATCPs in any future discussion about Antarctic tourism (see Table 9.1).

\section{Box 9.1: General Principles of Antarctic Tourism}

All tourism activities undertaken in Antarctica will be conducted in accordance with the Antarctic Treaty, its Protocol on Environmental Protection, and relevant ATCM Measures and Resolutions;

Tourism should not be allowed to contribute to the long-term degradation of the Antarctic environment and its dependent and associated ecosystems, or the intrinsic natural wilderness and historical values of Antarctica. In the absence of adequate information about potential impacts, decisions on tourism should be based on a pragmatic and precautionary approach, that also incorporates an evaluation of risks;

Scientific research should be accorded priority in relation to all tourism activities in Antarctica;

Antarctic Treaty Parties should implement all existing instruments relating to tourism and nonGovernmental activities in Antarctica and aim to ensure, as far as practicable, that they continue to proactively develop regulations relating to tourism activities that should provide for a consistent framework for the management of tourism;

All operators conducting tourism activities in Antarctica should be encouraged to cooperate with each other and with the Antarctic Treaty Parties to coordinate tourism activities and share best practice on environmental and safety management issues;

All tourism organisations should be encouraged to provide a focus on the enrichment and education of visitors about the Antarctic environment and its protection.

We argue that a more comprehensive future vision for Antarctic tourism should take the perspective of tourism as a system (for a similar argument see (ASOC, 2009a) in which a variety of activities and services are linked together through various supply chains (Font et al., 2006) and not as a single activity (for example the tourist landing). In several chapters of this thesis, we have seen that crucial drivers and impacts of the Antarctic tourism industry lay outside of ATS control. Determining workable boundaries of the Antarctic tourism system, and addressing the issue on the appropriate spatial and temporal scale, is an important exercise that requires further debate. These general principles do suggest that besides further 
elaboration into criteria and indicators concerted action is necessary towards the establishment of an ATS monitoring system.

There is a growing literature on the potential of public-private partnerships (Hartman et al., 1999), NGO-state cooperation (Bastmeijer and Verschuuren, 2005), and the sustainable governance of resources and human activities beyond the effective control of the state (Bierman, 2007). A shared strategic vision would increase the adaptive capacity of the ATS to respond to any emerging crisis in a swift, structured and effective way. Following recent insights from the literature on adaptive (co)management, trust and leadership would be required to successfully move in this direction (Olsson et al., 2004; Folke et al., 2005), as well as experimentation with various policy options (Huitema et al., 2009). The ATS could organise the creation of this tourism vision by leadership of one ATCP, a commission of ATCPs, or a combination of ATCPs with NGOs and industry organisations. Scenario analysis could be an important step in the creation of a shared future vision (see chapter eight). It can be questioned whether the annual three-day discussion during ATCMs will be sufficient to transform the general principles into a more elaborate shared vision.

A combination of the instruments discussed in section five could be adopted in view of this policy vision. Control may be increased by demanding minimal requirements for quality and experience of organisers, staff and crew, thereby improving supervision and enforcement in the field. By establishing zones with different levels and types of activities, the needs of different stakeholder groups can be met, while preserving parts of the Antarctic for wilderness. A similar approach has been developed and proposed by Davis (1999). Another option is to apply existing instruments in different ways (such as the proposal of ASOC to apply the ASPA and ASMA instruments on larger geographic scales), or by developing innovative new approaches. In analysing the scope of policy instruments it is striking to see the dominance of command-and-control instruments as opposed to market based instruments (Pearce and Barbier, 2001), especially when control is difficult in the remote Antarctic. Market-based policy instruments, such as taxation and cap-andtrade approaches, may provide some of these innovative policy options.

An important strategic issue is how to deal with the potential increase of nonIAATO members or tour operators, one-off expeditions, and activities from nonParty states (Molenaar, 2005). Active engagement and close cooperation between ATCPs and non-Treaty Parties from where tourism activities are organised is warranted to anticipate such developments. Also, active cooperation of the ATS with global institutions, such as the IMO, creates a more nested governance structure and increases its robustness (Ostrom, 2005; see chapter seven). Further, a greater understanding of what goes on in the field is essential, which requires the improvement of monitoring and observation programmes. In doing so, it makes sense to cooperate with expert organisations, like SCAR and COMNAP. Many of the instruments would merit from further legal, economic or integrated policy research 
to analyse their design, effectiveness, and implementation. At the 2009 ATCM in Baltimore the CEP has commissioned a status report on the trends in Antarctic tourism development, the environmental impacts of tourism, the effectiveness of existing management controls, and the identification of new analytical methods to analysing existing data (Australia et al., 2009). This CEP study would definitely be a step in the right direction.

In section four of this chapter, we saw that many interviewees doubt whether the ATS will ever be capable or willing to control tourism. The central role that selfregulation currently plays in onsite management and rule enforcement, and the difficulties that the ATS is facing in performing these tasks, suggests that it would be wise to involve the tourism industry in policy development. Organisations like IAATO will probably remain important in implementing any future tourism policy. The value of IAATOs work in coordination and environmental management underlines the importance of a continuing co-operation between the ATS and IAATO. However, the ATCPs have a clear responsibility under the ATS. Also, for various reasons sustainability issues may not be adequately addressed by self-regulation alone. For example, if more restrictive measures in respect of future tourism developments are considered necessary, IAATO may not be able to agree on such measures. Therefore the ATS would be wise to develop plans for generating the financial means to play a more hierarchical role in monitoring and enforcement of policy, for example though an ATS tourist tax or a tradable permits system (Tietenberg, 2002) based on tourist visitor days.

\subsection{Conclusion}

It has to be noted that the number of interviews conducted presents a small sample of the Antarctic tourism community. However, each of the interviewees is directly involved and functions as organiser, regulator or researcher of Antarctic tourism, and represents many years of experience. The dispersal of potential knowledgeable interviewees worldwide also complicates generating a large sample of respondents. Interviewees were selected from a variety of influential countries in the Antarctic tourism debate. Another potential bias in the data could be formed by socially desirable answers of interviewees to questions. The semi-structured interview approach and the building of trust during the considerable length of the interviews are believed to have reduced this bias. It is believed that audiorecording, sending back the transcription for approval, guaranteeing anonymity, and critical questioning during the interviews has resulted in a reliable account of the stakeholder's views.

It can be concluded that there are considerable differences in the way stakeholders perceive the role of tourism in Antarctica, the robustness of the regulatory system, and the appropriateness of policy instruments. This is in line with other recent investigations in this field (Haase et al., 2007; Haase, 2008). Applying the adaptive 
concept of sustainable development on Antarctic tourism has proven insightful. It becomes clear that different perspectives exist on the role of tourism in the sustainable development of Antarctica and on the role policy could play. In the absence of a local population and economy, it is not clear what should be the main aim of sustainable tourism development in Antarctica. Existing agreements (e.g. the Protocol) leave open much space for interpretation. In addition, tourism is organised by complex networks of actors operating at different spatial levels, which raises questions about the proper allocation of responsibilities (e.g. IMO, ATS, IAATO). At the most recent ATCM, a number of policy steps have been taken with regard to the regulation of Antarctic tourism, such as the codification of a set of operational rules in international law; the adoption of a list of general principles, and the commissioning of a CEP status report. Although these are steps in the right direction, they neither make the ATS future proof nor tourism sustainable. It is concluded that the creation of a shared policy vision should be the top priority of the Antarctic tourism regulatory debate. Issues of scale, distribution, form and control of tourism should be part of this vision. The absence of a sovereign state triggers experimentation with new forms of governance and the development of innovative policy instruments. 

Chapter 10

CONCLUSIONS

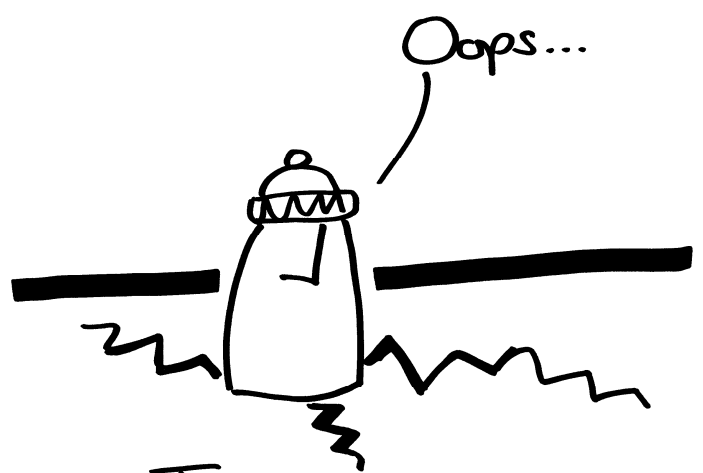

Thin ice 


\subsection{Research objectives}

Tourism in Antarctica is growing rapidly in volume and diversifying into an everwider range of activities, transport modes and destinations. At the same time, the regulatory options for controlling tourism developments in this remote region and global common are limited. This configuration has raised concerns among academics, NGOs and policy makers. The central aim of this thesis is to explore the sustainability challenges of Antarctic tourism in the context of sustainable development. In chapter one the following central research question was formulated:

What sustainability challenges will we be facing as tourism in Antarctica develops in the future; and how can these challenges be tackled in the context of this global common?

To address this question the following research objectives were formulated:

1. To identify the main development factors and actors driving and constraining Antarctic tourism and analyse opportunities for future tourism development;

2. To assess the risks and impacts of Antarctic tourism development for the environment, tourism operations and other users;

3. To explore the future of Antarctic tourism by developing a set of plausible and consistent future scenarios and analyse the implications;

4. To analyse stakeholder perspectives on the options for Antarctic tourism governance towards sustainability.

This chapter will summarise the main conclusions for each of the research objectives coming from different chapters in this thesis and discuss these conclusions in view of the sustainable development concept. In addition, reflections will be presented on the methods applied in this study. The chapter will close with an outlook on future research for sustainable Antarctic tourism.

\subsection{Conclusions}

\subsubsection{ANALYSIS OF THE MAIN FACTORS AND ACTORS DRIVING AND CONSTRAINING ANTARCTIC TOURISM DEVELOPMENT}

Objective one was primarily addressed in chapter three. A myriad of factors constraining and driving tourism development in Antarctica were analysed based on stakeholder discussions during three participatory workshops, supplemented with literature review and data analysis. Factors were combined in the Antarctic Tourism Opportunity Spectrum (ATOS). The ATOS collectively defines the opportunities and constraints for the development of tourism in Antarctica, and for different stake- 
holders to influence these opportunities. Factor categories include: factors influencing access, other resource related users, attractions and activities, infrastructures and facilities, operational factors, acceptability of impacts, and regulation and management frameworks. In each of these categories a range of directly involved actors can be identified, including tourists, ships owners, tour operators, suppliers, scientists, base personnel, various kinds of NGOs, guides, lecturers, and policy makers.

Factors and actors influencing access, such as logistical and infrastructural developments, prove to be particularly important. This is no surprise in a region as remote as Antarctica, with substantial geographical barriers of entry. The compatibility of tourism activities with other users, predominantly science operations, can provide both constraints and opportunities, for example in the case of facility and infrastructure sharing (see chapter three and six). The wilderness and wildlife attractions in Antarctica are unique, as well as the opportunities for adventure activities and other special interest activities. The remoteness of Antarctica calls for cooperation among tour operators and sophisticated operational procedures and requirements (see chapter seven). The unique and vulnerable ecosystems makes that our tolerance towards impact is lower than elsewhere. At the same time the role of formal regulation in controlling tourism development is limited due to an international governance system (see chapter nine). It has been demonstrated that in each of these factor categories internal changes are occurring. In addition, a range of contextual factors that occur on a global scale (see chapter eight) influences each of the factor categories. These contextual factors widen the range of actors even further with international tour agents, international air carriers, gateway city stakeholders, and so on. Often these contextual factors and actors are beyond the regulatory reach of Antarctic institutions and bodies (e.g. energy prices, climatic changes, economic development, etc.). The ATOS model addresses the issue of scale in sustainable Antarctic tourism and illustrates the open en volatile nature of the current Antarctic tourism development setting.

With regard to future opportunities and trends, we conclude that there are more opportunities than those currently exploited. Antarctic tourism development is driven by an increasing operational scale (e.g. larger ships), efficiency (e.g. aircruise operations), and continuous innovation and diversification (e.g. adventure activities). On the longer term, the smaller expedition ships are considered uneconomic to build and operate. Therefore, we expect to see more of the larger cruise liners entering Antarctic waters, increasing air-cruise operations and land-based tourism development. Niche operations offering various activities, from more adventurous to more luxurious, will most likely continue as well.

In this thesis, the ATOS model has been instrumental in identifying important sustainability challenges for future Antarctic tourism development. By incorporating contextual influences from global level changes, uncertainties, knowledge gaps and causal relationships were discovered that extend lower spatial and temporal scales 
(i.e. local and direct effects). Examples of such strategic challenges include: the implications of global environmental change on tourism in Antarctica, such as increased access, invasive species and loss of indigenous species. Other causal relations include safety risks and associated indirect impacts for other users, the potential development of permanent land-based facilities (in relation to other users), and the robustness of self-governance (operational factors). Some of the implications of these future trends are assessed in subsequent chapters. The integrated nature of the model provides added value to the academic literature as the factors on which it is built have previously been studied primarily in isolation and global factors have largely been ignored (Stewart et al. 2005). The extension of the original (local) ROS model with a contextual dimension can be of value for future investigations of the relation between tourism, nature protection and global (environmental) change, in Antarctica as well as other destinations.

\subsubsection{ASSESSMENT OF THE RISKS AND IMPACTS OF ANTARCTIC TOURISM DEVELOPMENT FOR THE ENVIRONMENT, TOURISM OPERATIONS AND OTHER USERS}

Many chapters in this thesis are dedicated to exploring different types of risks and impacts of future tourism development in Antarctica. As indicated above, using sustainable development as an interpretive concept implies incorporating different geographical scales (local and global) and time periods (past, present and future) into the analysis. The scope of analysis extends from local environmental impacts to global emissions (see chapter four) and intrinsic Antarctic wilderness values (chapter six); from human safety risks to the interference of other users (see chapter five) and interdependency of users (chapters six and seven. In addition, the analysis includes effects of regulation, as well as potential impacts of tourism on formal regulation (chapter six) and self-governance practices (chapter seven).

The local environmental impacts of tourism in Antarctica have long been recognised, and addressed in scientific studies and policy discussions. This recognition is not surprising given the pristine nature of the Antarctic wilderness and the reliance of tour operations on local landing sites. There is increasing awareness of potential cumulative impacts at landing sites, but currently there is no convincing evidence for this. The global environmental impacts of visiting Antarctica, however, have been systematically overlooked in environmental impact assessments. Recently more attention is given biosecurity issues and biological invasions in Antarctic ecosystems (Frenot et al., 2005). A survey of the literature highlighted the narrow spatial delimitation of existing environmental impact studies. As chapter four shows, this is a serious omission. The long distances travelled, both by ship and aircraft, result in an impressive amount of emissions of close to 15 tonnes of $\mathrm{CO}_{2}$ equivalents per capita per typical tourist trip, including transport to and from the gateway cities. Compared to other tourism destinations this is very high. Our results provide a strong case for including global GHG emissions in any future environmental impact assessments of Antarctic tourism. Climate warming is part of the multiple stressors affecting the Antarctic Peninsula, including increasing tourism 
activities. GHG emissions are a clear example of impact that "spills over the system boundary" (Weaver and Rotmans, 2006; see chapter two). Although the Antarctic Treaty System would not be able to address the total GHG emissions associated with Antarctic tourism, awareness could be raised among passengers regarding the global impacts of their trip. It is also important to conclude that Antarctica, along with other long-haul dependent destinations, is vulnerable to international GHG mitigation policies that would lead to substantial increases in transportation costs.

In recent years, attention for human safety has increased significantly as a result of incidents occurring recently during private expeditions, adventure trips and expedition cruises. Issues of safety risk are not only important for ensuring safety for tourists, but also for avoiding the involuntary spin-off effects for other users. SAR operations of NAPs and other tour operators are costly and involve safety risks. Chapter five demonstrates that risk analysis of the determinant factors of incidents is therefore a worthwhile exercise. In an analysis of recent incidents of adventure tourism and private expeditions a range of common risk determinants were identified, including preplanning factors, operational factors, activity type factors, and environmental factors. These factors are not only insightful for understanding risk in Antarctic tourism operations but also for identifying policies for reducing risks or mitigating negative effects caused by incidents. It is argued that this is a more sensible approach to ensuring human safety than to target particular segments of the tourism industry, such as adventure tourism or private expeditions. Particularly the preplanning factors, such as contingency planning and obtaining insurance, are considered important safety requirements for minimising risks through policy. By extending permit procedures and EIA requirements with these safety requirements, a substantial part of the potential risks and spin-off effects can be brought under control. Nevertheless, one has to be aware that safety risks and the interdependency of actors in the field will remain part of operating in extreme and remote regions like Antarctica.

It may very well be that the growing volume, operational scale and changing form of tourism may not pose demonstrable impacts on Antarctic ecosystems or human safety (due to environmental management or lack of monitoring effort). Still, the erosion of intrinsic wilderness values provides a compelling argument for academic authors, as well as stakeholders, to prohibit or restrict human activities or developments in Antarctica (Codling, 2001; Bastmeijer, 2005). Chapter six shows that particularly the potential development of permanent land-based tourism infrastructures and facilities can be seen in this light. Small-scale forms of land-based tourism are already occurring in Antarctica, using tented camps and facilities of NAPs for accommodation. Although the likelihood of large-scale development is contested, the potential impacts on the environment, the wilderness values, and the Antarctic governance system could be substantial. The international community has a unique opportunity to protect the Antarctic wilderness in its (almost) purest form. In our view, the potential implication of land-based tourism development for environmental quality, wilderness value, jurisdiction, and geopolitical 
tension is at odds with sustainable development criteria. It is argued that the issue of permanent land-based tourism infrastructure and facilities requires a precautionary approach. A number of basic regulatory options are described and discussed, such as regulation through existing instruments or a full prohibition of landbased facilities in Antarctica. A compromise approach would be to restrict such constructions with the exception of areas already in use by existing scientific stations. Such a system could build towards the financial support of science, which is consistent with the consideration of science as a paramount value within the ATS. The choice for any of these regulatory options would depend on the consideration of wilderness values in international Antarctic policy-making.

Given the characteristics of the formal tourism regulatory regime of the ATS, it is very likely that Antarctic tourism regulation will continue to rely heavily on selfregulation in the future. Actually, much of the impetus towards environmentally sound tourism regulation comes from IAATO, a tourism industry association that has managed to unite most tour operators under one umbrella. The institutional analysis in chapter seven based on the governance theory of Ostrom (2005) has identified some of the strengths and weaknesses of IAATO. The strengths of IAATO are the proportional benefits that an IAATO membership creates for tour operators in managing wilderness space, providing administrative services, the positive reputation, and the participatory collective decision-making arrangements. Weaknesses of the self-regulatory system are the non-excludability of other resource users (the free-riding potential), the enormous scale of the resource pool and the uncertain position of IAATO within the ATS. For the moment, the strengths outweigh the weaknesses, resulting in a stable institution. However, increasing membership of diverse tourism companies as well as contextual factors in the future may affect this balance. The research has shown that lack of policy support from the ATS will likely weaken the self-regulatory framework and affect its robustness. Trustworthy partnerships, accreditation schemes and professional monitoring are some of the suggestions made to improve ATS support and recognition of self-regulatory organisations.

\subsubsection{ANALYSIS OF FUTURE SCENARIOS AND IDENTIFICATION OF IMPLICATIONS}

Future explorations for Antarctic tourism, as well as global tourism, are scarce. Future visions of Antarctic tourism are regularly produced by stakeholders but rarely go beyond the "business-as-usual" perspective and provide no integral and coherent set of different scenarios. The integrated scenario analysis performed in chapter eight is based on internal perspectives of Antarctic tourism stakeholders as well as contextual factors derived from global scenario studies. Three participatory scenario workshops were organised in the Netherlands and New Zealand for developing and discussing draft scenarios (up to 2030) while benefitting from the input of a range of Antarctic tourism stakeholders. Scenarios were drafted on assumptions derived from the factor analysis (chapter three) and two sets of relevant global scenario studies, the fourth Global Environmental Outlook and the Millen- 
nium Ecosystem Assessment. The resulting four scenarios differ along the lines of geographical orientation (i.e. globalisation versus fragmentation) and ethical orientation (i.e. market versus environment). In each of the four resulting scenarios, Antarctic tourism develops in different ways regarding scale of activity, form of activity, and control over activities of institutions.

Tourism initially continues to grow in all scenarios but reacts in different ways to the changing internal and contextual conditions. In "The Sky is the Limit", (globalisation/market) opportunities for tourism are optimal but also for the development of other resource related activities. The resulting infrastructural developments drive the expansion of land-based tourism serviced by air links along with increasing operational scales in ship-based tourism. In "Business as Unusual", (globalisation/environment) climate change drives tourism activities in the Polar Regions, activities which remain largely ship-based. International emission mitigation policies increases the barrier of entry and Antarctic tourism regulations manages to keep a fairly clean sheet in terms of impacts. In "Cold Hostage", (fragmentation/market) national resource interests in Antarctica overshadow international cooperation. Tourism activities continue on the sideline for elite groups in places away from resource exploitation activities. In "Special Interest Tourism", (fragmentation/environment) wider-scale interest in Antarctica fades and a diversity of smaller-scale ship-based and land-based niche tourism products remains.

Stakeholders responded to earlier drafts of these scenarios during the workshops in terms of consistency, plausibility, desirability, and policy recommendation. Suggestions regarding consistency were incorporated in subsequent drafts of the scenarios. Participants considered the scenarios fairly plausible. Remarkable enough, the most extreme scenario, "The Sky is the Limit", was deemed most plausible during both the New Zealand and Netherlands workshop. In fact, participants often made suggestions that would make the scenarios more extreme, regarding tourist numbers, operational scales, and tourism form. Although plausible, participants considered the scenarios not desirable, with the exception of "Special Interest Tourism" that was believed to be not necessarily undesirable, with exception of the lack of concerted action. Consequently, policy recommendations were suggested for all scenarios.

The wide range of the scenarios confirm the openness and volatility of the Antarctic tourism system, particular under influence of global contextual factors. Analysis of the similarities and the differences highlights a number of challenges and uncertainties. Most of the scenarios are characterised by growing scales and forms of tourism activities, such as larger cruise vessels and land-based tourism developments. Both were considered a major challenge. Stakeholders believe that there is much potential for future growth in tourist numbers resulting from growing affluence (in all scenarios), growing world populations, ageing (in all scenarios), and technological innovations. Other scenarios suggest that tourism growth may eventually balance out, or decline, as a result of increasing operational limits. The likeli- 
hood of cumulative environmental impacts, catastrophic incidents with loss of life and ecological impact, or rogue operators from non-Treaty Party States are seen as major challenges for the future. Challenges are exacerbated by uncertainties of the participants about the capability of the Antarctic Treaty System and industry selfregulation to control tourism development. Finally, the scenarios point at a number of global developments that might lead to new commercial and industrial interests, and opportunities or deadlocks for its current activities, including energy shortages, water shortages, and global terrorism.

Scenario analysis is instrumental in understanding sustainability challenges on a longer temporal scale and on aggregated levels of scale. Scenarios can play an important role in developing a strategic vision, if they find their way to the relevant policy makers and other stakeholders. Using scenarios in policy development allow stakeholders to identify future uncertainties and common threats to which they might not have been aware. Scenario analysis thereby contributes to the rationale for policy-making to be more proactive and adaptive; the scenarios developed could provide a tool to make this new approach operational. Participatory scenario analysis can also stimulate social learning among different stakeholders in the Antarctic tourism system. The results from our small-scale experimental workshop settings in the Netherlands and New Zealand demonstrate the practical relevance and usefulness of scenario studies for discussing and preparing for the future of tourism in Antarctica.

\subsubsection{ANALYSIS OF STAKEHOLDER PERSPECTIVES ON OPTIONS FOR ANTARCTIC TOURISM GOV- ERNANCE TOWARDS SUSTAINABILITY}

The fourth objective relates the sustainability challenges discussed in this thesis to the reality of present day stakeholders and their perspectives on governance options. Chapter two introduced sustainable development as a contested concept, due to inherent ambiguity, normativeness, subjectivity and complexity (Grosskurth and Rotmans, 2005). In several chapters of this thesis perspectives of Antarctic stakeholders on tourism development and regulation are presented, based on policy documents (chapter six), interviews (chapter seven), and participatory workshops (chapter eight). In chapter nine stakeholder perspectives are analysed more thoroughly regarding the role of tourism in sustainable Antarctic development (SD objective), the capability of, and the need for, the ATS to control tourism development, and preferred policy options (SD action perspective). In the absence of a local population and economy, it is not clear what should be the main aim of sustainable tourism development in Antarctica. Existing agreements (e.g. the Protocol) leave open much space for interpretation. To demonstrate these different perspectives an adaptive concept of sustainable tourism development (Hunter, 1997) is used as a framework to map opinions expressed during an international interview round with key stakeholders. 
From the analysis of interviews it can be concluded that perspectives of stakeholders on the role of tourism in sustainable development diverge along the weaker and stronger sustainability continuum (Robinson, 2004; Williams and Millington, 2004). Some of the operators see tourism as a harmless activity that creates ambassadors for Antarctic conservation against more devastating activities that the Antarctic may face in the future (SD through a tourism imperative). The second perspective (SD through product-led tourism) sees tourism as a potential source of income for other local stakeholders, such as science. In both of these perspectives, it is believed that tourism should be praised for the benefits and not be restricted or further regulated. According to the third perspective, (SD through environment-led tourism) tourism is allowable as long as there are no environmental impacts or other types of negative effects, such as risks for human safety. Policy should focus on mitigating unacceptable levels of proven impact. Most of the interviewees agreed with this perspective. The fourth perspective (SD through neotenous tourism) sees larger scale tourism development and certain activities as a threat to wilderness value and scientific value that urges for a precautionary approach. This implies that particular forms of tourism (e.g. land-based tourism), scale of operation (e.g. large cruise liners) or volumes of tourists should be prohibited or restricted. Depending on the sustainability perspective that one favours, these policy approaches can be applied. Also, we would like to stress that by setting up a system of zones, multiple visions can be integrated into an overall management approach.

Perspectives also diverge regarding the capability of the ATS to control tourism development, and the need for more formal tourism regulation. Many stakeholders express a wish for a stronger, more hierarchical, role of the ATS but doubt if this is feasible in the deliberative governance setting of the Treaty. At the same time, reliance on self-regulation of the tourism industry also has its risks, as the weaknesses of self-regulation might become more prominent in the future (Haase et al., 2009). Tourism is organised by complex networks of actors operating at different spatial levels (e.g. IMO, ATS, IAATO), which raises questions about the proper allocation of responsibilities. It is concluded that besides focusing on the objective of tourism policy, attention should go out to the action perspective by knowing the strengths and weaknesses of Antarctic governance institutions in policy development, implementation and enforcement. Without a clear policy objective and action perspective, it will be very difficult to agree on a set of policy instruments.

By comparing the scenarios developed in chapter, eight with the sustainability perspectives in chapter nine one gets a sense of their compatibility and some of the implications for policy (see Table 10.1). The first and the third perspective have a clear preference for either the environment or the market; therefore, they are most compatible with the scenarios developed under the same assumptions. The perspective of SD through a tourism imperative seems to fit most naturally with the Cold Hostage, and the Sky is the Limit scenarios. SD through an environmental imperative is most compatible with Business as (un)Usual and Special Interest Tour- 
ism. The other two perspectives do not correspond with specific scenario assumptions but rather in terms of favourable scenario outcomes. In the Business as (un)Usual scenario current business ethics and cooperation between users continues into the future and therefore fits naturally to the SD as a product perspective. In Special Interest Tourism developments remains small scale and therefore match with the perspective of neotenous tourism development. Coupling perspectives to scenario preferences has not been empirically tested in this research project. To avoid socially desirable answers the four sustainability perspectives have not been explicitly part of the interview guideline. However, the scenarios illustrate that maintaining and specifying the environmental imperative of the Environmental Protocol is important. In chapter eight, we have seen that scenarios two and four were considered more desirable than the other two (see Table 8.4). Although some remarks of stakeholders can be related to the tourism imperative perspective, this does not necessarily imply that these stakeholders are in favour of future scenarios developed under the same assumptions. An observation made in comparing the results of both methodologies is that future challenges from the integrated scenario analysis are more extreme than the perspectives of individual stakeholders during interviews. During interviews, in their roles as stakeholders (often carried out in their respective offices), interviewees present a perspective on the future based on their interests. During workshops, stakeholders focus more on the tourism system as a whole, at aggregated spatial and temporal levels of analysis.

Table 10.1: Compatibility of sustainability perspectives and scenarios

\begin{tabular}{l|l|}
\hline Sustainability perspective & Most compatible with scenario(s): \\
$\begin{array}{ll}\text { 1) SD through a tourism imperative } & \text { 1) The Sky is the Limit; } \\
\text { 3) Cold Hostage }\end{array}$ \\
\hline 2) SD through tourism as a product & 2) Business as (un)Usual \\
\hline 3) SD through an environmental imperative & 2) Business as (un)Usual; \\
\hline 4) SD through neotenous tourism & 4) Special Interest Tourism \\
\hline
\end{tabular}

At the most recent ATCM in Baltimore, a number of policy steps have been taken with regard to the regulation of Antarctic tourism, such as the codification of a set of operational rules in international law; the adoption of a list of key principles, and the commissioning of a CEP status report. In the list of principles the long-term degradation of the Antarctic environment and associated ecosystems, intrinsic wilderness values and historic values are explicitly discouraged. Although these are steps in the right direction, they neither make the ATS future proof nor tourism sustainable. For example, it is not clear what these principles mean for actual developments and localities, such as the construction of land-based facilities or frequently visited sites. The codification of operational rules in international law would also be stronger when combined with a fitting action perspective on its implementation and enforcement. It is concluded that the international debate on a 
shared vision should continue and focus on more detailed policy implications of these general principles. Issues of volume, operational scale, distribution, form and control of tourism should be more explicitly part of this debate. To monitor the performance of tourism activity against these principles (e.g. long-term degradation, science prioritisation, cooperation) concerted action is necessary. It is suggested that experimentation with new forms of governance (e.g. public-private partnerships), existing policy instruments (e.g. zoning instruments) and the development of innovative policy instruments (e.g. cap-and-trade approaches) provide options for future governance. It is to be hoped that a potential backlash in tourist numbers resulting from the global economic crisis is not causing policy makers to postpone addressing these issues.

\subsection{Reflection on concepts and methods}

In this thesis, the concept of sustainable development was applied to examine future challenges of tourism in Antarctica. Attempts to do so have been scarce in the literature. Explicit attempts have taken a very narrow sustainability concept focusing primarily on local management (Splettstoesser et al., 2004; Snyder, 2007), or based on observations taken on a single journey (Lambert, 2007). The Antarctic case is presenting many peculiarities that complicate a straightforward application of existing concepts, such as the absence of sovereign government and an indigenous human population, the remoteness and extremeness, the vulnerability of both ecosystems and human actors, and the role of science in Antarctica. For example, diversification of the portfolio of tourism products is typically seen as contributing towards sustainable tourism as the tourist destination, including the local communities dependent on tourism, becomes less vulnerable for sudden shifts in demand. The absence of a clear local recipient community and the pristine nature of the environment make that in Antarctica diversification is typically seen as a major concern.

It was recognised from the start that there is no such thing as a one size fits all concept of sustainable tourism (Hunter, 1997). What constitutes "sustainable" has to be defined and negotiated by those involved (Saarinen, 2006). A number of key elements have been identified in chapter two that would need attention in any interpretation of sustainable tourism: the objective of sustainable tourism, the appropriate delimitation in time and space, and the appropriate mix of hierarchical and deliberative governance approaches in developing, implementing and enforcing policy. Examining future challenges of Antarctic tourism with these criteria has proven a worthwhile exercise. This thesis has enriched the knowledge base of Antarctic tourism by contributing an integrative model of tourism development, a deepening of insight on potential and actual risks and impacts, a set of Antarctic tourism scenarios, and a range of perspectives and policy options for sustainable tourism governance. 
With these general sustainability principles, this thesis also contributes to the theoretical literature on sustainable tourism, especially in terms of scaling issues in tourism analysis and governance. As indicated earlier in this thesis, sustainable tourism studies have primarily focused on the local destination level and hierarchical modes of governance. The Antarctic case illustrates that results may differ or contradict at different levels of scale, and that forms of self-regulation, or institutional entrepreneurship (Van Wijk, 2009), can be very instrumental in reaching sustainability objectives. Scaling issues in sustainability assessment for tourism have been recognised by other authors (e.g. Hunter, 2002; Amelung, 2006). It is only logical that the tourism research community will respond by developing, or taking on board, research approaches (e.g. Weaver and Rotmans, 2006) and governance concepts (Ostrom, 2005) capable of addressing these scaling issues.

In parts of this thesis, additional theoretical concepts were used to strengthen both integrative and in-depth analysis. The analysis of factors driving and constraining tourism development elicited from stakeholder workshops benefitted from linking with the Recreation Opportunity Spectrum concept, a concept well established in the tourism literature (Clark and Stankey, 1979; Butler and Waldbrook, 1991; Boyd and Butler, 1996). The institutional robustness analysis of the Antarctic tourism self-regulatory regime was framed on Elinor Ostrom's theory of collective action (Ostrom, 2005). Both of these theoretical frameworks have a proven record of applications worldwide and have elicited valuable insights for the Antarctic setting. Earlier applications of these theoretical frameworks support this claim (e.g. Buck, 1998; Davis, 1999).

In this thesis, an integrative and trans-disciplinary research approach was followed, employing a range of methodologies. A choice was purposefully made for a participatory approach to highlight and analyse different views and initiate collective thinking about future scenarios (Hisschemoller et al., 2001). Participatory approaches have added value as a means of knowledge production and extended peer review, i.e. societal scrutiny of the usefulness of research results (Funtowicz and Ravetz, 1994). The participatory scenario analysis (Van Asselt et al., 2005) performed in this thesis has resulted in a richer future knowledge base from which policy makers and analysts can draw. A series of participatory scenario workshops were organised for Antarctic tourism stakeholders to develop and analyse a range of future scenarios and identify sustainability challenges and implications. These participatory workshop were particularly useful at the start of the research process to provide input as well as guidance on the most pertinent sustainability challenges of Antarctic tourism. Workshops were combined with literature survey to establish the state of knowledge on Antarctic tourism and to explore the main concerns of ATCPs and organisations tabled at the ATCMs in recent years. Existing Antarctic visitor data was analysed to establish a factual record on temporal and spatial distribution and growth. In addition, observations were made of Antarctic tourism operations and policy making during fieldwork experiences. Combining these multi- 
disciplinary methodologies for the purpose of the participatory integrated assessment (PIA) performed in this thesis has proven worthwhile.

In several ways, the participatory scenario workshops have functioned as an experimental setting in this thesis. What happens when you confront stakeholders with a range of future scenarios and ask them to collectively discuss implications? The workshops demonstrate the usefulness of scenarios in identifying critical issues and bridging perspectives between stakeholders. Two different approaches were combined for the scenario analysis (for an overview of approaches see Bischop et al., 2007). First, scenarios were developed based on a matrix of two uncertainties or polarities, elaborated into future storylines by participating stakeholders (an approach coined by Schwartz, 1991). Second, sets of existing global scenarios were analysed for the Antarctic tourism purpose; an approach called incasting (Bischop et al., 2007). Using both approaches allowed for ideas emerging from the bottom up and the top down, and can be considered a scenario innovation coming from this project.

Ensuring a critical level of participation during workshops is difficult when there is no policy mandate or guarantee of outcome for stakeholders (see also Van Asselt et al., 2005). The third scenario workshop experienced a lack of stakeholder participation, which is a critical factor for ensuring the validity in participatory methods. Since the workshops identified a range of factors that would require additional analysis (e.g. global environmental impact, robustness of self-regulation, implications of land-based facilities) attention shifted to these issues during the second part of the process. It was also decided to combine participatory scenario analysis with a round of in-depth stakeholder interviews to generate input from a diverse selection of international stakeholders and an alternative source of information. Participants with different interests are likely to withhold information during participatory sessions (Creighton, 2005); information that can be elicited by individual in-depth interviews. Some limitations were also encountered in relation to data availability, for example in calculating $\mathrm{CO}_{2}$ emissions. Overall it is believed that by combining and triangulating different research methods and by reflecting on the validity of different sources of information this bias has been sufficiently tackled (Neuman, 2003).

As a PhD project, a participatory scenario analysis is a challenging task in which an inexperienced researcher has to balance between academic quality and societal usefulness, and move between expert and facilitator roles in participatory settings. These challenges of PIA can be more easily tackled within a larger research team in which roles are more clearly defined, experienced facilitators are hired, and policy makers (or other stakeholders) more clearly support the process (see also Lamers et al. in press). The combination of integrative chapters and in-depth chapters in this thesis has contributed to meeting both societal and academic needs. As an experimental setting, the workshops do demonstrate that a similar approach con- 
vened by an ATS commission, and performed by an interdisciplinary research team would likely generate great discussions and results.

\subsection{Future research}

The analysis of sustainability challenges and impact areas in this thesis is by no means complete. Covering the full range of Antarctic tourism challenges goes beyond the scope of this thesis. In the course of this thesis several research topics are mentioned that could be picked up in future research.

First of all, the explorative research approach followed in this thesis could well be followed up by a larger scale assessment in which sustainable tourism development in Antarctica could be defined into a more narrow concept along with a set of criteria and indicators. Another idea that came up from the participatory workshops would be to follow up this project with a scenario backcasting exercise, in which an ideal future state is collectively described and different steps are traced back to the present to analyse how to reach that state (Bischop et al., 2007; Robinson, 1990). As indicated above, an interdisciplinary research team, experienced facilitators and active support from policy makers would be essential to make this type of project a success. Many of the impact areas of Antarctic tourism would merit from further research, using a similar integrative or a more disciplinary approach. There may be other factors or impact areas of significance for sustainable tourism development in Antarctica, for example impacts on historical huts and heritage sites, on-site tourism management practices of tour operators and NAPs, and tourist perceptions of acceptable governance modes, acceptable operational modes, and acceptable levels of risk and impact.

In their review of polar tourism research Stewart et al. (2005) have identified a lack of studies focused on polar tourism in relation to global environment change. In this thesis, a start was made to calculate $\mathrm{CO}_{2}$ emissions of Antarctic tourism. This could undoubtedly be done in a more sophisticated way but data is not publicly available on emissions or fuel consumption of ships. With this data, a more refined calculation could be made that could be used for awareness raising of global impacts and carbon off-set programmes among passengers and operators, encouraging eco-efficiency during operations and ship-building, and policy development. Another potential research avenue to pursue is assessing the global environmental impacts of the expanding global cruise industry.

Focusing on the global level does not mean that research attention for local impacts and management practices should be neglected. During field observations, remarkable differences in attitudes and practices between tour operators and NAPs were noted. Comparing operational rules and practices between science operators, between tour operators, and between science and tour operators seems a worthwhile exercise, especially as activities are increasing. Implications of these 
differences can contribute to suggesting ways to further standardise these practices. The use of Geographical Information Systems (GIS) to aid research in this field is promising.

Antarctic tourism governance could benefit tremendously from comparative research with other remote destinations, such as the Galapagos Island and the Arctic region (e.g. Greenland, Svalbard), to explore management and monitoring practices, governance modes and policy instruments. Some work has been done in this field (Tracey, 2001; Norway, 2004) but opportunities still abound. There is a lot of scope for research on the use and effectiveness of various policy instruments for tourism in Antarctica. It would be wise to pro-actively investigate the advantages and disadvantages of a wide set of regulatory tools that the ATS and IAATO can use in future regulation and management. Both Polar Regions are facing multiple stressors, such as climatic changes, resource extractions, feedbacks from historical resource depletion, tourism activity, ecosystem shifts, and possibly biological invasions. The interdependency and magnitude of these stressors is unknown. It is also not known what the main role of tourism is in the global changes of the Polar Regions: instigator, follower or victim? To what degree does the tourism industry adapt to climate changes in the Polar Regions, and are there different interests of ship-based and land-based operations?

This thesis has identified the significance of self-regulation as a crucial governance approach towards sustainable development in Antarctica. The insights gained in this study can be meaningful, and show the way, for many tourism businesses operating in the global regulatory void. Research into associations and partnerships of international tourism businesses could result in important factors for success and failure of these self-regulatory practices, and suggest ways for robust nested governance regimes.

Globally, Antarctic tourism (and Arctic tourism) studies are undertaken on an ad hoc basis: scattered across the globe, for short periods of just a few years, without a common research agenda. The recently founded International Polar Tourism Research Network (IPTRN) aims at tackling this issue by synchronising the activities of dozens of polar tourism researchers worldwide. The same applies to the emerging field of social sciences and humanities in the traditionally natural sciences dominated Antarctic research scene. The Social sciences and Humanities Antarctic Research Exchange (SHARE) aims to bridge this gap between these researchers and raise the profile of social sciences in Antarctica. The author is a founding member of both networks. 



\section{Epilogue}

In 2009 the $50^{\text {th }}$ anniversary of the Antarctic Treaty was celebrated at the Antarctic Treaty Consultative Meeting in Baltimore, United States. Tourism was practically non-existent when the Antarctic Treaty was signed in 1959. In the past five years that I have been involved in this topic, the regulatory climate of Antarctic tourism has warmed steadily into a hot topic during Antarctic Treaty Consultative Meetings. Future challenges of Antarctic tourism have grown in profile because of incidents and growing concerns of stakeholders. Five years of thinking about Antarctica, meeting remarkable Antarcticans, and three visits to the region have also infected me with the polar virus. The cold Antarctic continent has found a warm place in my heart; an "ambassador" has been created. With this thesis, I aim to contribute to the understanding of future challenges, the merits of a future oriented perspective in policy-making, and the development of sustainable policies for tourism in Antarctica. With this thesis, I hope that the integrity of Antarctic ecosystems and the splendour of its scenery can be preserved for future generations. 



\section{Bibliography}

7 Seas Consulting (2007). Report by the Ice Master on board of Le Diamant. Report prepared for the International Association of Antarctica Tour Operators (IAATO). T. Roeder. Bad Steben, Germany.

AAD (2008). Antarctic Sculpture Garden. Australian Antarctic Division Retrieved 22 January 2008, from www.aad.gov.au/default.asp?casid=9685.

Alcamo, J. (2001). Scenarios as tools for international environmental assessments. Environmental issue report 24. Experts' corner report: Prospects and Scenarios 5. T. Ribeiro. Copenhagen: European Environmental Agency.

ALE (2003). Multi-Year Application to the US Environmental Protection Agency: Initial Environmental Evaluation of Antarctic Flight Logistics. Arlington, Virginia, USA: Antarctic Logistics \& Expeditions.

Amelung, B. (2006). Global (Environmental) Change and Tourism. Issues of Scale and distribution. Maastricht: Universitaire Pers.

Amelung, B. and M. Lamers (2006). Scenario Development for Antarctic Tourism: Exploring the Uncertainties. Polarforschung 2-3: 133-139.

Amelung, B. and M. Lamers (2007). Estimating the $\mathrm{CO} 2$ emissions from Antarctic tourism. Tourism in Marine Environments 4(2-3).

ANAN (2003). Antarctic Non-government Activity News 2003 Issues. 19-10-2004, from http://www.aad.gov.au/default.asp?casid=4974.

ANAN Archive (2001). Antarctic Non-government Activity News Archive. Retrieved 19-10-2004, from http://wwwold.aad.gov.au/goingsouth/tourism/News/2001/default.asp.

ANAN Archive (2002). Antarctic Non-government Activity News Archive. Retrieved 19-10-2004, from http://wwwold.aad.gov.au/goingsouth/tourism/News/2002/default.asp.

Antarctic Treaty System (1959). Antarctic Treaty. Retrieved 4-5-2009, from www.ats.aq.

Antarctic Treaty System (1991). Protocol on Environmental Protection to the Antarctic Treaty. Retrieved 19-9-2007, from http://www.ats.aq/.

Antarctic Treaty System (2004). Final Report of the XXVII ATCM. Antarctic Treaty Consultative Meeting, Cape Town, South Africa.

Antarctic Treaty System (2005). Final Report of the XXVIII ATCM. Antarctic Treaty Consultative Meeting, Stockholm, Sweden.

Antarctic Treaty System (2006). Final Report to the XXIX ATCM. Antarctic Treaty Consultative Meeting, Edinburgh, United Kingdom.

Antarctic Treaty System (2007a). Final Report - Part II: Measures, Decisions and Resolutions. Antarctic Treaty Consultative Meeting XXX, New Delhi, India.

Antarctic Treaty System (2007b). Final Report of the XXX ATCM. Antarctic Treaty Consultative Meeting, New Delhi, India.

Antarctic Treaty System (2008). Final Report of the XXXI ATCM. Antarctic Treaty Consultative Meeting XXXI, Kyiv, Ukraine. 
Antarctic Treaty System (2009). Resolution 7: General Principles of Antarctic Tourism. Antarctic Treaty Consultative Meeting XXXII, Baltimore, United States. Retrieved 8-9-2009, from http://www.ats.aq/devAS/info_measures_report.aspx?id=448\&lang=e

Aplet, G., J. Thomson and M. Wilbert (2000). Indicators of Wildness: Using Attributes of the Land to Assess the Context of Wilderness. Forest Service Proceedings RMRS-P-15, United States Department of Agriculture.

Argentina (2006). IP31 Tourism development in the Antarctic Peninsula: a regional approach. Antarctic Treaty Consultative Meeting XXIX, Edinburgh.

Argentinean Government (1969). Argentinean Law No. 18.513.

ASOC (1999). IP121 Large Scale Antarctic Tourism. Antarctic Treaty Consultative Meeting XXIII, Lima, Peru.

ASOC (2001). IP4O Antarctic tourism. Antarctic Treaty Consultative Meeting XXIV, St. Petersburg, Russia.

ASOC (2003). Port State Control: an update on international law approaches to regulate vessels engaged in Antarctic non-governmental activities. Antarctic Treaty Consultative Meeting XXVI, Madrid, Spain.

ASOC (2006). IP120 Strategic Issues posed by Commercial Tourism in the Antarctic Treaty Area. Antarctic Treaty Consultative Meeting XXIX, Edinburgh, United Kingdom.

ASOC (2007). IP79 The Case Against Tourism Landings from Ships Carrying More than 500 Passengers. Antarctic Treaty Consultative Meeting XXX, New Delhi.

ASOC (2008). IP41 A decade of Antarctic tourism: Status, change, and actions needed. Antarctic Treaty Consultative Meeting XXXI, Kyiv, Ukraine.

ASOC (2009a). Key Elements of a Strategic Vision for Antarctic Tourism. Antarctic Treaty Consultative Meeting XXXII, Baltimore, United States.

ASOC (2009b). Managing Antarctic Vessels - Avoiding Future Disasters. Antarctic Treaty Consultative Meeting XXXII, Baltimore, United States.

Australia (2004a). ATME\#15 Accreditation of non-government operations. Antarctic Treaty Meeting of Experts on Tourism and Non-governmental Activities, Tromso, Norway.

Australia (2004b). ATME\#16 An approach to monitoring for non-government activities in Antarctica. Antarctic Treaty Meeting of Experts on Tourism and Non-governmental Activities, Tromso, Norway.

Australia (2005). WP38 Protection of Antarctica's Intrinsic Values: Policy on NonGovernmental Activities. Antarctic Treaty Consultative Meeting XXVIII, Stockholm, Sweden.

Australia, France and New Zealand (2009). WP12 Environmental Aspects and Impacts of Tourism and Non-governmental Activities in Antarctica: Draft Project Scope. Antarctic Treaty Consultative Meeting XXXII, Baltimore, USA.

Bachleitner, R. and A. H. Zins (1999). Cultural Tourism in Rural Communities: The Residents' Perspective. Journal of Business Research 44(3): 199-209. 
Baraona, R. (1999). Calificacion ambiental del proyecto "Dessarollo del Turismo Antartico por Via Aerea" de la empresa Aerolineas DAP. Retrieved 12-12006, from www.e-seia.cl/portal/antarticos/archivos/RCA_ant_1.doc.

Bastmeijer, C. (2002). The Antarctic Environmental Protocol and its Domestic Legal Implementation. The Hague: Kluwer Law International.

Bastmeijer, C. (2003). Tourism in Antarctica: Increasing Diversity and the Legal Criteria for Authorisation. New Zealand Journal of Environmental Law 7: 85-118.

Bastmeijer, C. (2004). Recht en beleid in Antarctica. In: B. Sliggers (Ed.). Extreem! Overleven op Antarctica. Haarlem: Teylers Museum.

Bastmeijer, C. (2005). Managing Human Activities in Antarctica: Should Wilderness Protection Count? New Zealand Yearbook of International Law 2005: 335353.

Bastmeijer, C. (2007). Special Offer: 7 Days Fly and Drive Antarctica. A paper on the role of wilderness protection in deciding whether (semi-) permanent tourist facilities in Antarctica should be prohibited. Science and Stewardship to Protect and Sustain Wilderness Values: Eight World Wilderness Congress Symposium, Rocky Mountains Research Station, Forest Service, US Department of Agriculture.

Bastmeijer, C., M. Lamers and J. Harcha (2008). Permanent Land-based Facilities for Tourism in Antarctica: The need for regulation. Review of European Community and International Environmental Law (RECIEL) 17(1).

Bastmeijer, C. and R. Roura (2004). Regulating Antarctic Tourism and the Precautionary Principle. The American Journal of International Law 98(4): 763781.

Bastmeijer, C. and R. Roura (2008). Environmental Impact Assessment in Antarctica. In: K. Bastmeijer and T. Koivurova (Eds.). Theory and Practice of Transboundary Environmental Impact Assessment. Den Haag: Brill/Martinus Nijhof Publishers.

Bastmeijer, C. and J. Verschuuren (2005). NGO-business collaborations and the law: sustainability, limitations of the law, and the changing relationship between companies and NGOs. In: E. Demirag (Ed.). Corporate Social Responsibility, Accountability and Governance. Global Perspectives. Sheffield: Greenleaf Publishing.

Bauer, T. (1994). The Future of Commercial Tourism in Antarctica. Annals of Tourism Research 21(2): 410-413.

Bauer, T. (2007). Antarctic Scenic Overflights. In: J. Snyder and B. Stonehouse (Eds.). Prospects for Polar Tourism. Wallingford: CABI.

Bauer, T. G. (2001). Tourism in the Antarctic: Opportunities, Constraints, and Future Prospects. New York: The Haworth Hospitality Press.

Baumert, K. A., T. Herzog and J. Pershing (2005). Navigating the Numbers: Greenhouse gases and international climate change agreements. Washington DC: World Resources Institute 1-132. 
BBC News (2005). Explorer dies in fall through ice. Retrieved 18-1-2005, from http://news.bbc.co.uk/2/hi/uk_news/england/cambridgeshire/4183295.st $\mathrm{m}$.

Beck, P. J. (1990). Regulating one of the last tourism frontiers: Antarctica. Applied Geography 10(4): 243-356.

Becken, S. (2002). Analysing International Tourist Flows to Estimate Energy Use Associated with Air Travel. Journal of Sustainable Tourism 10(2): 114-131.

Becken, S. and D. Simmons (2002). Understanding energy consumption patterns of tourist attractions and activities in New Zealand. Tourism Management 23(4): 343- 354.

Bentley, T. and S. Page (2001). Scoping the extent of adventure tourism accidents. Annals of Tourism Research 28(3): 705-726.

Berte, J. and A. Hubert (2006). Technical Presentation for a Press Conference. Retrieved 4-5-2009, from http://www.polarfoundation.org/docs/projects/station_antarctica/station _technical_pdf_060531.pdf.

Bertram, E., B. Stonehouse and S. Muir (2007). Gateway Ports in the Development of Antarctic Tourism. In: J. Snyder and B. Stonehouse (Eds.). Prospects for Polar Tourism. Wallingford: CABI.

Bierman, F. (2007). 'Earth system governance' as a crosscutting theme of global change research. Global Environmental Change 17(3-4): 326-337

Bischop, P., A. Hines, T. Collins (2007). The Current State of Scenario Development: An overview of techniques. Foresight 9(1): 5-25.

Boyd, S. and R. Butler (1996). Managing ecotourism: an opportunity spectrum approach. Tourism Management 17(8): 557-566.

Braungart, M., W. McDonough and A. Bollinger (2007). Cradle-to-Cradle design: creating healthy emissions strategy for eco-effective product and system design. Journal of Cleaner Production 15: 1337-1348.

Briassoulis, H. (2002). Sustainable tourism and the question of the commons. Annals of Tourism Research 29(4): 1065-1085.

Brown, F. (1998). Tourism Reassessed: Blight or Blessing? Oxford: ButterworthHeinemann.

Buck, S. J. (1998). The Global Commons: an introduction. Washington D.C.: Island Press.

Budget Travel Online (2005). The 10 Big Trends in Cruise Ship Vacations. Retrieved 21-11-2006, from http://budgettravelonline.com/btdyn/content/article/2005/06/04/AR2005060400670_2.html.

Burger, P. (2006). Why any substantial definition of sustainability must fail - and why this is a good, not a bad story. International Sustainable Development Research Conference, Hong Kong, University of Hong Kong.

Butler, R. (1999). Sustainable tourism: A state-of-the-art review. Tourism Geographies 1(1): 7-25.

Butler, R. and L. Waldbrook (1991). A New Planning Tool: the Tourism Opportunity Spectrum. Journal of Tourism Studies 2(1): 1-14. 
Carey, P. (2005). Small ship or large ship? In: J. Rubin (Ed.). Lonely Planet Antarctica 3rd Edition. Lonely Planet Publications: 298-299.

Carpenter, S., P. Pingali, E. Bennet and M. Zurek, Eds. (2005). Ecosystems and human well-being: scenarios. Washington DC: Islands Press.

Cash, D. W., N. W. Adger, F. Berkes, P. Garden, L. Lebel, P. Olsson, L. Pritchard and O. Young (2006). Scale and Cross-Scale Dynamics: Governance and Information in a Multilevel World. Ecology and Society 11(2): 8-19.

Cessford, G. (1997). Antarctic Tourism. A Frontier for Wilderness Management. International Journal of Wilderness 3(3): 7-11.

Chanceaulme, O. (1999). Proyecto de Turismo Antartica Soyuz (Union Antartida) Peninsula Fildes, Isla Rey Jorge, Archipielago Shetland del Sur. Evaluacion de Impacto Medioambiental Inicial. Retrieved 19-1-2006, from http://www.e-seia.cl/portal/antarticos/archivos/ant_2.doc.

Chiang, E. (2000). Tourism risks from an operational perspective. Proceedings of the Antarctic Tourism Workshop, 23 June 2000, Christchurch, Antarctica New Zealand.

Chilean Government (2000). Chilean Presidential Decree No. 429: Ministry of Foreign Affairs.

Clark, R. N. and G. H. Stankey (1979). The Recreation Opportunity Spectrum: A Framework for Planning, Management, and Research. General Technical Report PNW-98 Pacific Northwest Forest and Range Experiment Station: U.S. Department of Agriculture and Forest Service.

Cleaver, F. (2002). Reinventing institutions and the social embeddedness of natural resource management. European Journal of Development Research 14(2): 11-30.

Cleveland, H. (1988). Introducing the global commons. In: H. Cleveland and L. Burdette (Eds.). The Global Commons. Minneapolis: H.H. Humphrey Institute of Public Affairs, University of Minnesota.

Codling, R. (2001). Wilderness and Aesthetic Values in the Antarctic. Polar Record 37(203): 337-352.

COMNAP (2002). IP27 The Interaction Between National Operators, Tourists and Tourism Operators. Antarctic Treaty Consultative Meeting XXV, Warsaw, Poland.

COMNAP (2003). IP37 Interaction Between National Operators, Tourists and Tourism Operators. Antarctic Treaty Consultative Meeting XXVI, Madrid, Spain.

COMNAP (2004). ATME\#25 Information Paper on the Interaction between National Antarctic Programs and Non-Government and Tourism Operations. Antarctic Treaty Meeting of Experts on Tourism and Non-governmental Activities, Tromso, Norway.

Creighton, J. L. (2005). The Public Participation Handbook. Making Better Decisions Through Citizen Involvement. San Francisco: Jossey-Bass.

Crosbie, K. (2005). Towards Site Guidelines: A Preliminary Analysis of Antarctic Peninsula Site Landing Data, 1990/00-2003/04. Antarctic Treaty Consultancy Meeting XXVIII, Stockholm, Sweden. 
DAP (2008). Company website of Aerovias DAP. Retrieved 22-1-2008, from www.aeroviasdap.cl/reyjorge-en.html\#precios.

Davis, P. (1998). Understanding visitor use in Antarctica: the need for site criteria. Polar Record 34(188): 45-52.

Davis, P. (1999). Beyond Guidelines. A model for Antarctic Tourism. Annals of Tourism Research 26(3): 516-533.

De Poorter, M. (2000). Tourism Risks from an Environmental Perspective. Proceedings of the Antarctic Tourism Workshop, 23 June 2000, Christchurch, Antarctica New Zealand.

De Ridder, W. (2006). Tool use in integrated assessments. Integration and synthesis report for the Sustainability A-test project. Bilthoven: Netherlands Environmental Assessment Agency

De Ridder, W., J. Turnpenny, M. Nilsson, A. von Raggamby (2007). A Framework for Tool Selection and Use in Integrated Assessment for Sustainable Development. Journal of Environmental Assessment Policy and Management 9(4): 423-441.

Dharmaratne, G. S., F. Yee Sang and L. J. Walling (2000). Tourism Potentials for Financing Protected Areas. Annals of Tourism Research 27(3): 590-610.

Dietz, T., E. Ostrom and P. Stern (2003). The Struggle to Govern the Commons. Science 302: 1907-1912.

Dingwall, P. and G. Cessford (1996). Pole positions. Ecodecision 20: 65-68.

Donachie, S. (1994). Henryk Arctowski Station: Mixing Science and Tourism. Annals of Tourism Research 21(2): 333-343.

Dyllick, T. and K. Hockerts (2002). Beyond the Business Case for Corporate Sustainability. Business Strategy and the Environment 11(2): 130-141.

Enzenbacher, D. (1992). Antarctic tourism and environmental concerns. . Marine Pollution Bulletin 25(9-12): 258-265.

Enzenbacher, D. (1993). Tourists in Antarctica: numbers and trends. Tourism Management 14(2): 142-146.

Enzenbacher, D. (1994). Tourism at Faraday Station: An Antarctic Case Study. Annals of Tourism Research 21(2): 303-317.

Enzenbacher, D. (2007). Antarctic Tourism Policy-making: Current Challenges and Future Prospects. In: G. Triggs and A. Riddell (Ed.). Antarctica: legal and environmental challenges for the future. London: The British Institute of International and Comparative Law: 155-189.

Ewert, A. and S. Hollenhorst (1989). Testing the Adventure Model: Empirical Support for a Model of Risk Recreation Participation. Journal of Leisure Research 21(2): 124-139.

Faulkner, B. and R. Russell (1997). Chaos and Complexity in Tourism: in search of a new perspective. Pacific Tourism Review 1: 93-102.

Feeny, D., F. Berkes, B. J. McCay and J. M. Acheson (1990). The Tragedy of the Commons: Twenty-two years later. Human Ecology 18(1): 1-19.

Fogg, G. E. (1992). A History of Antarctic Science. Cambridge: Cambridge University Press. 
Folke, C., T. Hahn, P. Olsson and J. Norberg (2005). Adaptive Governance of SocialEcological Systems. Annual Review Environmental of Resources 30(8): 1-33.

Font, X., R. Tapper, K. Schwartz and M. Kornilaki (2006). Sustainable Supply Chain Management in Tourism. Business Strategy and the Environment 17(4): 260-271.

Fowler, A. N. (2000). COMNAP: The National Managers in Antarctica. Baltimore: American Literary Press, Inc.

France (2004). ATME\#23 Tourism and non-governmental activities in Antarctica: deficiencies in the current legal framework. Antarctic Treaty Meeting of Experts on Tourism and Non-governmental Activities, Tromso, Norway.

France (2005). IP12 Creation of Areas of Special Tourist Interest. Antarctic Treaty Consultative Meeting XXVIII, Stockholm, Sweden.

Frenot, Y., S. Chown, J. Whinam, P. Selkirk, P. Convey, M. Skonicki and D. Bergstrom (2005). Biological invasions in the Antarctic: extent, impacts and implications. Biological Review 80: 45-72.

Funtowicz, S. and J. Ravetz (1994). Uncertainty, Complexity and Post-Normal Science. Environmental Toxicology and Chemistry 13(12): 1881-1885.

Garrod, B. (1998). Beyond the Rhetoric of Sustainable Tourism. Tourism Management 19(3): 199-212.

Genest, E. (2004). Polittica Antartica Argentina. Retrieved 22-1-2008, from www.dna.gov.ar/DIVULGAC/SINAPA04.DOC.

Germany (2005). IP20 The Admissibility of Land-Based Tourism in Antarctica under International Law. Antarctic Treaty Consultative Meeting XXVIII, Stockholm, Sweden.

Gibbons, M. (2000). Mode 2 society and the emergence of context-sensitive science. Science and Public Policy 27(3): 159-163.

Gibbons, M., C. Limoges, H. Nowotny, S. Schwartzman, P. Scott and M. Trow (1994). The New Production of Knowledge: The Dynamics of Science and Research in Contemporary Science. Newbury Park: Sage.

Giddings, B., B. Hopwood and G. O'Brien (2002). Environment, economy, and society: fitting them together into sustainable development. Sustainable Development 10: 187-196.

Gill, A. (2004). Tourism Communities and Growth Management. In: A. A. Lew, C. M. Hall and A. M. William (Ed.). A companion to tourism. Malden, Mass.: Blackwell.

Glasson, J., K. Godfrey and B. Goodey (1995). Towards visitor impact management. Aldershot: Ashgate Publishing.

Gössling, S. (2002). Global environmental consequences of tourism. Global Environmental Change 12(4): 283-302.

Gössling, S., P. Peeters, J.-P. Ceron, G. Dubois, T. Patterson and R. B. Richardson (2005). The eco-efficiency of tourism. Ecological Economics 54(4): 417-434.

Greenpeace (1994). Treading Lightly: A Minimal Impact Antarctic Station. Amsterdam: Greenpeace International. 
Greeuw, S., M. Van Asselt, J. Grosskurth, C. Storms, N. Rijkens-Klomp, D. Rothman and J. Rotmans (2000). Cloudy crystal balls. Environmental issues series 17. Copenhagen: European Environmental Agency: 1-116.

Grosskurth, J. (2008). Regional Sustainability: Tools for integrated governance. Maastricht: Universitaire Pers.

Grosskurth, J. and J. Rotmans (2005). The SCENE Model: getting a grip on sustainable development in policy making. Environment, Development and Sustainability 7(1): 135-151.

Haase, D. (2008). Tourism in the Antarctic: Modi Operandi and Regulatory Effectiveness Gateway Antarctica. Christchurch: University of Canterbury. Unpublished PhD thesis.

Haase, D. and M. Lamers (2006). The Future Governance of Antarctic Tourism. Workshop Report Maastricht/Christchurch: ICIS/Gateway Antarctica.

Haase, D., M. Lamers and B. Amelung (2009). Heading into uncharted territory? Exploring the institutional robustness of self-regulation in the Antarctic tourism sector. Journal of Sustainable Tourism 17(4): 411-430.

Haase, D., B. Storey, A. McIntosh, A. Carr and N. Gilbert (2007). Stakeholder Perspectives on Regulatory Aspects of Antarctic Tourism Tourism in Marine Environments 4(2-3): 167-183.

Hall, C. M. (1992a). Adventure, sport and health tourism. In: B. Weiler and C. M. Hall (Eds.). Special Interest Tourism. London: Belhaven Press.

Hall, C. M. (1992b). Tourism in Antarctica: Activities, Impacts, and Management. Journal of Travel Research 30(4): 2-9.

Hall, C. M. and M. Johnston (1995). Introduction: Pole to Pole: Tourism Issues, Impacts and the Search for a Management Regime in Polar Regions. In: C. M. Hall and M. Johnston (Eds.). Polar Tourism. New York: John Wiley.

Hall, C. M. and M. Wouters (1994). Managing Nature Tourism in the Sub-Antarctic. Annals of Tourism Research 21(2): 355-374.

Hall, C. M. and M. Wouters (1995). Issues in Antarctic Tourism. In: C. M. Hall and M. Johnston (Eds.). Polar Tourism. New York: John Wiley.

Hardin, G. (1968). The Tragedy of the Commons. Science 162: 1243-1248.

Hartman, C. L., P. S. Hofman and E. R. Stafford (1999). Partnerships: A path to sustainability. Business Strategy and the Environment 8: 255-266.

Headland, R. (1990). Chronological List of Antarctic Expeditions and Related Historical Events. Cambridge: Cambridge University Press.

Headland, R. (1994). Historical Development of Antarctic Tourism. Annals of Tourism Research 21(2): 269-280.

Headland, R. (2009). A chronology of Antarctic exploration: a synopsis of events and activities from the earliest times until the international polar years, 2007-09. London: Bernard Quaritch Ltd.

Healy, R. G. (1994). The "common pool" problem in tourism landscapes. Annals of Tourism Research 21(3): 596-611.

Healy, R. G. (2006). The commons problem and Canada's Niagara falls. Annals of Tourism Research 33(2): 525-544.

Hemmings, A. (2000). Icewatch. Living Planet. Fall. 
Hemmings, A. and R. Roura (2003). A square peg in a round hole: fitting impact assessment under the Antarctic Environmental Protocol to Antarctic tourism. Impact Assessment and Project Appraisal 21(1): 13-24.

Hemmings, A. D. (2004). Commercial Penetration of Antarctica. ECOlink. October 2005: 6-8.

Herr, R. A. (1996). The regulation of Antarctic tourism: a study in regime effectiveness. In: O. S. Stokke and D. Vidas (Eds.). Governing the Antarctic: the effectiveness and legitimacy of the Antarctic Treaty System. Cambridge: Cambridge University Press: 203-223.

Hessels, L.K., H. van Lente (2008). Re-thinking new knowledge production: A literature review and a research agenda. Research Policy 37: 740-760.

Hisschemoller, M., R. Hoppe (1996). Coping with Intractable Controversies: the case for problem structuring in policy design and analysis. Knowledge and Policy 8(4): 40-60.

Hisschemoller, M., R. Tol, P. Vellinga (2001). The relevance of participatory approaches in integrated environmental assessment. Integrated Assessment 2: 57-72.

Hofman, R. and J. Jatko (2000). Assessment of the Possible Cumulative Environmental Impacts of Commercial Ship-Based Tourism in the Antarctic Peninsula Area. Workshop, La Jolla, California, 7-9 June 2000, Washington, National Science Foundation.

Hughes, J. and B. Davis (1995). The Management of Tourism at Historic Sites and Monuments. In: C. M. Hall and M. Johnston (Eds.). Polar Tourism. New York: John Wiley.

Huitema, D., E. Mostert, W. Egas, S. Moellenkamp, C. Pahl-Wostl and R. Yalcin (2009). Adaptive Water Governance: Assessing the Institutional Prescriptions of Adaptive (Co-)Management from a Governance Perspective and Defining a Research Agenda. Ecology and Society 14(1): 26.

Hummel, J. (1994). Kiezen voor bepaalde categorieen ecotoeristen. Circumpolar Journal 9(3-4).

Hunter, C. (1997). Sustainable Tourism as an Adaptive Paradigm. Annals of Tourism Research 24(4): 850-867.

Hunter, C. (2002). Sustainable Tourism and the Touristic Ecological Footprint. Environment, Development and Sustainability 4: 7-20.

Huynen, M. (2008). Future Health in a Globalising World. Maastricht: Universitaire Pers.

IAATO (1997). IP75 Overview of Antarctic tourism activities: a summary of 19961998 and five year projection 1997-2002. Antarctic Treaty Consultative Meeting XXI, Christchurch, New Zealand.

IAATO (1998). IP86 Overview of Antarctic tourism activities. Antarctic Treaty Consultative Meeting XXII, Tromso, Norway.

IAATO (1999). IP98 Overview of Antarctic Tourism Activities. Antarctic Treaty Consultative Meeting XXIII, Lima, Peru.

IAATO (2000). IP33 Overview of Antarctic Tourism. Special Antarctic Treaty Consultative Meeting XII, The Hague, The Netherlands. 
IAATO (2001). IP73 Overview of Antarctic Tourism. Antarctic Treaty Consultative Meeting XXIV, St. Petersburg, Russia.

IAATO (2002a). IP72 Guidelines for Tourist Operations in Antarctica. Antarctic Treaty Consultative Meeting XXV, Warsaw, Poland.

IAATO (2002b). IP73 Overview of Tourism. Antarctic Treaty Consultative Meeting $\mathrm{XXV}$, Warsaw, Poland.

IAATO (2002c). Report of the International Association of Antarctica Tour Operators (IAATO) 2001-2002. Antarctic Treaty Consultative Meeting XXV.

IAATO (2003a). IP71 IAATO Overview of Tourism. Antarctic Treaty Consultative Meeting XXVI, Madrid, Spain.

IAATO (2003b). IP96 Adventure Tourism in Antarctica. Antarctic Treaty Consultative Meeting XXVI, Madrid, Spain.

IAATO (2004a). ATME\#11 Six Year Survey of the Dominant Tourist Activities and Trends Since the Ratification of the Environmental Protocol and a Five Year Estimated Forecast of Upcoming Activities. Antarctic Treaty Meeting of Experts on Tourism and Non-governmental Activities, Tromso, Norway.

IAATO (2004b). IP63 IAATO Overview of Antarctic Tourism 2003-2004 Antarctic Season. Antarctic Treaty Consultative Meeting XXVII, Cape Town, South Africa.

IAATO (2005a). 2004-2005 Summary of Seaborne, Airborne, and Land-based Antarctic Tourism. Available on www.iaato.org/tourism_stats.html.

IAATO (2005b). IAATO Overview of Antarctic Tourism 2004/05 Antarctic Season. Antarctic Treaty Consultative Meeting XXVIII, Stockholm, Sweden.

IAATO (2005c). Report of the International Association of Antarctic Tour Operators. Antarctic Treaty Consultative Meeting XXVIII, Stockholm - Sweden.

IAATO (2006a). Bylaws and Operational Procedures. International Association of Antarctica Tour Operators, 20-3-2007, from

http://www.iaato.org/bylaws.html.

IAATO (2006b). IAATO Overview of Antarctic Tourism 2005-2006 Antarctic Season. Antarctic Treaty Consultative Meeting XXIX 2006, Edinburgh - United Kingdom.

IAATO (2006c). IP85 Land-Based Tourism and the Development of Land-Based Tourism Infrastructure in Antarctica: An IAATO Perspective. Antarctic Treaty Consultative Meeting XXIX, Edinburgh, United Kingdom.

IAATO (2007a). IP121 IAATO Overview of Antarctic Tourism 2006-2007 Antarctic Season. XXX Antarctic Treaty Consultative Meeting, New Delhi.

IAATO (2007b). Membership Directory. International Association of Antarctica Tour Operators, 13-8-2007, from http://apps.iaato.org/iaato/directory/list.faces.

IAATO (2008a). Bylaws and Operational Procedures. International Association of Antarctica Tour Operators, 2-6-2008, from http://www.iaato.org/bylaws.html.

IAATO (2008b). IP85 IAATO Overview of Antarctic Tourism 2007-2008 Antarctic Season and Preliminary Estimates for 2008-2009 Antarctic Season. Antarctic Treaty Consultative Meeting, Kyiv, Ukraine. 
IAATO (2008c). Membership Directory. International Association of Antarctica Tour Operators, 17-3-2008, from

http://apps.iaato.org/iaato/directory/list.faces.

IAATO (2009). IP86 rev. 1 IAATO Overview of Antarctic Tourism: 2008-2009 Antarctic Season and Preliminary Estimates for 2009-2010 Antarctic Season Antarctic Treaty Consultative Meeting XXXII, Baltimore, United States.

IAATO (undated). Website of the International Association of Antarctica Tour Operators: available at: www.iaato.org.

IPCC (2001). Climate Change 2001: Mitigation: Contribution of Working Group III to the Third Assessment Report of the Intergovernmental Panel on Climate Change (IPCC). Cambridge: Cambridge University Press.

Johnson, D. (2002). Environmentally sustainable cruise tourism: a reality check. Marine Policy 26: 261-270.

Johnston, M. (1997). Polar tourism regulation strategies: controlling visitors through codes of conduct and legislation. Polar Record 33(184): 13-20.

Joyner, C. C. (1994). Fragile Ecosystems: Preclusive Restoration in the Antarctic. Natural Resources Journal 34: 879-904.

Joyner, C. C. (1998). Governing the Frozen Commons. The Antarctic Regime and Environmental Protection. Columbia: University of South Carolina Press.

Kaltenborn, B. and L. Emmelin (1993). Tourism in the High North: Management Challenges and Recreation Opportunity Spectrum Planning in Svalbard, Norway. Environmental Management 17(1): 41-50.

Kasemir, B., J. Jaeger, C. C. Jaeger and M. T. Gardner, Eds. (2003). Public Participation in Sustainability Science: A Handbook. Cambridge: Cambridge University Press.

Keijzers, G. (2002). The Transition to the Sustainable Enterprise Journal of Cleaner Production 10(4): 349-359.

Kershaw, A. (1998). Destination Last Wilderness. In: G. Tetley (Ed.). Antarctica 2010: A Notebook. Proceedings of the Antarctic Futures Workshop 28-30 April 1998. Christchurch: Antarctica New Zealand.

Keys, H. (1999). IP80 Towards Additional Protection of Antarctic Wilderness Areas. Antarctic Treaty Consultative Meeting XXIII, Lima, Peru.

Kok, K., D. Rothman and M. Patel (2006). Multi-scale narratives from an IA perspective: Part 1. European and Mediterranean scenario development. Futures 38(3): 261-284.

Kriwoken, L. K. and D. Rootes (2000). Tourism on Ice: environmental impact assessment of Antarctic tourism. Impact Assessment and Project Appraisal 18(2): 138-150.

KZ Expedition Consulting (2007). Report on the Disposal of Shipboard Waste at Sea by $M / V$ Le Diamant in Antarctica 2007. Prepared for the International Association of Antarctica Tour Operators (IAATO).

Lambert, R.A. (2007). 'Observing' Sustainable Tourism in Antarctica: the International Association of Antarctica Tour Operators' Observer Scheme. The University of Nottingham, 1-9-2009, from www.nottingham.ac.uk/ttri/2007-2.pdf. 
Lamers, M. (2006). Permanent Land-based Tourism in Antarctica: Nightmare on the Horizon or Unfeasible? Christchurch: Graduate Certificate in Antarctic Studies 2005/06, Gateway Antarctica, University of Canterbury.

Lamers, M. and B. Amelung (2006). The Future of Tourism in Antarctica Workshop report Maastricht University: ICIS.

Lamers, M. and B. Amelung (2007a). The Environmental Impacts of Tourism in Antarctica. A global Perspective. In: P. Peeters (Ed.). Tourism and Climate Change Mitigation. Methods, greenhouse gas reductions and policies. Breda: Stichting NHTV.

Lamers, M., B. Amelung and J. Stel (2007b). Tourism in Antarctica: Scenarios and policy implications. Workshop report. Maastricht: International Centre for Integrated assessment and Sustainable development.

Lamers, M. and B. Amelung (in press). Business as (un)usual. An integrated scenario analysis of Antarctic tourism. In: Hall, M. and J. Saarinen (Eds.). Tourism and Change in Polar Regions: Climate, Environment and Experiences. London: Routledge.

Lamers, M., D. Haase and B. Amelung (2008). Facing the Elements: Analysing trends in Antarctic Tourism. Tourism Review 63(1).

Lamers, M., D. Haase and B. Amelung (2009). Self-regulation in Antarctic tourism: exploring the conditions for success and failure. In: Lakhsmi, L. (Ed.) Tourism and Law: Cross Country Perspectives. Hyderabad: Amicus Books.

Lamers, M., J. Stel and B. Amelung (2007). Antarctic Adventure Tourism and Private Expeditions. In: J. Snyder and B. Stonehouse (Eds.). Prospects for Polar Tourism. Wallingford: CABI.

Lamers, M., B. Ottow, G. Francois, Y. von Korff (in press). Beyond dry feet: Experiences from a regional water management planning case in the Netherlands. Ecology and Society.

Landau, D. (2000). Tourism Scenarios. Proceedings of the Antarctic Tourism Workshop. Christchurch: Antarctica New Zealand.

Landau, D. (2001). Antarctic Tourism: What are the limits? World Tourism Convention: Striking a New Balance-Exploring New Horizons, Hobart, Tasmania.

Landau, D. and J. Splettstoesser (2007). Antarctic Tourism: What are the limits? In: J. Snyder and B. Stonehouse (Eds.). Prospects for Polar Tourism. Wallingford: $\mathrm{CABI}$.

Landis, M. J. (2001). Antarctica: Exploring the Extreme. Chicago: Review Press Inc. Lindberg, K., S. McCool and G. H. Stankey (1997). Rethinking Carrying Capacity. Annals of Tourism Research 24: 461-465.

Maher, P., G. Steel and A. McIntosh (2001). Antarctica: Tourism, Wilderness, and "Ambassadorship". Science and stewardship to protect and sustain wilderness values: Seventh World Wilderness Congress symposium, Port Elizabeth, South Africa.

Martens, P. (2006). Sustainability: science or fiction? Sustainability: Science, Practice \& Policy 2(1): 1-5.

Mason, P. and S. Legg (1999). Antarctic Tourism: activities, impacts, management issues, and a proposed research agenda. Pacific Tourism Review 3: 71-84. 
Mathieson, A. and G. Wall (1982). Tourism: Economic, Physical and Social Impacts. London: Longman.

McCool, S. and D. Lime (2001). Tourism Carrying Capacity: Tempting Fantast or Useful Reality. Journal of Sustainable Tourism 9: 372-388.

McIntosh, R. W., C. Goeldner and R. Brent (1995). Tourism: Principles, practices, philosophies. New York: John Wiley \& Sons.

McKee, R. (2006). South Georgia Government Update 2006. 17th Annual General IAATO Meeting, Washington DC.

McKercher, B. (1999). A chaos approach to tourism. Tourism Management 20: 425434.

Mehta, L., M. Leach and I. Scoones (2001). Environmental Governance in an Uncertain World. IDS Bulletin 32(4): 1-9.

Merriam-Webster (2007). Merriam-Webster's Online Dictionary. Retrieved 10-12007, from http://www.m-w.com/dictionary/facility.

Mill, R. C. and A. M. Morrison (1992). The tourism system: An introductory text. Englewood Cliffs: Prentice-Hall.

Molenaar, E. J. (2005). Sea-Borne Tourism in Antarctica: Avenues for Further Intergovernmental Regulation. International Journal for Marine and Coastal Law 20(2): 247-295.

Mowforth, M. and I. Munt (2000). Tourism and Sustainability: New Tourism in the Third World. London: Routledge.

Murray, C. and J. Jabour (2004). Independent expeditions and Antarctic tourism policy. Polar Record 40(215): 309-317.

Naveen, R., S. Forrest, R. Dagit, L. Blight, W. Trivelpiece and S. Trivelpiece (2000). Censuses of penguin, blue-eyed shag, and southern giant petrel populations in the Antarctic Peninsula region, 1994-2000. Polar Record 36(199): 323-334.

Naveen, R., S. Forrest, R. Dagit, L. Blight, W. Trivelpiece and S. Trivelpiece (2001). Zodiac landings by tourist ships in the Antarctic Peninsula region. Polar Record 37(201): 121-132.

Neuman, W. L. (2003). Social Research Methods. Qualitative and Quantitative Approaches (Fifth Edition). Boston: Allyn and Bacon

Neumann, A. and T. Bunge (2006). New Challenges Pose New Management Problems: The Permanent Installation of a Bronze Sculpture. Environmental Policy and Law 36(3-4): 158-163.

New Zealand (2004a). ATME\#07 An Analysis of the Existing Legal Framework for the Management of Tourism and Non-Governmental Activities in Antarctica: Issues, Some Proposals and Comments. Antarctic Treaty Meeting of Experts on Tourism and Non-governmental Activities, Tromso, Norway.

New Zealand (2004b). ATME\#10 Practical Experience of an Observer Scheme for Antarctic and Sub-Antarctic Tourism. Antarctic Treaty Meeting of Experts on Tourism and Non-governmental Activities, Tromso, Norway.

New Zealand (2005). WP21 Land-based Tourism in Antarctica. Antarctic Treaty Consultative Meeting XXVIII, Stockholm, Sweden. 
New Zealand (2007). WP13 Environmental Impact of Tourism and Other NonGovernmental Activities in the Antarctic Treaty Area. Antarctic Treaty Consultative Meeting XXX, New Delhi, India.

New Zealand and Australia (2006). WP15 rev. 1 Regulation of Land-Based Infrastructure to Support Tourism in Antarctica. Antarctic Treaty Consultative Meeting XXIX, Edinburgh, United Kingdom.

New Zealand and United States (2004). ATME\#26 Observations on Jon Johanson's South Pole Flight. Antarctic Treaty Meeting of Experts on Tourism and Non-governmental Activities, Tromso, Norway.

Nordic Council (2003). Nordic Council of Ministers, Tourism Ad Hoc Working Group. Towards a Sustainable Arctic Tourism: An integrated strategy for the sustainable development of tourism in the Nordic Arctic. Virum: Ramboll.

Norway (2004). ATME\#24 Polar Tourism: Experience gained and lessons learned from Svalbard. Antarctic Treaty Meeting of Experts on Tourism and Nongovernmental Activities, Tromso, Norway.

Norway (2007). WP37 rev 1 The M/S Nordkapp incident. Antarctic Treaty Consultative Meeting XXX, New Delhi, India.

Olearius, G. (2007) GIS als wirtschaftsgeographisches Instrument bei touristischen Entwicklungsprojekten: Das Beispiel der Markterschließung des Antarktistourismus. Unpublished Master thesis. Geographisches Institut, Aachen: RWTH.

Olson, M. (1965). The Logic of Collective Action: Public Goods and the Theory of Groups. Cambridge, MA: Harvard University Press.

Olsson, P., C. Folke and F. Berkes (2004). Adaptive Comanagement for Building Resilience in Socio-Ecological Systems. Environmental Management 34(1): 75-90.

Ostrom, E. (1990). Governing the Commons: The Evolution of Institutions for Collective Action. New York: Cambridge University Press.

Ostrom, E. (1998). A behavioural Approach to the Rational Choice Theory of Collective Action. American Political Science Review 92(1): 1-22.

Ostrom, E. (2000). Collective Action and the Evolution of Social Norms. The Journal of Economic Perspectives 14(3): 137-158.

Ostrom, E. (2005). Understanding Institutional Diversity. New Jersey: Princeton University Press.

Ostrom, E. (2006). The value-added of laboratory experiments for the study of institutions and common pool resources. Journal of Economic Behavior \& Organisation 61(2): 149-163.

Ostrom, E., J. Burger, C. B. Field, R. B. Norgaard and D. Policansky (1999). Revisiting the commons: Local lessons, global challenges. Science 284(5412 ): 278282.

Ostrom, E., T. Dietz, N. Dolsak, P. Stern, S. Stonich and E. Weber, Eds. (2002). Drama of the Commons. National Research Council. Committee on the Human Dimensions of Global Change. Washington D.C.: National Academy Press. 
Ostrom, E. and R. Gardner (1993). Coping with Asymmetries in the Commons: SelfGoverning Irrigation Systems Can Work. The Journal of Economic Persectives 7(4): 93-112.

Ostrom, E., J. Walker and R. Gardner (1992). Covenants with and without a sword: Self-governance is possible. The American Political Science Review 86(2): 404-417.

Page, S. (2003). Tourism Management: Managing for change. Oxford: ButterworthHeinemann.

Page, S. and R. K. Dowling (2002). Ecotourism. New York: Prentice Hall.

Pearce, D. (1981). Tourist development. New York: Longman.

Pearce, D. and E. B. Barbier (2001). Solving Environmental Problems II: Choosing Policy Instruments. In: D. Pearce and E. B. Barbier (Eds.). Blueprint for a Sustainable Economy. London Earthscan: 196-209.

Peeters, P., S. Gössling and V. Williams (2007). Air transport greenhouse gas emissions. In: P. Peeters (Ed.). Tourism and Climate Change Mitigation: Methods, greenhous gas reductions and policies. Breda: NHTV Academic Studies No. 6

Penner, J. E., D. H. Lister, J. D. Griggs, D. J. Dokken and M. McFarland (1999). Aviation and the Global Atmosphere: Summary for Policymakers. Arendal/Nairobi: GRID/UNEP/Intergovernmental Panel on Climate Change.

Pfeiffer, S. and H.-U. Peter (2004). Ecological studies towards the management of an Antarctic tourist landing site (Penguin Island, South Shetland Islands). Polar Record 40(215): 245-252.

Philips, C. (1990). WWF's 1990 position on Antarctic Conservation and the Role of NGOs. Report of the First Latin-American Workshop of NGOs about Antarctic Conservation, Santiago, Chile.

Pidgeon, N. and K. Henwood (2004). Grounded Theory. In: M. A. Hardy and A. Bryman (Eds.). Handbook of data analysis. London: Thousand Oaks, CA: Sage: 625-648.

Polk, W. (1998). Welcome to Hotel Antarctica: The EPA's Interim rule on Environmental Impact Assessment of tourism in Antarctica. Emory International Law Review 12: 1395-1442.

Powell, R.B., S. Kellert, S. Ham (2008) Antarctic tourists: ambassadors or consumers? Polar Record 44(230): 233-241.

Priest, S. (2001). The semantics of adventure programming. In: J. Miles and S. Priest (Ed.). Adventure Programming. Pennsylvania State College: Venture Publishing.

Prosser, R. (1994). Societal Change and the Growth in Alternative Tourism. In: E. Cater and G. Lowman (Ed.). Ecotourism: A Sustainable Option? Chichester: John Wiley \& Son Ltd.

Ravetz, J. (1999). What is Post-Normal Science? Futures 31(7): 647-653.

Republic of Liberia (2009). Report of investigation in the matter of sinking of passenger vessel Explorer (O.N. 8495), 23 November 2007, in the Bransfield near the South Shetland Islands Monrovia: Bureau of Maritime Affairs. 
Richardson, M. (2000). Regulating Tourism in the Antarctic: Issues of Environment and Jurisdiction. In: D. Vidas (Ed.). Implementing the Environmental Protection Regime for the Antarctic. Dordrecht: Kluwer Academic Publishers.

Riddle, M. J. (1998). Scientific Studies of Antarctic Life are still the Essential Basis for Long term Conservation Measures. In: W. Davison, C.-H. Williams and P. Broady (Eds.). Antarctic Ecosystems: Models for Wider Ecological Understanding. Christchurch: New Zealand Natural Sciences: 297-302.

Riffenburgh, B. (1998). Impacts on the Antarctic environment: tourism vs government programmes. Polar Record 34(190): 193-196.

Ringland, G. (1998). Scenario planning: Managing for the Future. Chichester: John Wiley \& Sons.

Robinson, J. (1990). Futures under glass: a recipe for people who hate to predict. Futures 22(8): 820-842.

Robinson, J. (2004). Squaring the circle: on the very idea of sustainable development. Ecological Economics 48(4): 369-384.

Robson, C. (2001). Real World Research. A Resource for Social Scientists and Practitioner-Researchers. Oxford: Blackwell.

Rohde, H. F. (1990). Engineering: An essential means for conserving Antarctica and achieving cost-effective built infrastructure. Proceedings of the First Pacific/Asia Offshore Mechanics Symposium, Seoul, Korea, The International Society of Offshore and Polar Engineers.

Rotmans, J. (1998). Methods for IA: The Challenges and Opportunities Ahead. Environmental Modelling and Assessment 3(3): 155-179.

Rotmans, J., M. Van Asselt, C. Anastasi, S. Greeuw, J. Mellors, S. Peters, D. Rothman and N. Rijkens (2000). Visions for a sustainable Europe. Futures 32(9-10).

Roura, R. (2007). Greenpeace. In: B. Riffenburgh (Ed.). The Encyclopedia of the Antarctic. London: Routledge.

Russell, R. and B. Faulkner (1999). Movers and shakers: chaos makers in tourism development. Tourism Management 20: 411-423.

Russell, R. and B. Faulkner (2004). Entrepreneurship, chaos and the tourism area lifecycle. Annals of Tourism Research 31(3): 556-579.

Saarinen, J. (2006). Traditions of sustainability in tourism studies. Annals of Tourism Research 33(4): 1121-1140.

Sanson, L. (1994). An Ecotourism Case Study in Sub-Antarctic Islands. Annals of Tourism Research 21(2): 344-354.

SATCM (1990). Report of Working Group II Special Antarctic Treaty Consultative Meeting XIth, Vina de Mar, Chile.

Schwartz, P. (1991). The Art of the Long View. New York: Doubleday/Currency.

Scott, S. (2001). How Cautious is Precautious? Antarctic Tourism and the Precautionary Principle. International and Comparative Law Quarterly 50: 963971.

Scully, T. and IAATO (2008). IP19 Chairman's Report from the Miami Meeting (March 17-19, 2008) on Antarctic Tourism. Antarctic Treaty Consultative Meeting, Kyiv, Ukraine.

Sharpley, R. (1999). Tourism, Tourists, and Society. Huntingdon: ELM Publications. 
Sharpley, R. (2000). Tourism and Sustainable Development: Exploring the Theoretical Divide. Journal of Sustainable Tourism 8(1): 1-19.

Simpson, S. (1989). Oasis of leisure and science: Architect's vision for ecologically clean Antarctic tourist centre. The Mercury, 1989.

Snyder, J. (1997). Alternative Future for Tourism to Antarctica: and a preliminary assessment of their resource management implications. Littleton: Strategic Studies, Inc.

Snyder, J. (2007). Tourism in the Polar Regions. The Sustainability Challenge. Paris: United Nations Environmental Programme/The International Society.

Snyder, J. and B. Stonehouse (2007). Prospects for Polar Tourism. Wallingford: CABI.

Splettstoesser, J. (2000). IAATO's Stewardship of the Antarctic Environment: a History of Tour Operator's Concern for a Vulnerable Part of the World. International Journal of Tourism Research 2: 47-55.

Splettstoesser, J. and M. Folks (1994). Environmental Guidelines for Tourism in Antarctica. Annals of Tourism Research 21(2): 231-244.

Splettstoesser, J., D. Landau and R. Headland (2004). Tourism in the Forbidden Lands: the Antarctica Experience. In: T. V. Singh (Ed.). New Horizons in Tourism. Strange Experiences and Stranger Practices. Wallingford: CABI

Steins, N. A. (2001). New directions in natural resource management: the offer of actor-network theory. IDS Bulletin 32(4): 18-25.

Stewart, E. and D. Draper (2008). The Sinking of the MS Explorer: Implications for Cruise Tourism in Arctic Canada. Arctic 61(2): 224-228.

Stewart, E., D. Draper and M. Johnston (2005). A Review of Tourism Research in the Polar Regions. Arctic 58(4): 383-394.

Stewart, E., V. Kirby and G. Steel (2006). Perceptions of Antarctic tourism: A question of tolerance. Landscape Research 31(3): 193-214.

Stonehouse, B. (1994). Ecotourism in Antarctica. In: E. Cater and G. Lowman (Ed.). Ecotourism: A Sustainable Option? New York: John Wiley \& Sons Ltd.: 195212.

Stonehouse, B. and K. Crosbie (1995). Tourist Impacts and Management in the Antarctic Peninsula Area. In: C. M. Hall and M. Johnston (Eds.). Polar Tourism. New York: John Wiley.

Summerson, R. and M. J. Riddle (2000). Assessing Wilderness and Aesthetic Values in Antarctica. In: W. Davison, C.-H. Williams and P. Broady (Eds.). Antarctic Ecosystems: Models for Wider Ecological Understanding. Christchurch: New Zealand Natural; Sciences: 303-307.

Swarbrooke, J., C. Beard, S. Leckie and G. Pomfret (2003). Adventure Tourism. The new frontier. Oxford: Butterworth-Heinemann.

Swart, R. J., P. D. Raskin and J. Robinson (2004). The problem of the future: sustainability science and scenario analysis. Global Environmental Change 14: 137-146.

Swithinbank, C. (1989). Non-government aircraft in the Antarctic 1988/89. Polar Record 24(154): 252.

Swithinbank, C. (1990). Non-government aircraft in the Antarctic 1989/90. Polar Record 26(159): 316. 
Swithinbank, C. (1992a). Non-government aircraft in the Antarctic 1990/91. Polar Record 28(164): 66-67.

Swithinbank, C. (1992b). Non-government aircraft in the Antarctic 1991-92. Polar Record 28(166): 232.

Swithinbank, C. (1993). Non-government aircraft in the Antarctic 1992/93. Polar Record 29(170): 244-245.

Swithinbank, C. (1994). Non-governmental aircraft in the Antarctic 1993/94. Polar Record 30(174): 221.

Swithinbank, C. (1995). Non-governmental aircraft in the Antarctic 1994/95. Polar Record 31(178): 346.

Swithinbank, C. (1996). Non-governmental aircraft in the Antarctic 1995/96. Polar Record 32(183): 355-356.

Swithinbank, C. (1997). Non-governmental aviation in Antarctica 1996/97. Polar Record 33(187): 340-341.

Swithinbank, C. (1998a). Forty Years on Ice. A lifetime of exploration and research in the polar regions. Sussex: The Book Guild Ltd.

Swithinbank, C. (1998b). Non-governmental aviation in Antarctica 1997/98. Polar Record 34(190): 249.

Swithinbank, C. (1999). Non-governmental aviation in Antarctica 1998/99. Polar Record 36(196): 51-52.

Swithinbank, C. (2000). Non-governmental aviation in Antarctica 1999/2000. Polar Record 36(198): 249-250.

Sysselmannen på Svalbard (2006). Tourism Statistics for Svalbard. Longearbyen: Governor of Svalbard.

Tangley, L. (1988). Who's polluting Antarctica? Bioscience 38(9): 590-594.

TIAS (2009). About Integrated Assessment. The Integrated Assessment Society website. Retrieved 2-4-2009, from http://www.tias.uniosnabrueck.de/integrated_assessment.php.

Tietenberg, T. (2002). The Tradable Permits Approach to Protecting the Commons: What Have We Learned? FEEM Fondazione Eni Enrico Mattei Research Paper Series C. Carraro. Milano: FEEM

Times Online (2003). Antarctica is for all of us. Time Online (issue October 4) Retrieved 1-5-2009, from

http://www.timesonline.co.uk/tol/travel/holiday_type/adventure/article1 024972.ece.

Tracey, P. J. (2001). Managing Antarctic Tourism. Unpublished PhD thesis. Institute of Antarctic and Southern Ocean Studies. Hobart: University of Tasmania.

Trozzi, C. and R. Vaccaro (1998). Methodologies for estimating air pollutant emissions from ships. Rome: Techne.

UNDP (2004). Human Development Report 2004: Cultural Liberty in Today's Diverse World. New York: United Nations Development Programme.

UNEP (2007). Global Environmental Outlook 4. London: Earthscan.

United Kingdom (2004a). ATME\#04 Tourism and Self-Regulation: A Commentary on IAATO. Antarctic Treaty Meeting of Experts on Tourism and Nongovernmental Activities, Tromso, Norway. 
United Kingdom (2004b). ATME\#08 The Regulation of Adventure Tourism. Antarctic Treaty Meeting of Experts on Tourism and Non-governmental Activities, Tromso, Norway.

United Kingdom (2004c). ATME\#09 Managing Adventure Tourism: The need for enhanced co-operation amongst parties. Antarctic Treaty Meeting of Experts on Tourism and Non-governmental Activities, Tromso, Norway.

United Kingdom (2005). WP18 Report of the Intersessional Contact Group on Accreditation Scheme for the Antarctic Tour Operators. Antarctic Treaty Consultative Meeting XXVIII Stockholm, Sweden.

United Kingdom (2008). Developing a Strategic Vision of Antarctic Tourism for the next Decade. Antarctic Treaty Consultative Meeting, Kyiv, Ukraine.

United Kingdom (2009). WP10 Strategic Vision of Antarctic Tourism fro the next Decade. Antarctic Treaty Consultative Meeting XXXII, Baltimore, USA.

United States (2004). ATME\#05 U.S. Policy on Private Expeditions to Antarctica and Current U.S. Framework for Regulation of Antarctic Tourism. Antarctic Treaty Meeting of Experts on Tourism and Non-governmental Activities, Tromso. Norway.

UNWTO (2006). World Tourism Barometer, Vol 4, No. 1, January 2006. Madrid: World Tourism Organisation.

Urry, J. (2002). The Tourist Gaze. Second edition. London: Sage Publications.

Uruguay (2005). IP56 Visitor programme to the "Artigas" Antarctic Scientific Base. Antarctic Treaty Consultative Meeting XXVIII, Stockholm, Sweden.

Van 't Klooster, S. and M. Van Asselt (2006). Practicing the scenario-axis technique. Futures 38(1): 15-30.

Van Asselt, M. and N. Rijkens-Klomp (2002). A look in the Mirror: Reflection on Participation in Integrated Assessment from a Methodological Perspective. Global Environmental Change 12(3): 167-184.

Van Asselt, M., J. Rotmans and D. Rothman (2005). Scenario Innovation. Experiences from a European Experimental Garden. London: Taylor and Francis.

Van der Sluijs, J.P. (2002) Integrated Assessment. In: M.K. Tolba (Ed.) Encyclopedia of Global Environmental Change, Chichester: John Wiley \& Sons: 250-253.

Van Notten, P. (2005). Writing on the Wall: Scenario development in times of discontinuity. Boca Raton: Dissertation.com.

Van Notten, P., J. Rotmans, M. Van Asselt and D. Rothman (2003). An updated scenario typology. Futures 35: 423-443.

Van Wijk, J. (2009) Moving beyond Heroes and Winners. Institutional Entrepreneurship in the Outbound Tour Operations Field in the Netherlands, 1980-2005. PhD Dissertation Vrije Universiteit, Amsterdam. PrintPartners Ipskamp.

Van Zeijl-Rozema, A., R. Cörvers, R. Kemp and P. Martens (2009). Governance for sustainable development: a framework. Sustainable Development 16(6): 410-421.

Vaughan, D. G., G. J. Marshall, W. M. Connolley, C. Parkinson, R. Mulvaney, D. A. Hodgson, J. C. King, C. J. Pudsey and J. Turner (2003). Recent rapid regional climate warming on the Antarctic Peninsula. Climatic Change 60: 243-274. 
Vicuna, F. O. (2000). Port State Jurisdiction in Antarctica: A New Approach to Inspection, Control and Enforcement. In: D. Vidas (Ed.). Implementing the Environmental Protection Regime for the Antarctic. Dordrecht: Kluwer Academic Publishers: 45-69.

Watkins, G. and F. Cruz (2007). Galapagos at Risk: A Socioeconomic Analysis of the Situation in the Archipelago. Puerto Ayora: Charles Darwin Foundation.

Watterson, J., C. Walker and S. Eggleston (2004). Revision to the Method of Estimating Emissions from Aircraft in the UK Greenhouse Gas Inventory: Report to Global Atmosphere Division, DEFRA. Oxon: Netcen.

Weaver, D. (2000). A broad context model of destination development scenarios. Tourism Management 21: 217-224.

Weaver, P. and J. Rotmans (2006). Integrated Sustainability Assessment: what is it, why do it and how? International Journal of Innovation and Sustainable Development 1(4): 284-303.

Weber, K. (2001). Outdoor Adventure Tourism. A Review of Research Approaches. Annals of Tourism Research 28(2): 360-377.

White, K. (1994). Tourism and the Antarctic Economy. Annals of Tourism Research 21(2): 245-268.

Wickson, F., A.L. Carew, A.W. Russell (2006). Transdisciplinary research: characteristics, quandaries and quality. Futures 38: 1046-1059.

Williams, C. C. and A. C. Millington (2004). The diverse and contested meanings of sustainable development. The Geographical Journal 170: 99-104.

World Commission on Environment and Development (1987). Our Common Future. Oxford: Oxford University Press.

WPTPA (2008). Workshop in Political Theory and Policy Analysis. Retrieved 17-72008, from http://www.indiana.edu/ workshop/inex.html.

WTO (1993). Sustainable Tourism Development: Guide for Local Planner. Madrid: World Tourism Organisation.

WTO (1995). Concepts, Definitions and Classifications for Tourism Statistics. Technical Manual 1. Madrid: World Tourism Organisation.

WTO (2001). Tourism 2020 Vision: Global Forecasts and Profiles of Market Segments. Vol. 7. Madrid: World Tourism Organisation. Vol. 7.

WTO (2002). Tourism and Poverty Alleviation. Madrid: World Tourism Organisation.

WTO (2003). Facts \& Figures. Madrid: World Tourism Organisation. 


\section{Interview guideline}

\section{Introductory remarks}

The aim of this research project is to develop integrated scenarios for tourism in Antarctica. For this purpose three participatory workshops have been organised with stakeholders and experts in the Netherlands and New Zealand. This interview guideline consists of the issues discussed and ideas coming from these participatory workshops. This interview guideline consists of both open questions and statements. In the case of a statement the respondent is asked to give a reaction and argue to what extent the statement is true or false. Your anonymity will be preserved if you wish so and the responses and information you provide during the interview will be treated with confidentiality. Depending on time availability, the interview will take between one to one-and-a-half hours. In case of time constraint, the interviewer will make a selection of questions and statements. After the interview, a summary report will be prepared and send to the respondent via email or post for review and additional comments. With permission of the respondent, the interview will be recorded with a digital voice recorder. Recording the interview will facilitate the quality and validity of response records and the summary report.

\section{A Personal information}

1 How long and how have you been involved in Antarctic tourism? How would you describe your role, responsibilities and tasks?

2 What is your underlying motivation to be involved in Antarctic tourism?

B The current status of Antarctic tourism

3 What is in your view the biggest misconception with regard to the current status of Antarctic tourism?

4 How would you describe the current growth trends in Antarctic tourism?

\section{The development factors of tourism in Antarctica}

5 What have been the most important factors driving and constraining the development of tourism in Antarctica in the past?

6 What will in your opinion be the most important development factors in the next 10 years?

7 Please react to the following five statements:

Cruise-only trips and land-based activities (with tourists flying in) will outcompete traditional ship-based tourism within the next 10 years.

8 Due to different points of view no comprehensive restrictions or regulations will be agreed upon by the ATCPs in the next 10 years.

9 Developments in tourism accessibility are driven by infrastructure developments of National Antarctic Programmes. 
10 Demand for Antarctic tourism will gradually decrease as a result of Antarctica's fading image as a remote and unspoilt place.

11 Climate change will greatly increase the number of suitable landing sites in Antarctica.

D Future states, implications and desirability

12 What is your top concern with regard to the future of Antarctic tourism?

13 To what extent are you concerned with the increasing scale of operation in Antarctic tourism?

14 Do you consider large scale land based tourism in Antarctica a feasible future state? To what extent do you consider such a development desirable?

15 Does the continuing growth of numbers and types of tour operators pose implications for the current self-regulatory regime? What kind of implications?

16 Are you concerned with a potential change in norms and values in Antarctic tourism operations as a result of a changing industry (e.g. new operators, corporate take-over)?

17 How would you describe the ideal state of Antarctic tourism in 25 years?

18 Please react to the following five statements:

18 More ATS rules and/or self-regulations lead to more "outlaw" operations and free-riders.

19 Cooperation between tour operators and science operators with regard to infrastructure and accommodation sharing should be discouraged.

20 Science and tourism are equal activities for which the same rules should be applied.

21 All kinds of tourist activities are allowable whenever they are pre-notified, safe, and cause no more than " $a$ minor or transitory impact on the environment".

22 Tourism is a potential threat to the stability of the Antarctic Treaty System.

\section{E Future governance}

23 Do you consider the current ATS regime capable of regulating future tourism in Antarctica in an adequate and effective way?

24 Which of the following regulatory options do you consider most desirable? Which are most feasible?

Extended port state control

Accreditation scheme

Official observers

Zoning system

Specific prohibitions and restrictions

Are there in your view other regulatory options that should be applied for a sustainable Antarctic future?

25 What position should the ATS and the ATCPS have regarding the selfregulatory regime by the Antarctic tourism industry in order to safeguard its success? 
26 What level of legal framing do you consider most suitable for future Antarctic tourism policy? Do you think that a more comprehensive ATS regulation for tourism is necessary? What kind of comprehensive ATS regulatory system for tourism would in your opinion be most feasible?

F The end

27 Do you have any final remarks or questions with regard to this topic, this interview, or this research project?

28 Can you recommend any other Antarctic tourism stakeholders for undertaking this interview? 



\section{List of acronyms and abbreviations}

\begin{tabular}{|c|c|}
\hline AAD & Australian Antarctic Division \\
\hline AGM & Annual General Meeting \\
\hline $\mathrm{ALCl}$ & Antarctic Logistics Centre International \\
\hline ALE & Antarctic Logistics and Expeditions \\
\hline ANAN & Antarctic Non-Government Activity Newsletter \\
\hline ANI & Adventure Network International \\
\hline ASMA & Antarctic Specially Managed Area \\
\hline ASPA & Antarctic Specially Protected Area \\
\hline ASOC & Antarctica and Southern Ocean Coalition \\
\hline ATCM & Antarctic Treaty Consultative Meeting \\
\hline ATCP & Antarctic Treaty Consultative Party \\
\hline ATME & Antarctic Treaty Meeting of Experts \\
\hline ATOS & Antarctic Tourism Opportunity Spectrum \\
\hline ATS & Antarctic Treaty System \\
\hline BA & Bas Amelung \\
\hline CEE & Comprehensive Environmental Evaluation \\
\hline CEP & Commission for Environmental Protection \\
\hline CCAMLR & $\begin{array}{l}\text { Convention on the Conservation of Antarctic Marine Living } \\
\text { Resources }\end{array}$ \\
\hline COMNAP & Council of Managers of National Antarctic Programmes \\
\hline CPR & Common Pool Resources \\
\hline $\mathrm{CO}_{2}$ & Carbon Dioxide \\
\hline CRAMRA & $\begin{array}{l}\text { Convention on the Regulation of Antarctic Mineral Resources } \\
\text { Activities }\end{array}$ \\
\hline DAP & Aerovias DAP (la aerolinea de Patagonia) \\
\hline $\mathrm{DH}$ & Daniela Haase \\
\hline DML & Dronning Maud Land \\
\hline DROMLAN & Capetown - Dronning Maud Land air link \\
\hline ECOS & Ecotourism Opportunity Spectrum \\
\hline EIA & Environmental Impact Assessment \\
\hline GCAS & Graduate Certificate in Antarctic Studies \\
\hline GEO & Global Environmental Outlook \\
\hline GIS & Geographical Information System \\
\hline IA & Integrated Assessment \\
\hline IAATO & International Association of Antarctica Tour Operators \\
\hline IEE & Initial Environmental Evaluation \\
\hline ICIS & $\begin{array}{l}\text { International Centre for Integrated assessment and Sustainable } \\
\text { development }\end{array}$ \\
\hline Int. & Interviewer \\
\hline IPCC & Intergovernmental Panel on Climate Change \\
\hline IPY & International Polar Year \\
\hline
\end{tabular}




$\begin{array}{ll}\text { ISA } & \text { Integrated Sustainability Assessment } \\ \text { IMO } & \text { International Maritime Organisation } \\ \text { M } & \text { Monitor: interviewees involved in monitoring Antarctic tourism } \\ \text { MEA } & \text { Millennium Ecosystem Assessment } \\ \text { ML } & \text { Machiel Lamers } \\ \text { NAP } & \text { National Antarctic Programme } \\ \text { NGO } & \text { Non-Governmental Organisation } \\ \text { O } & \text { Organiser: interviewees involved in organising Antarctic tourism } \\ \text { OD } & \text { Origin-Destination } \\ \text { OECD } & \text { Organisation for Economic Cooperation and Development } \\ \text { Protocol } & \text { Protocol on Environmental Protection to the Antarctic Treaty } \\ \text { R } & \text { Regulator: interviewees involved in regulating Antarctic tourism } \\ \text { ROS } & \text { Recreation Opportunity Spectrum } \\ \text { SAR } & \text { Search and Rescue } \\ \text { SCAR } & \text { Scientific Committee on Antarctic Research } \\ \text { SD } & \text { Sustainable Development } \\ \text { SSSI } & \text { Site of Special Scientific Interest } \\ \text { Treaty } & \text { Antarctic Treaty } \\ \text { UNEP } & \text { United Nations Environment Programme } \\ \text { UNDP } & \text { United Nations Development Programme } \\ \text { UNWTO } & \text { United Nations World Tourism Organisation } \\ \text { UK } & \text { United Kingdom } \\ \text { USA } & \text { United States of America } \\ \text { WCED } & \text { World Commission on Environment and Development } \\ \text { WTO } & \text { World Tourism Organisation } \\ \text { WWF } & \text { World Wildlife Fund } \\ & \end{array}$




\section{Summary}

In the last decade, Antarctic tourism has grown rapidly both in terms of volume and diversity. This growth is taking place in a vulnerable part of the world that is largely deprived of human activities and knows no indigenous human population. Antarctica is the only terrestrial land mass on this planet that is not governed by a sovereign state. The Antarctic region is a global common collectively governed by the member countries of the Antarctic Treaty System. In this thesis, it is demonstrated that this configuration poses a range of challenges for sustainability.

\section{CHAPTER 1}

In chapter one the Antarctic tourism case is introduced and contextualised in global tourism developments. A definition and historical overview of tourism development in Antarctica is provided, as well as the main characteristics of Antarctic tourism activity, management and regulation. Based on these characteristics a range of operational and regulatory challenges are identified, such as potential safety risks and environmental impacts, knowledge gaps, effectiveness in decision making and enforceability. It is argued that a strategic vision is needed and knowledge upon which this vision can be based. The objective of this thesis is therefore to identify and assess the main sustainability challenges of Antarctic tourism development and to explore ways to tackle these challenges in the Antarctic governance context. This is done by reaching the following sub-goals:

- Analysing the main driving and constraining factors in the development of Antarctic tourism;

- Identifying and assessing risks and impacts of tourism development for the environment, tourism operations, and other users of the Antarctic;

- Exploring a range of plausible future scenarios and analysing the implications for policy;

- Analysing the perspectives of stakeholders on sustainable Antarctic tourism and policy options.

The sustainable development concept is proposed as theoretical framework in this thesis to identify and discuss these sustainability challenges. Four sustainability challenges are addressed more thoroughly: the global environmental impacts of Antarctic tourism, the development of adventure tourism and the interdependency of stakeholders in dealing with the associated safety risks, the potential impacts of the development of permanent land-based facilities for tourism, and the significance and robustness of the tourism industry self-regulatory regime. Chapter one closes by providing an outline of the structure of this thesis. 


\section{CHAPTER 2}

In chapter two the conceptual and methodological framework of this research is presented. It is demonstrated that 'sustainable development' and 'sustainable tourism' are ambiguous and contested notions. Evaluation of tourism in the context of sustainable development therefore depends on the perspective taken, the delimitation of tourism in time and space, and the level of control one can exercise over tourism development. It is argued that the complex and dynamic nature of tourism along with the research objective require a transdisciplinary and integrated research approach. The main characteristics of Integrated Assessment are introduced providing a methodological framework. Finally, methodologies for data collection and analysis are introduced, such as literature survey, data analysis, participatory methods, scenario analysis, in-depth interviews, and positioned in the structure of this thesis.

\section{CHAPTER 3}

Chapter three analyses the main factors that drive and constrain Antarctic tourism development. Based on material elicited at three stakeholder workshops, data analysis and literature review, this chapter presents the Antarctic Tourism Opportunity Spectrum (ATOS) based on the Recreation Opportunity Spectrum (ROS) literature (e.g. Clark and Stankey, 1978). This model is composed of the following factor categories: factors influencing access, other users, attractions, facilities, operational factors, the acceptability of impacts, and regulation and policy. In addition to the internal factors, the model incorporates a contextual level of global factors that may (potentially) influence Antarctic tourism development. The use of the ROS concept, originally designed for the operational level of national park management, is extended to the more strategic level of future tourism trends and challenges. A trend analysis using the ATOS demonstrates that future tourism opportunities vary between larger scale-operations and the continued development of smaller-scale niche products. There is, however, much scope for both industry segments to further diversify and grow.

\section{CHAPTER 4}

The rapid growth and diversification of tourism in Antarctica raises concerns about its effects on the environment. Research and policy-making have, so far, focused on the impacts of tourism on Antarctica's ecosystems at the local scale. The global impacts of tourism have largely been ignored. This chapter presents an inventory of greenhouse gas emissions produced by Antarctic tourism. Results demonstrate that Antarctic tourism ranks among the most energy-intensive segments in the world tourism market. To raise awareness among tourists, tour operators and policy makers, it is argued that greenhouse gas emissions should be included in environmental impact assessments. Improving the global environmental performance of Antarctic tourism would be challenging, as it depends highly on long-haul flights, which goes largely beyond the responsibility of the Antarctic Treaty System. It is 
argued that the energy-intensity of Antarctic tourism can have major consequences for the industry when global greenhouse gas emission mitigation policies are implemented.

\section{CHAPTER 5}

Chapter five addresses the issue of human safety risks in Antarctic adventure tourism and independent expeditions. Issues of safety risks in Antarctica go beyond passenger safety, as tour operators are highly interdependent on National Antarctic Programmes' and other operators' Search-and-Rescue capabilities in case of emergency. The chapter presents a definition of adventure tourism and an overview of activities that can be classified as such. Based on various Antarctic information databases an analysis of the different risk determinants is made. It is argued that human safety risks and related claims on other parties are not determined by activity type only, but on a range of other factors, such as contingency planning, experience, and location. The various risk determinants suggest a range of policy options for prevention and mitigation of safety risks.

\section{CHAPTER 6}

The potential development of permanent land-based facilities and infrastructures for tourism in Antarctica has received much attention in the tourism regulatory debate at recent ATCMs. The debate focuses on the question whether such development should be allowed in Antarctica. A number of state governments have proposed to prohibit such developments; however, the question has not yet received a clear answer. Chapter six provides a definition of permanent land-based facilities for tourism and gives an overview of current and past land-based tourism facilities in Antarctica. Next, it is discussed whether such facilities are likely to further develop in the near future and an inventory is made of arguments in favour and against such developments. Environmental implications are discussed along with other issues, such as erosion of wilderness values, legal implications due to emerging property rights issues. Based on this information, a number of basic regulatory options are described and discussed, such as regulation of land-based facilities through existing instruments, a full prohibition, and a prohibition with the exemption of areas already in use by NAPs.

\section{CHAPTER 7}

Chapter seven analyses the main strengths and weaknesses of self-regulation in the Antarctic tourism sector. Elinor Ostrom's theory of collective action and especially the design principles for robust management of common pool resources provide a useful framework for this analysis (e.g. Ostrom, 2005). The chapter examines why formal tourism legislation has been limited and describes the self-regulation of tourism management that occurs through the International Association of Antarctica Tour Operators (IAATO). The success of IAATO is attributed to the high degree of organisation in the Antarctic tourism sector, largely because of the perceived 
benefits of cooperation. The chapter argues that, under current conditions, the Antarctic tourism self-regulatory regime is a robust institution. However, with increasing numbers of tourists and operators the institutional structure may be weakened in the future. Based on Ostrom's theory it is argued that relation of the self-regulatory regime to the formal ATS needs to be strengthened to ensure a sustainable future for Antarctic tourism.

\section{CHAPTER 8}

In chapter eight an integrated scenario analysis is performed for tourism development in Antarctica. During three scenario workshops in the Netherlands and New Zealand, to which a range of Antarctic tourism stakeholders were invited, future scenarios were developed. These scenarios were further enriched with available academic literature and documentation, and linked to the global scenarios of the UNEP Global Environmental Outlook and the Millennium Ecosystem Assessment. The resulting analysis systematically explores four future pathways, based on different assumptions, and identifies a range of potential future developments, such as the development of air links, increasing scale of tourism companies and operations, land-based facility developments, increasing diversity of activities, and the emergence of rogue operators. The scenarios were generally considered plausible to fairly plausible by the participating stakeholders. The scenarios were, however, considered far from desirable. Consequently, a range of policy suggestions was made by the participants to improve the Antarctic regulatory system and increase ATS control over tourism activities. Based on its merits it is concluded that scenario analysis can play an important role in developing a strategic policy vision for tourism in Antarctica.

\section{Chapter 9}

Chapter nine addresses the perceived governance aspects for attaining sustainable tourism development in Antarctica. Stakeholder interviews on the development and regulation of tourism in Antarctica are analysed using the adaptive conceptualisation of sustainable tourism of Hunter (1997). The chapter particularly focuses on three interdependent questions: what do we want to achieve (sustainability objective); what can we achieve (regulatory capability); and how can we achieve this (regulatory options)? The results show that although most interviewees seem to strive for high environmental and safety standards, perspectives on acceptable form and shape of tourism diverge widely. Perspectives also deviate on the capability of both the ATS and the self-regulatory regime of the industry to control tourism development in Antarctica, and the preferred policy options. Based on the interviews a range of suggestions are presented for the ATS to steer Antarctic tourism towards sustainability, such as developing a strategic vision on tourism, exploring ways to generate financial means to set up an environmental monitoring programme, carrying out applied research on incentive-based and restrictive policy instruments, and building partnerships with self-regulatory regimes like IAATO. 


\section{CHAPTER 10}

Chapter ten summarises the main conclusions coming from this thesis and links these to the main research objectives of this study. The central aim of this thesis is to explore strategic challenges of future Antarctic tourism in the context of sustainable development. A transdisciplinary and integrated research approach is taken to meet this objective. Tourism in Antarctica is developing as a result of a range of factors related to access, other users in the region, attractions and facilities, operational factors, normative criteria for impacts, and regulatory mechanisms. A number of impact areas with a considerable potential for future change are studied in greater detail, including: the global environmental impacts of tourism in Antarctica; the human safety risks of Antarctic adventure tourism; the legal and environmental implications of the development of permanent land-based facilities and infrastructures for tourism; and the robustness of self-regulation in the Antarctic tourism sector. The general prognosis is that Antarctic tourism will further develop in the future; but the growth rate and form of development are uncertain as a result of these factors and more contextual influences. Through an integrated scenario analysis, based on storylines developed by stakeholders and a range of global scenario studies, different futures were explored for implications. In Antarctica the options for formal regulation of tourism is limited. Stakeholder interviews provide a wide perspective on governance options sustainable tourism development in Antarctica. It is argued that, although the future is uncertain and data sometimes difficult to obtain, the combination of research methods applied in this thesis has shed new light on sustainability challenges of tourism in Antarctica. Research on other impacts areas, management practices, innovative policy instruments, and comparative cases studies are proposed as promising field for future research in this field. Finally, it is argued that Antarctic tourism research could benefit from international coordination of polar tourism research and social sciences research in Antarctica. 



\section{Samenvattting}

In de afgelopen decennia is het toerisme naar Antarctica snel gegroeid, zowel in aantallen toeristen als in diversiteit aan activiteiten. Deze groei vindt plaats in een kwetsbaar deel van de wereld waar relatief weinig menselijke activiteiten plaatsvinden en die geen inheemse bevolking kent. Antarctica is de enige landmassa op aarde die niet wordt bestuurd door een soevereine staat. Het Antarctisch gebied is een mondiaal gemeengoed gezamenlijk bestuurd door de partijstaten van het Antarctisch Verdragsysteem. In deze dissertatie wordt aangetoond dat deze omstandigheden gezamenlijk kunnen leiden tot een reeks duurzaamheiduitdagingen.

\section{HOOFDSTUK 1}

In hoofdstuk 1 wordt het onderwerp toerisme in Antarctica ingeleid en geplaatst in de context van mondiale toeristische ontwikkelingen. Het hoofdstuk geeft een definitie van Antarctisch toerisme, de historische ontwikkeling wordt geschetst, alsmede de belangrijkste kenmerken van toeristische activiteiten, management en regulering in Antarctica. Op basis van deze kenmerken worden een aantal operationele en regelgevende uitdagingen beschreven, zoals de potentiële veiligheidsrisico's en milieugevolgen, kennishiaten, effectiviteit van besluitvorming en de beperkingen van beleidshandhaving. Er wordt beargumenteerd dat een strategische visie op Antarctisch toerisme nodig is, evenals kennis waarop deze visie kan worden gebaseerd. Het doel van deze dissertatie is om de belangrijkste duurzaamheiduitdagingen te identificeren en te verkennen in de Antarctische bestuurlijke context. Dit gebeurt door middel van de volgende subdoelen:

- Analyse van de belangrijkste actoren en factoren in de ontwikkeling van Antarctisch toerisme;

- Identificatie en analyse van de mogelijke risico's en gevolgen van de toeristische ontwikkeling voor het milieu, toeristische activiteiten en andere gebruikers van het Antarctisch gebied;

- Verkenning van toekomstscenario's en analyse van de gevolgen voor het beleid;

- Analyse van de perspectieven van belanghebbenden over duurzaam Antarctisch toerisme en de ter beschikking zijnde beleidsopties.

Vier duurzaamheiduitdagingen zullen in het bijzonder worden behandeld: de mondiale milieu gevolgen van toerisme in Antarctica; de ontwikkeling van avontuurlijke en extreme vormen van toerisme en de wederzijdse afhankelijkheid van belanghebbenden ten aanzien van veiligheid; de mogelijke gevolgen van de ontwikkeling van permanente faciliteiten voor toerisme aan land; en de betekenis en de stabiliteit van zelfregulering voor duurzaam toerisme. Hoofdstuk een wordt afgesloten met een overzicht van de structuur van deze dissertatie. 


\section{HOOFDSTUK 2}

In hoofdstuk twee wordt het conceptuele en methodologische kader van dit onderzoek gepresenteerd. Duurzame ontwikkeling en duurzaam toerisme zijn dubbelzinnige en omstreden begrippen. Evaluatie van duurzame toerismeontwikkeling is daarom afhankelijk van bestaande perspectieven op het doel van duurzame ontwikkeling, de afbakening in tijd en ruimte, en de mate van bestuurlijke controle die uitgeoefend kan worden. In dit hoofdstuk wordt betoogd dat het complexe en dynamische karakter van toerisme en de doelstelling van het identificeren van duurzaamheiduitdagingen vragen om een transdisciplinaire en geïntegreerde onderzoeksaanpak. De belangrijkste kenmerken van een dergelijke aanpak worden geïntroduceerd. Ten slotte worden de gebruikte methoden voor het verzamelen en analyseren van data uiteengezet en geplaatst in de structuur van deze dissertatie, zoals literatuurstudie, data-analyse, participatieve methoden, scenarioanalyse en interviews.

\section{HOOFDSTUK 3}

Hoofdstuk drie analyseert de belangrijkste drijvende krachten en beperkende factoren voor toerismeontwikkeling in Antarctica. Op basis van inzichten verzamelt tijdens drie scenarioworkshops met belanghebbenden, data-analyse en literatuurstudie, presenteert dit hoofdstuk de Antarctic Tourism Opportunity Spectrum (ATOS), een model waarin de belangrijkste ontwikkelingsfactoren geïntegreerd zijn. Dit model bestaat uit de volgende categorieën: toegangsfactoren, andere gebiedsgebruikers, attracties, faciliteiten, operationele factoren, de aanvaardbaarheid van negatieve effecten, en de mogelijkheden tot het voeren van beleid. Naast deze interne factoren heeft het model een contextueel niveau van mondiale factoren die (mogelijk) van invloed kunnen worden op de ontwikkeling van Antarctisch toerisme. ATOS bouwt voort op het ROS concept (Recreation Opportunity Spectrum, zie Clark en Stankey, 1978), oorspronkelijk ontworpen voor het beheer van Amerikaanse nationale parken op operationeel niveau, en is in deze dissertatie aangepast voor de strategische analyse van toekomstige trends en uitdagingen. Een trendanalyse met behulp van de ATOS toont aan dat de toekomst kansen biedt voor zowel schaalvergroting als de verdere diversificatie van toeristische producten.

\section{HOOFDSTUK 4}

De snelle groei en diversificatie van het toerisme in Antarctica leidt tot bezorgdheid over de gevolgen hiervan voor het milieu. Zowel onderzoek en beleid hebben zich, tot nu toe, gericht op de gevolgen van toerisme voor Antarctische ecosystemen op lokaal niveau. De mondiale effecten van toerisme zijn grotendeels genegeerd. In dit hoofdstuk wordt een eerste schatting gemaakt van de uitstoot van broeikasgassen door Antarctisch toerisme. Uit onze berekeningen blijkt deze uitstoot per persoon per reis enorm te zijn, met de luchtvaart en scheepvaart als belangrijkste bronnen. Antarctisch toerisme behoort tot de meest energie-intensieve vormen van toerisme op de wereldmarkt. Om toeristen, reisorganisaties en beleidsmakers bewuster 
te maken van deze uitstoot betogen we dat broeikasgasemissies opgenomen zouden moeten worden in de reguliere milieueffectenrapportages ter naleving van het Milieu Protocol. Verbetering van de mondiale milieuprestaties van het Antarctisch toerisme hangt nauw samen met de langeafstandsvluchten van en naar vertrekhavens; dit ligt grotendeels buiten de verantwoordelijkheid van het Antarctisch Verdragsysteem. Wel wordt er betoogd dat de energie-intensiteit van Antarctisch toerisme grote gevolgen kan hebben voor de industrie wanneer internationale maatregelen voor de inperking van broeikasgasemissies worden geïmplementeerd.

\section{HOOFDSTUK 5}

Hoofdstuk vijf behandelt het probleem van de menselijke veiligheid in avontuurlijke en extreme vormen van toerisme en onafhankelijke expedities in Antarctica. Veiligheidsrisico's in Antarctica gaan verder dan veiligheid van toeristen; organisatoren zijn sterk afhankelijk van Nationale Antarctische Programma's (wetenschappelijke expedities vanuit verschillende landen) en andere touroperators bij het verlenen van hulp in geval van nood. Met alle financiële en risicovolle gevolgen van dien. Een reeks recente incidenten met (zogenaamde) avontuurlijke en extreme vormen van toerisme hebben een politiek debat op gang gebracht over het beperken van deze risico's. Het hoofdstuk presenteert een definitie van avontuurlijk toerisme en een overzicht van activiteiten die als zodanig kunnen worden geclassificeerd. Op basis van een analyse van recente incidenten laten we zien dat veiligheidrisico's uit verschillende determinanten bestaan. De veiligheid van de mens en verwante claims op andere partijen wordt niet bepaald door alleen het type activiteit, maar ook door factoren als de voorbereiding, de ervaring, en de locatie van de activiteit. Op basis van de verschillende risicodeterminanten worden een aantal beleidsopties besproken voor preventie en beperking van veiligheidsrisico's.

\section{HOOFDSTUK 6}

De potentiële ontwikkeling van permanente faciliteiten en infrastructuren voor toerisme op Antarctische bodem heeft veel aandacht gekregen in debatten op recente ATCMs. Het debat is gericht op de vraag of een dergelijke ontwikkeling werkelijkheid mag worden in Antarctica. Een aantal partijstaten hebben een verbod voorgesteld, maar een consensus is op deze kwestie nog niet bereikt. Hoofdstuk zes geeft een definitie van permanente faciliteiten voor toerisme en geeft een overzicht van huidige en voormalige faciliteiten in Antarctica. Vervolgens wordt besproken of het waarschijnlijk is dat voorzieningen voor toerisme zich in de toekomst verder ontwikkelen en wordt er een inventaris gemaakt van argumenten vóór en tegen dergelijke ontwikkelingen. Argumenten gaan in op de mogelijke milieugevolgen, de aantasting van intrinsieke wilderniswaarden, en de juridische implicaties van opkomende eigenaarschaprechten. Op basis van deze informatie worden een aantal beleidsopties beschreven en besproken, zoals de regulering van permanente installaties door middel van bestaande instrumenten, een volledig verbod, en een verbod met uitzondering van gebieden al in gebruik door NAP's. 


\section{HOOFDSTUK 7}

Hoofdstuk zeven analyseert de belangrijkste sterke en zwakke punten van zelfregulering in de Antarctische toerismesector. De theorie van collectieve actie (collective action) van Elinor Ostrom (2005), en in het bijzonder de ontwerpprincipes voor robuust beheer van gemeenschappelijke goederen, bieden een inzichtelijk theoretisch kader voor deze analyse. In het hoofdstuk wordt allereerst onderzocht waarom formele toerismewetgeving beperkt is. Vervolgens wordt de zelfregulering van de toerismesector, via de International Association of Antarctica Tour Operators (IAATO), beschreven. Het succes van IAATO wordt toegeschreven aan de hoge graad van organisatie, omwille van de vermeende voordelen van samenwerking. $\mathrm{Er}$ wordt betoogd dat het zelfreguleringregime onder de huidige omstandigheden robuust is. Maar met een toenemend aantal toeristen en touroperators kan de institutionele structuur zwakker worden in de toekomst. Op basis van Ostrom's theorie wordt gesteld dat de relatie tussen zelfregulering en formele wetgeving vanuit de Verdragspartijen moet worden versterkt om een duurzame toekomst van Antarctisch toerisme te garanderen.

\section{HOOFDSTUK 8}

In hoofdstuk acht wordt een geïntegreerde scenarioanalyse uitgevoerd voor de toeristische ontwikkeling in Antarctica. Tijdens drie scenario workshops in Nederland en Nieuw-Zeeland, waaraan door een breed gezelschap aan belanghebbenden werd deelgenomen, zijn toekomstscenario's ontwikkeld. Deze scenario's zijn verder verrijkt met wetenschappelijke literatuur en documentatie, en gekoppeld aan grootschalige mondiale scenariostudies als de Global Environmental Outlook en de Millennium Ecosystem Assessment. In de resulterende analyse worden vier toekomstpaden verkend, op basis van verschillende veronderstellingen. Een scala aan mogelijke toekomstige ontwikkelingen wordt in kaart gebracht, zoals de ontwikkeling van luchtverbindingen, schaalvergroting van toeristische ondernemingen en activiteiten, permanente faciliteiten op Antarctische bodem, toenemende diversiteit van activiteiten, en de opkomst van touroperators die de regels omzeilen. De scenario's worden over het algemeen plausibel tot zeer plausibel geacht door de deelnemende belanghebbenden. De scenario's worden echter allesbehalve wenselijk geacht. Op basis van de scenarioanalyse zijn door de deelnemers beleidsopties uitgedacht ter verbetering van het Antarctisch regelgevingsysteem en de beheersing van toeristische activiteiten. Tot slot wordt er betoogd dat scenarioanalyse een belangrijke rol zou kunnen spelen bij de ontwikkeling van een strategische beleidsvisie voor toerisme in Antarctica.

\section{HOOFDSTUK 9}

Hoofdstuk negen behandelt de bestuurlijke aspecten van duurzame toerisme in Antarctica. Interviews met belanghebbenden over de ontwikkeling en regulering van toerisme worden geanalyseerd met behulp van de adaptieve conceptualisatie van duurzaam toerisme van Hunter (1997). Het hoofdstuk is vooral gericht op drie 
onderling afhankelijke vragen: wat willen wij bereiken (duurzaamheiddoelstelling), wat kunnen wij bereiken (regelgevende capaciteit); en hoe kunnen we dit bereiken (beleidsopties)? Uit de interviewresultaten blijkt dat hoewel de meeste ondervraagden lijken te streven naar hoge milieu- en veiligheidsnormen, perspectieven over het aanvaardbare volume en de vorm van toerisme sterk verschillen. Meningen verschillen ook over de capaciteit van zowel formele regulering als zelfregulering om toerisme in Antarctica te beheersen en de beleidsstappen die hiervoor nodig zijn. Op basis van de interviews worden suggesties gedaan om Antarctisch toerisme in de richting van duurzaamheid te loodsen, zoals het ontwikkelen van een strategische visie voor toerisme, het verkennen van systemen om financiële middelen te genereren voor milieumonitoring, het uitvoeren van toegepast onderzoek over marktinstrumenten en restrictieve beleidsinstrumenten, en het opzetten van partnerschapverbanden met zelfreguleringorganisaties zoals IAATO.

\section{HOOFDSTUK 10}

Hoofdstuk tien vat de belangrijkste conclusies, voor elk van de onderzoeksdoelstellingen, uit deze dissertatie samen. Ook wordt er gereflecteerd over de gebruikte concepten en methoden, en de vooruitzichten voor toekomstig onderzoek over het onderwerp. Het hoofddoel van dit onderzoek is het in kaart brengen van duurzaamheiduitdagingen van Antarctisch toerisme. Het proefschrift laat zien dat toerisme in Antarctica zich ontwikkelt als gevolg van drijvende en beperkende factoren. Deze factoren kunnen op zichzelf voor toekomstige uitdagingen zorgen, zoals de mondiale milieugevolgen; de veiligheidsrisico's van Antarctisch toerisme; de juridische implicaties en milieugevolgen van de ontwikkeling van permanente toeristische faciliteiten en infrastructuren op Antarctische bodem; en de stabiliteit van zelfregulering in de Antarctische toerismesector. De algemene prognose is dat Antarctisch toerisme zich zal verder ontwikkelen, maar dat de snelheid en vorm van deze ontwikkeling onzeker is als gevolg van de genoemde factoren. Door middel van een geïntegreerde scenarioanalyse op basis van scenario's ontwikkeld door belanghebbenden en mondiale scenariostudies, zijn een viertal sterk uiteenlopende toekomstpaden verkend. Tijdens een internationale interviewronde blijken belanghebbenden bovendien uiteenlopende perspectieven te hebben over de doelstelling en de beleidsinstrumenten voor duurzaam toerisme in Antarctica. Er is betoogd dat de combinatie van onderzoeksmethoden toegepast in dit proefschrift nieuw licht werpen op de uitdagingen van duurzaam toerisme in Antarctica. Vergelijkend onderzoek in andere afgelegen gebieden en onderzoek naar vernieuwende beleidsinstrumenten worden, onder andere, gezien als veelbelovende gebieden voor toekomstig onderzoek. Tot slot wordt er gesteld dat onderzoek naar pooltoerisme kan profiteren van internationale coördinatie van onderzoeksprogramma's en onderzoekers. 



\section{Dankwoord \& acknowledgements}

Het doen van een promotieonderzoek naar toerisme in Antarctica is een droom waarvan ik zelf niet wist dat ik hem had. Toen deze droom zich iets meer dan vijf jaar geleden als een concrete mogelijkheid voordeed duurde het echter niet lang om mezelf ervan te overtuigen dat dit iets voor mij was. Naast een droom is dit promotieonderzoek het resultaat van de nodige arbeid. Daarnaast zou dit proefschrift er niet zijn geweest zonder de betrokkenheid van een groot aantal mensen die ik op deze plaats graag wil bedanken.

Op de eerste plaats wil ik mijn promotor Prof. Dr. Jan H. Stel en copromotor Dr. Bas Amelung bedanken. Jan, ik heb je grote betrokkenheid bij het onderwerp en het onderzoek zeer gewaardeerd en realiseer me dat het dankzij jouw ervaring en uitgebreide internationale netwerk een stuk gemakkelijker was dit project tot een goed einde te brengen. Bas, jouw postdoc-project naar toerisme in het Antarctisch Schiereilandgebied was voor mij een zege omdat ik mezelf vanaf dat moment letterlijk niet meer op een eiland bevond. Ik heb veel geleerd van je analytisch vermogen en je schrijfkunsten; bovendien heb ik je activisme tegen valse economische beloften en voorliefde voor de ingezonden brief altijd erg kunnen waarderen.

Dank ben ik verschuldigd aan de leden van de leescommissie van wie ik, naast goedkeuring, ook veel bruikbare suggesties ontving voor verbetering van dit manuscript. Belangrijk zijn ook geweest mijn collega's bij ICIS met wie ik elke dag weer uitdagingen en successen deel. De laagdrempeligheid en ontspannen sfeer bij ICIS hebben de afgelopen jaren een omgeving gecreëerd waarin het prettig werken was. Dit promotietraject werd financieel gesteund door het Nederlands AntArctisch Programma (NAAP) van de Nederlandse Organisatie voor Wetenschappelijk Onderzoek (NWO) (subsidienummer: 851.20.025).

In de loop van dit onderzoek heb ik verschillende keren nauw samengewerkt met collega-onderzoekers van andere universiteiten. I would like to thank Dr. Daniela Haase, of the University of Canterbury in New Zealand, for cooperation and joint efforts on more than one occasion. Being in the same (PhD) position has been a pleasure and I am looking forward to future cooperation. Ook de prettige samenwerking en betrokkenheid van Prof. Mr. Kees Bastmeijer van de Universiteit van Tilburg, heb ik zeer gewaardeerd. Ik hoop dat we deze samenwerking ook in de toekomst kunnen voortzetten.

Dit onderzoek was ook niet mogelijk geweest zonder de deelnemers aan de workshops in Nederland en Nieuw Zeeland, en zonder de belanghebbenden uit Nederland, Duitsland, het Verenigd Koninkrijk, Canada, de Verenigde Staten, Chili, en Argentinië, die bereid waren zich door mij te laten interviewen: Bedankt, Vielen Dank, Thank you, Grazias! Daarnaast zijn er de personen en instanties die het mo- 
gelijk hebben gemaakt dat ik tot drie keer toe het Antarctisch gebied heb mogen bezoeken. I would like to thank Prof. Dr. Bryan Storey and staff at Gateway Antarctica in Christchurch, New Zealand, for making the New Zealand workshop possible and allowing me to participate in the Graduate Certificate in Antarctic Studies. Special thanks to the GCAS class of 2005/06, and Antarctica New Zealand, for making my stay in New Zealand and Antarctica among the most wonderful experiences off my life. I would like to thank the Alfred Wegener Institute (AWI), as well as the base personnel at Bellingshausen station, Base Jubany/Dallman Lab., Arctowski Station, and the Brazillian National Antarctic Programme for their hospitality during the King George Island expedition in 2008. Ik wil ook Waterproof Expeditions bedanken voor de mogelijkheid om het Antarctische veldwerk af te ronden en voor de onvergetelijke expeditiecruise naar het Antarctisch Schiereiland.

De laatste alinea is gereserveerd voor mijn liefste dochtertje Madieke en liefste vriendin Sanne. Madieke, je bent er nog maar iets langer dan een jaar maar hebt jezelf toch al stevig in mijn leven verankerd. De zorg en aandacht die je van me vroeg en de guitige blikken die ik van je kreeg, zorgden voor de nodige relativering tijdens de afronding van dit onderzoek. Sanne, je was erbij toen ik dit promotietraject kreeg toegewezen en je bent erbij nu ik het afrond. We hebben het de afgelopen jaren goed gehad samen en we hebben de periodes dat ik vanwege het onderzoek weg was goed doorstaan. Het komend jaar gaan we trouwen en beginnen we samen aan een nieuw hoofdstuk. 


\section{Curriculum Vitae}

Machiel Lamers was born in Zevenaar on March 20th 1978. After completing secondary education (Andreas Scholengemeenschap, Zevenaar), in 1996 he enrolled as a student in Culture and Science Studies (Faculty of Arts and Culture) at Maastricht University. After having chosen the thematic focus of tourism, Machiel started an intership at the International Centre for Integrated assessment and Sustainable development (ICIS). Courses in Tourism and Leisure Studies followed at Lancaster University in the United Kingdom, after which he returned to ICIS to write his Master thesis on tourism development in Kenya. In 2001, Machiel received a M.A. Degree in Arts and Culture. In 2003, a M.A. followed in Cultures and Development Studies (Department of Social and Cultural Anthropology) from the Catholic University of Leuven, Belgium.

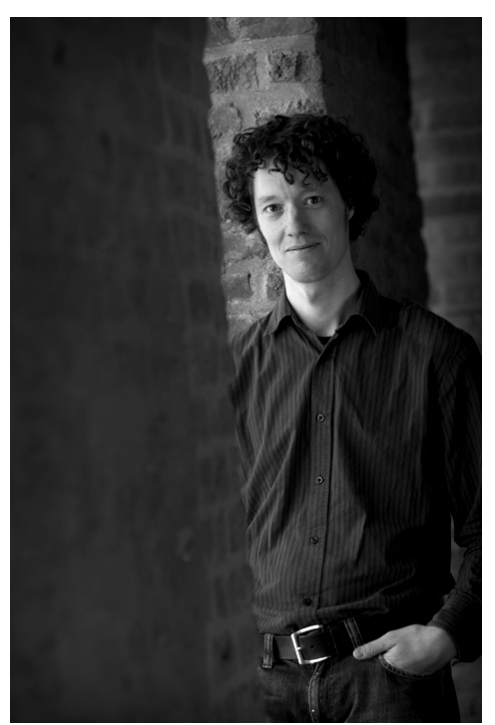

In 2004 Machiel started as a PhD researcher at ICIS on a NWO funded project on scenario analysis for tourism development and regulation in Antarctica. In 2005 he participated in the international programme Graduate Certificate in Antarctic Studies (GCAS), at the University of Canterbury, in Christchurch, New Zealand. A two-week fieldtrip to the Antarctic Ross Sea region was part of the GCAS programme. Two more fieldwork expeditions to the Antarctic Peninsula followed in 2008 and 2009. This thesis is the result of his $\mathrm{PhD}$ research project.

Next to this PhD, Machiel has worked on several other projects, including the European funded NeWater project on adaptive water management and the EUROPOLAR project on collaboration in European polar research. Machiel Lamers teaches in several course at the University College Maastricht and the Maastricht Graduate School of Governance on topics related to sustainable development, globalisation, participatory methods and integrated assessment. 